\title{
Hypertension in pregnancy:
}

\section{Gaining insight into women's}

\section{mental health and birth}

\section{experience 6-12 months}

\section{postpartum}

\author{
Lynne Roberts
}

A thesis submitted as part of the requirements for the

Doctor of Philosophy Degree

Centre for Midwifery, Child and Family Health, Faculty of Health, University of Technology Sydney

September 2019 


\section{Certificate of Original Authorship}

I, Lynne ROBERTS, declare that this thesis is submitted in fulfilment of the requirements for the award of Doctoral Degree, in the Centre for Midwifery, Child and Family Health, Faculty of Health at the University of Technology Sydney.

This thesis is wholly my own work unless otherwise reference or acknowledged. In addition, I certify that all information sources and literature used are indicated in the thesis.

This document has not been submitted for qualifications at any other academic institution.

This research is supported by the Australian Government Research Training Program.

Signature:

Date: 


\section{Acknowledgements}

Undertaking a PhD project was a big decision and required a great deal of work and commitment. I have worked hard on this project to focus on how to improve the care midwives provide to women with a complicated pregnancy. Although I was passionate about the topic of my research, it would not have been possible to complete this without the guidance, love and support that I received from many people.

The first person I want to thank is my primary supervisor, Caroline Homer. Caroline and I began this PhD with a history; we had worked together for many years and she had previously been my supervisor when I completed the Master of Midwifery Degree. We had an established friendship and relationship and knew we worked well together so I was thrilled when she offered to be my PhD supervisor. According to Caroline, my $\mathrm{PhD}$ is the longest in known research history due to the many years of her asking (nagging) before I was ready and agreeable to take on the task. I was simply waiting for the right time and the right project!

Caroline is the wisest, most generous, inspirational and patient woman I know. Generous with her time, sharing her knowledge and expertise and always there when you need a lift back on track and a turn in the right direction. Caroline has always given me time to learn new skills and helped me to master them. She instilled in me at an early stage of this journey that "doing a PhD is a learning process - learning how to research". My learning curve was steep but achievable with Caroline's direction. I thank her for this guidance and for her seemingly endless reading and reviewing of drafts, ideas and thoughts, valuable feedback and encouragement, and generally just being there.

I also want to thank my co-supervisor, Greg Davis. Greg and I have worked together for many years caring for women with complicated pregnancies and undertaking research projects. Working on a $\mathrm{PhD}$ project has enhanced our working relationship and friendship. Greg is a very practical person and was 
always good at bringing me back to ground when things got tough. He has the most amazing eye for detail, can find a typo or extra space in any given page of text and can move words around to improve the flow and meaning of the text. I thank him for all his reading, reviewing and editing of drafts, his thoughts and feedback. I especially thank him for his support in the general running of the project, his advice on the work/life balance, and his 'go to person' recommendations if he could not help me.

The qualitative component of this project involved interviewing women which was something new to me. I had fabulous help with learning the fine art of interviewing from my dear friend and colleague, Nicki Watts. Nicki generously gave up her time to work with me in coming up with the interview questions and attended the first few interviews with me. I cannot thank her enough for 'holding my hand' while I overcame my nerves about interviewing.

Throughout the PhD years my friends have always been there for me. They may not have realised how important their friendship was during this time but I thank them for being in my life. Their sense of humour, our regular lunches, chats and annual weekend getaways have kept me in touch with the real world and given me a break from my PhD. I appreciate the love, support and laughs we all share and for your help with propping me up during challenging times.

The P4 Study Team has been extremely supportive and encouraging throughout this project. They have enabled me to claim one component of the large study as mine and always supported me with my work. I thank them all for this support and their friendship, respect, trust and belief in me. I also thank Professor Sam Harvey for his assistance in selecting the screening instruments used in this project and for introducing me to SPPS.

A project like this cannot be undertaken without the women who volunteer to participate. I thank the women who participated, for their time and commitment, and I especially thank those who shared their birth experience story with me. I know that this was not easy for all and often elicited emotional memories that 
some found difficult to speak about. I would like to think that all the women who participated feel that they have contributed to improving the birth experience of women in future times.

Lastly, but importantly, I thank my family. My husband, Mark and our sons Alex and Lachlan have all tried hard not to annoy me too much. They have somehow known when to give me space, time and peace to work on my project. They have also accepted that I have sometimes been distracted and yet given me many words of encouragement and support. I particularly thank Mark for playing a sport that takes six hours (golf) so I could have time to write without feeling like I have neglected our relationship. I also thank him for showing me the importance of getting away from the laptop and going out to enjoy a walk or an outing. To Alex and Lachlan, I thank them for their patience, understanding and neck massages. Throughout this PhD project we have kept our close bond and managed to laugh at the end of the day. Thank you for your love and for always being there for me and each other. 


\section{It happened for a reason: A dedication}

In 1993 I gave birth to my first son. He was born by emergency caesarean section at 30 weeks gestation. I had early onset preeclampsia and the only way to treat me was for him to be born.

I remember seeing his tiny face before he was taken to the resuscitaire to be cared for by the midwives and doctors. My memory of the following few days is patchy. He was born on a Saturday night and I spent the next three days in the intensive care unit at one hospital and he was transferred to the intensive care unit of another hospital. I finally saw him on the Monday.

My time in intensive care was necessary but distressing. There was no night and day differentiation in that place, just constant medications, checks, measures and alarms with a nurse sitting at the end of my bed, watching. I had no concept of time. I truly felt as though I was dying and told my husband and family this on several occasions. My thoughts were with my son, who I had not met yet. I had photos my brother had taken, but photos could not replace the feeling of giving my baby a cuddle or touching him.

On his way to see our son at the other hospital, my husband stopped off at a late night chemist and bought a teddy bear. It was the only one he could find late on a Saturday night. It didn't matter what it looked like, he didn't want his son to die without owning a teddy bear. I still have this bear and it holds many special memories for me. When my husband first visited our son he told the nurses that his name will be Alexander - he didn't want his son to die without having a name.

I cannot begin to imagine what this situation was like for my husband, family and friends.

When I first met Alexander I was not overwhelmed by all the tubes, machines and equipment. I was able to see through all the lifesaving technology and find 
my tiny boy. Through my tears I managed to say 'I'm sorry' to him and gently stroke his tiny, fragile body. My first meeting with him was short as I was still very unwell and I had twisted my doctors' arm hard enough to let me leave the hospital for this short period.

We both made good progress and I was home after a week. Coming home without my baby was another difficult time but I focussed on doing the one thing that only I could do for him - supply him with breast milk. This was a task I did very well indeed. He ran the usual course for a preterm baby such as being ventilated, having arterial lines, total parental nutrition (TPN) and lipids, jaundice requiring phototherapy, scans and X-rays and feeding issues. Imagine my joy when he had his first breast feed at five weeks old!

Alexander came home when he was almost seven weeks old. I was kept busy caring for him, feeding him and taking him to his many appointments for paediatrician check-ups, hearing and sight tests and physiotherapy. Keeping busy kept my mind off what had happened.

When Alexander had his first birthday we celebrated with family, food and cake. It was a very happy day and a significant milestone for Alexander considering his difficult start to life. However, throughout the day I was distressed. I was constantly recalling what happened this time last year and reliving my traumatic birth experience. I thought I just needed some more time to recover and I seemed to cope with the next birthday a little better than the previous one. A turning point for my recovery came a few years later when a psychiatrist said to me 'you don't need to get over it, in fact you probably won't get over it. What you need is to find ways to cope with what happened and move on to enjoy your life'. And that is what I have done!

Since this experience and advice I have been determined to learn more about preeclampsia and to help improve the birth experience for the women who develop this complication in their pregnancy. My first step in achieving this was becoming a member of the multidisciplinary team caring for women with a 
complicated pregnancy, particularly those with hypertension. Working as part of this team was extremely rewarding and I felt like I was making a difference to the care women were receiving. I started teaching the topic of hypertension in pregnancy in my workplace and at university, and soon became the resource midwife for anything to do with hypertension. I wanted all midwives to be well informed on hypertension so that the best care would be given. I was already a member of a support group based in Melbourne and I decided to start my own support group in Sydney. I was willing to give anything a go that meant a better experience for women and their babies following a pregnancy complicated by hypertension.

When I decided to undertake a $\mathrm{PhD}$, there was never a question on what the topic would be. Anyone who knew me would give you the same answer, so it is no surprise that I have carried out a project about women's mental health and improving the birth experience for women who have their pregnancy complicated by hypertension.

This is a piece of work very dear to me and it will always hold a special place in my heart. Behind the toil of this project is a great personal passion and drive that has kept me focused and determined to do a good job. For all the women, their babies, their partners, family and friends, and everyone else who has been touched by preeclampsia or hypertension in pregnancy, I dedicate this work to you. May my work be helpful for all health care providers in improving the care we provide and therefore improving the birth experience for women who experience hypertension in their pregnancy. 


\section{TABLE OF CONTENTS}

Certificate of Original Authorship ....................................................... ii

Date:

Acknowledgements.......................................................................... ii

It happened for a reason: A dedication ................................................. vi

The Postpartum Physiology, Psychology and Paediatric follow-up Study .xiii

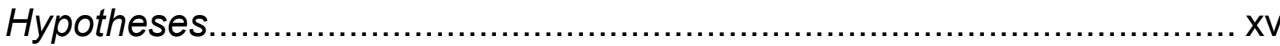

Publications .....................................................................................

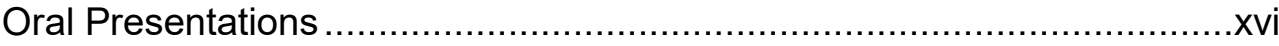

Poster presentations ........................................................................

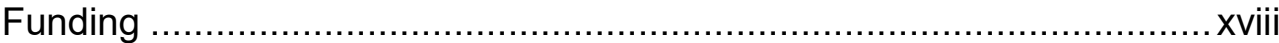

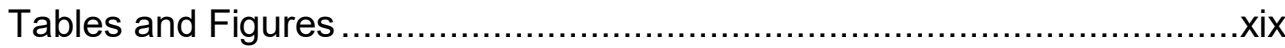

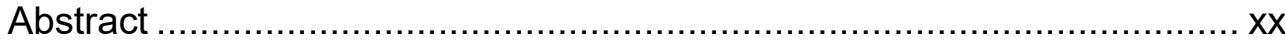

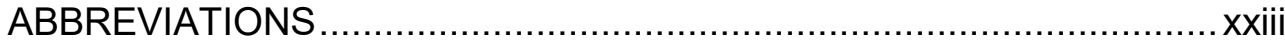

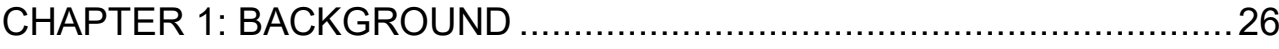

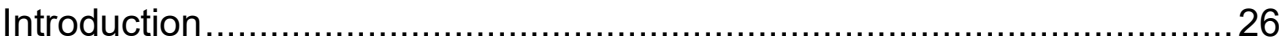

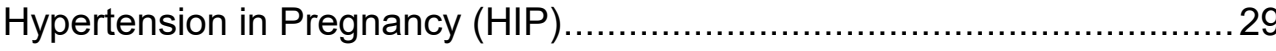

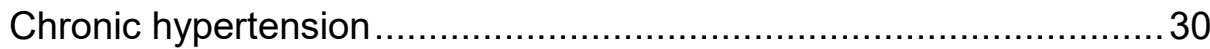

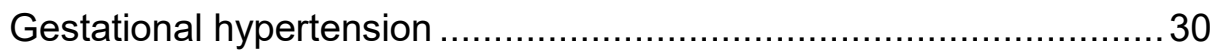

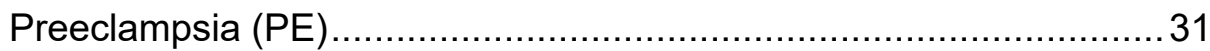

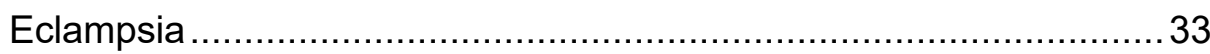

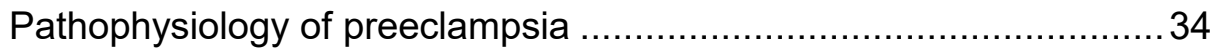

A brief history of preeclampsia..................................................... 34

Implications for women and babies ............................................. 37

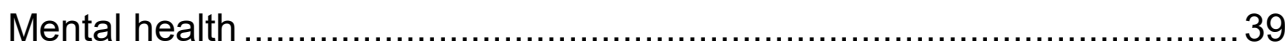

Depression ............................................................................. 40

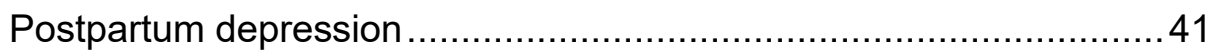

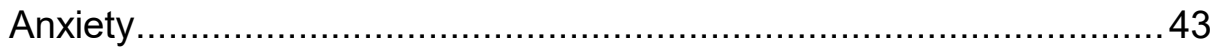

Depression and anxiety occurring together ..................................... 45

Posttraumatic Stress Disorder ..................................................... 46

Posttraumatic stress and childbirth ........................................... 49

Support for depression, anxiety and posttraumatic stress disorder ..........50

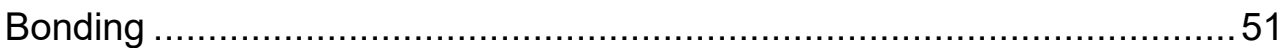

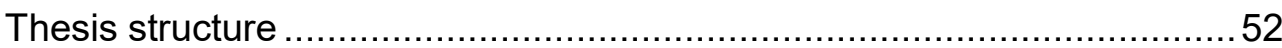

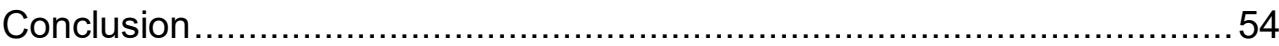




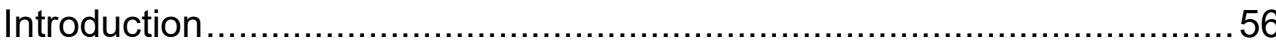

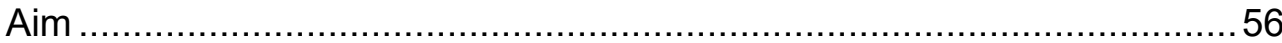

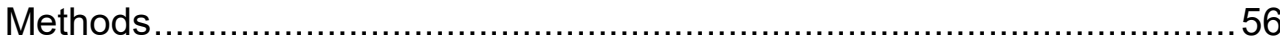

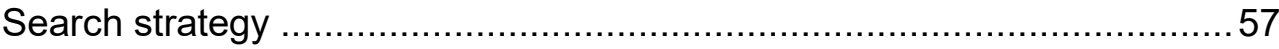

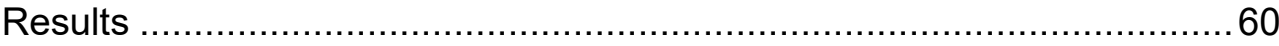

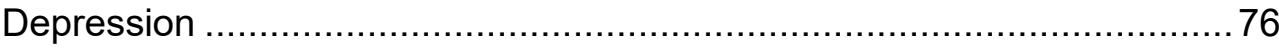

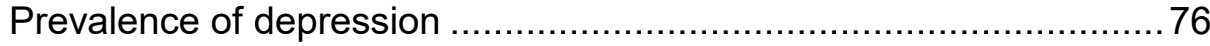

Depression symptom severity ................................................... 77

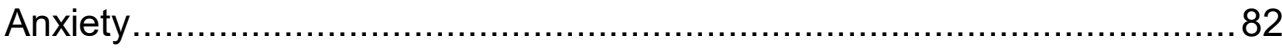

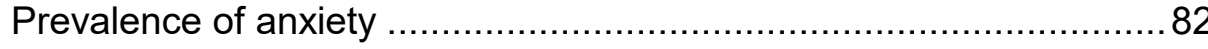

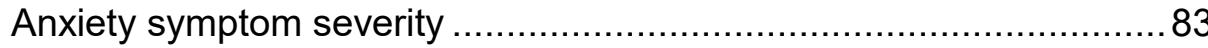

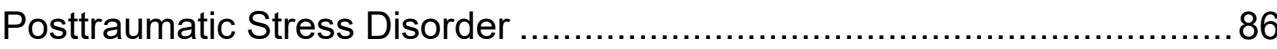

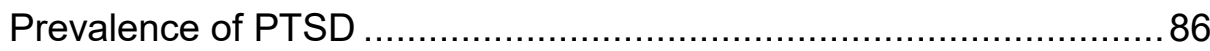

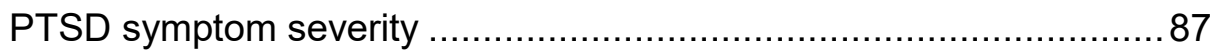

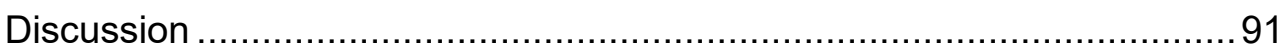

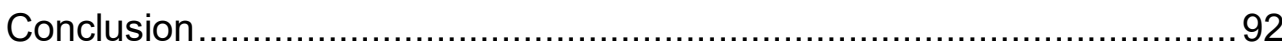

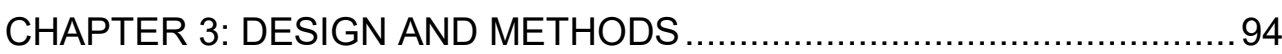

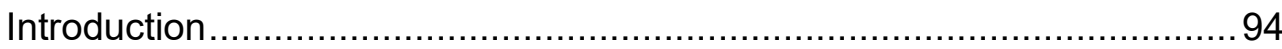

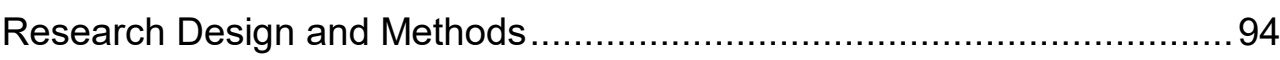

Mixed Methods Design ............................................................ 94

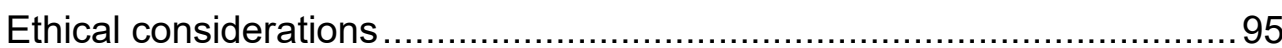

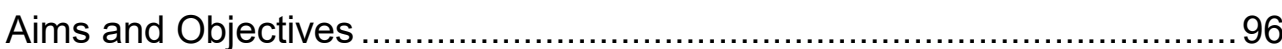

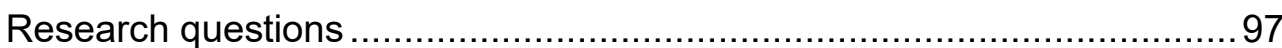

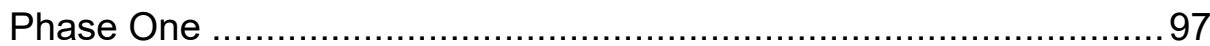

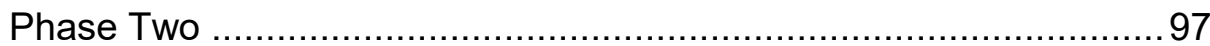

Phase One: Using a survey to compare mental health and birth .............97 experience

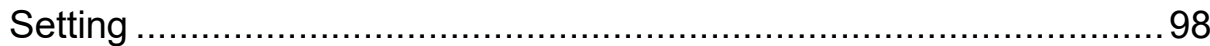

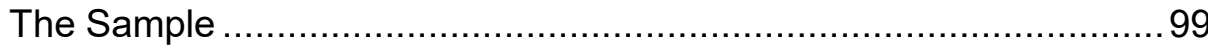

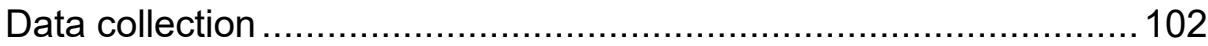

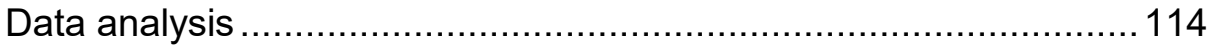

Phase Two: Interviews with women .............................................. 117

Qualitative descriptive design ................................................. 118

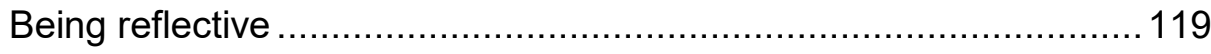


Ethical amendments and considerations

Setting

Eligibility criteria 123

Identifying the women 123

Recruitment details 123

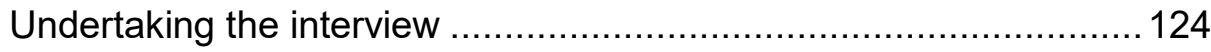

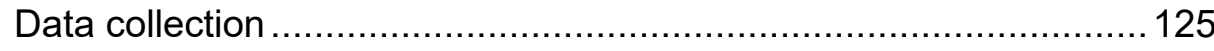

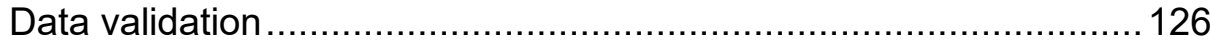

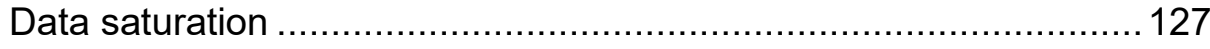

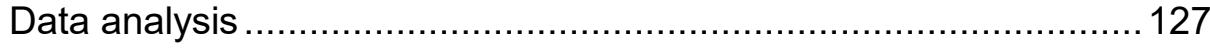

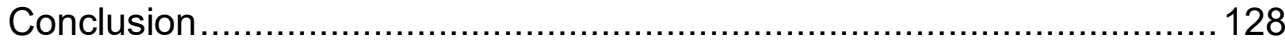

CHAPTER 4: WOMEN'S MENTAL HEALTH OUTCOMES AND BIRTH..129 EXPERIENCE

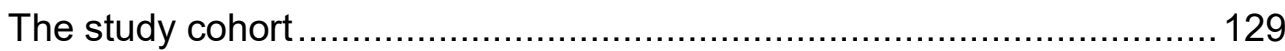

Pregnancy booking .................................................................. 130

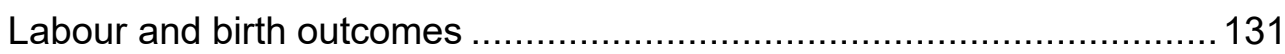

Neonatal outcomes................................................................... 133

Mental health at six months postpartum........................................... 134

Possible depression.......................................................... 135

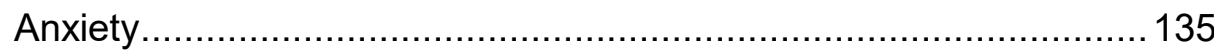

Possible posttraumatic stress disorder......................................... 135

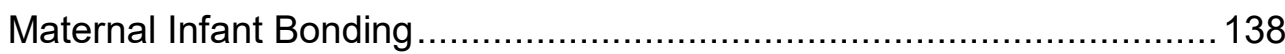

Possible contributors to depression and posttraumatic stress disorder ... 138

Depression ................................................................................ 138

Posttraumatic Stress Disorder ................................................ 139

Reporting a traumatic birth experience .............................................. 139

Women's birth experience ........................................................... 141

Likert Scale to assess birth experience......................................... 141

Open ended questions............................................................... 143

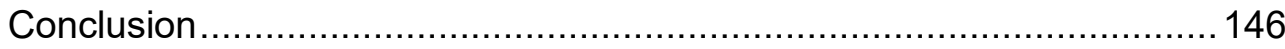

CHAPTER 5: THE HYPERTENSION IN PREGNANCY EXPERIENCE .. 147

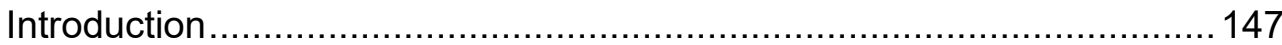

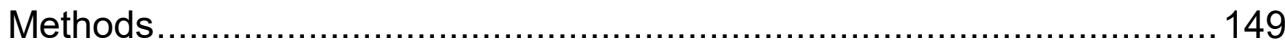

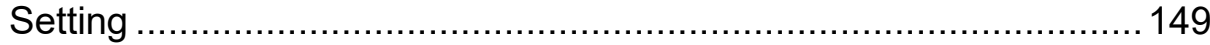

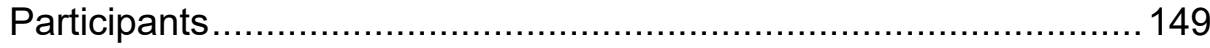




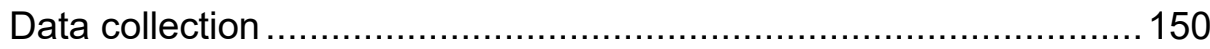

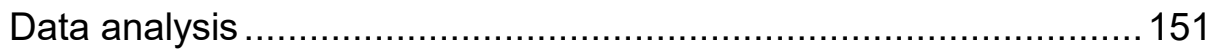

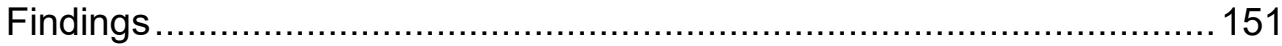

Reacting to the diagnosis.......................................................... 156

Challenges of being a mother ................................................. 158

Processing and accepting the situation...................................... 160

'Moving on' from the experience .................................................... 161

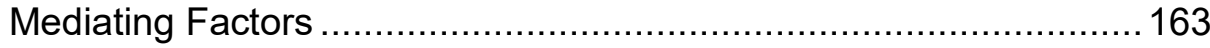

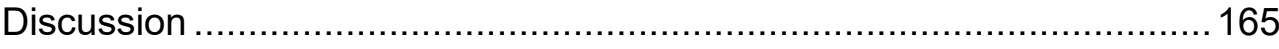

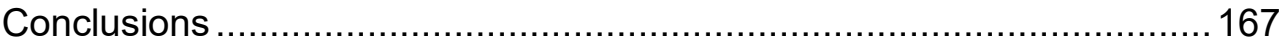

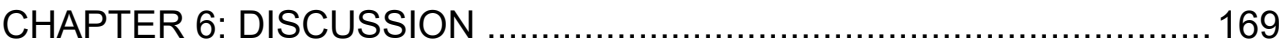

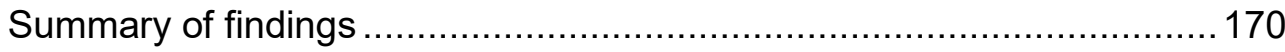

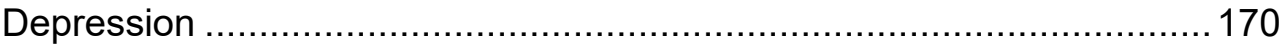

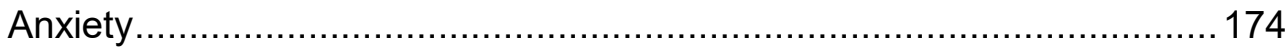

Posttraumatic Stress Disorder (PTSD) ............................................ 177

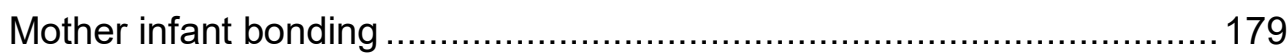

The birth experience ................................................................... 180

Essential elements of care ................................................................ 183

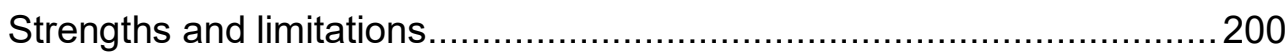

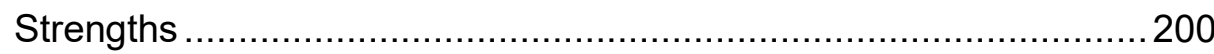

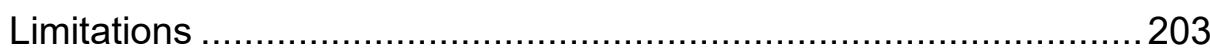

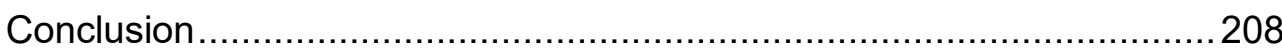

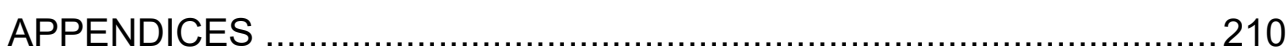

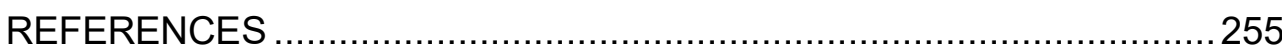




\section{The Postpartum Physiology, Psychology and Paediatric follow-up Study}

This PhD research project is one component of a large study, the Postpartum Physiology, Psychology and Paediatric follow-up (P4) Study (Davis et al. 2016), which is being conducted by the Obstetric Medicine Research Group (OMRG) at St George Hospital, Sydney. I am the overall P4 Study coordinator but I designed and led the mental health component of the study from the outset which makes up this $\mathrm{PhD}$.

The P4 study is a prospective observational cohort study investigating the physical and mental health of women as well as the health and development of their children. Maternal and paediatric data are collected at six months, 2 years and 5 years postpartum following either a normotensive pregnancy or one complicated by hypertension (Figure a.). As the P4 Study coordinator I undertake all the postpartum measurements, collect data from the women, either from their medical record or directly from them via questionnaires, and organise the appointments for their children. The six month postpartum maternal psychological health component of the P4 Study is my PhD project, that is, the assessment of depression anxiety, PTSD and birth experience six months after a pregnancy complicated with either gestational hypertension $(\mathrm{GH})$ or preeclampsia (PE) and normotensive pregnancy. Both my $\mathrm{PhD}$ supervisors are investigators in the P4 Study - Associate Professor Gregory Davis is the Principal Investigator.

I have worked with the OMRG from the inception of the P4 Study. I have been involved in the design, ethics approval application and subsequent annual reports, questionnaire and case report form design, screening instrument selection, recruitment, carrying out assessments, accurate data collection and entry, and all follow-up required. The study is still actively recruiting and following-up women and their babies. 
Figure a. Model of the P4 Study

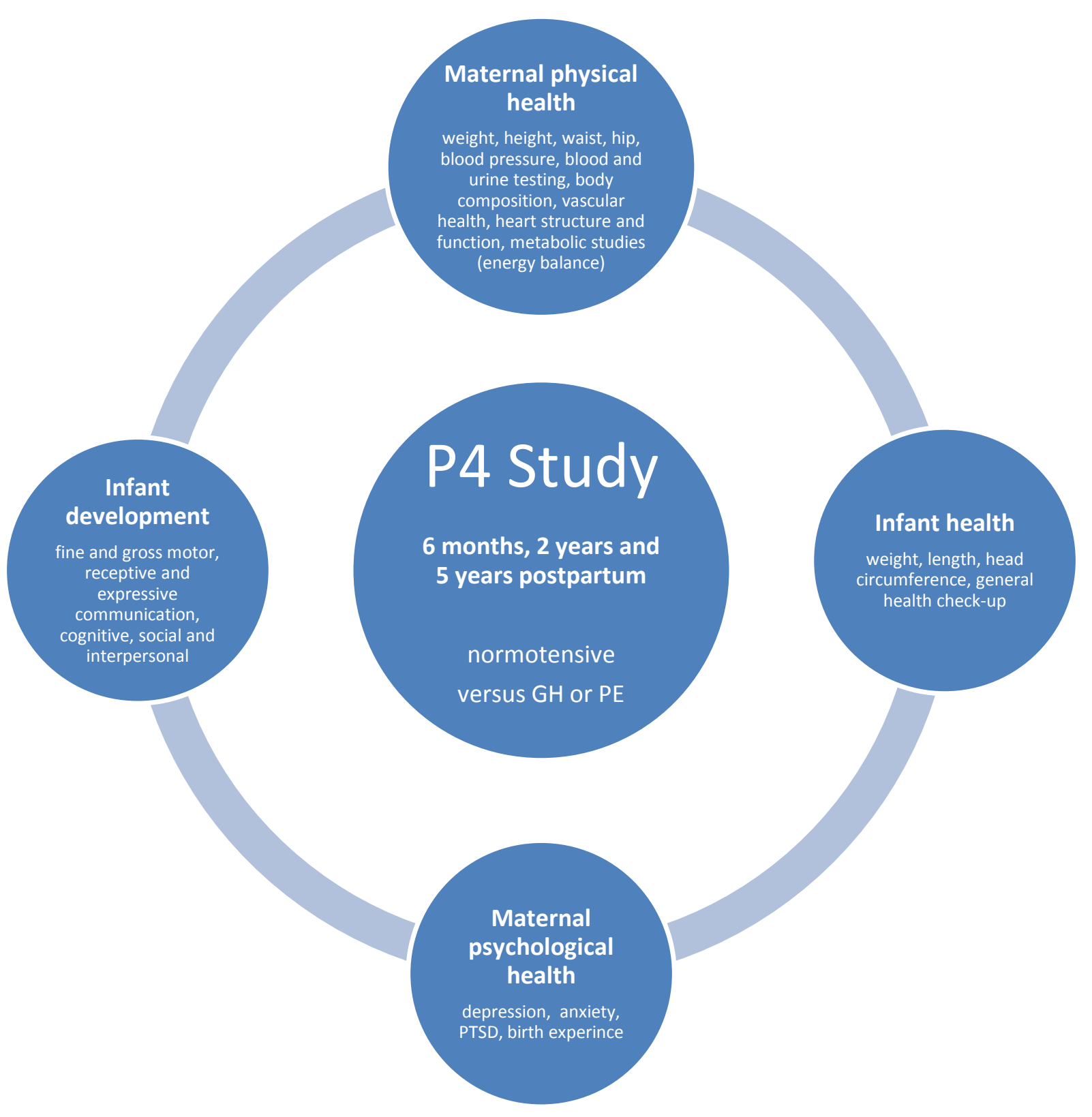




\section{Figure b. Hypotheses and Outcomes of the P4 Study}

\section{Hypotheses}

1. That women who have had hypertension in pregnancy:

a). Have risk factors for CVD that are only recognised by comparison with a new 'normal' range for blood pressure and other cardiovascular risk factors;

b). Have a higher prevalence of psychological morbidity postpartum.

2. That the offspring of women who have had hypertension in pregnancy have a greater likelihood of abnormal growth and development six months after birth.

\section{Outcomes}

1. The primary outcome is the prevalence of women in the formerly hypertensive groups with mean 24 hour systolic or diastolic BP two standard deviations greater than the mean BP derived from women who had normal pregnancies.

2. Secondary outcomes are:

a) physiological measures: central BP, body composition, energy balance, cardiac function, renal function, lipids, insulin resistance (HOMA score) and urinalysis;

b) psychological measures: depression, anxiety, post-traumatic stress and mother-infant bonding; and

c) infant health: physical health and development.

3. Development of guidance for the assessment, treatment and follow up of:

a) Women who have increased risk factors for later CVD;

b) Women who have psychological morbidity after hypertension in pregnancy; and

c) Children with physical or developmental impairment after maternal hypertension in pregnancy. 


\section{P4 Study Funding}

The P4 Study is funded in part by the St George and Sutherland Medical Research Foundation and generous philanthropic donations. This funding covers the general operational costs of the study at St George Hospital and is insufficient to fund the study being carried out at other sites.

\section{Publications and presentations}

There have been a number of publications and conference presentations resulting from the P4 Study. Those related to this PhD project are listed below. I took the lead role on all the publications and presentations related to this $\mathrm{PhD}$.

\section{Publications}

Roberts LM, Davis GK, Homer CS. 2017. Pregnancy with gestational hypertension or preeclampsia: A qualitative exploration of women's experiences. Midwifery. 46:17-23.

Davis GK, Roberts L, Mangos G, Henry A, Pettit F, O'Sullivan A, Homer CS, Craig M, Harvey SB, Brown MA. 2016. Postpartum physiology, psychology and paediatric follow up study (P4 Study) - Study protocol. Pregnancy Hypertension. 6(4):374-379.

\section{Oral Presentations}

Roberts LM. 2018. Women's mental health following a hypertensive pregnancy. Nursing and Midwifery Research Showcase. St George Hospital. Sydney, Australia.

Roberts LM. 2018. How do women report their birth experience six months following a normotensive versus hypertensive pregnancy? Society of Obstetric 
Medicine of Australia and New Zealand, Annual Scientific Meeting. Cairns, Australia.

Roberts LM. 2018. The P4 Study. St George Hospital Hypertension in Pregnancy Education Day. Sydney, Australia.

Roberts LM. 2017. Hypertension in pregnancy: Gaining insight into women's mental health and birth experience 6-12 months postpartum. Australian College of Midwives $20^{\text {th }}$ National conference. Adelaide, Australia.

Roberts LM. 2017. Women's mental health after hypertension in pregnancy. $31^{\text {st }}$ ICM Triennial Congress, Toronto, Canada. (this presentation was part of an expert panel session titled Hypertension in pregnancy - How can midwives make a difference?)

Roberts LM. 2016. Postpartum, Physiology, Psychology, Paediatric follow-up study (P4 Study). St George Hospital Nursing and Midwifery Grand Rounds. Sydney, Australia.

Roberts LM. 2016. Hypertension in pregnancy: Gaining insight into women's mental health and birth experience 6-12 months postpartum. Society of Obstetric Medicine of Australia and New Zealand, Annual Scientific Meeting. Alice Springs, Australia.

Roberts LM. 2015 Hypertension in pregnancy and the P4 Study. St George Hospital Midwifery Seminar. Sydney, Australia.

\section{Poster presentations}

Roberts LM, Davis GK, Henry A, Homer, CS. 2018. Hypertension in pregnancy: Gaining insight into women's mental health and birth experience 612 months postpartum. $18^{\text {th }}$ Congress of the International Society of Hypertension in Pregnancy, Amsterdam, The Netherlands. 
Roberts LM, Homer SE, Davis GK. 2016. Women's mental health after hypertension in pregnancy. $31^{\text {st }}$ ICM Triennial Congress, Toronto, Canada.

Roberts LM, Homer SE, Davis GK. 2015. Does hypertension in pregnancy impact the women's mental health postnatally? St George and Sutherland Medical Research Foundation Symposium. Sydney.

Roberts LM, Homer SE, Davis GK. 2015. Does hypertension in pregnancy impact the women's mental health postnatally? Australian College of Midwives $19^{\text {th }}$ National Conference. Gold Coast.

Roberts LM, Homer SE, Davis GK. 2015. Does hypertension in pregnancy impact the women's mental health postnatally? SOMANZ Annual Scientific Meeting. Melbourne.

\section{Funding}

I gratefully acknowledge the following funding I have received to undertake this $\mathrm{PhD}$ project and assist in presenting my research at conferences:

$2017 \$ 1500$ Scholarship from the Australian College of Nursing to attend the ACM conference in Adelaide.

$2016 \$ 3000$ Health Services Practice Research Student Development Award UTS to attend the 31st ICM Triennial Congress- Midwives Making a Difference in Toronto, Canada.

$2015 \$ 1500$ Scholarship from the Australian College of Nursing to attend the ACM conference on the Gold Coas.t

2013 Australian Government Research Training Program funding this PhD. 


\section{Tables and Figures}

Table 2.1 The definition of hypertension in pregnancy and the inclusion criteria for the included studies

Table 2.2 Results of included studies reporting on hypertension in pregnancy and postpartum mental health

Table 2.3 Summary of screening instruments for depression

Table 2.4 Summary of screening instruments for anxiety

Table 2.5 Summary of screening instruments for PTSD

Table $3.1 \quad$ Likert Scale statements

Table 4.1 Demographic details of the enrolled women by group

Table 4.2 Labour and birth outcomes for mother and baby by group

Table 4.3 Mental health outcomes for women by group

Table 4.4 Predicting the likelihood of scoring above the threshold score for depression and PTSD or reporting a traumatic birth

Table 4.5 Likert Scale scores regarding birth experience

Table 5.1 Demographic characteristics of women interviewed

Figure a Model of the P4 Study

Figure b Hypotheses and Outcomes of the P4 Study

Figure 1.1 Definition of preeclampsia

Figure 1.2 Symptoms of depression

Figure 1.3 Symptoms of general anxiety

Figure 1.4 Diagnosing Posttraumatic Stress Disorder

Figure 2.1 Process of paper selection

Figure 2.2 Summary of papers selected for review

Figure 4.1 What women reported being happy with

Figure 4.2 What women reported being unhappy with

Figure 5.1 Women's experiences of having either gestational hypertension or preeclampsia.

Figure 6.1 Levels of continuity of care

Figure 6.2 Categories of social support 


\section{Abstract}

\section{Background}

Pregnancy and childbirth, while usually joyful experiences, can be traumatic leading to depression, anxiety and post-traumatic stress disorder (PTSD). Women may be more prone to psychological morbidity following a complicated pregnancy and/or birth.

Hypertension in pregnancy (HIP) is the most common medical complication of pregnancy. Women diagnosed with HIP require more intensive monitoring, antenatal admissions, a longer postnatal stay that may include acute care, and some give birth to a preterm baby requiring time in a nursery.

There are reports of the short and long term health risks following HIP, particularly cardiovascular health, but there is limited knowledge about the impact on mental health, birth experience, and whether the care received influences women's experiences.

\section{Aim}

The aim of this study was to investigate the mental health (depression, anxiety and posttraumatic stress disorder) and childbirth experiences at six to 12 months postpartum in women who had HIP and those who had normal blood pressure (normotensive) in pregnancy.

\section{Methods}

This was a longitudinal prospective observational study using mixed methods. There were two phases:

1) the mental health of women and their birth experience following a normotensive pregnancy or one complicated by hypertension, using a quantitative design; and, 
2) the experience of women who had HIP, using a qualitative approach.

At six months postpartum, women completed four screening instruments: the Edinburgh Postnatal Depression (EPDS), General Anxiety Disorder (GAD), Posttraumatic Stress Diagnostic, and Maternal Infant Bonding (MIB) scales. Birth experience data were collected using a seven point Likert Scale and two open ended questions. The qualitative component used individual, face-to-face, semi-structured interviews with a subset of 20 women at 10-12 months postpartum.

Descriptive statistics, univariate and multivariate logistic regression and ordinal regression analyses were conducted on the quantitative data, with a thematic analysis undertaken on the interview transcripts.

\section{Results}

There were 237 women in the normotensive (NT) group and 84 in the hypertensive (HT) group. Both groups had similar demographic characteristics. Compared to the NT group, the HT group experienced more interventions during labour and birth, with the HT group having higher rates of induction of labour $(70 \%$ versus $29 \%, p=<0.001)$ and caesarean sections ( $43 \%$ versus $18 \%, p=<0.001$ ) compared to the NT group.

Women in the HT group recorded significantly higher mean EPDS score $(p=0.03)$ and more scored above the threshold for possible depression $(p=0.03)$ compared to women in the NT group. There were no differences in anxiety, PTSD or bonding scores between groups. The proportion of women who identified their birth experience as traumatic was greater in the HT group $(p=0.006)$. The strongest predictor of possible depression in the whole cohort was being a first time mother (AOR 5.03; 95\% Cl 1.19-21.3), and for PTSD it was having a preterm baby (AOR 7.46; 95\% $\mathrm{Cl} 0.61-91.17$ ). Women in the NT group were three to five times more likely to respond positively to the birth experience questions. 
The qualitative study identified the themes: reacting to the diagnosis, challenges of being a mother, processing and accepting the situation, and moving on from the experience. Mediating factors that improved the women's experience were: feeling safe and trusting the care providers, continuity of care and carer, and valuing social support from partner, family and friends.

\section{Discussion}

Although the results showed more depressive symptoms in the women in the HT group and more reported their birth as a traumatic event, the prevalence of depression and PTSD was less than that previously reported in the literature. In an effort to further improve social, emotional and mental health outcomes for women, four elements of care are suggested. These are based on the quantitative and qualitative findings and current evidence: providing continuity of midwifery care in a collaborative model, facilitating social support for the woman, prevention and early identification of poor mental health, and keeping mother and baby connected.

\section{Conclusion}

Women have profound experiences after the diagnosis of HIP. They face challenges for months after the birth of their baby. It is essential for women to have access to appropriate multidisciplinary collaborative models of care, prompt referral to mental health services, and social support following a pregnancy complicated with hypertension. Furthermore, it is essential that maternity care providers keep the woman and her baby connected despite the physical separation that sometimes occurs. 


\section{ABBREVIATIONS}

\begin{tabular}{|c|c|}
\hline AAPEC & Australian Action on PreEClampsia \\
\hline ALT & alanine aminotransferase \\
\hline AOR & adjusted odds ratio \\
\hline AST & aspartate amino transaminase \\
\hline BDI & Beck Depression Inventory \\
\hline BP & blood pressure \\
\hline BSSS & Breslau Short Screening Scale \\
\hline CASP & Critical Appraisal Skills Programme \\
\hline CBT & Cognitive Behavioural Therapy \\
\hline CES-D & Center for Epidemiological Studies Depression Scale \\
\hline $\mathrm{Cl}$ & confidence interval \\
\hline COPE & Centre Of Perinatal Excellence \\
\hline CPAP & continuous positive airway pressure \\
\hline CTG & cardiotocograph \\
\hline DBP & diastolic blood pressure \\
\hline \multirow[t]{2}{*}{ DSM-IV } & Diagnostic and Statistical Manual of Mental Disorders $\left(4^{\text {th }}\right.$ \\
\hline & Edition) \\
\hline \multirow[t]{2}{*}{ DSM-V } & Diagnostic and Statistical Manual of Mental Disorders $\left(5^{\text {th }}\right.$ \\
\hline & Edition) \\
\hline EDC & expected date of confinement \\
\hline EPDS & Edinburgh Postnatal Depression Scale \\
\hline GAD & general anxiety disorder \\
\hline $\mathrm{GH}$ & gestational hypertension \\
\hline GP & General Practitioner \\
\hline HADS & Hospital Anxiety and Depression Scale \\
\hline HDP & hypertensive disorders of pregnancy \\
\hline HELLP & haemolysis, elevated liver enzymes, low platelets \\
\hline HIP & hypertension in pregnancy \\
\hline HREC & Human Research Ethics Committee \\
\hline $\mathrm{HT}$ & hypertensive \\
\hline IBM SPSS & Statistical Package for the Social Sciences \\
\hline
\end{tabular}




\begin{tabular}{|c|c|}
\hline ICU & Intensive Care Unit \\
\hline ID & identification \\
\hline IES & Impact of Event Scale \\
\hline ISSHP & $\begin{array}{l}\text { International Society of the Study of Hypertension in } \\
\text { Pregnancy }\end{array}$ \\
\hline MIB & Mother to Infant Bonding \\
\hline NHMRC & National Health and Medical Research Council \\
\hline NICE & National Institute for Health and Care Excellence (UK) \\
\hline P4 Study & Postpartum Physiology, Psychology and Paediatric Study \\
\hline $\mathrm{NICU}$ & Neonatal Intensive Care Unit \\
\hline NSW & New South Wales \\
\hline NT & normotensive \\
\hline OMRG & Obstetric Medicine Research Group \\
\hline OR & odds ratio \\
\hline PDS & Posttraumatic stress Diagnostic Scale \\
\hline PDS-5 & Posttraumatic stress Diagnostic Scale for DSM-V \\
\hline $\mathrm{PE}$ & preeclampsia \\
\hline PIS\&CF & Participant Information Sheet and Consent Form \\
\hline PMHS & Perinatal Mental Health Service \\
\hline $\mathrm{PP}$ & postpartum \\
\hline PPD & postpartum depression \\
\hline PPV & positive predictive value \\
\hline PRISMA & $\begin{array}{l}\text { Preferred Reporting Items for Systematic Reviews and } \\
\text { Meta-Analyses }\end{array}$ \\
\hline PSS & Posttraumatic stress Symptom Scale \\
\hline PSSR-SR & PTSD Symptom Scale Self-Report questionnaire; \\
\hline PTB & preterm birth \\
\hline PTSD & posttraumatic stress disorder \\
\hline SBP & systolic blood pressure \\
\hline SCL-90 & 90 item Symptom Check List \\
\hline STAI & State Trait Anxiety Inventory \\
\hline TPN & total parental nutrition \\
\hline UOR & unadjusted odds ratio \\
\hline
\end{tabular}


US

UTS

ZDS
United States

University of Technology Sydney

Zung Depression Scale 


\section{CHAPTER 1: BACKGROUND}

\section{Introduction}

Generally speaking, pregnancy and childbirth are happy events and society commonly assumes that it is an entirely positive experience for women. While this is true for the majority, those women who experience a complicated pregnancy or birth may have a very different experience. Increased levels of depression, anxiety and posttraumatic stress disorder (PTSD) have been reported amongst postpartum women following a complicated pregnancy (Simpson \& Catling 2016). The pregnancy, childbirth and parenthood experience differs for each woman and, further to having a complicated pregnancy, can depend on factors such as relationships, social networks, prior mental health issues and isolation (Austin, Fisher \& Reilly 2015).

Worldwide about $10 \%$ or pregnant women and $13 \%$ of women who have just given birth, experience a mental health disorder, primarily depression (World Health Organisation 2019). These rates are higher (15.6\% and $19.8 \%$ respectively) in low to middle income countries (World Health Organisation 2019). One in seven women experience depression in the year following birth and one in five experience anxiety, commonly in combination with depression, in the same period (Austin, Hadzi-Pavlovic, Priest, Reilly, Wilhelm, Siaint, et al. 2010). The global prevalence of postpartum PTSD is less certain and has been reported as 1-2\% (Ayers \& Pickering 2011) following childbirth, although a literature review by Simpson and Catling (2016), which included papers from several countries, found that $20-48 \%$ of women reported their birth as a traumatic event which could potentially lead to signs of PTSD.

In Australia, it is estimated that postnatal depression and/or anxiety affects one in six women sometime in the first 12 months following the birth of their child (Howard et al. 2014; Woolhouse et al. 2012), although it is not always clear whether these symptoms develop during or after the pregnancy (Howard et al. 2014). The reported rate may be influenced by the woman's relationships, 
social networks, feelings of isolation and previous life stressors (Austin, Fisher \& Reilly 2015). The prevalence of PTSD in Australia is reported at $6 \%$ in the postpartum population (Alcorn, O'Donovan, et al. 2010).

Pregnancy and childbirth are likely to be more stressful for women experiencing a pregnancy with complications. A complicated pregnancy is defined as a pregnancy where there is an increased risk of maternal and/or fetal complications, compared to a healthy pregnancy (Fairbrother et al. 2016) and implies a threat to the woman's health and well-being, her baby, or both (Lowdermilk, Perry \& Cashion 2010). One example of such a pregnancy is one complicated by a hypertensive disorder.

A complicated pregnancy that leads to life-threatening conditions, prolonged hospital stay, additional interventions and mother-baby separation may lead to poor mental health (Alcorn, O'Donovan, et al. 2010) and pre-existing depression may further increase the risk of PTSD (Andersen et al. 2012). Additionally, a complicated pregnancy may lead to fear, particularly in relation to subsequent pregnancy and birth (Tan et al. 2013). Considerable psychological distress may be experienced by women who give birth preterm, as may be the case in hypertensive pregnancy, particularly when the baby requires care in a specialised nursery for an extended period of time (Alcorn, O'Donovan, et al. 2010)

All of these factors are commonly experienced by women with or PE. As a psychological manifestation, stress may coexist with depression, anxiety and trauma reactions (Alcorn, O'Donovan, et al. 2010). It is therefore likely that women who experience $\mathrm{GH}$ or PE may be more at risk of poor mental health in the postpartum period, but it is not clear whether this is in fact accurate. A systematic review on depression, anxiety and PTSD following PE was undertaken by Delahaije et al. (2013) which showed mixed, and sometimes conflicting results, possibly due to the various study methodologies. However, the authors concluded that the associations that, in general, there was a higher prevalence/severity of psychopathology in women with previous PE compared 
to women without PE. All studies included in this review originated in The Netherlands, demonstrating a lack of evidence from Australian studies in this area of research.

Hypertension in pregnancy (HIP) is common and complicates $10 \%$ of pregnancies (Tranquilli et al. 2014). Annually this equates to approximately 30,000 pregnancies in Australia and 13 million globally. HIP is one of the leading causes of maternal and perinatal morbidity and mortality (Gillon et al. 2014). The two pregnancy-specific disorders are gestational hypertension (GH) and preeclampsia (PE).Women with other hypertensive disorders, including preexisting or secondary hypertension, are not included in this project as women with these diagnoses were excluded from the P4 Study.

Poor mental health can negatively impact both maternal and infant health. In addition to the effect on a woman's emotional welfare and daily functioning, it may impair her parenting ability and the formation of a relationship with her baby (Brockington, Butterworth \& Glangeaud-Freudenthal 2016). Long term and/or untreated poor maternal mental health have been associated with poor infant wellbeing, particularly with regard to behaviour and cognitive development (Beck \& Barnes 2006; Stein et al. 2014).

In the postpartum period, poor mental health is often undetected and untreated (Austin, Highet \& the Expert Advisory Committee 2017), potentially leading to a burden on the woman, her family, the health system and society. Government guidelines emphasize the importance of interventions targeting women displaying the early signs and symptoms of poor mental health (Austin, Highet \& the Expert Advisory Committee 2017; National Health Service 2014; NSW Health 2008; World Health Organisation 2008). However, it is not always clear which women in the postpartum period would benefit from intervention. If women who experience HIP are at risk of poor mental health, targeted screening and treatment may be useful. It is important that women are appropriately screened for mental health conditions in the perinatal period and provided with appropriate treatment and management pathways, and ongoing 
psychosocial support (Austin, Highet \& the Expert Advisory Committee 2017). It is equally important for midwives and other health care providers to be aware of the women who are more at risk of poor mental health to enable timely screening, referral and management pathways.

This chapter includes definitions and details of the topics that underpin this research project. This information will be presented firstly on the hypertensive disorders in pregnancy, with a focus on gestational hypertension and preeclampsia, and secondly, the mental health disorders depression, anxiety and PTSD.

\section{Hypertension in Pregnancy (HIP)}

HIP is defined by the International Society for the Study of Hypertension in Pregnancy (ISSHP) as a systolic blood pressure (BP) greater than or equal to $140 \mathrm{mmHg}$ and/or a diastolic BP greater than or equal to $90 \mathrm{mmHg}$ (Tranquilli et al. 2014). This definition is consistent with those of the Society of Obstetric Medicine of Australia and New Zealand (SOMANZ) (Lowe et al. 2015) and other associations around the world (Duetsche Gesellschaft fur Gynakologie und Geburtshilfe (DGGG) 2007; National High Blood Pressure Education Program Working Group 2000; Sandelowski 2003). The diagnosis of hypertension in pregnancy (HIP) is made when the elevated BP is confirmed by repeating the measurement several times over several hours in a day stay unit or overnight stay in hospital (Lowe et al. 2015; Tranquilli et al. 2014). Both the woman's systolic and diastolic levels of BP are important as an elevation of either has been associated with adverse maternal and fetal outcomes (Lowe et al. 2015).

Hypertensive disorders in pregnancy include those existing prior to the pregnancy (chronic hypertension) and those specifically related to, and caused by the pregnancy (gestational hypertension $(\mathrm{GH})$ and preeclampsia (PE)) (Brown et al. 2018; Lowe et al. 2015; Tranquilli et al. 2014). Women with either of the two pregnancy-specific disorders, GH or PE, were included in the P4 
study, and women with pre-existing hypertension were excluded. A description of the hypertensive disorders of pregnancy follows.

\section{Chronic hypertension}

Chronic hypertension exists prior to the pregnancy or is confirmed before the first 20 completed weeks of the pregnancy (Lowe et al. 2015). This category includes two main sub-groups: essential hypertension and secondary hypertension (Lowe et al. 2015).

Essential hypertension is high blood pressure without a known cause (Lowe et al. 2015), although there is often a family history of hypertension. Secondary hypertension is less common and is caused by an underlying health condition such as kidney disease, endocrine disorders, diabetes or congenital vascular abnormalities (Lowe et al. 2015). A sub-group within the essential hypertension classification is known as white coat hypertension. This occurs when women have elevated blood pressure in the clinical setting, but normal blood pressure recordings as measured by home monitoring or 24 hour ambulatory monitoring (Lowe et al. 2015).

Women who are diagnosed with chronic hypertension require increased monitoring during pregnancy as they have a $25 \%$ chance of developing superimposed PE (Brown et al. 2018). These rates may be higher for women who have underlying renal disease (Brown et al. 2018).

\section{Gestational hypertension}

$\mathrm{GH}$ is defined as the new onset of hypertension after 20 weeks gestation in the absence of proteinuria, without biochemical or hematological abnormalities, and not usually accompanied by fetal growth restriction (Brown et al. 2018). Pregnancy outcomes are usually good, however $25 \%$ of women with $\mathrm{GH}$ will develop PE, with the greatest risk being for women who present at less than 34 weeks gestation (Brown et al. 2018; Saudan et al. 1998). There are currently no 
tests available that can reliably predict which women with $\mathrm{GH}$ will develop PE at a later stage of their pregnancy (Brown et al. 2018), therefore continued monitoring of the woman and her baby is essential. Long term health check-ups are also necessary as women who have a history of $\mathrm{GH}$ are at increased risk of future cardiovascular disease (Wikström et al. 2015).

\section{Preeclampsia}

$P E$ is defined as the new onset of hypertension after 20 weeks gestation plus the involvement of at least one maternal organ system (most commonly the kidneys) and/or the unborn baby (Figure 1.1) (Brown et al. 2018; Lowe et al. 2015). BP should return to normal within three months postpartum (Brown et al. 2018; Lowe et al. 2015). Furthermore, there may be long term effects on the baby into adulthood (Wu et al. 2009), including hypertension and increased weight (Tenhola et al. 2006).

$\mathrm{PE}$ is a progressive disorder that usually worsens over time and the earlier it presents, the greater the risk of developing severe disease. It's course is unpredictable and increases the risk of adverse outcomes for both the woman and her baby. These adverse outcomes include placental abruption, pulmonary oedema, cerebral haemorrhage, eclampsia (seizures), in-utero fetal death or stillbirth (Lowe et al. 2015). PE contributes significantly to maternal, fetal and neonatal morbidity and mortality and the only known treatment is for the woman to give birth (Brown et al. 2018; Lowe et al. 2015; Tranquilli et al. 2014). This commonly means the baby is born preterm, requiring care in a specialised nursery. Resolution of the maternal disease usually occurs over a few postpartum days but may take weeks or months (Lowe et al. 2015; Tranquilli et al. 2014). 
Figure1.1 Definition of preeclampsia

Preeclampsia is gestational hypertension accompanied by one or more of the following new onset conditions at or after 20 weeks gestation:

Proteinuria. Although proteinuria is not required for a diagnosis to be made, it will be present in $75 \%$ of women diagnosed with PE.

Other maternal organ dysfunction including:

Acute kidney injury (serum creatinine $\geq 90 \mathrm{umol} / \mathrm{L}$ )

Liver involvement (ALT or AST >40IUL), with or without right upper quadrant or epigastric pain

Neurological complications (severe headache, visual disturbances, eclampsia, clonus, altered mental status, blindness, stroke)

Haematological complications (thrombocytopaenia: platelet count $<150000$

$\mu \mathrm{L}$, disseminated intravascular coagulation, haemolysis)

Utero-placental dysfunction (fetal growth restriction, abnormal umbilical artery Doppler wave form analysis, stillbirth)

PE may be diagnosed or recognised for the first time intrapartum or in the early postpartum period

Adapted from ISSHP Classification, Diagnosis, and Management Recommendations for International Practice (Brown et al. 2018)

PE is largely a silent disorder and in many cases there is an absence of symptoms until the mother and/or her unborn baby are very ill (Cowan, Redman \& Walker 2016). Ideally, women would be diagnosed at a time when she can be monitored and the birth can be planned to prevent serious complications (Cowan, Redman \& Walker 2016). However, in reality PE can fulminate quickly with little warning and may present in the postpartum period (Brown et al. 2018). The variability of the presentation and effects on the women and her unborn baby makes diagnosis challenging and women are often shocked and ill prepared for the diagnosis (Cowan, Redman \& Walker 2016).

A serious manifestation of PE is the HELLP syndrome (Brown et al. 2018; Lowe et al. 2015). The acronym HELLP was first used by Weinstein (1982) to 
describe a syndrome comprising Haemolysis, Elevated Liver enzymes and a Low Platelet count. Haemolysis arises as red blood cells become fragmented passing through narrow blood vessels. The elevated liver enzymes are thought to result from vasospasm and resulting cellular damage in the liver and may lead to sub-capsular hematoma or, rarely, liver rupture. Thrombocytopaenia may be due to increased consumption and/or destruction of platelets (Sibai et al. 1993). Although widely used in the literature, HELLP syndrome is not a separate disorder to PE and to avoid confusion, the term is not recommended by ISSHP (Brown et al. 2018). An explanation of HELLP has been included, as some of the references cited in this thesis refer to severe PE as HELLP syndrome.

\section{Eclampsia}

Eclampsia is the onset of seizures in women with PE and may occur in the antenatal, intrapartum and postpartum periods (Brown et al. 2018; Lowe et al. 2015). There are no reliable clinical markers to predict eclampsia, however neurological symptoms such as headache, visual disturbances or an altered level of consciousness are considered signs of impending eclampsia (Lowe et al. 2015). Not all women will have these warning signs and eclampsia is a rare event in Australia, occurring in $8.6 / 10,000$ singleton pregnancies $(0.1 \%$ of all births) (Thornton et al. 2013).

Previously it was thought that HIP was limited to the pregnancy and up to three months postpartum, and women made a recovery with little effect on their longterm health (Gamble et al. 2019). However it is now established that HIP, particularly PE, is associated with health problems beyond the pregnancy and postpartum period with a two to three times increased risk of cardiovascular disease (CVD) in later life including hypertension, coronary artery disease and stroke (Bellamy et al. 2007; McDonald et al. 2008; Williams 2011; Wu et al. 2017). Furthermore, there may be long term impacts on the baby into adulthood (Wu et al. 2009), including hypertension and increased weight (Tenhola et al. 2006). 


\section{Pathophysiology of preeclampsia}

The pathophysiology and etiology of PE is complex and not fully understood (Amaral et al 2017). However, there are several theories including a genetic predisposition and defective trophoblast invasion resulting in reduced placental perfusion leading to multiple maternal physiological disturbances (Baker \& Kingdom 2004). The abnormality in placentation leads to the release of angiogenic factors causing endothelial dysfunction (Uzan et al. 2011) resulting in vasoconstriction and vasospasm. The vasospasm causes BP to rise and decreases perfusion to other organs in the body and the unborn baby. It is thought that the tissue hypoxia explains the organ dysfunction and damage that is observed in the women (Brown et al. 2018; Lowe et al. 2015; Tranquilli et al. 2014).

Many hypotheses have been suggested as to the cause of PE. Scientific contributions throughout history have influenced the current understanding of the pathophysiology (Bell 2010) and have helped to shape current management.

\section{A brief history of preeclampsia}

The writings from ancient times suggest that, despite the lack of medical knowledge, the concept of eclampsia was recognised (Bell 2010). The first known description comes from the times of Hippocrates in the $5^{\text {th }}$ Century BC where it was documented that a headache accompanied by heaviness and convulsions during pregnancy was considered 'bad' (Bell 2010). Women who showed signs of eclampsia were treated by altering diets, purging and bloodletting in an effort to restore fluid balance in their body (Bell 2010).

In the Middle Ages, Christian beliefs influenced treatment and included charms, faith healing and prayers (Cianfrani 1960). In 1619, the word 'eclampsia' was first recorded (Ong 2004) and by the $18^{\text {th }}$ Century eclampsia had been 
distinguished from epilepsy and thought to be caused by nature trying to free the body of morbid elements (Temkin 1971).

In the late 1800 s, a causation theory of excessive toxins in the body led to a diet of fruit, vegetables and milk products as the toxins were believed to stem from meat (Chesley 1978). Around this time, the pre-eclamptic state was recognised and women with headaches and oedema were put on bed rest and bled to theoretically prevent convulsions (Johns 1843).

PE and eclampsia became more defined in the late 18th and early-mid 19th centuries, as signs and symptoms were more readily recognised (Bell 2010). In 1797, a connection was made between oedematous women and eclampsia (Chesley 1978), and albumin was discovered in the urine of women with eclampsia in 1843 (Thomas 1935). Johns (1843) listed pre-eclamptic symptoms including headache, temporary loss of vision, severe pain in the stomach, and oedema of the hands and face, while the discovery of hypertension and eclampsia was made by Vaquez and Nobecourt in 1897 (Chesley 1978).

Early in the $20^{\text {th }}$ Century there were two main approaches to treating PE and eclampsia; aggressive or conservative treatment (Bell 2010). Aggressive management meant facilitating prompt birth, usually by caesarean section, but this led to high maternal mortality rates and therefore became the less popular course of treatment (Chesley 1978). However, there was a belief that stimulating labour and birth increased the rates of eclampsia (Bell 2010). Conservative management was used up till the 1930s and often meant just treating the convulsions. Treatment included sedating the woman, keeping her in a dark, quiet room, and avoiding all stimuli until labour began naturally (Chesley 1978).

By the late 1960s, routine antenatal care included BP measurement, urinalysis and monitoring of maternal weight gain as a detection and surveillance method for PE. Once PE was diagnosed, management usually involved women being hospitalised with bed rest, frequent BP measurements, urinalysis, and weighing, 
in addition to fetal monitoring (Bell 2010). Health care providers were more aware of the symptoms of PE and included maternal headaches, blurred vision, and epigastric pain in their assessment (Bell 2010).

Antihypertensive medications were used over the later part of the $20^{\text {th }}$ Century to prevent or manage eclampsia and for acute hypertension (Bell 2010). At this time, consideration was also given to all aspects of the pregnancy and factors such as gestational age, maternal and fetal condition and the state of the cervix were taken into account when deciding on the timing of birth (Hibbard 1988). The classification of hypertension in pregnancy was further refined when Hibbard (1988), an obstetrician, formed subgroups in the 'hypertensive disorders of pregnancy' category in the late 1980s. He recognised a category of hypertension that was specific to pregnancy and created a subgroup termed 'pregnancy induced hypertension'. In this subgroup he listed PE as well as hypertension that developed in pregnancy but excluded the features of PE such as proteinuria. Although terminology has changed, this classification forms the basis of what we use today (Brown et al. 2018; Lowe et al. 2015; Tranquilli et al. 2014).

Since 2000, when the first Australian consensus statement regarding HIP was published by the Australasian Society for the Study of Hypertension in Pregnancy (ASSHP) (Brown et al. 2000), there have been several international and national guidelines published to standardise the diagnosis and treatment of HIP. These guidelines have undergone regular updates to incorporate current evidence, with the most recent being published by the International Society for the Study of Hypertension in Pregnancy (ISSHP) in June 2018 (Brown et al. 2018). The diagnosis of PE today is based on BP measurements, urinary and blood laboratory testing, physical examination and fetal ultrasound scanning. The timing and mode of birth depends on a balance of gestational age, maternal and fetal wellbeing and the severity of PE (Brown et al. 2018). It is likely that, as the current evidence continues to evolve, a more comprehensive understanding of HIP will be gained and guidelines will be updated accordingly. 


\section{Implications for women and babies}

Having HIP, particularly PE, can lead to a worrying and stressful time for the woman (Duffy et al. 2019). This stress may be due to the increased surveillance and assessment that is required following diagnosis (Duffy et al. 2019). Women diagnosed with HIP require frequent monitoring of themselves and their unborn baby (Brown et al. 2018; Lowe et al. 2015). This includes regular BP measurements, blood and urine testing to monitor organ function, physical examination and fetal wellbeing assessment through cardiotocograph (CTG) monitoring and ultrasound scanning including Doppler flow studies (Brown et al. 2018; Lowe et al. 2015). This monitoring may be done in a day stay setting where the woman attends several days a week for a few hours, or she may be admitted to hospital for closer surveillance (Brown et al. 2018; Lowe et al. 2015). Fetal surveillance in a day stay setting has been associated with good perinatal outcomes in women with various obstetric complications, including well controlled hypertension (Turnbull et al. 2004).

The stress of having HIP, particularly PE, may be further increased when the decision is made to end the woman's pregnancy (Duffy et al. 2019) to prevent further deterioration of maternal and/or fetal health (Brown et al. 2018; Lowe et al. 2015). This involves inducing the labour and/or performing a caesarean section (CS).

Induction of labour is an intervention to stimulate the onset of labour (RANZCOG 2016). It is undertaken when the risk of continuing the pregnancy is greater than the risk associated with the baby being born (McDonnell 2011). In the recent 2017 Mothers and Babies Report (Centre for Epidemiology and Evidence 2018), the induction of labour (IOL) rate was reported at $32.3 \%$ in New South Wales (NSW) for the year 2017. There are numerous indications for $\mathrm{IOL}$, however the most common reason in this report was prelabour rupture of membranes (15.5\%), with HIP listed fourth and accounting for $6.7 \%$ of IOLs (Centre for Epidemiology and Evidence 2018). Australian data do not present the real issue of IOL for HIP as the Australian Institute of Health and Welfare (2018) reports only on a select group of women (aged 20-34 years, 37-41 
weeks gestation, singleton pregnancy, vertex presentation) which is not always applicable to women experiencing HIP. Although there are no rates mentioned, specific health issues, such as hypertension, is listed first on the indications for IOL according to RANZCOG (2016). A large population data study linked birth and hospital details of women diagnosed with HIP in seven different countries, including Australia (Roberts et al. 2011). This study reported an IOL rate amongst women diagnosed with HIP at $24.6 \%$ and $29.02 \%$ in NSW and Western Australia (WA) respectively. The full extent of the IOL rate amongst women diagnosed with HIP is difficult to ascertain as HIP is often grouped with other medical conditions of pregnancy and IOL rates are often not reported within the HIP cohort.

A CS is an operation in which a baby is born through an incision made in the woman's abdomen and uterus (RANZCOG 2016). In the most recent Mothers and Babies Report (Centre for Epidemiology and Evidence 2018) the rate of CS in NSW in 2017 was $33.8 \%$ (21.3\% elective and $12.5 \%$ emergency CS). There were no indicators for CS listed in this report. A CS rate of $28.5 \%$ is reported by the Australian Institute of Health and Welfare (2018), however, this rate refers to the same select group of women as for IOL. In the HIP cohort studied by Roberts et al. (2011), a CS rate of $24.7 \%$ in NSW and $30 \%$ in WA was reported. For the same reasons mentioned above under IOL, the rate and impact of CS in women with HIP is not fully understood.

Both IOL and CS involve interventions and potential complications that the woman may not have prepared for. Her postnatal stay may be extended for continued monitoring and some women will need to spend time in an acute care setting such as the High Dependency Unit (HDU) or Intensive Care Unit (ICU) (Brown et al. 2018; Lowe et al. 2015; Tranquilli et al. 2014) during their postnatal admission. In addition to these maternal factors, women with HIP commonly give birth to a preterm baby (Roberts et al. 2011), who will require care in a nursery, which can further contribute to her worry and stress. Women may be separated from their baby if an ICU and/or nursery admission is 
required and further complicated if the baby needs to be transferred to another hospital for higher level care.

The care of women with HIP should encompass both their physical and mental health. Medical care, from an obstetrician and obstetric physician for example, is essential for women with HIP but it is equally important for midwifery care to continue. This midwifery and medical care is best provided in a multidisciplinary collaborative team approach, based on mutual respect, with both professions striving to help the women through her complicated pregnancy (Berg 2005). This model ensures comprehensive care utilising the specialised skills from each discipline is provided to the women (Benagiano \& Brosens 2014) and improves communication between medical staff, midwives and the women (Gonzalez \& Yukihiro 2013).

\section{Mental health}

Good mental health is a fundamental and essential component of health where individuals can cope with the normal stressors in life, work productively and contribute to the community (World Health Organisation 2014). It is associated with increased learning, creativity, positive social relationships, improved physical health and life expectancy (World Health Organisation 2014). In contrast, mental health conditions can cause distress, impact on everyday functioning and relationships, and are associated with poor physical health and early death from suicide (Beyond Blue 2019).

The specific mental health conditions addressed in this thesis are depression, anxiety and posttraumatic stress disorder (PTSD). For clarity, the terms mental health conditions and poor mental health are used throughout the thesis when discussing the general mental health of women. The specific terms depression, anxiety and PTSD are used when discussing these conditions specifically. 


\section{Depression}

One of the mental health disorders addressed in this thesis is depression. Depression, also named major depressive disorder or clinical depression is a mood disorder that causes a persistent feeling of sadness and loss of interest (American Psychiatric Association 2013). It affects the way people feel, think and behave and can lead to a variety of emotional and physical problems, which can impact on usual life-style activities (American Psychiatric Association 2013).

Depression is characterised by an episode of symptoms which lasts for at least two weeks, although most episodes last substantially longer, and escalates to a feeling of extreme hopelessness and the inability to function (American Psychiatric Association 2013; Austin, Hadzi-Pavlovic, Priest, Reilly, Wilhelm, Saint, et al. 2010; Buist \& Bilsztra 2006). According to the American Psychiatric Association (2013), depression is diagnosed if five or more symptoms are present for a two week period and represent a change from previous functioning (Figure 1.2).

\section{Figure 1.2 Symptoms of depression}

Depressed mood most of the day, nearly every day (feels sad, empty, hopeless) Diminished interest or pleasure in all, or almost all, activities, most of the day, nearly every day

Significant weight loss or gain, or decrease or increase in appetite nearly every day

Insomnia or hypersomnia nearly every day

Psychomotor agitation or retardation

Fatigue or loss of energy nearly every day

Feelings of worthlessness or excessive or inappropriate guilt nearly every day

Diminished ability to think or concentrate nearly every day

Recurrent thoughts of death

American Psychiatric Association (2013) 
In order to make a formal diagnosis of depression, the symptoms need to be causing significant distress in the person's normal functioning in social, family or work environments and not attributable to the use of any substances or another medical condition (American Psychiatric Association 2013).

\section{Postpartum depression}

Depression can occur at any time in life, including the perinatal period. The perinatal period begins at the time of conception through to the end of the first year following birth (Austin, Hadzi-Pavlovic, Priest, Reilly, Wilhelm, Saint, et al. 2010). The perinatal period is associated with a significant increase in risk for the onset or relapse of poor mental health, most likely due to the significant changes in a woman's life at this time (Austin, Hadzi-Pavlovic, Priest, Reilly, Wilhelm, Saint, et al. 2010; Buist \& Bilsztra 2006; Woolhouse et al. 2012).

According to the Australian Clinical Practice Guideline on Mental Health Care in the Perinatal Period (Austin, Highet \& the Expert Advisory Committee 2017), the symptoms of depressive disorders in the perinatal period are the same as those at other times and can range from mild to severe. In Australia, depression has been reported in one in ten pregnant women (Buist \& Bilsztra 2006) and one in six women at some time in the first postpartum year (Woolhouse et al. 2012).

Data from the 2010 Australian National Infant Feeding Survey (Australian Institute of Health and Welfare 2012) showed that $20 \%$ of women who had a child aged two years or less, had been diagnosed with depression. The majority of these women reported that this diagnosis was given in the perinatal period (Australian Institute of Health and Welfare 2012). Furthermore, of all the women diagnosed with depression, one in five were diagnosed for the first time during the perinatal period (Australian Institute of Health and Welfare 2012).

Persistence of depressive symptoms beyond one year postpartum has been reported in Australian studies as one in 11 women at four years following the birth (Giallo et al. 2017), and one in six women at six to seven years postpartum 
(Giallo, Cooklin \& Nicholson 2014). Interestingly, it is reported globally that many women meeting the Diagnostic and Statistical Manual of Mental Disorders criteria for depressive disorders (American Psychiatric Association 2013) are not identified (Coates, Schaefer \& Alexander 2004) and only one in ten women receive the mental health care they need (Bowen et al. 2012). The onset of postpartum depression (PPD) can occur at any time up to one year following the birth of the baby with the maximum prevalence occurring at three months postpartum (Beck 2006; Gavin et al. 2005). The most significant contributor to PPD is a previous mental health disorder (Robertson et al. 2004) with $20-40 \%$ of women who have experienced a previous episode, relapsing after a subsequent birth (Parent Infant Research Institute 2009). The Australian Clinical Practice Guideline on Mental Health Care in the Perinatal Period lists other risk factors for postpartum depression including social isolation, cultural isolation, life stressors (family problems, violence, disability) and multiple trauma (Austin, Highet \& the Expert Advisory Committee 2017).

Controversies exist regarding PPD, including whether it is a distinct disorder or part of major depressive disorder, and whether childbirth is a trigger for the onset (PACT Consortium 2015). One view is that PPD is separate from major depressive disorder, and that its risk is confined to the immediate postpartum period (PACT Consortium 2015), due to some women being sensitive to the fluctuations in hormones during this time (Bloch et al. 2005). The opposing viewpoint is that PPD is an episode of major depressive disorder that presents in the postpartum period (PACT Consortium 2015).

Women who experience PPD have difficulties completing everyday tasks and their ability to care for and nurture their child is compromised (ClosaMonasterolo et al. 2017). They also tend to experience problems with sleep, appetite, concentration and mood, and a reduction in overall happiness which may trigger suicidal thoughts (Closa-Monasterolo et al. 2017; Murray, Halligan \& Cooper 2010), all of which may affect their ability to care for themselves and their child. 
The literature around postnatal depression following a pregnancy complicated with hypertension is limited and mixed findings are reported. A systematic review undertaken by Delahaije et al. (2013), included six papers that reported on the prevalence and/or severity of depression following PE compared to depression reported by women who did not experience PE (Baecke, Spaanderman \& Van Der Werf 2009; Blom et al. 2010; Brusse et al. 2008; Engelhard et al. 2002; Gaugler-Senden et al. 2012; Stramrood et al. 2011). Delahaije et al. (2013) conclude that although nearly all studies showed a positive association between PE and the prevalence or severity of depressive symptoms, three studies did not reach significance (Brusse et al. 2008; Gaugler-Senden et al. 2012; Stramrood et al. 2011).

\section{Anxiety}

This thesis also examines anxiety symptoms in the postpartum period. The national guidelines in Australia highlight that feeling stressed or worried is a normal response to a demanding situation (Austin, Highet \& the Expert Advisory Committee 2017). These feelings usually subside once the triggering stimulus has passed or been removed. However, if these feelings continue or they exist without a reason or cause, the condition is classified as anxiety (American Psychiatric Association 2013).

Anxiety is feeling unreasonable fear, worry, and apprehension, or feelings of dread over something unlikely to happen (American Psychiatric Association 2013). Fear is an emotional response to a real or pending threat, whereas anxiety is the anticipation of a future threat (American Psychiatric Association 2013). Anxiety is associated with increased muscle tension and alertness in preparation for future danger, and cautious behaviour (American Psychiatric Association 2013). When anxiety becomes overpowering and distressing it may be diagnosed as an anxiety disorder (American Psychiatric Association 2013). There are subcategories of anxiety disorders including separation anxiety, social anxiety, panic disorder and generalised anxiety disorder (American Psychiatric Association 2013). The essential feature of separation anxiety 
disorder is excessive fear regarding separation from home or attachment figures (American Psychiatric Association 2013). The prevalence of separation anxiety disorder is highest in children under 12 years of age and decreases through adolescence and into adulthood (American Psychiatric Association 2013). Social anxiety disorder includes intense fear of social situations in which the individual fears being judged by others in a negative way (American Psychiatric Association 2013). The prevalence decreases with age and is more common in women (American Psychiatric Association 2013). Panic disorder refers to recurrent panic attacks with no obvious cue or trigger (American Psychiatric Association 2013). Attacks come on quickly as a surge of fear or discomfort with physical symptoms such as palpitations, sweating, shortness of breath and chest pain (American Psychiatric Association 2013). The prevalence of panic disorders increases from adolescence to adulthood and then decreases after 64, with women more frequently affected than men (American Psychiatric Association 2013). Generalised anxiety disorder is excessive worry where the person cannot control the worry, interfering with everyday tasks at home and work (American Psychiatric Association 2013). It is the most common of the anxiety disorders, with the prevalence peaking in middle age, and seen twice as often in women. Figure 1.3 on the next page shows the diagnostic criteria for generalised anxiety disorder as described in the DSM-V (American Psychiatric Association 2013).

Women who experience excessive worrying have an impaired ability to do everyday activities efficiently as the worry consumes their time and energy (American Psychiatric Association 2013). This problem may be exacerbated if they experience fatigue, sleep disturbance, lack of concentration and always feeling on edge (American Psychiatric Association 2013). This can have serious consequences, impairing their ability to cope with everyday life including caring for and bonding with their baby (Muzik et al. 2013) and, later, encouraging confidence in their children (American Psychiatric Association 2013). 


\section{Figure 1.3 Symptoms of generalised anxiety disorder}

Excessive anxiety and worry occurring more days than not, for at least six months about an activity or event

The worry is difficult to control

The anxiety and worry are associated with three or more of the following symptoms:

-Restlessness, feeling on edge

-Being easily fatigued

-Difficulty concentrating

-Irritability

-Muscle tension

-Sleep disturbance (difficulty falling or staying asleep, restless)

-The anxiety, worry, or symptoms cause significant impairment in social, occupational or other important areas or functioning

-The disturbance is not attributable to a substance or another medical condition

-The disturbance is not better explained by another disorder

American Psychiatric Association (2013)

The systematic review by Delahaije et al. (2013) included two papers that investigated the severity of anxiety symptoms in women following PE compared with women who were normotensive (Baecke, Spaanderman \& Van Der Werf 2009; Brusse et al. 2008). Both studies showed higher scores among women who had been diagnosed with $\mathrm{PE}$, but these differences were not significant (Delahaije et al. 2013).

\section{Depression and anxiety occurring together}

Depression and anxiety are usually considered separate conditions but they commonly coexist (Salcedo 2018). It is estimated that $60 \%$ of those with anxiety will also have symptoms of depression, and vice versa (Salcedo 2018). In the general population, adults with depression and anxiety usually have more 
depressive symptoms and episodes than those with depression alone (Pollack 2005). In addition, comorbid depression and anxiety lead to greater health care costs due to the challenges in treating the combined conditions (Boulanger et al. 2009).

During pregnancy, comorbidity with both conditions could lead to a higher incidence of preterm birth, compared to other vulnerable groups of women (Field et al. 2010). Studies have suggested that postpartum depression has received considerable research attention while postnatal anxiety has been relatively neglected (Bener, Gerber \& Sheikh 2012; Yelland, Sutherland \& Brown 2010). It has been established that depression and anxiety can coexist and that this comorbidity may be an indicator of the severity of mental health impairment (Austin, Hadzi-Pavlovic, Priest, Reilly, Wilhelm, Siaint, et al. 2010).

\section{Posttraumatic Stress Disorder}

The third mental health disorder addressed in this thesis is posttraumatic stress disorder (PTSD). PTSD has probably been part of history, known by many other names, for far longer than has been recognised. An early account from Samuel Pepys' diary in 1666 following the Great Fire of London describes symptoms of what we know today as PTSD. "I cannot sleep at night without great terrors of the fire, and this very night could not sleep to almost two in the morning through great terrors of the fire." (Cited in Daly, 1983, p. 66)

The posttraumatic stress response was documented during the First World War (1914-1918) with the concept of 'shell shock' (Andreasen 2010). Interest in PTSD decreased after the First World War but was reignited with the beginning of the Second World War in 1939. Following the Second World War, soldiers were seen to be experiencing symptoms similar to those seen previously, such as anxiety, reliving the events and having sensitivity to stimuli (Andreasen 2010). These symptoms were known by different names including traumatic war neurosis, combat fatigue, battle stress and gross stress reaction (Andreasen 2010). Over the next few decades, symptoms similar to those that the combat 
soldiers experienced were reported by civilians following natural disasters, head injuries, industrial accidents and burns (Adler 1945; Hamburg, Artz \& Reiss 1953; Nemiah 1963). Due to the realisation that war and non-war trauma could result in similar symptoms, psychiatrists developed a framework for the diagnosis and treatment of this disorder (Andreasen 2010).

The first framework to standardise these trauma-related symptoms came from the American Psychiatric Association in 1952 with the publication of the Diagnostic and Statistical Manual of Mental Disorders (DSM) (American Psychiatric Association 1952). In this edition, a category named Gross Stress Reaction covered the physical and mental stress following a natural catastrophe or warfare. Since this publication, the classification, diagnosis and treatment of PTSD have undergone several revisions. In the most recent revision of the DSM (DSM-V) published in 2013, PTSD is placed under the 'Trauma and Stressor Related Disorders' heading (American Psychiatric Association 2013).

PTSD is described as a set of reactions following exposure to a traumatic event (Figure 1.4). This exposure may be directly experiencing the trauma, witnessing it or being exposed to it in other ways, such as the traumatic event occurring to a close family member or friend (American Psychiatric Association 2013). Most people will have some symptoms of PTSD in the days following a traumatic event (Blanchard \& Hickling 2004) and will make a complete recovery, even in the absence of treatment (American Psychiatric Association 2013).

A diagnosis of PTSD may be considered if the emotional symptoms persist beyond 30 days following the exposure to the traumatic event and are associated with significant distress, impairment of the person's social interactions, capacity to work and in family life (American Psychiatric Association 2013). PTSD usually develops shortly after the event (Blanchard \& Hickling 2004) and symptoms can vary in response to reminders of the event or to a new life stressor (Blanchard \& Hickling 2004). 
In the DSM-V, PTSD is divided onto eight domains (American Psychiatric Association 2013). Each domain must be met in order for a diagnosis of PTSD (Figure 1.4).

Figure 1.4 Diagnosing Posttraumatic Stress Disorder

1. Exposure to actual or threatened death, serious injury, or sexual violence -Directly experiencing the event

-Witnessing, in person, the event as it happened to others

-Learning that the traumatic event happened to a close family member or close friend

-Experiencing repeated or extreme indirect exposure to details of the event

2. Intrusion Symptoms (at least one of these must be present)

-Recurrent, involuntary and distressing memories of the event

-Recurrent distressing dreams related to the event

-Dissociative reactions, such as flashbacks, in which the person feels the event was recurring

-Intense or prolonged psychological distress when exposed to matters that symbolise or resemble an aspect of the event

-Marked psychological distress when exposed to matters that symbolise or resemble an aspect of the event

3. Avoidance Symptoms (at least one of these must be present)

-Avoiding distressing memories, thoughts, or feelings about, or related to, the event

-Avoiding reminders of the event, such as people, places, conversations or situations, that arouse distressing memories, thoughts or feelings

4. Negative alterations in cognition and mood (at least two must be present) -Inability to remember an important part of the event -Persistent and exaggerated negative beliefs about self, others or the world -Distorted cognition about the cause of the event that leads to the person blaming themselves or others 
-Persistent negative emotional states like fear, anger, guilt or shame

-Diminished interest or participation in activities

-Feeling detached from others

-Persistent inability to experience positive emotions like happiness, satisfaction or loving feelings

5. Alterations in arousal (at least two must be present)

-Irritable behaviour and angry outbursts

-Reckless or self-destructive behaviour

-Hypervigilance

-Exaggerated startle response

-Problems with concentration

-Sleep disturbances such as difficulty falling and staying asleep or restless sleep

6. Duration of the disturbance (2-5) is more than one month

7. The disturbance causes significant distress in social, occupational, or other important areas of functioning

8. The disturbance is not attributed to a medical condition or to the effects of a substance such as medication or alcohol

American Psychiatric Association (2013)

\section{Posttraumatic stress and childbirth}

Despite PTSD being reported for many years, it is only recently that childbirth has been recognised as an event that could be perceived as traumatic and precipitate PTSD symptoms (Gamble \& Creedy 2007; Olde et al. 2006; Porcel et al. 2013). PTSD symptoms experienced by women following a traumatic childbirth experience are similar to those shown by the general population in relation to other traumatic events (Borg-Cunen et al. 2014). 
What constitutes a traumatic birth varies between women, is subjective and can be difficult to define (Simpson \& Catling 2016). Beck (2004) describes a traumatic birth as being in the eye of the beholder, as what one woman perceives as traumatic another may not. Porcel et al. (2013) describe it as a birth that involves actual or threatened serious injury or death to the woman or her baby where the woman feels strong fear, helplessness, loss of control or horror. Some researchers have reported a significant prevalence of PTSD following events such as perinatal loss, stillbirth and preterm birth (Engelhard, Van Den Hout \& Arntz 2001; Holditch-Davis et al. 2003; Turton et al. 2001). In some instances, childbirth can be a complex event and lead to a life threatening situation which may result in a variety of psychological responses (Borg-Cunen et al. 2014). This is certainly true for a pregnancy complicated by hypertension, hence the inclusion in this study.

The prevalence of PTSD following childbirth varies widely. In a recent systematic review and meta-analysis by undertaken by Yildiz, Ayers and Phillips (2017), the mean PTSD prevalence rate was reported as $4.9 \%$ at six months postpartum in the general global community, and $16.6 \%$ at six months postpartum in women from a high-risk pregnancy group.

It is important to recognise PTSD symptoms following childbirth, as the consequences in the woman's everyday life, future childbearing decisions and relationships with her baby and partner may be adversely affected (Davies et al. 2008; Dikmen-Yildiz, Ayers \& Phillips 2018; Hairston et al. 2018; Soltani et al. 2015; Yildiz, Ayers \& Phillips 2017).

\section{Support for depression, anxiety and posttraumatic stress disorder}

The potential negative effect of poor mental health on the woman, her relationship with her partner, mother-infant bonding and child development reinforces the need for early identification and effective treatment. Furthermore, there is increasing evidence that if individuals at risk of poor mental health can 
be identified early, targeted interventions can prevent around $25 \%$ of mental health conditions occurring (Cuijpers, Beekman \& Reynolds 2012).

There is a range of therapies for preventing and treating these postpartum mental health disorders that have been shown to be effective. These are summarised in the recent Australian guidelines (Austin, Highet \& the Expert Advisory Committee 2017). They include having support from family, friends and caregivers in the form of advice and information, practical help or emotional support. Participating in a social support group, such as a mothers group, playgroup, or a sporting group, may help to improve depressive symptoms postnatally and structured psychoeducation may also beneficial (NICE 2015). The latter is a therapeutic intervention facilitated by a psychologist or psychiatrist, that teaches problem-solving and communication skills and provides education and resources in either a one-to-one or group environment (NICE 2014). Cognitive behavioural therapy (CBT) is a highly effective treatment commonly used by psychologists for a range of mental health disorders such as depression, anxiety or PTSD, and is the most widely used evidence-based practice to improve mental health (Field, Beeson \& Jones 2015). CBT helps to challenge and modify the person's beliefs to promote behavioural change and improve functioning by teaching new coping strategies in stressful situations (Cuijpers et al. 2012).

\section{Bonding}

As poor mental health can interfere with the development of the mother-infant bond, bonding is also included in this thesis. The emotional bond that a mother feels towards her baby is critical to her child's social, emotional and cognitive development (Rossen et al. 2016). Maternal health and wellbeing during pregnancy can influence and strengthen the development of this bond, while factors such as a pregnancy complication, traumatic birth, or stress, can weaken the bond (Rossen et al. 2016).

While experiencing poor mental health in the postpartum period, some women will have neutral or negative feelings towards their infant (O'Higgins et al. 2013). 
Persistence of these feelings may adversely affect mother-infant bonding, especially during the first year of life (Muzik et al. 2013; O'Higgins et al. 2013). The human brain undergoes great development and growth in the first two years of life and this development is fostered by a loving relationship with a caregiver, usually the mother (Winston \& Chicot 2016). A lack of positive engagement or bonding affects the development of the child's brain and their social, emotional and cognitive wellbeing (Winston \& Chicot 2016). Without good initial bonding, children are less likely to become happy, independent and resilient adults (Winston \& Chicot 2016). O'Higgins et al. (2013) showed that early postnatal bonding was a major predictor of good bonding at one year and women experiencing postpartum depression struggled with early mother-infant bonding. Similarly, the mother's uncertainty over bonding styles may limit her ability to bond with her newborn during the early postpartum period (Hairston et al. 2018) leading to later attachment issues. Given that the beginning of an infant's life is a critical time for the development of the mother-infant bond, infants of women with postpartum depression may be at risk of short and long term attachment problems (Hairston et al. 2018; Winston \& Chicot 2016).

The project described in this $\mathrm{PhD}$ thesis investigated whether women who experienced HIP were at increased risk of depression, anxiety and PTSD in the postpartum period and whether there were mediating factors that helped them cope with the experience.

\section{Thesis structure}

This thesis has six chapters. The chapters are organised as follows: Introduction and Background (this chapter), Literature Review (Chapter 2), Design and Methods (Chapter 3), Results (Chapters 4 and 5), and the Discussion and Conclusion (Chapter 6 ). The following gives a brief overview of the contents of the chapters. 


\section{Chapter 1: Background}

Chapter 1 has provided the essential background information important to this study. The definitions of hypertension in pregnancy, particularly gestational hypertension and preeclampsia, and the mental health disorders, depression, anxiety and posttraumatic stress, were presented. The effect that these may have on the woman and her baby, including the formation of early bonding, were discussed.

\section{Chapter 2: Literature review}

Chapter 2 presents a narrative literature review. This review examines whether there is an association between depression, anxiety and PTSD in postpartum women with a history of HIP, accessing multiple electronic databases. The literature on this topic was limited, with 17 papers identified and included in the review. The evidence regarding each of the mental health disorders is presented and discussed separately.

\section{Chapter 3: Design and methods}

Chapter 3 describes the design and mixed methods approach of the two phases that make up the study. Phase One investigated the mental health and birth experiences of women following a pregnancy complicated by hypertension compared with women who had normal blood pressure in pregnancy using a survey design. Phase Two, the qualitative descriptive component, explored the birth experiences of women who had hypertension in their pregnancy, through face to face interviews. Included in this chapter are the rationales for choosing this study design and instrument selection, and a description of the analyses of the quantitative and qualitative data. 


\section{Chapter 4: Mental health and birth experience}

Chapter 4 presents the analysis of the quantitative component (Phase One). It begins with an overall description of the study cohort and then reports the outcomes of the women's pregnancy, labour and birth followed by the results of the mental health and birth experience questionnaires that were completed at six months postpartum.

\section{Chapter 5: The hypertension in pregnancy experience}

Chapter 5 is the second Results chapter and presents the results of the qualitative component of the study: the interviews. The birth experiences for women who experienced hypertension in their pregnancies are presented from their perspectives, and the challenges they faced identified. Furthermore, factors that helped them cope with the experience were identified. These results were published in the Midwifery journal (Roberts, Davis \& Homer 2017). The article is presented in this chapter in its original format with permission from the journal.

\section{Chapter 6: Discussion}

In this final chapter, the quantitative and qualitative findings are discussed in light of the current evidence and research available. This leads into a discussion on suggestions concerning the care women receive following a diagnosis of hypertension in pregnancy and how care can be improved to better their birth experience and resulting postpartum mental health. This chapter concludes with a description of the strengths and limitations of the study.

\section{Conclusion}

The background information contained in this chapter provided the definitions and some perspective relevant to my research project. In addition, it mapped out the structure of this thesis. The next chapter is a narrative review of the 
literature relevant to the project examining women's mental health following a pregnancy complicated with hypertension. This aim of this review was to examine whether there is an association between depression, anxiety and PTSD in postpartum women with a history of HIP and identify the gaps in the literature on this topic. 


\section{CHAPTER 2: LITERATURE REVIEW}

\section{Introduction}

A narrative literature review was undertaken to identify what had been published previously in the area of mental health following a pregnancy complicated with hypertension. The review was principally done early in the project in 2013, and updated in June 2019. The review examined what is known about mental health following a pregnancy complicated with hypertension, but importantly identified the gaps in knowledge, and the uncertainties that this project was aiming to answer. The review also helped identify the most appropriate screening instruments for the study.

\section{Aim}

The aim of this chapter was to undertake a review of the literature and examine whether women who had HIP were more likely to have postnatal mental health problems compared to women without HIP, specifically depression, anxiety or PTSD. The question posed in this review was: is there an association between depression, anxiety and PTSD in postpartum women with a history of HIP?

\section{Methods}

A narrative literature review was undertaken examining depression, anxiety and PTSD following a pregnancy complicated by HIP. A narrative literature review was considered suitable as it is based on critiquing the available literature, summarising the body of evidence, drawing conclusions about the topic and assists in identifying gaps or inconsistencies in the body of knowledge (Dudovskiy 2018). 


\section{Search strategy}

A comprehensive search of the literature was undertaken using the electronic databases of EBM Reviews (Cochrane Database of Systematic Reviews), EMBASE, Ovid MEDLINE(R), CINAHL (Cumulative Index to Nursing \& Allied Health), Maternity and Infant Care, PsycINFO and Google Scholar. The key search terms used were: preeclampsia, gestational hypertension, hypertensive disorders, pregnancy complications, depression, anxiety and post-traumatic stress disorder. All possible combinations and spellings of these key search terms were used. Additionally, the reference lists of suitable papers were manually screened for further studies that may have been missed in the initial search.

The search was limited to primary publications published in English from the year 2000 onwards, with available full text. Publications that were only available in abstract form, conference abstracts, and study protocols were excluded as were systematic reviews (Figure 2.1).

Two systematic reviews were excluded from this review. There was a concern that including the systematic reviews could lead to double counting of some studies. All relevant individual studies within these systematic reviews were included in this review. One systematic review (Furuta, Sandall \& Bick 2012) focussed on the relationship between PTSD and severe maternal morbidity. Several pregnancy complications were included, with PE being the primary variable in four publications (Baecke, Spaanderman \& Van Der Werf 2009; Engelhard et al. 2002; Hoedjes, Berks, Vogel, Franx, Visser, et al. 2011; Stramrood et al. 2011). The other systematic review (Delahaije et al. 2013) reported on depression and/or anxiety following a pregnancy complicated with severe PE and included six publications (Baecke, Spaanderman \& Van Der Werf 2009; Blom et al. 2010; Brusse et al. 2008; Engelhard et al. 2002; Gaugler-Senden et al. 2012; Stramrood et al. 2011).

Following title and abstract screening, 45 publications were identified for possible inclusion and the full text was sourced. Subsequent to full text reading, 
19 were considered relevant and were further assessed using the Critical Appraisal Skills Programme (CASP) (Critical Appraisal Skills Programme 2010). The CASP is a tool developed in 1993 in England which is widely used to systematically examine research articles to identify the strengths, weaknesses and usefulness of a study by appraising the validity, results and clinical relevance. Using the CASP checklist to assess the papers, 17 publications were assessed as suitable to include in the review. One publication was excluded as it reported on general quality of life following HIP and not specifically on depression, anxiety or PTSD (Rep et al. 2007). Although depression and anxiety are included in the screening instrument used (SQL-90), the overall results were reported as one score so specific effects on depression and anxiety could not be determined. The second publication excluded grouped the results of mental health following HIP with that of women who had experienced a postpartum haemorrhage and it was not possible to distinguish results specific to the HIP cohort. 
Figure 2.1. Publication selection

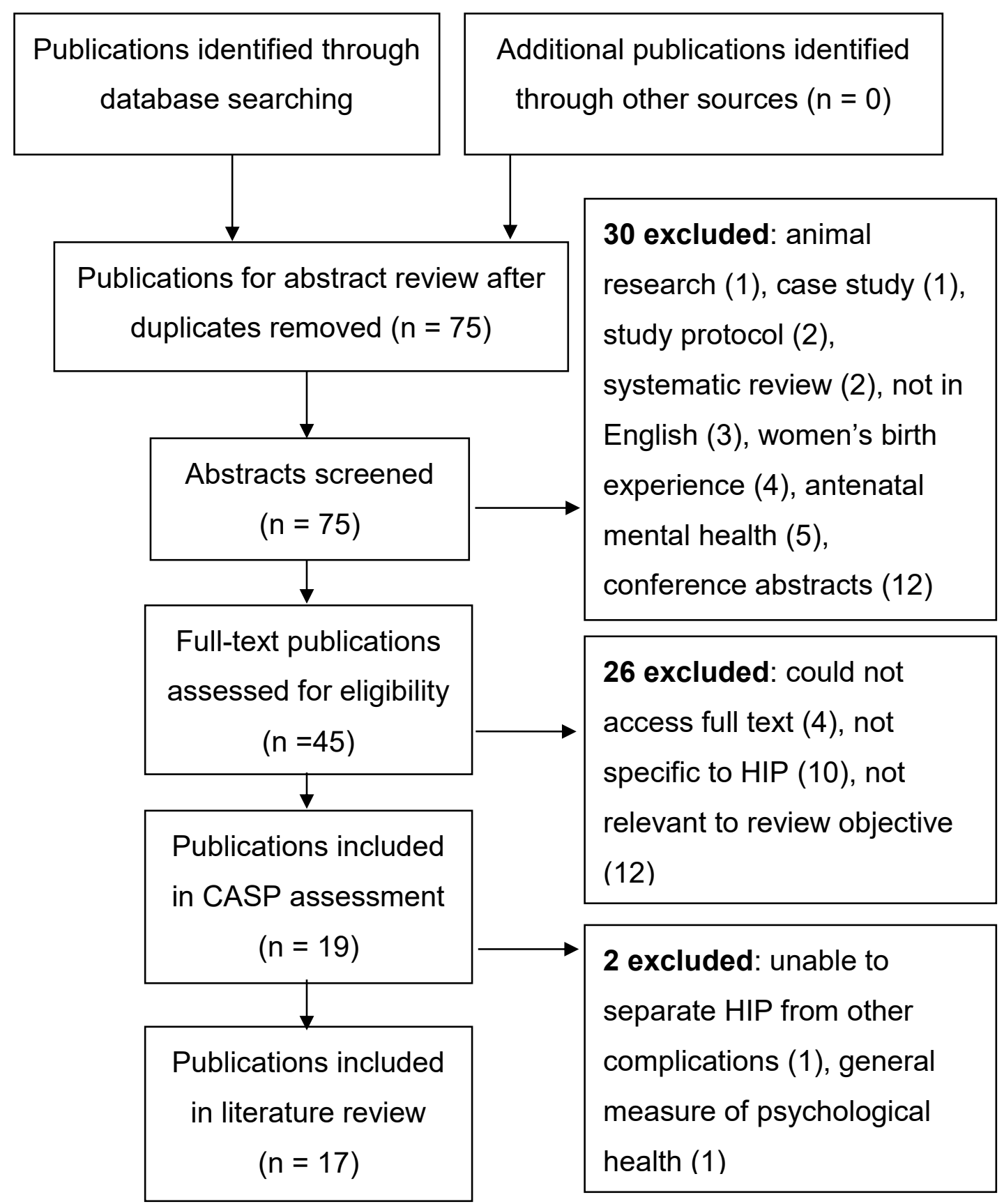




\section{Results}

The studies identified were grouped into three categories according to the mental health disorder addressed, that is, depression, anxiety or PTSD. Some studies reported on more than one of these conditions and were included in more than one group.

\section{The definition of HIP and the inclusion criteria}

In the included studies, the definition of HIP was sourced from different national and international guidelines (American College of Obstetricians and Gynecologists 2002; Duetsche Gesellschaft fur Gynakologie und Geburtshilfe (DGGG) 2007; National High Blood Pressure Education Program Working Group 2000; Tranquilli et al. 2014). (Table 2.1). Although these different sources were used, the definitions of the hypertensive disorders were consistent. However, the use of different study populations was not all directly comparable. For example, the severity of HIP varied, with some only including women with severe HIP and some only included women at a specific preterm gestation. Some studies reported on both prevalence and symptom severity. The results of depression, anxiety and PTSD were reported separately. 
Table 2.1. The definition of hypertension in pregnancy and inclusion criteria for the included studies

\begin{tabular}{|c|c|c|c|c|}
\hline \multirow{2}{*}{$\begin{array}{l}\text { Author } \\
\text { Year }\end{array}$} & \multirow[t]{2}{*}{ Source } & \multirow{2}{*}{$\begin{array}{l}\text { Gestational } \\
\text { Hypertension }\end{array}$} & \multicolumn{2}{|l|}{ Preeclampsia } \\
\hline & & & Mild & Severe \\
\hline $\begin{array}{l}\text { Abedian et al. } \\
2015\end{array}$ & ACOG & Not eligible & \multicolumn{2}{|c|}{ At least $\mathrm{BP} \geq 140 / 90$ and proteinuria $\geq 30 \mathrm{mg} / \mathrm{dl}$} \\
\hline $\begin{array}{l}\text { Baecke et al } \\
2009\end{array}$ & $\begin{array}{l}\text { National High Blood } \\
\text { Pressure Education } \\
\text { Program Working } \\
\text { Group }\end{array}$ & Not eligible & \multicolumn{2}{|c|}{$\begin{array}{l}\text { BP } \geq 140 / 90 \text { after } 20 \text { weeks gestation and proteinuria } \geq 300 \mathrm{mg} / 24 \text { hour } \\
\begin{aligned} \text { Two groups: } & <37 \text { weeks gestation } \\
& \geq 37 \text { weeks gestation }\end{aligned}\end{array}$} \\
\hline $\begin{array}{l}\text { Blom et al } \\
2010\end{array}$ & ISSHP & $\begin{array}{l}\mathrm{BP} \geq 140 / 90 \\
\text { after } 20 \\
\text { weeks } \\
\text { gestation }\end{array}$ & \multicolumn{2}{|c|}{$\mathrm{BP} \geq 140 / 90$ after 20 weeks gestation and proteinuria $\geq 300 \mathrm{mg} / 24 \mathrm{hour}$} \\
\hline $\begin{array}{l}\text { Brusse et al } \\
2008\end{array}$ & ACOG & Not eligible & Not eligible & $\begin{array}{l}\text { BP } \geq 140 / 90 \text { and de novo proteinuria } \geq 300 \mathrm{mg} / \text { day and one or } \\
\text { more of: } \\
\text { - } \mathrm{BP} \geq 160 / 110 \mathrm{mmHg} \text { on } 2 \text { occasions at least } 6 \text { hours } \\
\text { apart } \\
\text { - Oliguria of }<500 \mathrm{ml} / 24 \mathrm{hour} \\
\text { - Persistent headache or cerebral or visual disturbances }\end{array}$ \\
\hline
\end{tabular}




\begin{tabular}{|c|c|c|c|c|}
\hline & & & & $\begin{array}{l}\text { - } \text { Epigastric pain } \\
\text { - Increased serum creatinine level } \\
\text { - Impaired liver function } \\
\text { - Thrombocytopenia } \\
\text { - } \text { Fetal growth restriction }\end{array}$ \\
\hline $\begin{array}{l}\text { Chen } \\
2019\end{array}$ & ACOG & Not eligible & Not stated & \\
\hline $\begin{array}{l}\text { Englehard et al } \\
2002\end{array}$ & $\begin{array}{l}\text { National High Blood } \\
\text { Pressure Education } \\
\text { Program Working } \\
\text { Group }\end{array}$ & Not eligible & $\begin{array}{l}\text { Not stated } \\
\text { Two groups: }\end{array}$ & $\begin{array}{l}<37 \text { weeks gestation } \\
\geq 37 \text { weeks gestation }\end{array}$ \\
\hline $\begin{array}{l}\text { Fields et al. } \\
2017\end{array}$ & Not stated & Not eligible & \multicolumn{2}{|c|}{$\begin{array}{l}\text { Hospital adaptation of the International Classification of Disease codes used in } \\
\text { record linkage }\end{array}$} \\
\hline $\begin{array}{l}\text { Gaugler- } \\
\text { Sedden et al } \\
2011\end{array}$ & Not stated & Not eligible & Not eligible & $\begin{array}{l}\text { DBP } \geq 110 \mathrm{mmHg} \text { and proteinuria } 1 \mathrm{~g} / \mathrm{L} \text {, with or without } \\
\begin{array}{l}\text { Eclampsia or HELLP (platelet count }<100,000 / \mu \mathrm{L}, \mathrm{AST} \\
\text { or } \mathrm{ALT}>70 \mathrm{U} / \mathrm{L} \text {, lactate dehydrogenase }>600 \mathrm{U} / \mathrm{L} \text { ) } \\
\text { Two groups: } \quad<24 \text { weeks gestation } \\
\quad 24-32 \text { weeks gestation }\end{array}\end{array}$ \\
\hline
\end{tabular}




\begin{tabular}{|c|c|c|c|c|}
\hline $\begin{array}{l}\text { Habli et al } \\
2009\end{array}$ & Not stated & Not eligible & Not eligible & $\begin{array}{l}\text { HELLP } \text { - serum haptoglobin level }<0.24 \mathrm{~g} / \mathrm{L} \text { and } / \text { or lactic } \\
\text { dehydrogenase levels }>600 \mathrm{U} / \mathrm{L}, \mathrm{AST}>70 \mathrm{U} / \mathrm{L}, \mathrm{ALT}>70 \mathrm{U} / \mathrm{L} \text { and } \\
\text { platelet count } \leq 100,000 / \mu \mathrm{L} \\
\begin{aligned} \text { Two groups: } \quad<28 \text { weeks gestation } \\
\quad \geq 28 \text { weeks gestation }\end{aligned}\end{array}$ \\
\hline $\begin{array}{l}\text { Hoedjes et al } \\
2011 \\
\text { PND }\end{array}$ & ACOG & Not eligible & $\begin{array}{l}\text { BP } \geq 140 / 90 \\
\text { and } \\
\geq 300 \mathrm{mg} / \text { day } \\
\text { proteinuria } \\
\text { after } 20 \\
\text { weeks } \\
\text { gestation }\end{array}$ & 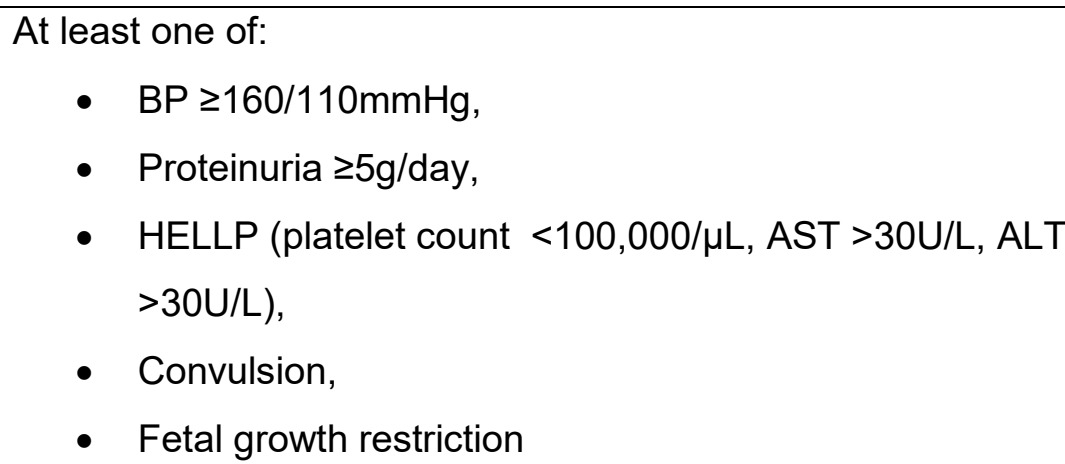 \\
\hline $\begin{array}{l}\text { Hoedjes et al } \\
2011 \\
\text { PTSD }\end{array}$ & $\begin{array}{l}\text { ISSHP (mild PE) } \\
\text { ACOG (severe PE) }\end{array}$ & Not eligible & $\begin{array}{l}\mathrm{BP} \geq 140 / 90 \\
\text { and } \\
\geq 300 \mathrm{mg} / \text { day } \\
\text { proteinuria } \\
\text { after } 20 \\
\text { weeks } \\
\text { gestation }\end{array}$ & $\begin{array}{l}\text { At least one of: } \\
\text { - } \text { BP } \geq 160 / 110 \mathrm{mmHg}, \\
\text { - } \text { Proteinuria } \geq 5 \mathrm{~g} / \text { day, } \\
\text { - } \text { HELLP (platelet count }<100,000 / \mu \mathrm{L}, \mathrm{AST}>30 \mathrm{U} / \mathrm{L}, \mathrm{ALT} \\
\quad>30 \mathrm{U} / \mathrm{L} \text { ), } \\
\text { - Convulsion, }\end{array}$ \\
\hline
\end{tabular}




\begin{tabular}{|c|c|c|c|c|}
\hline & & & & - $\quad$ Foetal growth restriction \\
\hline $\begin{array}{l}\text { Mautner et al } \\
2009\end{array}$ & German Guidelines & Not stated & Not stated & Not stated \\
\hline $\begin{array}{l}\text { Mommersteeg } \\
\text { et al. } \\
2009\end{array}$ & ISSHP & Not eligible & \multicolumn{2}{|c|}{$\begin{array}{l}\text { DBP } \geq 90 \text { with proteinuria }(\geq 0.3 \mathrm{~g} / 24 \mathrm{~h}) \\
20-32 \text { weeks gestation }\end{array}$} \\
\hline $\begin{array}{l}\text { Porcel et al } \\
2013\end{array}$ & None & Self-reported & Self-reported & Self-reported \\
\hline $\begin{array}{l}\text { Postma et al } \\
2014\end{array}$ & ISSHP & Not eligible & \multicolumn{2}{|c|}{$\begin{array}{l}\text { De novo hypertension after } 20 \text { weeks gestation plus proteinuria } \\
\text { Eclampsia: new onset of seizures in women with preeclampsia } \\
\text { Two groups: } \quad<34 \text { weeks gestation } \\
\qquad \begin{array}{l}234 \text { weeks gestation }\end{array}\end{array}$} \\
\hline $\begin{array}{l}\text { Postma et al } \\
2016\end{array}$ & ISSHP & Not eligible & \multicolumn{2}{|c|}{$\begin{array}{l}\text { De novo hypertension after } 20 \text { weeks gestation plus proteinuria } \\
\text { Eclampsia: new onset of seizures in women with preeclampsia }\end{array}$} \\
\hline $\begin{array}{l}\text { Stramrood et al } \\
2011\end{array}$ & ISSHP & Not eligible & Not stated & Not stated \\
\hline
\end{tabular}

Abbreviations: ACOG, American College of Obstetricians and Gynaecologists; ALT, alanine aminotransferase; AST, aspartate amino transaminase; BP, blood pressure; DBP, diastolic blood pressure; HELLP, Haemolysis, Elevated Liver enzymes, Low Platelets; ISSHP, International Society for the Study of Hypertension in Pregnancy; PE, preeclampsia. 
Figure 2.2. Summary of papers selected for review

Abedian et al. (2015) was a descriptive study from Iran. Women diagnosed with $P E(n=100)$ were studied at two weeks and again at six weeks postpartum for depression, anxiety and PTSD. The main focus of the paper was PTSD and the aim was to compare PTSD in primiparous $(n=56)$ and multiparous $(n=44)$ women.

Baecke, Spaanderman \& Van Der Werf (2009) was a cohort study from The Netherlands that included 170 women six to 18 months postpartum, and measured depression, anxiety and PTSD. Women with PE were included at term and preterm and compared to a normal group who gave birth at term and preterm. The main focus of this study was cognitive function after PE.

Blom et al. (2010) was a cohort study from The Netherlands that recruited 4941 women over a four year period with various pregnancy complications; HIP contributing 254 to the cohort and 770 in the normal comparison group. Women were recruited in the antenatal period and depression was measured at two months postpartum.

Brusse et al. (2008) was a pilot study from The Netherlands that assessed 20 women three to seven months postpartum. Depression and anxiety were measured in 10 women with a history of severe PE and 10 women who had a history of an uncomplicated pregnancy formed the normal comparison group. The main focus of this study was cognitive function after PE.

Chen et al. (2019) was a cohort study from China that examined depression at six week postpartum. The study cohort consisted of 90 women with a history of PE and 90 women, matched for the same time period of giving birth, who had normal blood pressure in pregnancy. The cohort was divided into two groups according to whether they screened positive for depression, and the analysis was performed comparing these two groups. 
Engelhard et al. (2002) was a cohort study from The Netherlands that recruited 113 women within two years of hospital admission. Women with a history of preterm and term PE were included and matched for gestational age with a normal group. Depression and PTSD were measured. The women and their partners completed the screening instruments via postal survey.

Fields et al. (2017) used medical data linkage to identify women for a long-term follow-up of cognitive impairment. Forty women who had a history of PE and 40 women with no such history were assessed at 35 to 40 years following their pregnancy. Depression and anxiety formed part of the overall assessment but are reported separately.

Gaugler-Senden et al. (2012) was a cohort study from The Netherlands that recruited 182 women who gave birth over an 11 year period. The cohort consisted of 104 women who had a history of preterm PE $(<32$ weeks gestation) and 78 women who had normal blood pressure in pregnancy, matched for gestational age at birth. Depression and PTSD was measured at two time points; women were asked to recall how they felt shortly after giving birth and at the current time which was seven years postpartum on average.

Habli et al. (2009) was a retrospective cohort study from the US, using the USbased HELLP Syndrome Support website to recruit 128 women. These women had experienced severe PE one to 31 years ago, with the mean follow-up being five years. Surveys were completed via post, telephone or interview.

Depression and anxiety were determined according to whether women reported being diagnosed by a physician with either of these mental health disorders.

Hoedjes et al. (2011) was a cohort study from The Netherlands that recruited 174 women within six weeks after the birth. Depression was measured in women who experienced mild or severe PE at three time points: six, 12 and 26 weeks postpartum. Comparisons were made between each time point and between mild and severe PE. 
Hoedjes et al. (2011) was a cohort study from The Netherlands, recruiting 149 women within six weeks after the birth. PTSD symptoms were measured in women who experienced mild or severe PE, at six and again at 12 weeks postpartum. Comparisons were made between each time point and between mild and severe PE.

Mautner et al. (2009) was a cohort study from Germany that recruited 90 women with a complicated pregnancy, between 24 and 37 weeks gestation. Depression was measured during the pregnancy, two to five days and three to four months postpartum. The cohort consisted of women with HIP $(n=18)$, gestational diabetes $(n=11)$, preterm birth (32) and an uncomplicated pregnancy $(n=29)$. Comparisons were made between time points and the different pregnancy groups.

Mommersteeg et al. (2016) was a long term follow-up study from The Netherlands examining depression and anxiety in women with a history of early onset PE (20 to 32 weeks gestation at onset), compared with an age matched non-PE group. Questionnaires regarding depression and anxiety were completed, on average 14 years after the index pregnancy.

Porcel et al. (2013) was a cross sectional online survey conducted via the worldwide Preeclampsia Foundation website. Women self-reported a diagnosis of HIP and were asked to invite friends and family who did not have a history of HIP to complete the survey, forming a normal comparison group. It was a large study with 1076 women in the HIP group and 372 in the normal comparison group. Time between the index pregnancy and the questionnaire completion is not specified.

Postma et al. (2014) was an observational cohort study from The Netherlands. It was a long term follow-up of women already participating in a research project. There were 46 women with a history of eclampsia, 51 with a history of PE and 48 women who had a normotensive pregnancy, matched for age. The average elapsed time since the index pregnancy was seven years. The main 
focus of this study was neurocognitive function after PE and eclampsia, however depression and anxiety were assessed.

Postma et al. (2016) was a retrospective cohort study from The Netherlands. Women with a history of eclampsia or PE were combined to form one group and the results were compared to women who were normotensive in their pregnancy. Although difficult to confirm, this study seems to have been an extension of the above study. The cohort consisted of 41 women with prior eclampsia, 49 with a history of PE, and 47 women with no such history. The main focus of the study was cerebral white matter lesions and cognitive functioning following HIP, with depression and anxiety included in the assessment.

Stramrood et al. (2011) was a prospective longitudinal cohort study from The Netherlands. The objective was to compare the prevalence and risk factors for PTSD in women with PE or preterm premature rupture of membranes (PPROM) compared to women with uncomplicated pregnancies. Women with PE were recruited in the antenatal period and depression and PTSD were measured at three time points: in pregnancy, six weeks and 15 months after the birth. The cohort consisted of women with PE or PPROM, and controls. 
Table 2.2. Summary of results from the included publications.

\begin{tabular}{|c|c|c|c|c|c|c|c|c|}
\hline \multirow{2}{*}{$\begin{array}{l}\text { Author } \\
\text { Year }\end{array}$} & \multirow{2}{*}{$\begin{array}{l}\text { Study } \\
\text { Design } \\
\text { Recruitment }\end{array}$} & \multirow[t]{2}{*}{ Location } & \multirow[t]{2}{*}{ Instrument } & \multirow{2}{*}{$\begin{array}{l}\text { When } \\
\text { measured }\end{array}$} & \multirow[t]{2}{*}{ Cohort (N) } & \multicolumn{3}{|l|}{ Results } \\
\hline & & & & & & Depression & Anxiety & PTSD \\
\hline $\begin{array}{l}\text { Abedian et al. } \\
2013\end{array}$ & $\begin{array}{l}\text { Descriptive } \\
\text { study }\end{array}$ & Iran & $\begin{array}{l}\text { BDI } \\
\text { STAI } \\
\text { PPQ }\end{array}$ & $\begin{array}{l}2 \text { weeks pp } \\
6 \text { weeks pp }\end{array}$ & $\begin{array}{l}P E(n=100) \\
56 \\
\text { primiparous } \\
44 \\
\text { multiparous }\end{array}$ & $\begin{array}{l}\text { No significant } \\
\text { difference at } \\
\text { both time } \\
\text { points } \\
\text { (no figures } \\
\text { given) }\end{array}$ & $\begin{array}{l}\text { No } \\
\text { significant } \\
\text { difference at } \\
\text { both time } \\
\text { points } \\
\text { (no figures } \\
\text { given) }\end{array}$ & $\begin{array}{l}\text { Mean } \\
\text { scores: } \\
\text { Primip } 4.4 \\
\text { Multip } 5.4 \\
(p=0.05) \\
\text { Prevalence: } \\
\text { Primip 21\% } \\
\text { Multip 32\% } \\
(p=0.24)\end{array}$ \\
\hline $\begin{array}{l}\text { Baecke et al } \\
2009\end{array}$ & $\begin{array}{l}\text { Cohort study } \\
\text { Recruited } \\
\text { after birth }\end{array}$ & $\begin{array}{l}\text { Netherlands } \\
1 \text { Hospital }\end{array}$ & $\begin{array}{l}\text { BDI } \\
\text { IES >25 } \\
\text { STAI }\end{array}$ & $\begin{array}{l}\text { 6-18 } \\
\text { months pp }\end{array}$ & $\begin{array}{l}\text { Preterm PE } \\
(n=48) \\
\text { Term PE } \\
(n=18) \\
\text { PTB }(n=32) \\
\text { Term birth } \\
(n=72)\end{array}$ & $\begin{array}{l}\text { Mean } \\
\text { scores: } \\
\text { Preterm PE } \\
2.7 \\
\text { Term PE } 1.3 \\
\text { PTB } 1.2 \\
\text { Term birth } \\
1.8 \\
(P=0.11)\end{array}$ & $\begin{array}{l}\text { Mean } \\
\text { scores: } \\
\text { Preterm PE } \\
39.9 \\
\text { Term PE } \\
39.6 \\
\text { PTB } 35.4 \\
\text { Term birth } \\
37.2 \\
(P=0.27)\end{array}$ & $\begin{array}{l}\text { Prevalence: } \\
\text { Preterm PE } \\
44 \% \\
\text { Term PE } \\
11 \% \\
\text { PTB 41\% } \\
\text { Term birth } \\
11 \% \\
(P<.001) \\
\text { Mean } \\
\text { scores: }\end{array}$ \\
\hline
\end{tabular}




\begin{tabular}{|c|c|c|c|c|c|c|c|c|}
\hline & & & & & & & & $\begin{array}{l}\text { Preterm PE } \\
25.3 \\
\text { Term PE } \\
10.5 \\
\text { PTB } 20.0 \\
\text { Term birth } \\
12.7 \\
(P<.001)\end{array}$ \\
\hline $\begin{array}{l}\text { Blom, et al } \\
2010\end{array}$ & $\begin{array}{l}\text { Prospective } \\
\text { cohort study } \\
\text { Recruited } \\
\text { antenatally }\end{array}$ & $\begin{array}{l}\text { Netherlands } \\
\text { Women in } \\
\text { Rotterdam } \\
\text { with EDC } \\
\text { 04/2002- } \\
01 / 2006\end{array}$ & EPDS $>12$ & $\begin{array}{l}2 \text { months } \\
\mathrm{pp}\end{array}$ & $\begin{array}{l}\text { PE }(n=183) \\
\text { Other } \\
(n=3917) \\
\text { Normal } \\
(n=770)\end{array}$ & $\begin{array}{l}\text { Prevalence: } \\
\text { PE } 16.9 \% \\
\text { GH } 7.6 \% \\
\text { PE increased } \\
\text { risk of PND } \\
\text { (OR } 2.58, \\
95 \% \text { Cl } 1.30- \\
5.14 \text { ) }\end{array}$ & & \\
\hline $\begin{array}{l}\text { Brusse et al } \\
2008\end{array}$ & $\begin{array}{l}\text { Cohort study } \\
\text { Recruited } \\
\text { after birth }\end{array}$ & $\begin{array}{l}\text { Netherlands } \\
1 \text { hospital }\end{array}$ & $\begin{array}{l}\text { CES-D } \\
\text { STAI }\end{array}$ & $\begin{array}{l}\text { 3-7 months } \\
\mathrm{pp}\end{array}$ & $\begin{array}{l}\text { PE }(n=10) \\
\text { Normal } \\
(n=10)\end{array}$ & $\begin{array}{l}\text { Median } \\
\text { scores: } \\
\text { PE } 7.5 \\
\text { Normal } 8 \\
(P=0.67)\end{array}$ & $\begin{array}{l}\text { Median } \\
\text { scores: } \\
\text { PE } 39 \\
\text { Normal } 31 \\
(P=0.21)\end{array}$ & \\
\hline $\begin{array}{l}\text { Chen et al. } \\
2019\end{array}$ & Retrospective & $\begin{array}{l}\text { China } \\
1 \text { hospital }\end{array}$ & EPDS $\geq 10$ & 6 weeks pp & $\begin{array}{l}\mathrm{PE}(\mathrm{n}=90) \\
\mathrm{N}(\mathrm{n}=90)\end{array}$ & $\begin{array}{l}\text { Mean } \\
\text { scores: } \\
\text { PE } 7.27 \\
\text { N } 4.42\end{array}$ & & \\
\hline
\end{tabular}




\begin{tabular}{|c|c|c|c|c|c|c|c|c|}
\hline & & & & & & $\begin{array}{l}(p=0.05) \\
\text { Prevalence: } \\
\text { PE 27\% } \\
\text { N 12\% } \\
(p=0.014)\end{array}$ & & \\
\hline $\begin{array}{l}\text { Englehard et } \\
\text { al } 2002\end{array}$ & $\begin{array}{l}\text { Cohort study } \\
\text { Recruited } \\
\text { after birth }\end{array}$ & $\begin{array}{l}\text { Netherlands } \\
1 \text { Hospital }\end{array}$ & $\begin{array}{l}\text { BDI>15 } \\
\text { PSS }\end{array}$ & $\begin{array}{l}\text { Within } 2 \\
\text { years of } \\
\text { hospital } \\
\text { admission }\end{array}$ & $\begin{array}{l}\text { Preterm PE } \\
(n=18) \\
\text { PTB }(n=29) \\
\text { Term PE } \\
(n=23) \\
\text { Term birth } \\
(n=43)\end{array}$ & $\begin{array}{l}\text { Prevalence: } \\
\text { Preterm PE } \\
33 \% \\
\text { PTB 24\% } \\
\text { Term PE } \\
26 \% \\
\text { Term birth } \\
7 \%\end{array}$ & & $\begin{array}{l}\text { Prevalence: } \\
\text { Preterm PE } \\
28 \% \\
\text { PTB 28\% } \\
\text { Term PE } \\
17 \% \\
\text { Term birth } \\
0 \%\end{array}$ \\
\hline $\begin{array}{l}\text { Fields et al. } \\
2017\end{array}$ & $\begin{array}{l}\text { Cohort study } \\
\text { Women } \\
\text { identified via } \\
\text { medical } \\
\text { record } \\
\text { linkage }\end{array}$ & US & $\begin{array}{l}\mathrm{BDI} \\
\mathrm{BAI}\end{array}$ & $\begin{array}{l}\text { Once, } \\
\text { average } \\
34.7 \text { years } \\
\text { since index } \\
\text { pregnancy }\end{array}$ & $\begin{array}{l}P E(n=40) \\
N(n=40)\end{array}$ & $\begin{array}{l}\text { Mean } \\
\text { scores: } \\
\text { PE } 4 \\
N 2 \\
(p=0.64)\end{array}$ & $\begin{array}{l}\text { Mean } \\
\text { scores: } \\
\text { PE } 3 \\
\text { N } 105 \\
(p=0.58)\end{array}$ & \\
\hline $\begin{array}{l}\text { Gaugler- } \\
\text { Senden et al } \\
2012\end{array}$ & $\begin{array}{l}\text { Cohort study } \\
\text { Recruited } \\
\text { after birth }\end{array}$ & $\begin{array}{l}\text { Netherlands } \\
1 \text { hospital } \\
\text { birthed } \\
1993-2004\end{array}$ & $\begin{array}{l}\text { ZDS } \\
\text { IES >19 }\end{array}$ & $\begin{array}{l}\text { In } 2008 \\
\text { Asked to } \\
\text { recall } \\
\text { symptoms } \\
\text { in pp period }\end{array}$ & $\begin{array}{l}\text { PE }(n=104) \\
\text { Normal } \\
(n=78)\end{array}$ & $\begin{array}{l}\text { Mean } \\
\text { scores: } \\
\text { Postpartum } \\
\text { recall: } \\
\text { PE } 11.78 \\
\text { N } 11.37\end{array}$ & & $\begin{array}{l}\text { Mean } \\
\text { scores: } \\
\text { Postpartum } \\
\text { recall: } \\
\text { PE } 29.72\end{array}$ \\
\hline
\end{tabular}




\begin{tabular}{|c|c|c|c|c|c|c|c|c|}
\hline & & & & $\begin{array}{l}\text { and at } \\
\text { current time }\end{array}$ & & $\begin{array}{l}(P=0.59) \\
\text { In 2008: } \\
\text { PE } 5.4 \\
\text { Normal } 5.51 \\
(P=0.87)\end{array}$ & & $\begin{array}{l}\text { Normal } \\
27.53 \\
(P=0.41) \\
\text { Currently: } \\
\text { PE } 28.66 \\
\text { Normal } \\
25.69 \\
(P=0.02)\end{array}$ \\
\hline $\begin{array}{l}\text { Habli et al } \\
2009\end{array}$ & Cohort study & $\begin{array}{l}\text { US } \\
\text { Advertised } \\
\text { on HELLP } \\
\text { Syndrome } \\
\text { Society } \\
\text { website }\end{array}$ & $\begin{array}{l}\text { Study } \\
\text { designed } \\
\text { survey }\end{array}$ & $\begin{array}{l}\text { 1-31 years } \\
\text { after birth }\end{array}$ & $\begin{array}{l}\text { HELLP } \\
(n=128)\end{array}$ & $\begin{array}{l}\text { Prevalence: } \\
32 \%\end{array}$ & $\begin{array}{l}\text { Prevalence: } \\
26 \%\end{array}$ & \\
\hline $\begin{array}{l}\text { Hoedjes et al } \\
2011\end{array}$ & $\begin{array}{l}\text { Prospective } \\
\text { cohort study } \\
\text { Recruited } \\
\text { within six } \\
\text { weeks pp }\end{array}$ & $\begin{array}{l}\text { Netherlands } \\
4 \text { hospitals }\end{array}$ & $\begin{array}{l}E P D S \geq 10 \\
E P D S \geq 13\end{array}$ & $\begin{array}{l}6 \text { weeks pp } \\
12 \text { weeks } \\
\text { pp } \\
26 \text { weeks } \\
\text { pp }\end{array}$ & $\begin{array}{l}\text { Mild PE } \\
(n=39) \\
\text { Severe PE } \\
(n=122)\end{array}$ & $\begin{array}{l}\text { Prevalence: } \\
(\geq 10) \text { at any } \\
\text { time: } \\
\text { Mild PE } \\
23.1 \% \\
\text { Severe PE } \\
44.3 \% \\
(P=0.018) \\
(\geq 13) \text { at any } \\
\text { time: }\end{array}$ & & \\
\hline
\end{tabular}




\begin{tabular}{|c|c|c|c|c|c|c|c|}
\hline & & & & & & $\begin{array}{l}\text { Mild PE } \\
15.4 \% \\
\text { Severe PE } \\
26.2 \% \\
(P=0.165)\end{array}$ & \\
\hline $\begin{array}{l}\text { Hoedjes et al } \\
2011\end{array}$ & $\begin{array}{l}\text { Prospective } \\
\text { cohort study } \\
\text { Recruited } \\
\text { within } 6 \\
\text { weeks pp }\end{array}$ & $\begin{array}{l}\text { Netherlands } \\
4 \text { hospitals }\end{array}$ & $\begin{array}{l}\text { Self-rating } \\
\text { Inventory } \\
\text { for PTSD }\end{array}$ & $\begin{array}{l}6 \text { weeks pp } \\
12 \text { weeks } \\
\text { pp }\end{array}$ & $\begin{array}{l}\text { Mild PE } \\
(n=35) \\
\text { Severe PE } \\
(n=114)\end{array}$ & & $\begin{array}{l}\text { Prevalence } \\
\text { total study } \\
\text { population: } \\
6 \text { weeks pp } \\
8.6 \% \\
12 \text { weeks pp } \\
5.1 \% \\
(P=0.083)\end{array}$ \\
\hline $\begin{array}{l}\text { Mautner et al } \\
2009\end{array}$ & $\begin{array}{l}\text { Prospective } \\
\text { cohort study } \\
\text { Recruited } \\
\text { antenatally } \\
\text { between } 24 \\
\text { and } 37 \\
\text { weeks } \\
\text { gestation }\end{array}$ & $\begin{array}{l}\text { Germany } \\
1 \text { tertiary } \\
\text { referral } \\
\text { hospital }\end{array}$ & $E P D S \geq 10$ & $\begin{array}{l}24-37 \\
\text { weeks } \\
\text { gestation } \\
2-5 \text { days } \\
\text { pp } \\
3-4 \text { months } \\
\text { pp }\end{array}$ & $\begin{array}{l}\text { HIP }(n=18) \\
\text { PTB }(n=32) \\
\text { Normal } \\
(n=29)\end{array}$ & $\begin{array}{l}\text { Mean } \\
\text { scores: } \\
\text { 2-5 days pp } \\
\text { HT } 7.83 \\
\text { PTB } 9.91 \\
\text { Normal } 4.69 \\
\text { 3-4 months } \\
\text { HT } 3.67 \\
\text { PTB } 6.53 \\
\text { Normal } 5.48 \\
\text { Prevalence } \\
\text { in HT: }\end{array}$ & \\
\hline
\end{tabular}




\begin{tabular}{|c|c|c|c|c|c|c|c|c|}
\hline & & & & & & $\begin{array}{l}39 \% \\
\text { antenatally } \\
27 \% 2-5 \\
\text { days pp } \\
17 \% 3-4 \\
\text { months pp }\end{array}$ & & \\
\hline $\begin{array}{l}\text { Mommersteeg } \\
\text { et al } \\
2016\end{array}$ & Cohort study & $\begin{array}{l}\text { Netherlands } \\
1 \text { hospital }\end{array}$ & $\begin{array}{l}\text { PHQ-9 } \geq 5 \\
\text { GAD-7 } \geq 5\end{array}$ & $\begin{array}{l}\text { Once, } \\
\text { average } 14 \\
\text { years after } \\
\text { index } \\
\text { pregnancy }\end{array}$ & $\begin{array}{l}P E(n=265) \\
N(n=268)\end{array}$ & $\begin{array}{l}\text { Prevalence: } \\
\text { PE 27\% } \\
\text { N 23\% } \\
(p=0.27) \\
\text { Mean } \\
\text { Scores: } \\
\text { PE } 3.6 \\
\text { N } 2.9 \\
(p=0.03)\end{array}$ & $\begin{array}{l}\text { Prevalence: } \\
\text { PE 31\% } \\
\text { N 27\% } \\
(p=0.33) \\
\text { Mean } \\
\text { Scores: } \\
\text { PE } 3.6 \\
\text { N } 3.5 \\
(p=0.72)\end{array}$ & \\
\hline $\begin{array}{l}\text { Porcel et al } \\
2013\end{array}$ & $\begin{array}{l}\text { Cross } \\
\text { sectional } \\
\text { online survey } \\
\text { First } \\
\text { pregnancy } \\
\text { 1990-2010 }\end{array}$ & $\begin{array}{l}\text { Worldwide } \\
\text { PE } \\
\text { Foundation } \\
\text { US based }\end{array}$ & $\begin{array}{l}\text { BSSS for } \\
\text { DSM IV } \geq 4\end{array}$ & Once & $\begin{array}{l}\text { HIP } \\
(n=1076) \\
\text { Normal } \\
(n=372)\end{array}$ & & & $\begin{array}{l}\text { Prevalence: } \\
\text { HIP } 43 \% \\
\text { Normal } 14 \% \\
(P=<0.01)\end{array}$ \\
\hline $\begin{array}{l}\text { Postma et al } \\
2014\end{array}$ & $\begin{array}{l}\text { Observational } \\
\text { cohort study } \\
\text { Recruited 1- } \\
27 \text { years after }\end{array}$ & Netherlands & HADS & $\begin{array}{l}\text { Once, at } \\
\text { least } 12 \\
\text { months } \\
\text { after the }\end{array}$ & $\begin{array}{l}\text { Eclampsia } \\
(n=46) \\
\operatorname{PE}(n=51)\end{array}$ & $\begin{array}{l}\text { Mean } \\
\text { scores: } \\
\text { Eclampsia } 5 \\
\text { PE } 4\end{array}$ & $\begin{array}{l}\text { Mean } \\
\text { scores: } \\
\text { Eclampsia } 7 \\
\text { PE } 6\end{array}$ & \\
\hline
\end{tabular}




\begin{tabular}{|c|c|c|c|c|c|c|c|c|}
\hline & $\begin{array}{l}\text { index } \\
\text { pregnancy }\end{array}$ & & & $\begin{array}{l}\text { index } \\
\text { pregnancy }\end{array}$ & $\begin{array}{l}\text { Normal } \\
(n=48)\end{array}$ & $\begin{array}{l}\text { Normal } 3 \\
(P=0.02)\end{array}$ & $\begin{array}{l}\text { Normal } 5 \\
(P<0.005)\end{array}$ & \\
\hline $\begin{array}{l}\text { Postma et al } \\
2016\end{array}$ & $\begin{array}{l}\text { Retrospective } \\
\text { cohort study }\end{array}$ & Netherlands & HADS & $\begin{array}{l}1-27 \text { years } \\
\text { since index } \\
\text { pregnancy } \\
\text { (mean=6 } \\
\text { years) }\end{array}$ & $\begin{array}{l}P E(n=90) \\
\text { Normal } \\
(n=47)\end{array}$ & $\begin{array}{l}\text { Mean total } \\
\text { scores: } \\
\text { PE } 11 \\
\text { N } 8 \\
(p<0.001)\end{array}$ & $\begin{array}{l}\text { Mean total } \\
\text { scores: } \\
\text { PE } 11 \\
\text { N } 8 \\
(p<0.001)\end{array}$ & \\
\hline $\begin{array}{l}\text { Stramrood et } \\
\text { al } \\
2011\end{array}$ & $\begin{array}{l}\text { Prospective } \\
\text { cohort study } \\
\text { Recruited } \\
\text { antenatally } \\
\text { when } \\
\text { hospitalised } \\
\text { (PE) or at } \\
\text { 38weeks } \\
\text { gestation } \\
\text { (controls) }\end{array}$ & $\begin{array}{l}\text { Netherlands } \\
1 \text { hospital } \\
1 \text { midwifery } \\
\text { practice }\end{array}$ & $\begin{array}{l}\text { BDI >20 } \\
\text { PSSR-SR }\end{array}$ & $\begin{array}{l}\text { Pregnancy } \\
6 \text { weeks pp } \\
15 \text { months } \\
\text { pp }\end{array}$ & $\begin{array}{l}P E(n=63) \\
\text { Normal } \\
(n=65)\end{array}$ & $\begin{array}{l}\text { Prevalence: } \\
\text { Pregnancy } \\
\text { PE 19\% } \\
\text { Normal } 7.7 \% \\
6 \text { weeks pp } \\
\text { PE 10.5\% } \\
\text { Normal } 6.2 \% \\
15 \text { months pp } \\
\text { PE 6.8\% } \\
\text { Normal 0\% }\end{array}$ & & $\begin{array}{l}\text { Prevalence: } \\
6 \text { weeks pp } \\
\text { PE } 10.5 \% \\
\text { Normal } 3 \% \\
15 \text { months } \\
p p \\
\text { PE } 11.4 \% \\
\text { Normal } 0 \%\end{array}$ \\
\hline
\end{tabular}




\section{Depression}

Of the 17 publications included, 15 examined the association between HIP and depression (Abedian et al. 2015; Baecke, Spaanderman \& Van Der Werf 2009; Blom et al. 2010; Brusse et al. 2008; Chen et al. 2019; Engelhard et al. 2002; Fields et al. 2017; Gaugler-Senden et al. 2012; Habli et al. 2009; Hoedjes, Berks, Vogel, Franx, Bangma, et al. 2011; Mautner et al. 2009; Mommersteeg et al. 2016; Postma et al. 2014; Postma et al. 2016; Stramrood et al. 2011). Eight reported on the prevalence of depression and ten on symptom severity, using mean or median scores of the screening instrument used. The majority of the studies were observational cohort studies $(n=14)$, and the other a descriptive design. The studies were conducted in The Netherlands $(n=10)$, United States (US) ( $n=2)$, and one each in Iran, China, and Germany. There were varied screening instruments used, and all except one have been validated in the adult population for accuracy and validity (Table 2.3).

\section{Prevalence of depression}

The reporting of the prevalence of depression after HIP varies widely from 744\% (Blom et al. 2010; Chen et al. 2019; Engelhard et al. 2002; Habli et al. 2009; Hoedjes, Berks, Vogel, Franx, Bangma, et al. 2011; Mommersteeg et al. 2016; Stramrood et al. 2011), which is up to four times higher than in the general postpartum population. This variation may be partly attributed to differences in study design, particularly in participant selection, severity of the hypertensive disorder, the screening instrument and the cut-off score used, or the timing of the evaluation.

When compared to women who did not have a history of HIP, a higher prevalence of depression was reported in women who experienced HIP (Blom et al. 2010; Engelhard et al. 2002; Mautner et al. 2009; Stramrood et al. 2011). It has been suggested that the impact on psychological or mental health was influenced by the severity of the HIP, as characterised by gestational age at the onset, the diagnosis ( $\mathrm{GH}$ vs $\mathrm{PE}$ ), maternal complications, or the adverse infant outcomes (Engelhard et al. 2002; Hoedjes, Berks, Vogel, Franx, Bangma, et al. 
2011). Blom et al. (2010) analysed data from women after GH or PE and reported the prevalence of postpartum depression to be higher in the PE group compared with the GH group (16.9\% versus $7.6 \%$ ). Similarly, when data from women after mild or severe PE were compared, the prevalence of depression was higher in women with more severe PE $(15.4 \%$ versus $26.2 \% \mathrm{p}=0.165)$ (Hoedjes, Berks, Vogel, Franx, Bangma, et al. 2011). These results suggest that the prevalence of postpartum depression increases as the severity of the hypertensive disorder increases however results were not always statistically significant (Hoedjes, Berks, Vogel, Franx, Bangma, et al. 2011; Mommersteeg et al. 2016).

A higher prevalence of depression was reported by women who gave birth preterm or term with PE compared to women who gave birth preterm or term with an otherwise uncomplicated pregnancy (Engelhard et al. 2002) (preterm PE 33\%, term PE 26\%, preterm birth 24\%, term birth 7\%) suggesting that the PE contributed to the depression. In contrast, a Dutch study reported no difference in depression for women who gave birth preterm with or without PE (Baecke, Spaanderman \& Van Der Werf 2009), suggesting that in that cohort it was the consequences of the preterm birth rather than the HIP per se were more strongly associated with depression.

When depression has been measured at several time points following HIP, the prevalence was shown to decrease over time. A decrease in prevalence from $27 \%$ at two-five days postpartum to $17 \%$ at three-four months postpartum was reported in one study (Mautner et al. 2009) and a decrease from $10.5 \%$ at six weeks postpartum to $6.8 \%$ at 15 months postpartum in another (Stramrood et al. 2011). However, there is no mention of any treatment undertaken during the period of the study, so it is unclear what contributed to the decline in depression.

\section{Depression symptom severity}

With regard to the severity of depressive symptoms, the evidence was mixed and inconclusive. Studies reported significantly higher mean scores by women 
following HIP compared with women with no such history (Chen et al. 2019; Mommersteeg et al. 2016; Postma et al. 2014; Postma et al. 2016). These results are not confirmed by others who report no significant difference in mean scores between women with or without prior HIP (Baecke, Spaanderman \& Van Der Werf 2009; Brusse et al. 2008; Fields et al. 2017; Gaugler-Senden et al. 2012), although there was a trend towards higher scores from women in the HIP group. Having a preterm birth, stillbirth or neonatal death was associated with higher depressive symptoms in one study $(\mathrm{B}=2.74,95 \% \mathrm{Cl}, 1.22-4.26$, $p<0.001$ ) (Mommersteeg et al. 2016) which reported on depression, on average, 14 years following the index pregnancy.

Abedian et al. (2015) reported no significant difference in scores between primiparous and multiparous women at both the two week and six week postpartum time points, following a pregnancy complicated with PE, although there were no details of the scores given in the publication. Baecke et al. (2009) found no significant differences in mean scores comparing four groups of women; preterm PE, term PE, preterm birth without HIP and term birth without HIP ( $p=0.11)$ (Baecke, Spaanderman \& Van Der Werf 2009). In a study of depression following eclampsia and PE, significantly higher mean scores were reported by eclamptic compared to preeclamptic women and those who were normotensive in pregnancy (eclampsia 5, PE 4, NT 3, p=0.02) (Postma et al. 2014).

Gaugler-Senden et al. (2012) compared mean scores of women with a history of preterm PE and preterm birth without PE at two time points. They reported no statistical difference in scores between the two groups at each time point, but noted that the mean scores improved with time. Women participating in this study were asked to recall and score symptoms from the immediate postpartum period for the first time point, and had an elapsed time of seven years, on average, since the index pregnancy at the second time point. 
Table 2.3 Summary of screening instruments for depression

\begin{tabular}{|c|c|c|c|c|c|}
\hline & Design & Score & Validated & Cost & Comments \\
\hline BDI & $\begin{array}{l}21 \text { questions. } \\
\text { Answer on feelings in past } 2 \\
\text { weeks } \\
\text { Scored on scale } 0-3\end{array}$ & $\begin{array}{l}>13 \text { indicates } \\
\text { depression } \\
\text { Higher scores } \\
\text { indicate greater } \\
\text { depressive symptoms }\end{array}$ & Yes & Yes & $\begin{array}{l}\text { Includes questions on tiredness } \\
\text { and sleeping difficulties }\end{array}$ \\
\hline CES-D & $\begin{array}{l}20 \text { questions } \\
\text { Answer on feelings in past } \\
\text { week } \\
\text { Scored on scale } 0-3\end{array}$ & $\begin{array}{l}\text { >15 indicates } \\
\text { depression } \\
\text { Higher scores } \\
\text { indicate greater } \\
\text { depressive symptoms }\end{array}$ & Yes & No & $\begin{array}{l}\text { Includes questions on tiredness } \\
\text { and sleeping difficulties }\end{array}$ \\
\hline EPDS & $\begin{array}{l}10 \text { questions } \\
\text { Answer on feelings in past } \\
\text { week } \\
\text { Scored on scale } 0-3\end{array}$ & $\begin{array}{l}\text { Higher scores } \\
\text { indicate greater } \\
\text { depressive symptoms }\end{array}$ & Yes & No & $\begin{array}{l}\text { Used widely through pregnancy } \\
\text { and the postpartum period }\end{array}$ \\
\hline HADS & $\begin{array}{l}14 \text { questions } \\
\text { Answer on feelings in past } \\
\text { week } \\
\text { Scored on scale } 0-3\end{array}$ & $\begin{array}{l}>10 \text { indicates } \\
\text { depression }\end{array}$ & Yes & No & $\begin{array}{l}\text { Mixture of questions regarding } \\
\text { depression and anxiety. } \\
\text { Depression and anxiety can be } \\
\text { scored separately }\end{array}$ \\
\hline
\end{tabular}




\begin{tabular}{|c|c|c|c|c|c|}
\hline & & $\begin{array}{l}\text { Higher scores } \\
\text { indicate greater } \\
\text { depressive symptoms }\end{array}$ & & & \\
\hline PQH-9 & $\begin{array}{l}9 \text { questions } \\
\text { Answer on feelings in past } 2 \\
\text { weeks } \\
\text { Scored on scale } 0-3\end{array}$ & $\begin{array}{l}>4 \text { indicates } \\
\text { depression } \\
\text { Higher scores } \\
\text { indicate greater } \\
\text { depressive symptoms }\end{array}$ & Yes & No & $\begin{array}{l}\text { Includes questions on difficultly } \\
\text { sleeping and energy levels }\end{array}$ \\
\hline SCL-90 & $\begin{array}{l}90 \text { questions } \\
\text { (13 questions on } \\
\text { depression) } \\
5 \text { point Likert Scale }\end{array}$ & & Yes & Yes & $\begin{array}{l}\text { Evaluates a broad range of ten } \\
\text { psychological problems, } \\
\text { depression one of them. } \\
\text { Includes question on low energy } \\
\text { levels }\end{array}$ \\
\hline ZDS & $\begin{array}{l}20 \text { questions } \\
\text { Scored on a scale of 1-4 } \\
\text { Answer on feelings in 'past } \\
\text { several days' }\end{array}$ & $\begin{array}{l}\text { Higher scores } \\
\text { indicate greater } \\
\text { depressive symptoms }\end{array}$ & Yes & No & $\begin{array}{l}\text { Includes questions on difficultly } \\
\text { sleeping and feeling tired }\end{array}$ \\
\hline
\end{tabular}


Abbreviations: BDI, Beck Depression Inventory (Beck, Steer \& Carbin 1988); CES-D, Center for Epidemiological Studies Depression Scale (Radloff 1977); EPDS, Edinburgh Postnatal Depression Scale (Cox, Holden \& Sagovsky 1987); HADS, Hospital Anxiety and Depression Scale (Zigmond \& Snaith 1983), PQH-9, Patient Health

Questionnaire (Kroenke, Spitzer \& Williams 2001); SCL-90, 90 item Symptom Check List (Schmitz et al. 2000); ZDS, Zung Depression Scale (Zung 1965) 


\section{Anxiety}

There were eight studies that investigated the association between HIP and anxiety (Abedian et al. 2015; Baecke, Spaanderman \& Van Der Werf 2009; Brusse et al. 2008; Fields et al. 2017; Habli et al. 2009; Mommersteeg et al. 2016; Postma et al. 2014; Postma et al. 2016). Prevalence of anxiety was reported in six of these studies and symptom severity in seven, using mean or median scores. Seven of the studies were observational cohort studies and one was a descriptive study. The studies originated from three different countries; The Netherlands $(n=5)$, US $(n=2)$ and Iran $(n=1)$. There were five different screening instruments used, all except one has been validated for accuracy and validity (Table 2.4 ).

\section{Prevalence of anxiety}

The prevalence of anxiety following HIP was included in two publications (Habli et al. 2009; Mommersteeg et al. 2016) and reported between 26-32\% which is slightly higher than the general postpartum population. Both of these studies were long term follow-up studies with assessment of anxiety undertaken up to 31years postpartum.

There was no difference found in the prevalence of mild anxiety in women who had experienced early onset PE compared to women without a history of PE (Mommersteeg et al. 2016), with a reported prevalence of $31 \%$ versus $27 \%$, respectively $(p=0.325)$. The average time elapsed since the index pregnancy in this study was 14 years. On further analysis adjusting for age, education level, body mass index (BMI), having a partner, being unemployed and physical activity, the results showed no difference in anxiety between the two groups of women.

The prevalence of anxiety in women who experienced the more severe classification of PE, HELLP syndrome, was reported as 26\% (Habli et al. 2009). In this study, anxiety was measured by women self-reporting a diagnosis of anxiety within one month of the birth, made by a physician and treated 
according. The gestation at the time of birth was not significant with $27 \%$ of those who gave birth at 28 weeks gestation or less and $26 \%$ of those women giving birth after 28 weeks gestation, reporting a diagnosis of postpartum anxiety ( $p>0.99)$.

\section{Anxiety symptom severity}

Seven studies reported on anxiety symptom severity using mean or median scores derived from a validated instrument (Abedian et al. 2015; Baecke, Spaanderman \& Van Der Werf 2009; Brusse et al. 2008; Fields et al. 2017; Mommersteeg et al. 2016; Postma et al. 2014; Postma et al. 2016). Higher scores were reported from women in the HIP group when compared with women in the normal comparison group, however the majority of studies did not reach statistical significance. The two studies that reported statistically significant higher anxiety scores in the PE group (Postma et al. 2014; Postma et al. 2016) were small studies where women completed the questionnaire, on average, six years after their pregnancy. The main focus of both these studies was cognitive functioning after a pregnancy complicated with PE, and there was no reporting of any other factors or life events that may have affected the woman's levels of anxiety.

No significant difference in anxiety scores was reported by primiparous compared with multiparous women at both the two week and six week postpartum time points, following a pregnancy complicated with PE (Abedian et al. 2015), although there were no details of the scores given in the publication. No significant difference in mean scores was found in the four groups studied by Baecke, Spaanderman and Van Der Werf (2009). These groups were women who experienced preterm PE, term PE, preterm birth without HIP and term birth without HIP ( $p=0.27)$. In a study examining anxiety following eclampsia and PE, statistically significant higher mean scores were reported by women who had experienced eclampsia compared to those women with a history of PE and those who were normotensive in pregnancy $(p<0.005)$ (Postma et al. 2014), suggesting that, not unexpectedly, the more severe the HIP, the more severe the anxiety. 
Table 2.4. Summary of screening instruments for anxiety

\begin{tabular}{|c|c|c|c|c|c|}
\hline & Design & Score & Validated & Cost & Comments \\
\hline BAI & $\begin{array}{l}21 \text { questions } \\
\text { Answered on } \\
\text { feelings in past } \\
\text { week } \\
\text { Scored on } \\
\text { scale } 0-3\end{array}$ & $\begin{array}{l}\text { 0-21 low anxiety } \\
22-35 \text { moderate anxiety } \\
>35 \text { potentially concerning } \\
\text { levels of anxiety }\end{array}$ & Yes & Yes & $\begin{array}{l}\text { Designed to minimise the overlap } \\
\text { between depression and anxiety }\end{array}$ \\
\hline GAD-7 & $\begin{array}{l}7 \text { questions } \\
\text { Answer on } \\
\text { feelings in past } \\
2 \text { weeks } \\
\text { Scored on } \\
\text { scale } 0-3\end{array}$ & $\begin{array}{l}0-5 \text { mild anxiety } \\
6-10 \text { moderate anxiety } \\
11-21 \text { severe anxiety }\end{array}$ & Yes & No & $\begin{array}{l}\text { Concludes with extra question about } \\
\text { the impact on everyday activities }\end{array}$ \\
\hline HADS & $\begin{array}{l}14 \text { questions } \\
\text { Answer on } \\
\text { feelings in past } \\
\text { week } \\
\text { Scored on } \\
\text { scale } 0-3\end{array}$ & $\begin{array}{l}>10 \text { indicates anxiety } \\
\text { Higher scores indicate } \\
\text { greater anxiety }\end{array}$ & Yes & No & $\begin{array}{l}\text { Mixture of questions regarding } \\
\text { depression and anxiety. Depression } \\
\text { and anxiety can be scored separately }\end{array}$ \\
\hline
\end{tabular}




\begin{tabular}{|l|l|l|l|l|l|}
\hline $\begin{array}{l}\text { SCL- } \\
90\end{array}$ & $\begin{array}{l}\text { 90 questions } \\
\text { (10 questions } \\
\text { on anxiety) } \\
5 \text { point Likert } \\
\text { Scale }\end{array}$ & Yes & Yes & $\begin{array}{l}\text { Evaluates a broad range of ten } \\
\text { psychological problems, anxiety is } \\
\text { one of them }\end{array}$ \\
\hline STAI & $\begin{array}{l}40 \text { questions } \\
\text { (20 on state } \\
\text { anxiety, } 20 \text { on } \\
\text { trait anxiety) } \\
4 \text { point Likert } \\
\text { Scale }\end{array}$ & $\begin{array}{l}\text { State and trait anxiety } \\
\text { scored separately. } \\
\text { Scores range from 20-80 } \\
\text { in each sub-scale } \\
>40 \text { clinically significant. } \\
\text { Higher scores indicate } \\
\text { greater anxiety }\end{array}$ & Yes & Yes & $\begin{array}{l}\text { Used widely in research } \\
\text { Lengthy questionnaire requiring 15-20 } \\
\text { minutes to complete }\end{array}$ \\
\hline
\end{tabular}

Abbreviations: BAI, Beck Anxiety Inventory (Beck et al. 1988); GAD-7, General Anxiety Disorder scale (Spitzer et al. 2006); HADS, Hospital Anxiety and Depression Scale (Zigmond \& Snaith 1983); SCL-90, 90 item Symptom Check List (Schmitz et al. 2000); STAI, State Trait Anxiety Inventory (Spielberger \& Sydeman 1994) 


\section{Posttraumatic Stress Disorder}

There were seven studies that investigated the association of PTSD with HIP (Abedian et al. 2015; Baecke, Spaanderman \& Van Der Werf 2009; Engelhard et al. 2002; Gaugler-Senden et al. 2012; Hoedjes, Berks, Vogel, Franx, Visser, et al. 2011; Porcel et al. 2012; Stramrood et al. 2011), with six reporting on prevalence and three reporting symptom severity using mean instrument scores. There were five observational cohort studies, one descriptive study and one cross-sectional on-line survey. The studies were conducted in The Netherlands $(n=5)$, Iran $(n=1)$ and the remaining one was a world-wide survey led by researchers in the US. All studies used validated instruments to screen for PTSD and there were five different instrument used (Table 2.5).

\section{Prevalence of PTSD}

The prevalence of PTSD following HIP varied between $5.1 \%$ and $43 \%$ across the seven studies. A higher prevalence of PTSD was reported in women who experienced HIP in some of the studies (Engelhard et al. 2002; Porcel et al. 2013; Stramrood et al. 2011). In the world-wide survey undertaken via the PE Foundation website (Porcel et al. 2013), 43\% of women with a history of HIP were screened positive for PTSD compared to $14 \%$ of women in the normal comparison group $(p<0.01)$. In this study, after adjusting for psychiatric treatment, parity and age at the time of the pregnancy, women with a history of PE were more than four times as likely to screen positive for PTSD when compared to women with a normotensive pregnancy $(\mathrm{OR}=4.46,95 \% \mathrm{Cl}: 3.20-$ $6.20)$.

The study by Stramrood, Wessel et al. (2011) measured PTSD at two postpartum time points (six weeks and 15 months) and compared results between women in the PE and normotensive groups at each of these time points. There were slight changes in prevalence in both groups $(10.5 \%$ to $11.4 \%$ in the PE group and $3 \%$ to $0 \%$ in the normotensive group), with the PE group consistently reporting a higher prevalence of PTSD. The other study to report PTSD prevalence at two time points (Hoedjes, Berks, Vogel, Franx, 
Visser, et al. 2011), found no statistically significant difference in PTSD prevalence in women with a history of $\mathrm{PE}$, at six weeks and 12 weeks postpartum, with reported rates of $8.6 \%$ and $5.1 \%$ respectively $(p=0.083)$.

Irrespective of the cause of the preterm birth, Baecke, Spaanderman et al. (2009) found that more women with a history of a preterm birth met the threshold score for PTSD than women who gave birth at term (preterm PE 44\%, preterm birth $41 \%$, term PE $11 \%$, term uneventful $11 \%$ ). This study suggests that the consequences of a preterm birth led to symptoms of PTSD, rather than the PE per se. $28 \%$ of women who gave birth preterm, with or without PE, met diagnostic criteria for PTSD in another study (Engelhard et al. 2002), again suggesting that the physical strain of PE does not contribute to the psychological morbidity, but the preterm birth is the trigger. However, when term women with and without a history of PE were compared, the term PE group reported a PTSD prevalence of $17 \%$ which is similar to the preterm PTSD prevalence, while the normotensive term group women had a PTSD prevalence of $0 \%$, suggesting that $\mathrm{PE}$ may be psychologically stressful.

A further study compared PTSD prevalence in multiparous and primiparous women with a history of PE (Abedian et al. 2015). Although the reported PTSD prevalence was higher in the multiparous PE group compared to the primiparous PE group, the result was not significant (32\% versus $21 \%$ respectively $p=0.24$ ) suggesting that parity is not a contributing factor.

\section{PTSD symptom severity}

There were three studies that reported on PTSD symptom severity following PE (Abedian et al. 2015; Baecke, Spaanderman \& Van Der Werf 2009; GauglerSenden et al. 2012), all with different study designs and all using a validated instrument to score PTSD symptoms.

When mean scores were compared between primiparous and multiparous women following PE, the results were not significantly different, although the 
multiparous women scored slightly higher (mean score 4.4 for primiparous women and 5.4 for multiparous women $p=0.05$ ) (Abedian et al. 2015).

With respect to gestational age at birth, the mean PTSD scores for women with a history of preterm birth, irrespective of the cause, were higher than the term birth group, suggesting that the consequences of a preterm birth contribute to more symptom severity (Baecke, Spaanderman \& Van Der Werf 2009).

Another study (Gaugler-Senden et al. 2012) compared mean PTSD scores between women with a history of preterm severe PE and preterm birth without $\mathrm{PE}$ at two time points. There was no difference reported in mean scores between the groups at the postpartum recall time-point. However, there was a significant difference (27.53 NT versus $29.72 \mathrm{PE}, \mathrm{p}=0.02$ ) between the groups at the time of the study being undertaken which was, on average, seven years after the index pregnancy, despite the mean score being slightly lower. There is no information about other life events that may have contributed to this difference. 
Table 2.5. Summary of screening instruments for PTSD

\begin{tabular}{|c|c|c|c|c|c|}
\hline & Design & Score & Validated & Cost & Comments \\
\hline BSSS & $\begin{array}{l}7 \text { yes/no } \\
\text { questions } \\
\text { Scored } 1 \text { for } \\
\text { 'yes', } 0 \text { for 'no' } \\
\text { Answered on } \\
\text { feelings in past } \\
\text { month }\end{array}$ & >4 PTSD & Yes & No & $\begin{array}{l}\text { Measures avoidance and numbing, } \\
\text { hyperarousal }\end{array}$ \\
\hline IES & $\begin{array}{l}22 \text { items } \\
\text { Scored on } \\
\text { scale 0-4 } \\
\text { Answered on } \\
\text { feelings in past } \\
\text { week }\end{array}$ & $\begin{array}{l}\text { 24-32 some symptoms } \\
\text { 33-37 probable diagnosis } \\
\text { of PTSD } \\
\text { >37 PTSD }\end{array}$ & Yes & No & $\begin{array}{l}\text { Measures intrusions, avoidance and } \\
\text { numbing, hyperarousal }\end{array}$ \\
\hline$P P Q$ & $\begin{array}{l}14 \text { items } \\
\text { Scored on } \\
\text { scale } 0-4\end{array}$ & $>18$ PTSD & Yes & No & $\begin{array}{l}\text { Designed to measure PTSD symptoms } \\
\text { related to childbirth and symptoms } \\
\text { during postnatal period }\end{array}$ \\
\hline
\end{tabular}




\begin{tabular}{|l|l|l|l|l|l|}
\hline & & & & & $\begin{array}{l}\text { Measures intrusions, re-experiencing, } \\
\text { avoidance and numbing, hyperarousal }\end{array}$ \\
\hline PSS & $\begin{array}{l}17 \text { items } \\
\text { Scored on a } \\
\text { scale 0-3 }\end{array}$ & 13 and over likely PTSD & Yes & Yes & $\begin{array}{l}\text { Measures re-experiencing, avoidance } \\
\text { and arousal } \\
\text { Based on DSM-IV }\end{array}$ \\
\hline $\begin{array}{l}\text { SRI for } \\
\text { PTSD }\end{array}$ & $\begin{array}{l}22 \text { items } \\
\text { Scored on a } \\
\text { scale 1-4 }\end{array}$ & >51 PTSD & Yes & & Based on DSM-IV \\
\hline
\end{tabular}

Abbreviations: BSSS, Breslau Short Screening Scale (Breslau et al. 1999); IES, Impact of Event Scale (Horowitz, Wilner \& Alvare 1979); PPQ, Perinatal Posttraumatic Stress Questionnaire (Callahan \& Borja 2008); PSS,

Posttraumatic stress Symptom Scale (Foa et al. 1993); SRI for PTSD, Self-rating inventory for PTSD (Hovens et al. 1994). 


\section{Discussion}

There is limited literature available to address the important issue of depression, anxiety and PTSD following pregnancies complicated by hypertension with only 17 studies identified that looked specifically at this association. The current evidence suggests that women with a history of HIP have a greater likelihood of depression and PTSD, but the heterogeneity, different study populations and different methods of assessment preclude any definitive interpretation. There was no association found between HIP and the prevalence or severity of postpartum anxiety in the majority of studies included in this review. The current literature also suggests that the severity of the HIP may be positively correlated with the severity of depressive, anxiety and PTSD symptoms. However, it is not clear what the main driver for the psychological morbidity might be - the physical strain of PE, the associated events such as a preterm birth or if it predated the pregnancy.

It is apparent that the literature on the psychological impact of HIP was methodologically varied, probably included selection and recall bias and most study sample sizes were small. There was a great variation in the study populations including gestation, severity of HIP and time since the index pregnancy. Furthermore several different instruments were used, along with different threshold cut-off scores to define an abnormal result. These methodological limitations made it difficult to determine if there is a true association between HIP and depression, anxiety and PTSD.

A key feature with the studies included in this narrative literature review is that they originate from just five countries; 11 from The Netherlands, three from the US, and one each from China, Germany and Iran. There is a paucity of evidence from an Australian population. It may not be possible to accurately translate the results of these studies to other countries, like Australia, due to the differences in culture, health care systems and management of HIP and/or mental health disorders. Cultural practices, differences in access and availability of, obstetric and psychiatric care and differences in emotional support provided 
may also influence the performance of the measuring tools. Some researchers (Guamaccia 1991; Sabone 2009) suggest that culture affects the response people make to psychiatric assessments due to the differences in their underlying attitudes, beliefs and behaviour. Beliefs of mental health distress, cultural understanding of mental health and culturally or context specific terms can also lead to different scores on measuring instruments (Bhui et al. 2003).

Previous reviews of women's mental health following HIP have made similar conclusions to those drawn here. A systematic review (Delahaije et al. 2013) reported on postpartum depression, anxiety and PTSD following a pregnancy complicated with HIP. The authors conclude that the evidence regarding depression is mixed but overall suggests an association between PE/HELLP and depression, with higher depression prevalence and severity in the women with previous PE/HELLP compared to women without such history. In regards to anxiety, there were no significant associations between PE and anxiety scores although higher scores were reported among women with PE. PTSD was reported in this same review and although higher PTSD prevalence and severity was reported by women following PE/HELLP, results were not statistically significant. In another systematic review (Furuta, Sandall \& Bick 2012) investigating the possible association between PTSD and several pregnancy complications, including $P E$, the authors conclude that there may be some evidence to suggest a link between PE and PTSD but the evidence was not robust (Furuta, Sandall \& Bick 2012). However, they suggest that PTSD and its symptoms may present following particularly severe cases of maternal morbidity (not specifically HIP), that involve poor neonatal outcomes.

\section{Conclusion}

While there is no definitive evidence that having HIP leads to increased postpartum depression, anxiety or PTSD, women who experience HIP may be at increased risk of developing these mental health disorders. This is particularly true for those women who experience the more severe forms of HIP and/or give birth preterm. Screening for these disorders in the postpartum 
period may be beneficial as this will alert clinicians to the need for additional follow-up and referral for women following HIP. More research on the benefits and risks of such an approach is needed. 


\section{CHAPTER 3: DESIGN AND METHODS}

\section{Introduction}

This chapter describes the mixed methods approach used to conduct the research. The project was divided into two phases. Phase One investigated the mental health and birth experiences of women following a pregnancy complicated by hypertension compared with women who had normal blood pressure in pregnancy using a survey design. Phase Two, the qualitative descriptive component, explored the birth experience of women who had hypertension in their pregnancy. The two phases of the project are discussed separately in this chapter and the findings presented as separate chapters (Chapters 4 and 5). For each phase, the chosen methodology and data collection methods, including the choice of screening instruments, is explained. Ethical considerations are included in addition to my personal reflections on reflexivity and challenges conducting the research.

\section{Research Design and Methods}

A mixed methods design, using both quantitative and qualitative approaches, was used. The study consisted of two phases. The first phase assessed the mental health of women and their birth experience using a quantitative design. The second phase aimed to better understand the experiences of women who had either gestational hypertension $(\mathrm{GH})$ or preeclampsia (PE) using a qualitative approach which enabled a deeper understanding.

\section{Mixed Methods Design}

Mixed methods research combines elements of quantitative and qualitative research approaches to provide a broader understanding of the problem being researched (Creswell 2013; Doorenbos 2014), through collecting a diverse range of data (Creswell 2013). A mixed methods design is useful in capturing 
the best of quantitative and qualitative methods, which generally leads to a better understanding of the research question (Creswell 2013).

The use of the mixed methods approach has grown in popularity over the past few decades (Buchbinder et al. 2002) with the most common approach being the triangulation design (Doorenbos 2014). The term 'triangulation' is used to describe a combination of at least two methodologies in the one study to decrease the bias inherent in using one method (Doorenbos 2014). For this study, the triangulation approach allowed different aspects of the research problem to be captured through the collection of both quantitative and qualitative data (Flick, von Kardorff \& Steinke 2004). The data were collected concurrently and were later integrated into the overall results to gain a deeper understanding of the research problem (Creswell 2013). The triangulation is described more fully in the Discussion chapter.

\section{Ethical considerations}

Ethical approval was given by the South East Sydney Local Health District (Northern Sector) Human Research Ethics Committee at Prince of Wales Hospital, Sydney: HREC/12/POWH/395. Site specific approval was given by St George Hospital Governance Office: SSA/12/G/224 (Appendix 1). Ethical ratification was granted by UTS: HREC Ref No 2013000234 (Appendix 2). Annual progress reports were submitted to the Research Support Office at Prince of Wales Hospital each year and acknowledgements were received.

When conducting research with human participants, consent and confidentiality are crucial considerations. In this study, consent was gained from all participants prior to participation. Eligible women were counselled about the study and given the Participant Information and Consent Form (Appendix 3 ) to assist in making an informed decision about the study. The Participant Information and Consent Form provided explanation of the purpose of the research, the data collection methods and how confidentiality and data storage needs were met. Formal written consent was obtained from each participant 
before commencing any study procedure. Participants were reminded that they were free to withdraw from the study at any stage without prejudice to their future care.

Confidentiality was maintained by allocating a study identification (ID) number to each woman. All identifying data were removed from the spreadsheets prior to undertaking the analyses. I was the only person who could re-identify the data and all data continue to be stored in a locked cabinet in a locked office accessible only by me. Electronic data continues to be stored on a password protected desk-top computer in my locked office. Following completion of the study, all data will be stored securely for 15 years, as per the National Health and Medical Research Council guidelines (NHMRC 2015) and then permanently destroyed.

\section{Aims and Objectives}

The overall objectives of this study were to investigate the mental health, specifically depression, anxiety and PTSD, of women and their childbirth experience at six to 12 months postpartum. Women who had a diagnosis of either $\mathrm{GH}$ or $\mathrm{PE}$, and women who had normal blood pressure in pregnancy were included. The specific aims were to:

- Describe depression, anxiety and Posttraumatic Stress Disorder (PTSD), of women in the local population six months after giving birth (Phase One)

- Identify any significant differences in mental health and the mother-baby relationship between women who had $\mathrm{GH}$ or PE and those who did not (Phase One)

- Identify any significant differences in how women felt about their birth experience between women who had GH or PE and those who did not (Phase One)

- Describe the pregnancy, birth and motherhood experience of the women who had either GH or PE (Phase Two) 


\section{Research questions}

The hypotheses for this project are that: women who experienced $\mathrm{GH}$ or PE will have poorer mental health (depression, anxiety and PTSD), a poorer relationship with their baby, and a worse birth experience than those women who did not experience hypertension in their pregnancy.

In order to meet the study aims, specific research questions were asked as detailed below.

\section{Phase One}

- Do women who experience GH or PE report more symptoms of depression, anxiety or PTSD than women who had normal blood pressure in pregnancy?

- Do women who experience GH or PE form the same relationship with their baby as women who had normal blood pressure in pregnancy?

- Do women who experience GH or PE describe their birth experience differently to women who had normal blood pressure in pregnancy?

\section{Phase Two}

- What are the pregnancy and birth experiences of women who are diagnosed with either $\mathrm{GH}$ or PE?

- Are there any mediating factors that help women during their pregnancy and birth experience?

In the following section, each phase of the study will be individually discussed in detail.

\section{Phase One: Using a survey to compare mental health and birth experience}

As stated earlier, Phase One used a quantitative approach. Quantitative research is a process for testing objective theories by investigating the 
relationship among variables (Daly et al. 2007). Data collected are in a quantified or numeric form (Clarke 2006). This form of research aims to establish statistically significant relationships, addresses questions by measuring and describing and, depending on the design, can address association, correlation and causation (Burns \& Grove 2005).

Quantitative methods may involve comparing variables. A variable is a factor that can be controlled or changed (Whiting 2008) and is either dependant or independent. The dependent variable is the variable that is thought to be affected by another variable while the independent variable is the cause or influence (Daly et al. 2007; Whiting 2008). There are also confounding variables which confuse or interfere with the relationship between the dependent and independent variables (Clarke 2006).

This project suited the quantitative process as the data collected from the screening instruments were in numeric form. The dependent variables were depression, anxiety and PTSD measured with validated instruments while the independent variable was the woman having either $\mathrm{GH}$ or $\mathrm{PE}$. Possible confounding variables included parity, pre-existing mental health disorders, having a caesarean section, giving birth prematurely, the baby requiring admission to a specialised nursery and the women being cared for in an acute care setting in the immediate postnatal period. If present, these variables could contribute to the development of depression, anxiety and/or PTSD.

\section{Setting}

The study was carried out at St George Hospital, a metropolitan teaching hospital located in southern Sydney, NSW which caters for approximately 2500 births per year. The hospital is classified by the NSW Ministry of Health as a Level Five Maternity Unit with the Special Care Nursery (SCN) classified at Level Four (Health System Planning and Investment Branch 2017). These classifications mean that women who are expected to give birth at less than 32 weeks gestation will be transferred to a higher level facility for the birth. The 
SCN at St George Hospital can accommodate babies who require continuous positive airway pressure (CPAP) or short term ventilation, but those needing long term ventilation are transferred to a facility with a Neonatal Intensive Care Unit (NICU) (Health System Planning and Investment Branch 2017). The nearest facility with a NICU is approximately $15 \mathrm{~km}$ away but, depending on the availability of neonatal cots, women and babies are sometimes transferred further afield.

Women booked to give birth at St George Hospital have several choices regarding their model of care. Some of these models, such as the birth centre and midwifery group practice, provide continuity of midwifery care and carer/s through the antenatal, intrapartum and postpartum periods. Other models, such as the midwife clinic and general antenatal clinic, offer limited continuity during the antenatal period with no known midwife during the intrapartum and postpartum periods. A small percentage of women have a private obstetrician.

Once a diagnosis of HIP has been confirmed, the woman is cared for by a multidisciplinary team, regardless of her insurance status and previous model of care. This team provides care in conjunction with the existing model care, and specialises in monitoring and treating hypertensive disorders. The team comprises midwives, a high risk obstetrician (unless the woman has a private obstetrician), and an obstetric physician. It offers continuity of care from both midwifery and medical clinicians antenatally, postpartum and follow-up for the mother six weeks to three months after birth.

\section{The Sample}

\section{Eligibility criteria}

This study was embedded in the larger P4 Study (discussed on page xiv). Women were eligible to participate in the P4 Study if they had given birth to a live single baby at St George Hospital, within the previous six months, had a good command of written and spoken English, and had no pre-existing medical 
conditions such as chronic hypertension, type I or II diabetes, kidney disease or other serious medical illnesses. Women with pre-existing or a history of mental health disorder were eligible.

\section{Sample size calculation}

The primary outcome of the P4 study was differences in blood pressure between the HT and NT groups. Therefore, the sample size calculation was based on blood pressure measures. The P4 study was powered on the proportion of average 24 hour average diastolic blood pressure (DBP) readings two or more standard deviations (SD) above the mean, for women who had normal BP in pregnancy (Davis et al. 2016). The calculated sample size for each of the hypertensive groups ( $\mathrm{GH}$ and PE) was 56 women, with a 95\% confidence level and $85 \%$ power. However, the aim was to recruit 90 women in each of these groups to allow for a $15 \%$ loss to follow-up and women becoming pregnant again during the five year study period. The number of women required in the normotensive group was calculated at 292 in order to construct a $95 \%$ reference range for normal values in a postpartum population (Davis et al. 2016).

Recruiting women to the P4 study was slower than expected and it was foreseen that the required sample size, based on BP measures, was not going to be reached in a time frame suitable for completion of this $\mathrm{PhD}$ project. Data collected from the first four years of recruiting to the P4 Study were used for this PhD project. Given the variability in the prevalence of mental health disorders reported in the literature discussed previously, a formal sample size calculation was deemed impractical. However the final sample size for this project: 237 women in the normotensive group and 84 in the hypertensive group (combined $\mathrm{GH}$ and $\mathrm{PE}$ ), was determined to be clinically relevant. 


\section{Identifying the women}

The ObstetriX system at St George Hospital was used to screen and identify eligible women. ObstetriX is an electronic perinatal database used in most NSW hospitals to record details of the pregnancy, labour, birth and postpartum stay for each woman booked into the hospital. A report, or query, was designed within this database to identify the women who gave birth at St George Hospital. This report also assisted with the eligibility screening by reporting data such as pre-existing medical problems, if an interpreter was required, whether it was a twin pregnancy and if there was a diagnosis of $\mathrm{GH}$ or PE.

\section{Recruitment details}

Women were informed of the study and recruited in the postpartum period. The invitation process occurred in one of two ways depending on whether the woman was on the postnatal ward or had been discharged:

1. The study was discussed with the woman and she was given the Participant Information and Consent Form prior to her discharge from the maternity ward. In these cases, a follow-up phone call was made at about four months postpartum if the woman had not responded to this invitation.

2. If the woman had been discharged from the postnatal ward, the invitation (Appendix 4) and Participant Information and Consent Form were posted to her home address four months following the birth of her baby. In this letter, the woman was asked to contact me if she was interested in participating in the study. A follow-up phone call was made two weeks after sending the letter if there was no response from the woman.

I was available to see women on the postnatal ward three days a week. The method of invitation was determined by whether the woman's postnatal stay aligned with my days of work.

For the purposes of this PhD project, women who gave birth from 1st January 2013 to 31st December 2016 were screened for eligibility, and if suitable were 
invited to participate. Screening and recruitment for the larger P4 Study continued beyond this time frame. A total of 321 women provided written, informed consent to participate in this study, 84 had either GH or PE while the remaining 237 were normotensive (had normal blood pressure) during their pregnancy.

\section{Data collection}

I was solely responsible for the data collection for the P4 study overall and, specifically, for this $\mathrm{PhD}$ project.

\section{General demographic data collection}

Prior to the six month postpartum assessment visit, data were sourced from the woman's paper based medical file stored in the Clinical Information Department of the Hospital and/or from her electronic file. The medical records were reviewed for details of previous pregnancies and births, along with any complications. For her most recent pregnancy, comprehensive details were recorded including her 'booking-in' (first antenatal visit) gestation, blood pressure, and Edinburgh Postnatal Depression Scale (EPDS) score.

The diagnosis of GH or PE was made by the attending medical staff, using the diagnostic criteria based on the SOMANZ Guidelines (Lowe et al. 2015). If the woman had a diagnosis or GH or PE in her recent pregnancy, details regarding the gestation of onset, antihypertensive medications used and any antenatal admissions were documented. Labour and birth details were collected in addition to the baby's birth weight, length, Apgar scores, details of nursery admissions and other medical issues.

Further information was obtained directly from the women. Each woman was asked to complete a questionnaire that was given to her at her six months postpartum assessment visit (Appendix 5). This questionnaire collected information on general demographics, her physical and mental health history 
and her physical and mental health since the birth of the baby. The questionnaire included questions specific to whether she had seen her local doctor regarding her mental health since giving birth and whether she had sought professional help, or been referred, for any mental health concerns. In addition, this questionnaire included the validated screening instruments which are described below.

\section{Mental health data collection at six months postpartum}

Mental health data were collected directly from the woman at six months postpartum through a questionnaire made up of four self-reporting validated instruments. Three instruments were used to screen for the mental health symptoms of depression, general anxiety and PTSD. The fourth instrument concerned the mother-infant bonding to determine if the mental health status of the woman affected her ability to bond with her baby. The selection of these instruments was made after the review of the literature and discussion with the psychiatrist associated with the P4 Study (Davis et al., 2016).

The instruments chosen were the Edinburgh Postnatal Depression Scale (EPDS) (Cox, Holden \& Sagovsky 1987), the General Anxiety Disorder (GAD-7) Scale (Spitzer et al. 2006), the Posttraumatic Stress Disorder Scale (PDS) (Foa 1995) or the PDS-5 (Foa et al. 2016), and the Mother to Infant Bonding Scale (MIB) (Taylor et al. 2005). Each of these screening instruments was selected for reliability, validity and ease of use for both the woman and researchers. It was important to select reliable instruments which were not too onerous for the woman to complete. The advantages of self-report instruments are that they incur minimal administration time and are economical to use. A limitation is that there is no clinical judgement involved (Foa et al. 1997) and there is limited opportunity for clarification of questions. They also rely on women having adequate literacy levels in English. If self-report instruments are used as a screening tool and respondents are followed up with a clinician as necessary, these limitations may be reduced (Foa et al. 1997). 
Each instrument is discussed in more detail in the next section.

\section{Edinburgh Postnatal Depression Scale (EPDS)}

The EPDS is a 10-item self-report instrument (Cox, Holden \& Sagovsky 1987). The woman is asked to select the most appropriate of four responses, for each of the ten statements that best describe how she has been feeling during the past seven days. Some of the possible responses include 'No, never' through to 'Yes, most of the time' or 'Hardly at all' to 'As much as I ever did'. Items on the scale correspond to various clinical depression symptoms, such as guilt, worry, low energy, anhedonia (not being able to enjoy yourself), and suicidal ideation. Each response is scored $0,1,2$ or 3 points according to the severity of symptoms. An overall assessment is determined by adding together these scores with a possible total score of 0-30. A higher score indicates more depressive symptoms.

The EDPS contains seven reverse scored statements in an effort to avoid acquiescent bias; when respondents to a questionnaire have a tendency to agree with all the questions or to indicate a positive response (Watson 1992). Both normal and reversed scored items are included in good quality instruments to ensure that the respondent considers all options carefully, to give a true response, leading to a more reliable result (Sauro \& Lewis 2011). The EDPS deliberately excludes some symptoms included in other depression screening instruments such as tiredness and irritability, as these are common feelings in the postnatal period (Cox, Holden \& Sagovsky 1987).

The EPDS was developed specifically as a tool for identifying signs of postnatal depression (Cox, Holden \& Sagovsky 1987). In the original validation study, a score of greater than 12 had a sensitivity of $86 \%$, specificity $78 \%$, and a positive predictive value (PPV) of 73\% (Cox, Holden \& Sagovsky 1987). However, since this original study, other researchers have found improved sensitivity, specificity and varying PPV. For example, Harris et al. (1989) demonstrated a sensitivity of $95 \%$, specificity of $93 \%$ and a PPV of $75 \%$ using a cut-off score of greater than 12, while Murray and Caruthers (1990) reported a sensitivity of $95.7 \%$, 
specificity of $81.1 \%$ and a PPV of $73 \%$ using the same cut-off score. These results suggest that the EPDS is a reliable and valuable screening instrument to identify depressive symptoms in postpartum women but it is important to note that it is not a diagnostic tool.

Today, the EPDS is widely used for screening the severity of depressive symptoms and to highlight the need for further care such as a full psychiatric assessment (NSW Health 2010). It is current policy in NSW that the EPDS is administered at the first point of contact with NSW Health during pregnancy (NSW Health 2010). This usually occurs at the first antenatal visit or is attended to as early as possible before 20 weeks gestation. Furthermore, it is now expected that all pregnant women in NSW are asked to complete the EPDS at 28 weeks gestation and six weeks postpartum no matter whether they are receiving maternity care through the public or private health system (Australian Government Department of Health 2017).

Cox, Holden and Sagovsky (1987) recommend a clinical assessment of women who score greater than 12 to confirm a diagnosis of depression. The EPDS has been validated, in relation to other standardised psychiatric measures, for use in the antenatal period (Murray \& Cox 1990), in the Australian postnatal population (Boyce, Stubbs \& Todd 1993), and in non-postnatal women (Cox et al. 1996). It is freely available, very easy for the woman to complete, and easy to score.

In the Australian guidelines, it is recommended that the woman completes the EPDS without help unless there are language and/or literacy problems (Cox, Holden \& Sagovsky 1987; NSW Health 2010). Most women complete the EPDS without difficulty in less than five minutes (Cox, Holden \& Sagovsky 1987). The EDPS may be administered any time during the pregnancy and after birth, with a minimum re-administration time of two weeks (Cox, Holden \& Sagovsky 1987; Murray \& Cox 1990; Murray \& Caruthers 1990). The EPDS was selected for this study because of its widespread use, proven reliability and validity, and ease of use. A cut off score of greater than 12 was used as the threshold for significant symptoms requiring follow-up. 
General Anxiety Disorder 7 (GAD-7) Scale

The GAD-7 is a self-report instrument, screening for and assessing the severity of generalized anxiety disorder (GAD) (Kroenke et al. 2007; Lowe et al. 2008; Spitzer et al. 2006). It comprises of seven items that describe prominent features of generalised anxiety such as excessive worry that is difficult to control, irritability and feeling on edge. Respondents are asked how often they have been bothered by each of the seven symptoms in the past two weeks. The response options are 'not at all', 'several days', 'more than half the days', and 'nearly every day'. Each response is scored 0, 1, 2, or 3 points according to the frequency of the symptoms. An overall assessment is determined by adding the scores for each core symptom, with a possible total score of 0-21. Scores greater than or equal to 5,10 , and 15 represents mild, moderate and severe anxiety levels, respectively (Spitzer et al. 2006; Swinson 2006). In addition to the seven statements, the GAD-7 concludes with a question about the impact that the symptoms have had on the respondent's everyday activities at home, work and socially.

The GAD-7 was developed in 2006 by Spitzer et al. (2006) as a tool for identifying probable GAD. The tool was evaluated for reliability and validity by comparing GAD-7 scores with the results of an interview with a mental health professional on a sample of 965 people of which 65\% were female (Spitzer et al. 2006). In this original validation, a score greater than or equal to 10 was determined to be the best threshold score for identification of GAD. At this threshold the specificity of the tool was $82 \%$ and the sensitivity $89 \%$ (Lowe et al. 2008; Spitzer et al. 2006).

The GAD-7 has been validated for use in the general population (Lowe et al. 2008), primary care settings (Kroenke et al. 2007), in clinical practice and research (Spitzer et al. 2006). It is freely available and easy to complete and score. The scale cannot be used as a replacement for clinical assessment and additional evaluation is needed to confirm a diagnosis of GAD (Kroenke et al. 2007; Lowe et al. 2008; Spitzer et al. 2006). 
The GAD-7 was selected for this study because of its reliability and validity, and ease of use. A cut off score of greater than or equal to 10 (moderate anxiety) was used as the threshold for requiring follow-up.

Posttraumatic stress Diagnostic Scale (PDS) and PDS-5

The Diagnostic and Statistical Manual of Mental Disorders (DSM) classifies all mental illnesses, their characteristics, and how they are diagnosed. At the beginning of this project the DSM-IV (American Psychiatric Association 1994) was in use. In May 2013, five months after this project began, the DSM released a fifth edition, the DSM-V (American Psychiatric Association 2013).The new edition included changes in how PTSD was diagnosed. PTSD was categorised with the anxiety disorders in the DSM-IV (American Psychiatric Association 1994), but was moved into a separate chapter called "Trauma- and Stress-Related Disorders" in the DSM-V (American Psychiatric Association 2013). In addition to this change, a new symptom cluster for PTSD 'Negative cognition and mood' was added which included inability to recall important aspects of an event and persistent inability to experience positive emotions. The changes in the DSM-V had a significant impact on this project including having to change from using the PDS to the PDS-5. The next section describes both of the instruments used and the reasoning behind their use.

PDS

The PDS is a self-report tool that screens for PTSD in respondents who have identified themselves as being previously exposed to a traumatic event either by directly experiencing it, witnessing it or being repeatedly confronted by it. It also assesses the severity of symptoms and functional level of respondents who have already been diagnosed with PTSD (Foa et al. 1997; Foa et al. 2016). The scale consists of 49 items and is divided into four sections;

i) identifying the traumatising event,

ii) event details, including when it occurred and the persons response,

iii) symptom severity, and

iv) impairment of life functioning caused by symptoms. 
The scale begins with a checklist of 12 traumatic events, including an 'other' category. If exposure to at least one of these traumatic events is not identified in this first part, the respondent does not continue. Pregnancy or childbirth is not listed in this checklist, although there are categories that may apply to the stressors of childbirth. These include 'life threatening situation' which could apply to a preterm baby or a serious complication affecting the woman. The 'other' category could also be used for stressors relating to pregnancy and childbirth.

There are 17 items referring to the frequency of the PTSD symptoms experienced in the preceding 30 days. These are scored on a four point scale from 'Not at all or only one time' to ' 5 or more times a week/almost always'. A score of $0,1,2$, or 3 is allocated according to the frequency of symptoms; the higher the frequency, the higher the score. Life impairment is measured by a 'yes' or 'no' response in areas such as work, relationships, leisure activities and general satisfaction with life.

The PDS was developed by Foa et al. (1993) and has been validated for accuracy (Foa et al. 1997; Foa et al. 2016) incorporating all diagnostic criteria of PTSD as set out in the DSM-IV (American Psychiatric Association 1994).

Validation of the instrument was undertaken using the gold standard structured clinical interview after the administration of previously validated self-report instruments and the PDS. Analysis showed an 82\% agreement between PTSD diagnosis using the PDS and the interview (Foa et al. 1997) in a sample of 1865 year olds who had experienced a variety of traumatic events.

The PDS was designed to evaluate PTSD symptoms following exposure to a broad range of stressful situations including war, natural disasters, assault, injury and life threatening conditions. Foa et al. (1997) suggest that the PDS can be used following exposure to any traumatic event by using the "other" category in the list of stressors. The PDS is not specifically designed to be used following childbirth and does not contain statements that specifically apply to childbirth. However, childbirth can be traumatic for some women for many 
different reasons including having a pregnancy or labour/birth complication, stillbirth, or being in a life threatening situation (Ayers \& Pickering 2011; De Schepper et al. 2015), making the PDS appropriate for use following childbirth.

The advantage of the PDS is that it measures all key diagnostic areas for PTSD; stressor identification, intrusion symptoms, avoidance symptoms, hyperarousal symptoms, duration of symptoms for more than 30 days, and impairment of everyday function (Foa et al. 1997; Foa et al. 1993; McCarthy 2008), unlike other validated self-report PTSD instruments. It is not meant to replace a diagnostic interview but is a useful tool for researchers and clinicians to efficiently identify people with possible PTSD and/or observe for a response to treatment when an interview is impractical (McCarthy 2008).

The PDS can be completed in approximately 10-15 minutes using the paper and pencil or online versions and requires a reading age of 13 years (Foa 1995). The paper and pencil version was selected for this project as it is more easily administered and completed in the research setting. The scale is subject to strict copyright laws and is only available for purchase through the distributor, Pearson Assessments. The question booklet is separate to the answer sheet making completion of the scale slightly awkward. The scoring system is more complicated than other self-report instruments used for this study, but is clearly explained, with examples, in the user training manual (Foa 1995) that is part of the PDS Starter Kit that was purchased from Pearson Assessments.

The fifth edition of the DSM was released in May 2013 (American Psychiatric Association 2013), included a new symptom cluster and there were no validated PSTD screening instruments that assessed symptom severity in all symptom clusters. The PDS remained the most comprehensive tool available so its use was continued.

\section{PDS-5}

In June 2015, the PDS was no longer available for purchase through Pearson Assessments. Professor Edna Foa, the designer of the PDS, was contacted 
and she provided an updated version called the PDS-V that had been designed to comply with the new DSM-V criteria. She also gave permission to make copies as needed for this study (Appendix 6).

The PDS-5 is a self-report measure of PTSD symptoms based on the DSM-V criteria (Foa et al. 2016). It is divided into four sections:

v) trauma screen;

vi) symptoms;

vii) distress and interference; and,

viii) symptom onset and duration.

The PDS-5 format is very different to the PDS and begins with a checklist of eight traumatic events, including an 'other' category. If exposure to at least one of these traumatic events is not identified in this first part, the respondent does not continue. Pregnancy or childbirth is not specifically listed in this checklist, although there are categories that apply to the stressors of childbirth. These include 'serious life threatening illness' and the 'other' category.

There are 20 items representing the severity of the PTSD symptoms experienced in the preceding month. These are scored on a five point scale from 'Not at all' to ' 6 or more times a week'. A score of $0,1,2,3$ or 4 is allocated according to the frequency of symptoms; the higher the frequency, the higher the score. There are two questions regarding interference with everyday life and two questions about the length of time symptoms have been present.

The PDS-5 has been validated for accuracy against previously validated selfreport instruments for PTSD (Foa et al. 2016). Foa et al. (2016) conclude that the PDS-5 is a valid and reliable measure of DSM-V PTSD symptomatology after testing it on 242 adults who had experienced a traumatic event. The advantage of the PDS-5 compared to other validated self-report PTSD instruments is that it measures all the key diagnostic areas for PTSD in the DSM-V. 
The PDS-5 is four pages with questions and answers on the same form. It is easily completed in 5-10 minutes and is quick and simple to score. During the validation process it was determined that a cut-off score of 28 is reliable for identifying a probable diagnosis of PTSD (Foa et al. 2016).

Using two different instruments to measure PTSD symptoms during the study was problematic in regards to data analysis. However, this was unavoidable as the initial instrument used was discontinued before recruitment to the study was complete. The two instruments varied in the symptom clusters included, scoring methods and total scores possible, making it difficult to compare the data obtained from each instrument. After discussion with the psychiatrist from the research team on how to analyse the symptom severity scores, it was decided to convert the scores into a percentage of the possible total score for each instrument (51 for the PDS and 80 for the PDS-5). By doing this calculation, it made it possible to make a reliable comparison between the two groups. The prevalence of PTSD was calculated by using cut-off scores for probable diagnosis of PTSD from each version which were compared as a categorical variable.

\section{Mother to Infant Bonding Scale (MIB)}

The MIB scale is a self-report instrument that assesses the relationship between mother and infant (Taylor et al. 2005; van Bussel, Spitz \& Demyttenaere 2010; Wittkowski, Wieck \& Mann 2007). It consists of eight statements that describe an emotional response from the mother to her infant such as 'loving', 'joyful', 'dislike', or 'resentful'. Each response is rated on a four point Likert Scale from 'very much' to 'not at all' and is scored 0, 1, 2, or 3 points according to the degree of the emotions reported. The MIB consists of five negative emotional responses, that are reverse scored, and three positive emotional responses. An overall assessment of the mother to infant bonding is determined by adding the scores with a possible total score of $0-24$. There is no threshold score reported but Taylor et al. (2005) state that low scores signify good mother to infant bonding. 
The MIB Scale was developed by Taylor et al. (2005) as a simple instrument for assessing the feelings of a mother towards her infant. It was designed to identify an "impaired" bond or a lack of feeling from the mother towards her infant (Taylor et al. 2005). They suggest that the MIB scale is most useful in revealing the extreme responses rather than slight differences within the normal population. The tool has been evaluated for reliability and validity and was found to be a good indicator of impaired mother-infant relationship (van Bussel, Spitz \& Demyttenaere 2010; Wittkowski, Wieck \& Mann 2007). The MIB scale is suitable for use in the general population (Taylor et al. 2005) and provides useful insights into a mother's feelings towards her child, for clinical and research purposes (Wittkowski, Wieck \& Mann 2007). Observational methods may be considered the gold standard for assessing the mother-infant relationship (Wittkowski, Wieck \& Mann 2007), but the MIB scale was selected as it is readily available, easy to administer and score, and simple for the woman to complete, taking less than five minutes.

\section{Birth experience data collection at six months postpartum}

Birth experience data were collected from the women in two ways. The women completed six questions about their birth experience and rated their response on a seven point Likert Scale. They were then asked to respond to two open ended questions. The questions asked were adapted from a previous study looking at birth experience (Forster et al. 2016). The questionnaires were labelled with the woman's study ID number only, to support anonymity, in an effort to encourage honest answers.

The two approaches to data collection are discussed separately in the following section.

\section{Likert Scale}

The Likert Scale is a psychometric scale that was developed in 1932 by psychologist Rensis Likert (Likert 1932). It is widely used to measure attitudes or opinions by using an ordinal rating scale (Sullivan \& Artino 2013). 
Respondents are asked to answer a series of statements about a topic, and rate the extent to which they agree or disagree with them, typically on a five or seven point scale (McLeod 2008; Sullivan \& Artino 2013). Each of the responses is allocated a numeric value to measure the attitude or opinion, with the centre value being a neutral point; neither agree nor disagree (McLeod 2008).

The Likert Scale offers a greater degree of understanding of opinion compared with asking a simple 'yes' or 'no' question (McLeod 2008) and is quantifiable. It is easily completed and, being quantitative data, is relatively easy to analyse (Latham 2006; McLeod 2008). However, there are disadvantages to using it. For example, respondents may not be completely honest when answering the statements and it may be overly simplistic or blunt. This is particularly evident when looking at behaviours that are socially unacceptable or when the respondent answers in a way to make themselves seem better than they really are, or answer according to what they feel is expected of them (Latham 2006; McLeod 2008). Furthermore, the scale offers an easy option for respondents who are disinclined to express an opinion, by including a neutral score (Latham 2006; McLeod 2008) which can dilute the range of results. Paulhus (1984) found that anonymity on self-administered instruments reduces social pressure and therefore may facilitate a more honest response to the questioning.

The six statements that the women were asked to respond to were based on previous qualitative work by Petrovska et al. (2017) and are shown in Table 3.1.

\section{Table 3.1. Likert Scale statements}

\begin{tabular}{||l|l||}
\hline Statement & Response options \\
\hline $\begin{array}{l}\text { During labour and birth, I } \\
\text { felt free to express my } \\
\text { feelings }\end{array}$ & Strongly disagree (1)-strongly agree (7) \\
\hline $\begin{array}{l}\text { During labour and birth, I } \\
\text { felt I was }\end{array}$ & $\begin{array}{l}\text { Completely out of control (1)-In complete control } \\
(7)\end{array}$ \\
\hline
\end{tabular}




\begin{tabular}{||l|l||}
\hline Physically, I coped & $\begin{array}{l}\text { Worse than expected (1)-Better than expected } \\
(7)\end{array}$ \\
\hline Emotionally, I coped & $\begin{array}{l}\text { Worse than expected (1)-Better than expected } \\
(7)\end{array}$ \\
\hline $\begin{array}{l}\text { When looking back at } \\
\text { labour and birth, I feel }\end{array}$ & Not proud of myself (1)-Very proud of myself (7) \\
\hline $\begin{array}{l}\text { Overall. How would you } \\
\text { describe your care during } \\
\text { labour and birth? }\end{array}$ & Very poor (1)-Very good (7) \\
\hline
\end{tabular}

Open ended questions

Open-ended questions are statements that require a response (Foddy 1993; Riiskjaer, Ammentorp \& Kofoed 2012). They are designed to permit the respondent to express an opinion without being influenced by the researcher (Foddy 1993) and encourage a meaningful answer using knowledge and/or feelings. They avoid the bias that may result from suggesting responses, which may occur in close-ended questions (Foddy 1993), but they have a higher rate of non-response.

The two questions used in this project were:

- Please describe any things about your labour and/or birth that you were particularly happy with.

- Please describe any things about your labour and/or birth that you were particularly unhappy with.

These two questions were asked to enhance the insights, regarding birth experience, gained from the Likert Scale results.

\section{Data analysis}

The IBM SPSS v. $24^{\circledR}$ software was used for the quantitative analyses. I undertook all the statistical analyses after attending short courses at UTS on 
managing data, and using SPSS. The analysis of the demographic, mental health and the birth experience data is described below.

\section{Demographic data}

Simple descriptive statistics were applied to the demographic data to compare the hypertensive (HT) group with the normotensive (NT group) in baseline characteristics and the labour and birth outcomes. Means, standard deviations, percentages and $p$-values were calculated. P-values were calculated using the Student's t-test, to compare means and a probability of $<0.05$ was considered statistically significant.

\section{Mental health}

Descriptive analyses were performed to compare the scores for depression, anxiety, PTSD and MIB questionnaires between women in the HT group and NT group. The mean scores of the EPDS, GAD-7 and MIB scales were compared using the appropriate statistical test. The Chi-squared test was used for categorical data and Student's t-test for continuous data when normally distributed. A probability of $<0.05$ was considered statistically significant. The number and percentage of women who met the threshold score for possible diagnosis of depression, anxiety or PTSD (using either instrument as described earlier) were determined. The Fisher exact test was used in the PTSD analysis due to the small number of women who met the threshold for a probable diagnosis of PTSD.

A univariate and multivariate logistic regression analysis was conducted to assess the possible contributors to depression, PTSD and reporting the birth as a traumatic even. This was done as a difference was found in these domains using simple descriptive analyses. Logistic regression models the chance of an outcome based on individual characteristics. In a univariate logistic regression analysis one variable is analysed at a time and in multivariate logistic regression multiple explanatory variables are analysed 
simultaneously, reducing the effect of confounding factors (Sperande 2014). All assumptions for these approaches were met (e.g. no multicollinearity) within the descriptive analysis.

A score of greater than 12 on the EPDS was used as the dependent variable for depression, while meeting the criteria and reporting the birth as traumatic were the dependent variables used for PTSD. The model contained seven independent variables: parity, having hypertension, history of mental health disorders, having a caesarean section, having a preterm birth, woman admitted to the ICU and baby admitted to the SCN. Each dependent variable was analysed separately to test the association between it and the number of potential explanatory independent variables. Each association from this analysis was estimated and the Odds Ratio calculated. The Adjusted Odds Ratio was calculated by performing the multivariate regression analysis controlling for the seven independent variables.

\section{Birth experience}

An ordinal logistic regression analysis was performed to compare the normotensive (NT) and hypertensive (HT) groups on the Likert Scale scores on the birth experience questions. Normal logistic regression is only suitable for a binary categorical outcome, whereas ordinal logistic regression can have more than two outcome variables. As a Likert Scale is constructed using a hierarchy of separate endpoints (Harrell 2001) and the outcome variable has more than two ordered categories (Kleinbaum \& Klein 2010), ordinal logistic regression was used in the analysis of the birth experience Likert Scale data. Ordinal logistic regression works with the cumulative distribution for the response variable and signifies the general trends across the ordinal values of the responses (Warner 2008).

A quantitative content analysis was undertaken to compare the NT and HT groups in regards to their response to the 'Happy' and 'Unhappy' questions. Content analysis converts qualitative data to quantitative data so that responses 
can be summarised and compared (Han \& Shavitt 1994). In essence it involves the classification of parts of a text through the application of a structured, systematic coding scheme from which conclusions can be drawn (Rose, Spinks \& Canhoto 2015). The responses from the women were coded into five categories: the care they received, the support they received, an aspect of their labour and/or birth, a characteristic of their baby, and feeling happy or unhappy about nothing. The number and percentage of women who commented on being happy or unhappy about a particular feature were calculated, and the two groups were compared.

\section{Phase Two: Interviews with women}

\section{Research questions}

- What are the pregnancy and birth experiences of women who are diagnosed with either GH or PE?

- Are there any mediating factors that help women throughout their experience?

Qualitative research in the health discipline evolved in the 1960s but it was not till the 1980s that it was truly recognised and supported as a separate method of inquiry (Sandelowski 2003). Its use in health research has been steadily increasing due to a movement away from the medical, science based research tradition (Greenhaigh et al. 2016) and a need for more understanding of real life situations (Tai \& Rola 2016).

Qualitative methods seek to explore and understand phenomena about people's lives and experiences, including those related to health (Cypress 2015; Streubert Speziale \& Carpenter 2007; Vaismororadi, Turunen \& Bondas 2013) and is particularly useful when little is known about the phenomenon in question (Cypress 2015). Qualitative methods enable life experiences to be explored in depth, and therefore gain greater insight and understanding of this experience from the participant's perspective (Vaismororadi, Turunen \& Bondas 2013). These approaches are often used when the researcher does not know 
beforehand, how the study will develop (Cypress 2015), and usually begins by focussing on one feature of a phenomenon about which little is known (Polit \& Beck 2014). The most common qualitative methods include phenomenology, grounded theory, ethnography, and qualitative descriptive, each having separate theoretical foundations (Andrews, Sullivan \& Minichiello 2004; Cypress 2015; Vaismororadi, Turunen \& Bondas 2013; Whitehead 2007).

Streubert Speziale and Carpenter (2007) recommend that researchers decide on a qualitative method by determining which approach best answers their research question. The qualitative descriptive approach is particularly useful to answer research questions about people's response to something or how they feel about a certain event (Sandelowski 2000). As my research explored the experiences of women who had hypertension in their pregnancy, this methodology was appropriate. I therefore chose the qualitative descriptive method for this study.

\section{Qualitative descriptive design}

The qualitative descriptive method thoroughly describes an event in everyday words (Sandelowski 2000; Sandelowski 2010) and can elicit meaning regarding the event (Holloway \& Todres 2005; Sandelowski 2010). It is useful when investigating previously unexamined or unfamiliar experiences (Marshall \& Rossman 2006; Sandelowski 2000) and can provide answers to important questions for practitioners and policy makers (Sandelowski 2000). The aim is to present an accurate and comprehensive summary of events, as experienced by the participants in the event (Sandelowski 2000). Marshall and Rossman (2006) suggest that qualitative descriptive methods provide valuable accounts of complex situations and a more detailed understanding of the experience.

Qualitative descriptive methodology allows the description of the data rather than the researcher's interpretations. This method is suited for research that focuses on the who, what, why, and where of events (Sandelowski 2000). 
Qualitative descriptive studies have been criticised for a lack of recognised theoretical foundation and therefore inferior to other qualitative methods such as grounded theory and ethnography (Annells 2007; Daly et al. 2007; Sandelowski 2010) . Despite this, Annells (2007) and Sandelowski (2000) declare that research of high merit can be generated using the descriptive method.

The qualitative descriptive approach was chosen to help gain insight into the experiences of women who had hypertension in their pregnancy.

\section{Being reflective}

Reflexivity is a key process used in qualitative research and is recognised as a technique for qualitative researchers to validate their research practices (Braun \& Clarke 2013; Cutcliffe \& McKenna 2002; Kingdon 2005). It is an integral process where the researcher continuously reflects on their own actions, values, experiences and perceptions and how these may influence the research setting, data collection and data analysis (Braun \& Clarke 2013). The reflective practice assists with 'situating oneself' in relation to the data to enable an understanding of the experience and how these experiences may relate to a broader context (Lambert, Jomeen \& McSherry 2010). Jootun, McGhee and Marland (2009) suggest including a reflexive account to increase the accuracy of the research process.

Reflexivity is an important tool used to support understanding of the phenomenon being studied and the researcher's role (Jootun, McGhee \& Marland 2009). Being reflective demonstrates an appreciation and honest awareness of the importance of the interaction between the researcher and the woman participating in the interview and helps to develop self-awareness (McGhee, Marland \& Atkinson 2007).

The concept of 'insider/outsider' knowledge and the impact this can have on conducting a qualitative research project has been described by Burns et al. (2012). In this project I was both an insider and an outsider: an insider with experience of having PE and a midwife with experience of caring for women 
with complicated pregnancies, and, an outsider as a researcher leading the interviews. Possessing insider knowledge can be advantageous when recruiting to the project, building trust and forming a rapport during the interviews, in addition to being sensitive to the emotional experiences described by the women (Burns et al. 2012). Conducting the interview in the woman's home gave me the opportunity to be the outsider and perceived as the researcher trying to gain a better understanding of the topic. Finding the middle ground where I was a research interviewer and midwife with experience in the topic was necessary. It was important to be reflective as a researcher to acknowledge my own values, personal feelings and experiences and how this could influence the interview process.

As described earlier, the foundations for my interest in this research were my own experience with $\mathrm{PE}$, and being a midwife wanting to improve women's experiences of PE. Throughout Phase Two, it was important to acknowledge my personal and professional values. Whilst recognising the possibility of a negative effect my experience could have on the research, my knowledge and experience of PE may allow me to better understand the experiences and the issues that the women shared during the interviews.

Allowing women to tell their stories which were sometimes emotional was sometimes challenging in my role as a midwife. The women shared stories of the frustration they felt at having a complicated pregnancy, their concerns for their health and that of their baby and the difficulties of transitioning to motherhood. They sometimes looked to me for answers, support or suggestions, acknowledging my understanding of their situation (Burns et al. 2012).

Throughout this phase of the project I remained aware of my own experience of PE and how this could influence the data collection and analysis. In an effort to minimise this, I made it clear to each woman at the time of recruitment that I was very interested in hearing her story and avoided discussions during the interview. At the completion of the interview, I often had a conversation with the 
woman regarding her experience, offering support and suggestions for such things as her future health and the next pregnancy. Even though the women knew I was a midwife, most of the women were not aware of my own experience so my personal views and feelings did not become part of the interview. Furthermore, the open ended questions were used to guide the interview in the same fashion for each woman, reducing the impact of my pregnancy and birth experience on the interview.

My skills at interviewing and further enquiry improved the more interviews I did. Some interviews contained personal and emotional recollections of the experience which I encouraged the woman to expand on her story. This demonstrated my empathy for the woman beyond the normal researcher and interviewer interaction (Burns et al. 2012; Leslie \& McAllister 2002).

During the analysis stage, the stories were examined in depth while having the research question, What are the pregnancy and birth experiences of women who are diagnosed with either GH or PE?' as the main focus. The final stage of the data analysis was completed by me and another researcher which helped to stay focussed on the research question and avoided my personal experience influencing the interpretation of the data. This process has been described by Braun and Clarke (2013) where they conclude that it is important to analyse the raw data objectively while meeting the aims of the research.

\section{Ethical amendments and considerations}

Conducting interviews was not included in the original ethics submission (approved $8^{\text {th }}$ March 2013), so an amendment was submitted in October 2013 and approved (Appendix 7). Women who had consented to the study prior to the amendment and subsequently agreed to participate in an interview were consented using the updated version of the Participant Information Sheet and Consent Form (PIS\&CF) (Version 4). Before commencing an interview, the woman was reminded that she could pause or stop the interview at any time and that her privacy and anonymity would be maintained throughout. 
Confidentiality was maintained by using a study ID number for each woman. I was the only person who could de-identify the data. There was the potential for the woman's voice to be recognised on the audio recording which could reveal her identity (Braun \& Clarke 2013). For this reason, audio recordings and transcripts were stored in password protected files.

When women became upset talking about their birth and pregnancy experience, their distress was acknowledged and the interview was paused if required. This occurred during five of the interviews. It was important to allow the women to express themselves and their emotions while maintaining the flow and direction of the interview (Braun \& Clarke 2013). At the conclusion of the interview I informally discussed the importance of the woman looking after her emotional and mental health.

\section{Setting}

The interviews were conducted at a mutually agreeable location where the woman felt comfortable telling her story. Seventeen were conducted in the woman's home and three in my office at the hospital. Whiting (2008) stresses the importance of interviews being conducted in a comfortable environment and Clarke (2006) suggested that the participant should be the one to choose the venue. The women who were interviewed chose the venue that suited them. The majority felt comfortable with me coming into their home as this meant they did not have to travel with their child or organise childcare. Three women felt that their home environment would not support a good interview and chose to come to my office. I was mindful that my office may be an intimidating venue for the woman, so I presented it as comfortable as possible and included the offer of tea or coffee. This was done to reduce the power imbalance between myself in my professional surrounds, and the woman. This power imbalance has been described by Braun and Clarke (2013) and may adversely affect the openness of the participant's storytelling. Power imbalance has also been reported when the researcher knows the participant, but interviewing strangers can also be problematic due to the challenges of developing a rapport within the short 
interview time (Braun \& Clarke 2013). I had previously met each woman whom I interviewed and had spoken to them on the phone on several occasions prior to the interview. Therefore we were not strangers and a degree of rapport had already been established. I did not know any of the women prior to their enrolment in the research project. This seemed to be an ideal situation for eliciting thorough storytelling.

Although Burns and Grove (2005) indicate that the ideal venue is a quiet and private place, this was not always possible when a one year old child was present and awake. The time of the interview was typically planned around the child's sleep pattern but this was not always successful.

\section{Eligibility criteria}

Women were already participating in the P4 Study. Those who had either GH or $\mathrm{PE}$ in their pregnancy were eligible to participate in an interview.

\section{Identifying the women}

When the women visited the hospital for the six month postpartum follow-up assessment visit, those who had experienced hypertension in their pregnancy were asked if they would agree to be interviewed about their pregnancy and birth experience in four to six months' time.

\section{Recruitment details}

The women who agreed to an interview were contacted at around 10 months postpartum to confirm consent, and organise the interview date. Interviews were conducted at 10-12 months postpartum.

In total, 38 women were asked at the six month visit to partake in an interview and 35 of these women agreed to be contacted at a later date. Not all women were able to be contacted at 10 months postpartum and some did not confirm 
their consent. Recruitment ceased after 20 interviews had been completed as data saturation had been reached. The remaining six women, who had agreed to be contacted and were not required, were thanked for their interest.

\section{Undertaking the interview}

Preparing for the interview is a very important stage of any project (DiCiccoBloom \& Crabtree 2006; Whiting 2008) and one that I embraced with enthusiasm. I had the theoretical and clinical knowledge of GH and PE as well as personal experience and an interest in the topic. I considered myself to have excellent communication skills after extensive experience with women in both clinical midwifery practice and research. However, I lacked experience in interviewing for qualitative research. For this reason I asked another researcher, a midwife who had knowledge of the topic and experience in qualitative research interview techniques, to guide me with the planning and conduct of the interviews. Together we planned the interviews, discussed possible prompt questions, and constructed the trigger questions. She attended the first five interviews with me as an observer while I conducted the interviews. I completed the last 15 interviews without supervision.

The timing of the interview is an important consideration and largely depends on the aim of the study (Bennett 1985). When the interview concerns feelings or reactions to the birth event, a time interval should be allowed for the woman to gain perspective on the whole birth experience (Bennett 1985). Simkin (1992) also recommends allowing time after the birth before interviewing and discusses the halo effect following childbirth. The halo effect is observed when a significant event takes place, such as childbirth, and the complications of the situation are overlooked in the excitement of the moment, in this case the birth of the baby (Simkin 1992). As time passes, this 'halo' or glow fades and the woman then reviews her birth experience more realistically and her perceptions of the experience may change (Bennett 1985; Simkin 1992). Although Bennett (1985) and Simkin (1992) do not offer suggestions for the exact timing to carry out interviews, they proposed that sometime between months and up to two 
years following the birth should give the researcher a true perspective of the woman's experience. Taking this into consideration, I decided to carry out the interviews at 10-12 months after the birth. I preferred not to wait till two years after the birth as I was concerned that there was a chance the woman could be pregnant again which may have altered her perception of the original hypertensive birth experience.

\section{Data collection}

Individual, face-to-face, semi-structured interviews were used to explore the woman's pregnancy and birth experience following GH or PE. This type of interview is widely used in health research (Whiting 2008) and is designed around a particular topic using a set of predetermined open-ended questions (DiCicco-Bloom \& Crabtree 2006). Braun and Clarke (2013) suggest that face to face interviews are an ideal way to acquire information on sensitive matters.

Despite face to face interviews being time consuming for the researcher and the participant, they generate detailed rich data from the participant's story from her own perspective (Braun \& Clarke 2013). Group interviews or focus groups were not considered appropriate for this project as I felt that the lack of privacy in this setting would not promote a relaxed environment for the woman to share her personal story, or for me to gain a deep understanding of her experience.

A series of trigger questions covered the pregnancy, diagnosis, birth, baby and postpartum details. There was flexibility in the questioning to allow for the woman's responses. The opening question, "Please tell me about your pregnancy and how you felt about it, before you were diagnosed with high blood pressure" was used to assist the woman to adjust to the interview environment, feel relaxed, and begin to tell her story. Whiting (2008) describes the necessity of building a rapport with the participant from the beginning of the interview and the importance of the opening question. The opening question should be openended and broad but related to the research topic (DiCicco-Bloom \& Crabtree 2006). Subsequent questions included: 
How did you feel when you were told you had high blood pressure in your pregnancy?

How was your care from the midwives and doctors after you found out about your complication?

How did you feel after the birth?

How was your baby after the birth?

What worried you the most about having high blood pressure in your pregnancy?

Each interview lasted approximately 45 minutes and was recorded using a digital voice recorder. Having a digital recorder left me free from taking notes in order to provide a more relaxed environment and better interaction with the woman. Digital recordings also allowed verbatim transcription of the interview. Whiting (2008) mentions concerns about the interviewer and interviewee feeing inhibited by the presence of the recorder but I found that by the second or third question, the distraction of the recorder disappeared. The recorded interview was listened to the same day and any comments about the interview were noted. I transcribed the interview recordings in their entirety within a week of the interview and later transferred them to NVivo for coding.

\section{Data validation}

Due to the subjective nature of qualitative data interpretation, it has been suggested that a process of validation or verification can make the analysis more precise and reduce bias (Burnard et al. 2008). Two methods of doing this are recommended; respondent validation where the transcript is returned to the interviewee for review, and peer review, where a second qualitative researcher analyses the data independently or in conjunction with another (Burnard et al. 2008). Returning interview transcripts to the participants for validation can help to refine the themes (Burnard et al. 2008). However it can be time consuming and there is a concern that participants may change their perception and views due to changes in their situation since the original interview (Burnard et al. 2008), or as a result of being part of the research (Long \& Johnson 2000). Peer 
review may reduce lone researcher bias and provide additional insights (Barbour 2001), however this approach has been questioned as each researcher may interpret the data differently (Seale 2000).

The advantages and disadvantages of each method of data validation were considered and the peer review approach was used. A second researcher with extensive prior experience in qualitative research, my primary $\mathrm{PhD}$ supervisor, assisted me with the data analysis and theme identification.

\section{Data saturation}

No new ideas, thoughts or themes emerged from the interviews after 17 had been completed. I continued until 20 interviews had been completed and I had confirmed that data saturation had been reached. Data saturation describes a time in a study that is recognised by the researcher (Saunders et al. 2018). Corbin and Strauss (2014) suggest that data saturation occurs when further data collection becomes counterproductive and there is no new information to add to the general story. By completing three more interviews the data may have become richer or more insightful (Saunders et al. 2018), without adding any new themes or ideas. Saunders et al. (2018) suggest that these decisions on data saturation can be difficult and rely on the researcher's judgement.

\section{Data analysis}

I began the data analysis after all the interviews had been transcribed. Firstly, data were separated into pregnancy, birth, infant and postpartum. This process is described by (Saldana 2013) as preparing the data, giving a greater familiarity with the contents before more detailed examination begins. The second stage, initial coding, was performed using NVivo. Line by line analysis was undertaken and nodes, a collection of quotes about a specific area of interest (QSR International 2014), were created. Transcripts were reread and recoded to ensure that initial coding was accurate and all useful data were included. The final stage of analysis was performed by myself and my primary supervisor, and themes were derived from the data codes. This thematic 
analysis was applied in order to describe different concepts in relation to the research question (Braun \& Clarke 2006). Subthemes were grouped into main themes.

\section{Conclusion}

This chapter has described the methods used to undertake both phases of this project. A mixed method approach, using both quantitative and qualitative methods, was used. General demographic data, screening instruments regarding mental health, mother-infant relationship and birth experience, and face to face interviews were undertaken to answer the research questions on mental health and birth experience of woman experiencing $\mathrm{GH}$ or $\mathrm{PE}$.

Descriptive statistics, regression analysis and content analysis were used in Phase One of the project while thematic analysis was used in Phase Two. Reflexivity, ethical considerations, and problems with questionnaire availability were also discussed. The following two chapters present the findings of the project. 


\section{CHAPTER 4: WOMEN'S MENTAL HEALTH OUTCOMES AND BIRTH EXPERIENCE}

This is the first of two chapters that describe the results of the project and presents the analysis of Phase One. It begins with a general description of the study cohort and then reports the findings of the women's pregnancy, labour and birth followed by the results of the mental health and birth experience questionnaires that were completed at six months postpartum.

\section{The study cohort}

Recruiting women to the P4 Study was challenging and labour intensive. Over the four year period of the study, $21 \%$ of women who gave birth at the study hospital were not invited to participate in the P4 Study as they were either ineligible or I was unable to see them at the appropriate time. Women were excluded from the study for pre-existing diabetes, pre-existing hypertension, renal disease, multiple pregnancy or if they required an interpreter.

The cohort was divided into two groups according to diagnosis. The woman's diagnosis was made by the medical team, in accordance with several guidelines (Brown et al. 2018; Lowe et al. 2015; Tranquilli et al. 2014), and recorded in her medical record. Women who had normal blood pressure in pregnancy were placed in the normotensive (NT) group and those who had either gestational hypertension $(\mathrm{GH})$ or preeclampsia $(\mathrm{PE})$ were assigned to the hypertensive (HT) group. There were 237 women in the NT group and 84 in the HT group. The disparity in the number of women in each group is due to $\mathrm{GH}$ and $\mathrm{PE}$ affecting $8 \%$ of pregnancies (Tranquilli et al. 2014), resulting in far fewer women with hypertension being eligible for participation in the study.

Both groups were similar in general demographic data (Table 1) with the mean age being 33 years in the NT group and 32 years in the HT group $(p=0.46)$. Ethnicity was similar across both groups with approximately $50 \%$ of each group identifying as Caucasian and $20 \%$ as Asian. The women in both groups were 
well educated with $90 \%$ of them having further education after finishing school. The majority of women ( $98 \%$ in both groups) were in a relationship at the time of questionnaire completion. A slightly higher proportion of women in the HT group reported a pre-existing mental health disorder which was either a current problem or had been in the past $(n=20 ; 24 \%)$ compared with the NT group $(n=36 ; 15 \%)$, but this difference was not statistically significant $(p=0.07)$. The HT group had a significantly larger proportion of primiparous women than the NT group (59 (70\%) vs. $119(50 \%), p=0.002)$.

\section{Pregnancy booking}

Scores and details of the Edinburgh Postnatal Depression Scale (EPDS) were collected from the women's pregnancy booking-in records. There were $18(8 \%)$ instances in the NT group and $6(7 \%)$ in the HT group where details of the EDS were unavailable. This was either due to the EPDS not being attended at the booking-in visit or data not being found in the records.

Both groups were similar in regards to their mental health status at the time of the pregnancy booking-in visit. The average timing of the booking-in EPDS completion was at 16 weeks gestation in both groups with an average score being $4 \pm 3$ and $5 \pm 4$ in the NT versus HT group $(p=0.28)$. The number of women who scored above the threshold score for possible diagnosis of depression (EDS > 12) was 3\% in the NT group versus $5 \%$ in the HT group but was not significantly different $(p=0.07)$. 
Table 4.1. Demographic details of the enrolled women by group

\begin{tabular}{|c|c|c|c|c|c|c|c|}
\hline & \multicolumn{3}{|c|}{$\begin{array}{l}\text { Normotensive Group } \\
\qquad \mathrm{N}=237\end{array}$} & \multicolumn{3}{|c|}{$\begin{array}{l}\text { Hypertensive Group } \\
\qquad N=84\end{array}$} & \multirow[b]{2}{*}{$p$-value } \\
\hline & $\mathrm{n}$ & $\%$ & mean & $\mathrm{n}$ & $\%$ & Mean & \\
\hline Age (years) & & & $33 \pm 5$ & & & $32 \pm 5$ & 0.46 \\
\hline First baby & 119 & 50 & & 59 & 70 & & 0.002 \\
\hline \multicolumn{8}{|l|}{ Ethnicity } \\
\hline -Caucasian & 126 & 53 & & 44 & 52 & & 0.87 \\
\hline -Asian & 52 & 22 & & 18 & 22 & & 0.91 \\
\hline -Other & 58 & 25 & & 22 & 26 & & 0.77 \\
\hline \multicolumn{8}{|l|}{ Highest education } \\
\hline -University degree & 152 & 64 & & 51 & 60 & & 0.52 \\
\hline -Trade-Certificate & 60 & 26 & & 25 & 30 & & 0.45 \\
\hline -Secondary school & 23 & 10 & & 8 & 10 & & 0.94 \\
\hline In a relationship & 231 & 98 & & 82 & 98 & & 0.94 \\
\hline $\begin{array}{l}\text { Booking EPDS } \\
\text { score }\end{array}$ & & & $4 \pm 3$ & & & $5 \pm 4$ & 0.28 \\
\hline Booking EPDS >12 & 6 & 3 & & 4 & 5 & & 0.31 \\
\hline $\begin{array}{l}\text { Mental health } \\
\text { history }\end{array}$ & 36 & 15 & & 20 & 24 & & 0.07 \\
\hline
\end{tabular}

\section{Labour and birth outcomes}

The women in the HT group experienced more intervention during their labour and birth than the women in the NT group (Table 2). The onset of labour occurred spontaneously for $62 \%$ of the NT group but in only $8 \%$ of the HT group $(p=<0.001)$. The HT group had a higher rate of induction of labour compared with the NT group ( $70 \%$ vs $29 \%$; $p=<0.001)$. 
The mode of birth for the study cohort was also significantly different between the two groups. More women in the NT group had a normal vaginal birth (67\% vs $38 \% ; p=<0.001$ ), and a larger portion of women in the HT group had a caesarean section, either planned or unplanned, without labouring ( $43 \%$ vs $18 \% ; p=<0.001)$. However, the rate of assisted vaginal birth, which includes forceps and vacuum extraction, was similar between the groups (15\% vs $19 \%$; $\mathrm{p}=0.36$ ).

Following the birth of their baby, three (1\%) women from the NT group required admission to the Intensive Care Unit (ICU) for their immediate postnatal care and monitoring compared to $15(18 \%)$ of the HT group $(p=<0.001)$. All women from the NT group who required admission to ICU experienced a severe postpartum haemorrhage requiring treatment and transfusion. One of these three women had a uterine rupture necessitating hysterectomy. The most common reason for the ICU admission for the women in the HT group was for monitoring while receiving intravenous magnesium sulphate for seizure prophylaxis and/or treatment $(n=13)$. Of these 13 women, six of them also required intravenous hydralazine for blood pressure control. The other two women from the HT group were admitted to ICU for a severe postpartum haemorrhage requiring treatment and transfusion $(n=1)$ and monitoring of poor kidney function in addition to blood pressure control with intravenous hydralazine $(n=1)$. The average length of stay in the ICU was two days in both groups.

There was a need for six women, three from the NT group (1\%) and three from the HT group ( $4 \%$ ), to be readmitted to hospital following their initial postnatal discharge. The reasons for readmission in the NT group were retained products of conception causing postpartum haemorrhage $(n=2)$ and wound infection $(n=1)$. One of the women readmitted with a postpartum haemorrhage required admission to ICU for two days for treatment and monitoring. In the HT group, readmission was due to wound infection $(n=2)$ and severe hypertension $(n=1)$. 
The majority of women were discharged from hospital breast feeding their baby and/or expressing (96\% NT, 99\% HT) and breast feeding rates were reported at six months postpartum as $78 \%$ in the NT group and $62 \%$ in the HT group.

\section{Neonatal outcomes}

The neonatal outcomes are presented in Table 2 . The average gestation at birth was $39 \pm 2$ weeks in the NT group and $38 \pm 2$ weeks in the HT group $(p=0.005)$. There were more preterm births (babies born before 37 weeks gestation) in the HT group (24\% vs $8 \%$; $p=<0.001$ ). Included in these preterm births are babies born at less than 32 weeks of gestation, of which there were some in both groups $(2(1 \%)$ vs $3(4 \%), p=0.08)$. There was a significantly larger proportion of babies admitted to either the Special Care Nursery (SCN) or the Neonatal Intensive Care Unit (NICU) in the HT group (36 (43\%) versus 33 (14\%), $p=<0.001)$. 
Table 4.2. Labour and birth outcomes for mother and baby by group

\begin{tabular}{|l|c|c|c|c|c|c|c|}
\hline & \multicolumn{2}{|c|}{$\begin{array}{c}\text { Normotensive } \\
\text { Group } \\
\text { N=237 }\end{array}$} & \multicolumn{3}{c|}{$\begin{array}{c}\text { Hypertensive } \\
\text { Group } \\
\text { N=84 }\end{array}$} & \\
\hline & $\mathrm{n}$ & $\%$ & Mean & $\mathrm{n}$ & $\%$ & Mean & $\begin{array}{c}\mathrm{p} \text { - } \\
\text { value }\end{array}$ \\
\hline Gestation at birth & & & 39.2 & & & 38.2 & 0.005 \\
(weeks) & 2 & 1 & & 3 & 4 & & 0.08 \\
$<32$ weeks & 18 & 8 & & 20 & 24 & & $<0.001$ \\
$<37$ weeks & 146 & 62 & & 7 & 8 & & $<0.001$ \\
\hline Labour & 68 & 29 & & 59 & 70 & & $<0.001$ \\
- Spontaneous & 23 & 9 & & 19 & 22 & & 0.003 \\
- Induction & & & & & & & \\
- No labour & 158 & 67 & & 32 & 38 & & $<0.001$ \\
\hline Mode of birth & 35 & 15 & & 16 & 19 & & 0.36 \\
- Normal Vaginal & & & & & & & \\
- Assisted Vaginal & 44 & 18 & & 36 & 43 & & $<0.001$ \\
- Caesarean Section & 4 & 2 & & 15 & 18 & & $<0.001$ \\
\hline Postpartum ICU & 4 & 14 & & 36 & 43 & & $<0.001$ \\
\hline Nursery admission & 33 & 14 & & & & & \\
\hline
\end{tabular}

ICU: Intensive Care Unit, Nursery admission: either Special Care Nursery or Neonatal Intensive Care Unit

\section{Mental health at six months postpartum}

All 321 women participating in the study completed the EPDS and General Anxiety Disorder (GAD-7) screening tools at six months postpartum. The Posttraumatic Stress Diagnostic Scale (PDS) was completed by 311 women at six months postpartum. The PDS was unavailable for the first nine women who joined the study as it was out of print, and one other woman did not complete the instrument. Nine women who did not complete the PDS were from the NT 
group and one was from the HT group. The results for each mental health disorder are reported separately in Table 4.3.

\section{Possible depression}

A statistically significant difference between the NT and HT groups was found in both the mean EPDS scores and the number of women who scored above the cut-off threshold for possible diagnosis of depression (EPDS score >12). The mean score of the instrument was $4 \pm 3$ in the NT group and $5 \pm 4$ in the HT group $(p=0.03)$. Five women $(2 \%)$ in the NT group recorded a score $>12$ compared to six women $(7 \%)$ in the HT group $(p=0.04)$.

\section{Anxiety}

There was no statistical difference found between the groups in both the mean scores of the GAD-7 and the number of women who met the cut-off score for moderate anxiety (GAD-7 score $>10$ ). The mean scores were $2 \pm 3$ in the NT group and $3 \pm 4$ in the HT group $(p=0.17)$. There were four women from each group who recorded a score greater than $10(2 \%$ versus $5 \%, p=0.21)$. Included in this are two women from the HT group who scored in the severe anxiety level (GAD-7>15).

\section{Possible posttraumatic stress disorder}

The mean symptom severity scores were 6.7 in the NT group and 8.2 in the HT group. Despite the clear difference, this was not statistically significant $(p=0.50)$. There was no statistical difference found between the groups in the number of women who met the criteria for possible diagnosis of PTSD. There were four women $(2 \%)$ in the NT group and two $(2 \%)$ in the HT group $(p=0.66)$ who reported PTSD symptoms that met the possible diagnosis criteria. None of these women reported their birth experience as being the traumatic event. Examples of the traumatic event for these women were a prior assault, being in a natural disaster or the recent death of the woman's mother. Of the women 
who met the criteria, two from the NT group and one from the HT group had a pre-existing diagnosis of PTSD.

The proportion of women who identified their recent birth experience as a traumatic event was significantly greater in the HT group (6 $(7 \%)$ versus $3(1 \%)$, $\mathrm{p}=0.01$ ). Despite reporting their birth as traumatic, none of these women reported PTSD symptom severity that met the possible diagnosis criteria.

Table 4.3. Mental health outcomes for women by group

\begin{tabular}{|l|c|c|c|c|c|c|c|}
\hline & \multicolumn{3}{|c|}{$\begin{array}{c}\text { Normotensive } \\
\text { Group N=237 }\end{array}$} & \multicolumn{3}{|c|}{\begin{tabular}{c}
\multicolumn{2}{c|}{ Gypertensive } \\
Group N=84
\end{tabular}} & \\
\hline & $\mathrm{n}$ & $\%$ & mean & $\mathrm{n}$ & $\%$ & mean & $\mathrm{p}$-value \\
\hline $\begin{array}{l}\text { Depression } \\
\text {-EPDS score } \\
\text {-EPDS >12 }\end{array}$ & 5 & 2 & & 6 & 7 & & $0.04^{*}$ \\
\hline Anxiety & & & & & & & \\
-GAD-7 score & 4 & 2 & & 4 & 5 & & $0.21^{*}$ \\
-GAD-7 >10 & & & & & & & \\
\hline PTSD (n=228/83) & & & 6.7 & & & 8.2 & 0.50 \\
-Score & 4 & 2 & & 2 & 2 & & $0.66^{*}$ \\
-Met criteria & 3 & 1 & & 6 & 7 & & $0.01^{*}$ \\
-Birth reported as \\
traumatic event
\end{tabular}

EPDS: Edinburgh Postnatal Depression Scale, GAD-7: General Anxiety

Disorder Scale, PTSD: Posttraumatic Stress Disorder

${ }^{*}$ Fisher's Exact Test used for analysis

\section{Mental health support}

In accordance with the HREC approval and safe clinical practice, when abnormal results were detected during the study, an appropriate referral was made. This was especially important in relation to mental health findings if there 
were concerns about the immediate health of the woman and her baby. Referrals were made to the local Perinatal Mental Health Service (PMHS) for women who scored above the threshold score on any of the instruments. A total of 14 women were offered referral to the PMHS. Six women declined referral as they had a history of the mental health disorder and were either currently seeing a mental health professional, or felt that they knew how to manage their condition. Three women declined the referral as they preferred to seek help from their general practitioner (GP). The remaining five women were referred to, and followed-up by, the PMHS. One appointment was made for a woman to have a debriefing session with a specialist obstetrician to gain a better understanding of the medical aspects of her birth experience.

At six months postpartum 10 women reported that they had visited their General Practitioner (GP) since the birth of their baby, regarding their mental health. Some of these visits were for follow-up of pre-pregnancy mental health disorders, but three women (1\%) from the NT group sought advice due to new feelings of anxiety or feeling overwhelmed with parenthood. In addition, one other woman from the NT group went to her GP to discuss her birth experience. This woman had her labour induced at 42 weeks gestation and experienced a postpartum haemorrhage. Relationship issues $(n=1)$ and follow-up of preexisting anxiety and depression $(n=2)$ led three women from the HT group to seek help from their GP. None of the women in the HT group reported a visit to their GP with a new mental health concern. Women also self-referred to a psychologist or counsellor without firstly seeing their GP. There were eight women from the NT group and five from the HT who saw a psychologist or counsellor in the first six postpartum months. This includes six from the NT group and two from the HT group who sought help initially from their GP. There was one woman from each group who reported taking medication for her poor mental health, one from the NT group was taking an herbal preparation for her pre-existing anxiety and one from the HT group was taking an antidepressant for her pre-existing depression and anxiety. 


\section{Maternal Infant Bonding}

The mean score for the Maternal Infant Bonding scale (MIB) was very low in both groups, demonstrating good maternal and infant relationship, and not statistically different. The mean scores were $1 \pm 1$ in the NT group and $1 \pm 2$ in the HT group $(p=0.7)$.

\section{Possible contributors to depression and posttraumatic stress disorder}

As a difference was demonstrated between the groups in regards to depression and an aspect of PTSD, a logistic regression model was developed. This was to assess if there was any impact of different factors on the likelihood of women scoring above the threshold for depression and PTSD, or reporting their birth experience as a traumatic event. Seven independent variables (factors) were used in the model: parity, a history of mental health disorder, hypertension in pregnancy, having a caesarean section, having a preterm baby, postpartum ICU admission for the woman and nursery admission for the baby. These variables were selected as they were suspected to be associated with higher rates of depression or PTSD. Depression, PTSD and traumatic birth were analysed separately, using univariate and multivariate analyses, (Table 4).

\section{Depression}

The model containing all predictors for depression was statistically significant, $X^{2}(7, N=321)=17.905, p=0.012$, indicating that the model was able to differentiate between women who did and did not score above the threshold score for depression. Three of the independent variables made a statistically significant contribution to the model (parity, having hypertension in pregnancy and having a history of mental health disorder). The strongest predictor of possible depression was parity, (Adjusted Odds Ratio (AOR) 5.03; 95\% Cl 1.1921.3). Women having their first baby were five times more likely to score above the threshold for possible depression than women having a subsequent baby. 


\section{Posttraumatic Stress Disorder}

The model containing all predictors for PTSD was statistically significant, $X^{2}(7$, $\mathrm{N}=311$ ) $=14.175, \mathrm{p}=0.048$, indicating that the model was able to differentiate between women who did and did not meet the criteria for possible diagnosis of PTSD. None of the independent variables made a statistically significant contribution to the model. However, the strongest predictor of possible PTSD was having a preterm baby. This recorded an AOR of $7.46(95 \% \mathrm{Cl} 0.61-91.17)$ indicating that women are seven and a half times more likely to meet the criteria for PTSD if their baby was born preterm.

\section{Reporting a traumatic birth experience}

The model containing all predictors for a traumatic birth was statistically significant, $X^{2}(7, N=311)=38.237, p=<0.001$, indicating that the model was able to differentiate between women who did and did not report a traumatic birth. Being admitted to the ICU was the only independent variable that made a statistically significant contribution to the model (AOR =318.953), however due to the small number of women who reported their birth as traumatic, this result is difficult to interpret. 
Table 4.4. Predicting the likelihood of scoring above the threshold score for depression and PTSD or reporting a traumatic birth

\begin{tabular}{|c|c|c|c|c|c|c|}
\hline & \multicolumn{2}{|c|}{ Depression } & \multicolumn{2}{|c|}{ PTSD } & \multicolumn{2}{|c|}{ Traumatic birth } \\
\hline & UOR $(95 \% \mathrm{CI})$ & AOR $(95 \% \mathrm{Cl})$ & UOR $(95 \% \mathrm{CI})$ & AOR $(95 \% \mathrm{Cl})$ & UOR $(95 \% \mathrm{Cl})$ & AOR $(95 \% \mathrm{Cl})$ \\
\hline Parity & $\begin{array}{r}3.46(0.9- \\
13.28)\end{array}$ & $\begin{array}{r}5.03(1.19- \\
21.3)^{*}\end{array}$ & $0.24(0.03-2.1)$ & $0.19(0.02-1.86)$ & $1.57(0.41-5.95)$ & $5.88(0.7-49.5)$ \\
\hline $\begin{array}{l}\text { History of } \\
\text { mental health }\end{array}$ & $4.23(1.24-14.4)$ & $\begin{array}{r}3.80(1.04- \\
13.94)^{*}\end{array}$ & $\begin{array}{r}4.98(0.98- \\
25.38)\end{array}$ & $\begin{array}{r}4.349(0.72- \\
26.34)\end{array}$ & $\begin{array}{r}2.46(0.60- \\
10.16)\end{array}$ & $\overline{1.46(0.21-10.0)}$ \\
\hline $\begin{array}{l}\text { Hypertension } \\
\text { in pregnancy }\end{array}$ & $\begin{array}{r}3.57(1.06- \\
12.02)\end{array}$ & $\begin{array}{r}4.34(1.13- \\
16.73)^{*}\end{array}$ & $1.38(0.25-7.69)$ & $0.86(0.11-6.71)$ & $\begin{array}{r}5.84(1.43- \\
23.93)\end{array}$ & $\begin{array}{r}2.87(0.34- \\
24.31)\end{array}$ \\
\hline $\begin{array}{l}\text { Caesarean } \\
\text { section }\end{array}$ & $1.76(0.5-6.17)$ & $1.09(0.25-4.73)$ & $0.57(0.07-4.97)$ & $0.27(0.02-3.22)$ & $1.46(0.36-5.98)$ & $1.06(0.17-6.82)$ \\
\hline Preterm birth & $\begin{array}{r}2.95(0.75- \\
11.63)\end{array}$ & $\begin{array}{r}1.40(0.19- \\
10.42)\end{array}$ & $\begin{array}{r}7.97(1.55- \\
41.07)\end{array}$ & $\begin{array}{r}7.46(0.61- \\
91.17)\end{array}$ & $\begin{array}{r}2.18(0.44- \\
10.91)\end{array}$ & $0.44(0.04-4.92)$ \\
\hline ICU admission & 0.00 & 0.00 & 0.00 & 0.0 & $\begin{array}{r}84.58(15.86- \\
451.2)\end{array}$ & $\begin{array}{r}318.95(16.74- \\
6078.0)^{*}\end{array}$ \\
\hline $\begin{array}{l}\text { Nursery } \\
\text { admission }\end{array}$ & $2.22(0.62-7.74)$ & $\begin{array}{r}2.18(0.33- \\
14.49)\end{array}$ & $\begin{array}{r}4.00(0.79- \\
20.31)\end{array}$ & $\begin{array}{r}2.29(0.19- \\
27.63)\end{array}$ & $\begin{array}{r}5.15(1.34- \\
19.76)\end{array}$ & $\begin{array}{c}0.23 \quad(90.01- \\
3.52)\end{array}$ \\
\hline
\end{tabular}

ICU: Intensive Care Unit, UOR: Unadjusted Odds Ratio, AOR: Adjusted Odds Ratio (adjusted for parity, history of mental health disorder, hypertension in pregnancy, caesarean section, preterm baby, postpartum ICU admission, and nursery admission for the baby), *statistically significant 


\section{Women's birth experience}

Women were asked about their birth experience in two different ways. These were responding to six statements using a seven point Likert Scale and answering two open ended questions. The results of each of these approaches are discussed separately below.

\section{Likert Scale to assess birth experience}

An ordinal logistic regression analysis was undertaken to compare the NT and HT groups on the Likert Scale scores regarding the six birth experience questions. There was a statistically significant difference between the scores from the women in the NT and HT groups for each question asked. Women in the NT group were 3-5 times more likely to respond more positively to the questions compared to the women in the HT group. The results of the Likert Scale scores regarding birth experience are shown in Table 4.5 on the next page. 
Table 4.5. Likert Scale scores regarding birth experience

\begin{tabular}{|c|c|c|c|c|c|c|c|c|c|}
\hline & & \multicolumn{7}{|c|}{ Satisfaction scores $\%$} & \multirow[b]{2}{*}{ OR $(95 \% \mathrm{Cl})$} \\
\hline & & 1 & 2 & 3 & 4 & 5 & 6 & 7 & \\
\hline & & \multicolumn{7}{|c|}{$\begin{array}{ll}\text { Strongly disagree } & \text { Strongly agree }\end{array}$} & \\
\hline $\begin{array}{l}\text { During labour and birth I felt free to } \\
\text { express my feelings }\end{array}$ & $\begin{array}{l}\text { NT } \\
\text { HT }\end{array}$ & $\begin{array}{l}1.3 \\
2.4\end{array}$ & $\begin{array}{l}0.9 \\
0.0\end{array}$ & $\begin{array}{l}0.9 \\
4.8\end{array}$ & $\begin{array}{l}3.4 \\
11.9\end{array}$ & $\begin{array}{l}6.9 \\
6.0\end{array}$ & $\begin{array}{l}21.5 \\
20.2\end{array}$ & $\begin{array}{l}65.2 \\
54.8\end{array}$ & $3.3(2.38-4.6)$ \\
\hline $\begin{array}{l}\text { During labour and birth I was in } \\
\text { complete control }\end{array}$ & $\begin{array}{l}\text { NT } \\
\text { HT }\end{array}$ & $\begin{array}{l}4.7 \\
14.3\end{array}$ & $\begin{array}{l}6.0 \\
15.5\end{array}$ & $\begin{array}{l}8.5 \\
13.1\end{array}$ & $\begin{array}{l}18.7 \\
19.0\end{array}$ & $\begin{array}{l}29.8 \\
15.5\end{array}$ & $\begin{array}{l}17.4 \\
13.1\end{array}$ & $\begin{array}{l}14.9 \\
9.5\end{array}$ & $4.37(2.03-9.43)$ \\
\hline Physically I coped better than expected & $\begin{array}{l}\text { NT } \\
\text { HT }\end{array}$ & $\begin{array}{l}6.4 \\
9.5\end{array}$ & $\begin{array}{l}2.6 \\
9.5\end{array}$ & $\begin{array}{l}5.5 \\
9.5\end{array}$ & $\begin{array}{l}11.5 \\
9.5\end{array}$ & $\begin{array}{l}14.0 \\
14.3\end{array}$ & $\begin{array}{l}26.0 \\
29.8\end{array}$ & $\begin{array}{l}34.0 \\
17.9\end{array}$ & $5.33(3.07-9.26)$ \\
\hline $\begin{array}{l}\text { Emotionally I coped better than } \\
\text { expected }\end{array}$ & $\begin{array}{l}\text { NT } \\
\text { HT }\end{array}$ & $\begin{array}{l}3.4 \\
4.8\end{array}$ & $\begin{array}{l}1.7 \\
8.3\end{array}$ & $\begin{array}{l}4.7 \\
11.9\end{array}$ & $\begin{array}{l}11.1 \\
13.1\end{array}$ & $\begin{array}{l}16.6 \\
13.1\end{array}$ & $\begin{array}{l}28.9 \\
27.4\end{array}$ & $\begin{array}{l}33.6 \\
17.9\end{array}$ & $5.27(3.03-9.15)$ \\
\hline $\begin{array}{l}\text { When looking back at labour and birth, I } \\
\text { feel proud of myself }\end{array}$ & $\begin{array}{l}\text { NT } \\
\text { HT }\end{array}$ & $\begin{array}{l}1.3 \\
1.2\end{array}$ & $\begin{array}{l}0.4 \\
3.6\end{array}$ & $\begin{array}{l}0.4 \\
6.0\end{array}$ & $\begin{array}{l}6.0 \\
15.5\end{array}$ & $\begin{array}{l}6.8 \\
15.5\end{array}$ & $\begin{array}{l}17.0 \\
20.2\end{array}$ & $\begin{array}{l}68.1 \\
38.1\end{array}$ & $5.0(3.42-7.31)$ \\
\hline $\begin{array}{l}\text { Overall, describe your care during } \\
\text { labour/birth?(1=very poor, } 7=\text { very good) }\end{array}$ & $\begin{array}{l}\text { NT } \\
\text { HT }\end{array}$ & $\begin{array}{l}0.4 \\
1.2\end{array}$ & $\begin{array}{l}0.9 \\
0.0\end{array}$ & $\begin{array}{l}1.7 \\
2.4\end{array}$ & \begin{tabular}{|l|}
1.3 \\
3.6
\end{tabular} & $\begin{array}{l}4.3 \\
9.5\end{array}$ & $\begin{array}{l}20.4 \\
19.0\end{array}$ & $\begin{array}{l}71.1 \\
64.3\end{array}$ & $3.09(2.28-4.2)$ \\
\hline
\end{tabular}

$\mathrm{OR}$ is proportional odds ratio derived from ordinal logistic regression 


\section{Open ended questions}

Women were asked to describe what they were happy or unhappy with in regards to their birth experience. There were four women who did not record a response to the 'happy' question ( $3 \mathrm{NT}, 1 \mathrm{HT}$ ), and six who did not respond to the 'unhappy' question (3 NT, 3 HT).

The responses to both questions were grouped into five categories: the care they received, the support they received, an aspect of their labour and/or birth, a characteristic of their baby, and feeling happy or unhappy in general.

\section{Feeling happy about the care received in hospital}

There were 92 women in the NT group (39\%) who reported that they were happy with their care. This included care from midwives and doctors, and lactation support staff. Continuity of care was specifically mentioned by 17 (19\%) of these women. In the HT group, 59 women (70\%) reported being happy with their care. They mentioned midwives, doctors and nursery staff. Four women in the HT group reported being happy with the continuity of care they received.

Women reported being happy with the support they received from midwives, doctors, partners, family and friends. 60 women in the NT group (25\%) reported they were happy with their support, 26 of these women included their partner and/or family/friends. In the HT group, 26 (31\%) reported being happy with their support, which included 14 women mentioning their partner and family/friends.

Several aspects of the labour and birth were mentioned by women in both groups. These included the length of labour, giving birth vaginally, having none or limited intervention, having effective pain relief and the organisation of their emergency caesarean section. In the NT group 148 women (63\%) reported being happy with their labour and birth compared to 24 (29\%) of the HT group. 
Meeting their baby, cuddling their baby or having a healthy, or live, baby was stated by women in both groups. Thirty -three (14\%) women in the NT group reported being happy with their baby, while 16 (19\%) of the HT group did.

There was one woman from each group who stated that she was not happy with anything regarding her labour and birth experience.

\section{Figure 4.1. What women reported being happy with}

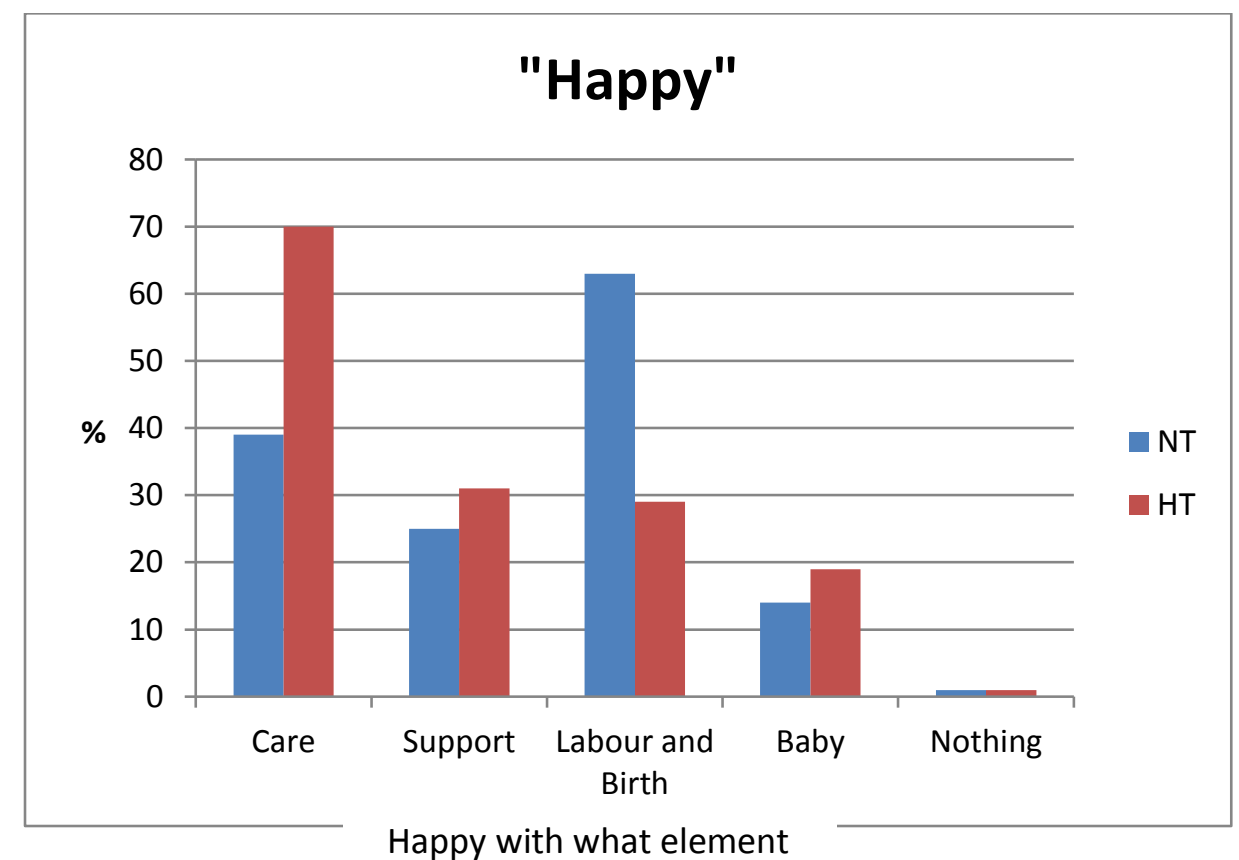

\section{Feeling unhappy about the care received in hospital}

There were 23 women in the NT group (10\%) who reported that they were unhappy with their care. This included midwives, nurses and doctors being rude or harsh, poor communication, and hospital difficulties such as long waits and sharing a room during the postnatal period. In the HT group, 10 women (12\%) reported being unhappy with an aspect of their care. They mentioned midwives being abrupt and hospital difficulties such as poor quality food, air conditioning problems, and a long postnatal stay.

Six women in the NT group (3\%) reported they were unhappy with their support, five of these women mentioned issues around their partner not being able to be 
with them outside of the partner visiting hours, especially overnight. In the HT group, four women (5\%) reported being unhappy with their support. All four of these women mentioned their partner was not permitted to stay with them during the induction of labour and/or overnight.

Several aspects of labour and birth complications were mentioned by women in both groups. These included the induction process, the pain, having an unexpected complication, and the process being more difficult than expected. In the NT group 113 women (48\%) reported being unhappy with a portion their labour and birth compared to $49(58 \%)$ of the HT group.

Some features of the baby that the women were unhappy about included having a preterm baby, the baby needing admission to the nursery, not seeing their baby for a while and not being able to do skin to skin. Eleven women in the NT group (5\%) reported being unhappy with an aspect of their baby, while $11(13 \%)$ of the HT group did.

There were 96 (41\%) women from the NT group who stated that they were not unhappy about anything regarding their labour and birth, and 24 (29\%) from the HT group.

Figure 4.2. What women reported being unhappy with

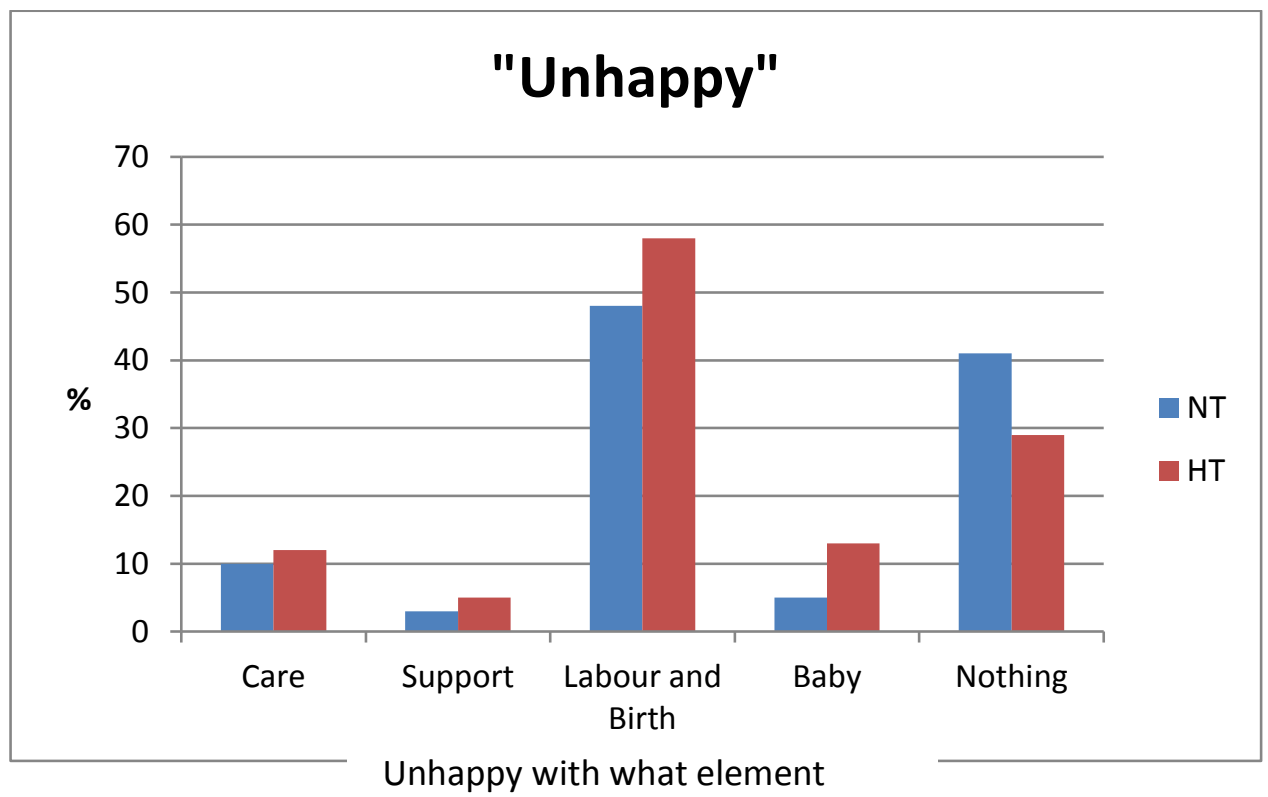

Unhappy with what element 


\section{Conclusion}

This chapter presented the results of the analysis of the quantitative component of the study. It covered a general description of the study cohort and then reported on the findings of the women's pregnancy, labour and birth, in addition to the results of the mental health and birth experience questionnaires.

Both groups were very similar in their general demographics, and the women in the HT group experienced more intervention during their labour and birth. More women from the HT group met the threshold for possible diagnosis of depression and reported their birth experience as a traumatic event. Parity, history of mental health disorder and having a diagnosis of either $\mathrm{GH}$ or PE were predictors of depression. Being admitted to ICU was a predictor for reporting the birth as a traumatic event. Overall the women in the NT group were more positive about their labour and birth experience. The limitations of this analysis, including the sample size, differences in numbers between the groups and the measures of 'satisfaction' will be discussed in the final chapter.

The following chapter presents the results of the qualitative component of the study. 


\section{CHAPTER 5: THE HYPERTENSION IN PREGNANCY EXPERIENCE}

This is the second Results chapter and presents the results of the qualitative component of the study. These results have been published in the Midwifery Journal: Roberts LM, Davis GK, Homer CS. 2017. Pregnancy with gestational hypertension or preeclampsia: A qualitative exploration of women's experiences. Midwifery. 46:17-23.The article is presented here in its original format, with acknowledgement from the Journal (Appendix 8), and is included in its published form as Appendix 9.

\section{Introduction}

Hypertensive disorders of pregnancy (HDP) are the most common medical complication of pregnancy, affecting $10 \%$ of pregnant women worldwide (American College of Obstetricians and Gynecologists 2013; Roberts \& Gammill 2005). Hypertension may exist prior to pregnancy or develop during pregnancy. There are two pregnancy-specific hypertensive disorders: gestational hypertension $(\mathrm{GH})$ and preeclampsia $(\mathrm{PE})$. By definition, $\mathrm{GH}$ is hypertension that develops after 20 weeks of pregnancy without any organ involvement and is a benign condition that usually has good maternal and fetal outcomes (Tranquilli et al. 2014). In PE, hypertension develops after 20 weeks gestation and is associated with at least one other organ involvement, most often the kidneys, but also liver, central nervous system, haematological system or the placenta (Tranquilli et al. 2014). Preeclampsia is a more significant disorder associated with increased rates of maternal and perinatal morbidity and mortality (Steegers et al. 2010).

Women who are diagnosed with $\mathrm{GH}$ or PE often require specialised care from a multidisciplinary team, antenatal hospital admissions, and a longer postnatal stay that may include time in an acute care setting such as an Intensive Care Unit (ICU). There are reports of the physical and psychological outcomes following pregnancy complicated by hypertension (Andersgaard et al. 2012; Anderson 2007; Bushnell \& Chireau 2011; Giguere et al. 2012; Williams 2011) 
and the long term health risks (Bellamy et al. 2007; McDonald et al. 2008), but there is scant research reporting on the woman's experience of HIP from her perspective, how she coped with it, and whether the care she received influenced her experience.

One of the few studies specifically about the woman's experience of HIP explored the needs of women who had been admitted to hospital (Barlow, Hainsworth \& Thornton 2008). Interviewed within three days of antenatal admission, this study showed that women sought support from partners and family and valued the support from other women in the hospital ward as they seemed to have an intrinsic understanding of the situation. There was no subsequent follow-up so it is not clear how they coped over time.

In a study from the United Kingdom, women at the postnatal clinic interviewed after a pregnancy complicated by PE, were asked about their understanding of future health risks (Brown et al. 2013). Women were mostly concerned about the next pregnancy, especially the recurrence of the HIP, the health of the baby and a long hospital admission, rather than their own health.

In high income countries, women with HIP are usually well managed with prompt, appropriate and effective interventions (Furuta, Sandall \& Bick 2014). Despite this, some experience a life threatening event which may lead to psychological sequelae (Vincent 2006). This may impact adversely on motherinfant attachment and child development (Sharp et al. 1995) and their overall experience.

It is important to better understand the perspectives of women with HIP in order to enhance their quality of care and to improve their pregnancy and birth experience. The aim of this study was to explore women's experiences of a pregnancy complicated by either GH or PE using a qualitative approach, to appreciate the woman's perspective, how she coped with it mentally, and whether the care she received influenced her experience. 


\section{Methods}

A qualitative descriptive study, as described by Sandelowski (2000), was undertaken. Qualitative descriptive methods are a useful form of enquiry when investigating previously unexamined experiences (Avis 2003; Sandelowski 2000) and afford a detailed understanding of important and sometimes complex situations (Sandelowski 2000). This approach enables life experiences to be explored in depth, and therefore gain insight and understanding of this experience from the participants' perspective (Vaismororadi, Turunen \& Bondas 2013).

\section{Setting}

The study was carried out at St George Hospital in Sydney, Australia, which caters for 2,500 births annually. The maternity unit is a regional referral metropolitan service where care can be provided to women and infants of medium to high risk (Centre for Epidemiology and Evidence 2016).

\section{Participants}

Women who were diagnosed with either $\mathrm{GH}$ or PE in their preceding pregnancy were purposefully recruited. Participants had previously consented to a five year follow-up study (Davis et al. 2016) being conducted at the hospital, and attended the hospital at six months postpartum for study measurements. Women initially met the researcher at recruitment in the immediate postpartum period, and again at the six month study visit. At the later visit, women were invited to participate in a face-to-face interview about their pregnancy and birth experience. Women who agreed to participate were contacted again at 10 months postpartum to confirm willingness to consent and organise a convenient place and time for the interview.

In total, 37 women were approached and 35 agreed to be contacted again. Six women were unable to be contacted and three declined consent at the second 
contact. Data saturation, where no new information or concepts arose from the interviews, was reached by the twentieth interview so recruitment ended at that point. The remaining six women were contacted and thanked for their offer of participation.

\section{Data collection}

Ethical approval was granted by the Local Health District Human Research Ethics Committee, the hospital Governance Unit and the university.

Semi-structured face-to-face interviews were conducted at 10-12 months postpartum. The timing of the interview was in line with suggestions from both Bennett (1985) and Simkin (1992) who propose that interviewing between months later and up to two years following the birth gives a more accurate perspective of the woman's experience.

Interviews were conducted at a mutually agreeable private place where the woman felt comfortable to share her story; 17 at the woman's home and three in a private office at the hospital. Each interview lasted about 45 minutes. The first five interviews were conducted by two female midwives who had extensive knowledge and clinical experience in caring for women with HIP. One midwife had considerable experience in interviewing women. The last 15 interviews were conducted by one midwife (first author). A series of open-ended questions guided the interview with flexibility in the questioning to respond to the woman.

The questions included:

Please tell me how you felt when you were told you had high blood pressure in your pregnancy?

How was your care from the midwives and doctors after you found out about your complication?

How did you feel after the birth?

How was your baby after the birth? 
What worried you the most about having high blood pressure in your pregnancy?

Looking back, how do you feel about your pregnancy now?

All interviews were digitally recorded. Recordings were de- identified and transcribed verbatim by the main interviewing midwife within three to four days of the interview and later transferred to the software programme NVivo for coding.

\section{Data analysis}

Data analysis began after all interviews had been transcribed. Firstly, data were separated into sections such as pregnancy, birth, baby and postpartum. This process is described by Saldana (2013) as preparing the data, giving a greater familiarity with the contents before more detailed examination begins. The second stage, initial coding, was performed using NVivo. Line by line analysis was then undertaken and nodes, a collection of quotes about a specific area of interest (QSR International 2014), were created. Transcripts were reread and recoded to ensure that initial coding was accurate and all useful data were included. The final stage of analysis was performed by two researchers and themes were derived from the data codes. This thematic analysis was applied in order to describe different concepts in relation to the research question (Braun $\&$ Clarke 2006). Sub-themes were grouped into main themes.

Direct quotes are provided to illustrate the themes. Numbers at the end of each quote have replaced names to protect the woman's identity and to show how different women had similar experiences.

\section{Findings}

The women interviewed were aged between 20 and 40 years, 15 were first time mothers and the gestation at which they gave birth varied from 30 to 41 weeks (Table 5.1). 
Table 5.1. Demographic characteristics of women interviewed

\begin{tabular}{|c|c|c|c|c|c|c|c|c|c|}
\hline ID & Age & Ethnicity & Parity & Diagnosis & $\begin{array}{l}\text { History } \\
\text { of HDP }\end{array}$ & $\begin{array}{l}\text { Postpartum } \\
\text { ICU admission }\end{array}$ & $\begin{array}{l}\text { Gestation at } \\
\text { birth (weeks) }\end{array}$ & $\begin{array}{l}\text { Birth Weight } \\
\text { (grams) }\end{array}$ & $\begin{array}{l}\text { Days in } \\
\text { SCN/NICU }\end{array}$ \\
\hline 1 & $30-35$ & Caucasian & $M$ & $\mathrm{PE}$ & $\mathrm{GH}$ & no & $34-36$ & 2720 & 0 \\
\hline 3 & $25-30$ & Asian & $P$ & $\mathrm{PE}$ & $\mathrm{N} / \mathrm{A}$ & no & $34-36$ & 2020 & $7-14$ \\
\hline 4 & $35-40$ & Asian & $P$ & $\mathrm{PE}$ & $\mathrm{N} / \mathrm{A}$ & no & $37-40$ & 2670 & 0 \\
\hline 6 & $35-40$ & Other & $M$ & $\mathrm{PE}$ & No & yes & $30-33$ & 1520 & $>28$ \\
\hline 7 & $25-30$ & Other & $P$ & $\mathrm{PE}$ & $\mathrm{N} / \mathrm{A}$ & no & $37-40$ & 3250 & 0 \\
\hline 8 & $20-25$ & Other & $P$ & $\mathrm{PE}$ & $\mathrm{N} / \mathrm{A}$ & no & $37-40$ & 2915 & $1-7$ \\
\hline 9 & $30-35$ & Other & $P$ & $\mathrm{PE}$ & $\mathrm{N} / \mathrm{A}$ & yes & $40-42$ & 3720 & $1-7$ \\
\hline 10 & $30-35$ & Caucasian & $\mathrm{P}$ & $\mathrm{GH}$ & $\mathrm{N} / \mathrm{A}$ & no & $37-40$ & 3360 & 0 \\
\hline 12 & $20-25$ & Caucasian & $P$ & $\mathrm{PE}$ & $\mathrm{N} / \mathrm{A}$ & no & $37-40$ & 3350 & 0 \\
\hline 13 & $30-35$ & Asian & $\mathrm{M}$ & $\mathrm{PE}$ & No & no & $37-40$ & 2680 & 0 \\
\hline 14 & $30-35$ & Caucasian & $P$ & $\mathrm{PE}$ & $\mathrm{N} / \mathrm{A}$ & no & $37-40$ & 3190 & 0 \\
\hline 15 & $30-35$ & Caucasian & $M$ & $\mathrm{GH}$ & No & no & $37-40$ & 4140 & 0 \\
\hline 16 & $30-35$ & Caucasian & $\mathrm{P}$ & $\mathrm{PE}$ & $\mathrm{N} / \mathrm{A}$ & no & $30-33$ & 1350 & $>28$ \\
\hline 17 & $30-35$ & Caucasian & $P$ & $\mathrm{PE}$ & N/A & no & $37-40$ & 3405 & $1-7$ \\
\hline 18 & $30-35$ & Caucasian & $P$ & $\mathrm{PE}$ & $\mathrm{N} / \mathrm{A}$ & no & $37-40$ & 2630 & 0 \\
\hline 19 & $35-40$ & Asian & $P$ & $\mathrm{PE}$ & $\mathrm{N} / \mathrm{A}$ & no & $34-36$ & 2470 & $1-7$ \\
\hline 20 & $30-35$ & Asian & $P$ & $\mathrm{PE}$ & $\mathrm{N} / \mathrm{A}$ & no & $30-33$ & 1775 & $>28$ \\
\hline
\end{tabular}


Note: Only ranges are provided for age, gestation and days in NICU/ICU to protect anonymity. $\mathrm{M}=$ multiparous, $\mathrm{P}=$ primiparous, $\mathrm{PE}=$ preeclampsia, $\mathrm{GH}=$ gestational hypertension, $\mathrm{ICU}=$ Intensive Care Unit, $\mathrm{SCN}=$ Special Care Nursery, NICU=Neonatal Intensive Care Unit. 
There were four main themes identified from the data: Reacting to the diagnosis, Challenges of being a mother, Processing and accepting the situation, and Moving on from the experience. Mediating factors that improved the experience were Feeling safe and trusting the care providers, Continuity of care and carer, and Valuing social support from partner, family and friends (Figure 5.1). 
Figure 5.1: Women's experiences of having either gestational hypertension or preeclampsia

DIAGNOSIS OF HYPERTENSION BIRTH OF BABY WOMAN HOME FROM HOSPITAL BABY COMES HOME 10-12 MONTHS OSTPARTUM

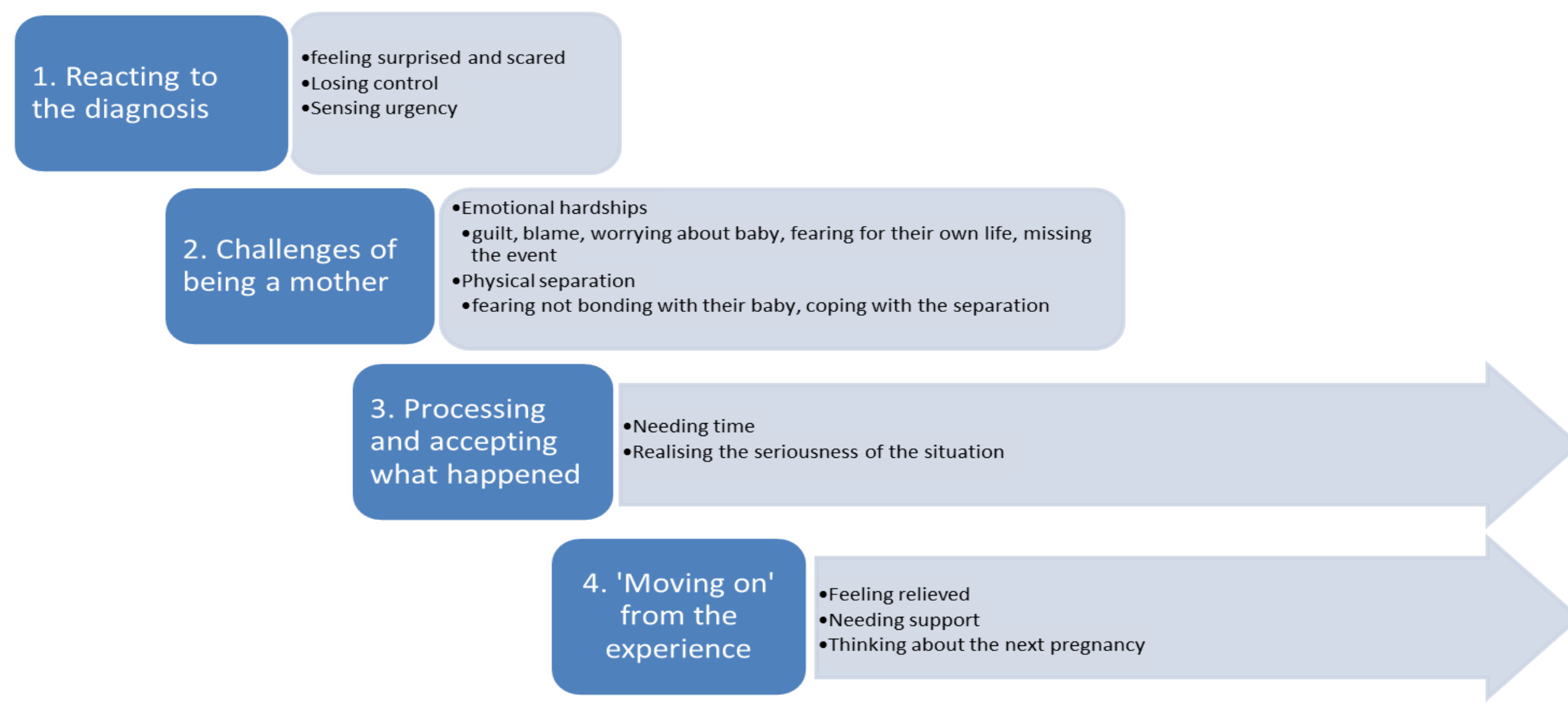

FEELING SAFE AND TRUSTING CARE PROVIDERS

HAVING CONTINUITY OF CARE

VALUING SOCIAL SUPPORT FROM PARTNER, FAMILY AND FRIENDS 


\section{Reacting to the diagnosis}

When women were informed of their diagnosis, they reacted by feeling surprised, scared or guilty. They described feeling unprepared and needed time to understand the significance of the diagnosis. This took time for all of them and often occurred well after the birth.

For some women, the diagnosis was unexpected. They said:

"I really don't know why it caused the blood pressure problem. I can't find out why, so I'm a bit surprised because I didn't have a blood pressure problem before" (20)

"When they said it had turned into preeclampsia, it was all a bit shocking. I don't think I processed at all about how I felt about it" (7)

For three women, the diagnosis came as no surprise due to a family history of hypertension. They said:

"All my life I remember mum saying she had preeclampsia and blood pressure and she'd had Caesars [caesarean sections] because of the preeclampsia. I hadn't appreciated the genetic link to preeclampsia which I now know is obviously exceptionally strong. So when I got admitted it was like, well, mum had preeclampsia" (16)

"I didn't need to worry about it, people are a lot worse and they come through and that kind of kept me aware that, and my mother had it as well and my grandmother, so, l'd sort of expected it" (1)

Many women felt scared of the potential dangers such as having a stroke or their baby dying, and of not knowing that something could be wrong. For example:

"You have that fear but you don't want to think about it or linger on that, you just want to make sure that baby's OK and you're OK. Just hope things go well" (4)

"It's a bit scary. Just the tablets and you know when you can have either infarct or something. You can have a stroke; you can have everything from hypertension" (3) 
"It's just too scary and I think the bit that scared me the most was I was asymptomatic - I don't feel anything" (11)

Most women also reacted by expressing guilt and questioned themselves. For example:

"Why did it happen to me? Could I have done something to prevent it?" (6)

"I've been questioning myself. I say why you have preeclampsia? Why your blood pressure is a problem? I think I have to change the way I'm living" (20)

A few women were disappointed with the subsequent loss of control over the situation. They said:

"I felt like I didn't have a voice and I didn't know what was going to happen to me so it was really nerve-racking" (15)

"I was pretty emotional because I couldn't control my own body. I felt betrayed by my own body because I couldn't do anything" (8)

Many women reacted to the sense of urgency once the diagnosis was given. Some examples were:

“They said 'You're going to have your baby tomorrow'. So I didn't really have time to think about how that changed things, it was just rush, rush, rush" (1)

"I think all of a sudden people were a lot more concerned. It very quickly changed everything" (5)

Once a diagnosis of $\mathrm{GH}$ or PE had been given, women reacted by feeling scared, surprised, guilty, with a loss of control of the situation. Women also felt a sense of urgency regarding the birth. 


\section{Challenges of being a mother}

Becoming and being a mother was challenging. These challenges began from the time of diagnosis and continued months after the birth.

All women worried about the health of their baby, what a preterm birth would involve and how this would affect their mothering. They said:

"I was thinking as long as he grows up fine, he comes out alive and kicking and there's no problems, that's all I been thinking of. I'm not thinking about myself" (3)

"I was worried about him. I was not worried about my own wellbeing. I think I just assumed that I would be OK and it was all about getting him delivered" (7)

Some women worried about not surviving and not being around for their baby. Some of the more dramatic examples included:

"I'm a little bit worried if my blood pressure is high or if something happen, if it too high I can die" (19)

"It crosses my mind that if I won't be around, who will take care of them? It's a scary thought - I just try not to dwell on that part" (11)

Those women who needed care in an acute care setting felt that they missed the birth or early parenting experience because of loss of recall and/or physical separation from the baby. For example, women who spent time in ICU at one hospital while their baby was transferred to another commented:

"I saw her one week later when I came out of the coma. I think initially when I came out I hadn't even realised that I had given birth" (6)

"I got my partner to take a photo when he went over but I would have rather seen her properly" (16)

"My husband went to see him every day and he brought the photos to me. I even can't see his face in all the photos because he has all the CPAP and tubes" (20) 
Some women voiced the challenges of being a mother and forming a bond with their baby after the birth. One woman said:

“Being away from her, it's not an easy thing you know. You think you've got another two months to prepare before she comes home and all of a sudden she's here and yet she's nowhere to be seen" (6)

"It just didn't feel real. It was like l'd had her but It was like going to visit someone else's child in a way. I just didn't get that bond........ couldn't stop thinking about her, but I just felt that the connection wasn't there and that obviously made me even more sad" (6)

Some described how seeing, touching, holding and feeding their baby helped them cope with the separation and isolation from the baby, and be a mother. They said:

"They got to bring him up to me in HDU, so he came up twice which was really nice" (7)

"I insisted on breastfeeding so every three hours I got a visit which made me happy. I wasn't so isolated from her then" (8)

The few women who were discharged from hospital care while their baby remained in a nursery disclosed sadness, emptiness and worry. These women were upset sharing this part of their story, expressing the challenges that they faced as a new mother. Some examples include:

"It was really horrible. That was really, really hard. I knew it was going to be hard but I didn't think it would be that hard. I was very afraid that he wouldn't be OK left in the hospital which is strange because you think he was around all the nurses and doctors and everyone's looking after him, but I think I just felt very worried that I was leaving him behind" (7) "I still felt short changed that I didn't get to take my baby home. My head knew why it couldn't happen, but I still wished it could" (16)

"I just feel so sorry for him; I have to leave him there" (20) 
Women described several challenges they faced while trying to be a mother to their baby. These challenges were more evident in those who had a preterm baby or were physically separated.

\section{Processing and accepting the situation}

Processing and accepting the situation took time. Women needed time to appreciate the seriousness of the problem and the effect that hypertension had on their pregnancy and birth plans.

Despite the urgency of the situation, they needed time to process the information at the time of diagnosis. For example:

“Ok, just take a few steps back now and let me digest” (9)

"I can't process that, I don't want to know yet. And then I remember thinking well what exactly does this mean?"

Most women accepted the situation as they felt that it was out of their control and they couldn't change things. They said:

"It just happened. Just deal with it.......you can't do anything about it; you can't change what is going to happen" (2)

"It was a case of well if that's what it is, then that's what it is" (17)

Some expressed disappointment that the birth did not go as planned but they accepted that the plan had to change. They said:

"I wanted to have a water birth with no intervention, so I was a bit disappointed in that but you know, stuff happens, you can't really change it" (14)

"I didn't have a choice. That upset me more than anything, having the caesarean. At the same time, the baby's first so it was more like, get her out, do whatever you have to do" (15) 
Some women said they were busy focussing on what was going on, caring for or visiting the baby and did not accept the seriousness until both were home. Their processing and acceptance came later. For example:

“You don't realise until you're well past that point, just how hard and stressful it was. You just get on with it at the time. That's just what you've got to do" (16)

"I don't think I dwelled on it too much. It was more like that happened and I have to push on with caring for a child and learning how to do that" (10)

Processing and acceptance sometimes occurred months later, for example:

"Afterwards when I think about it, I think gee, that was pretty scary and I was a lot sicker than I thought or wanted to admit to myself at the time. I don't like thinking about it too much because it still makes me feel anxious" (7)

"I didn't really deal with it till at least six months afterwards and that's when I really started to think about the birth and how it could have been better. So it was all about learning to let go" (8)

Processing and accepting the situation occurred at different times for different women, and took up to many months depending on the severity of the disorder and the situation.

\section{'Moving on' from the experience}

Moving on from the experience meant that women expressed relief and felt that everything was going to be all right. The time taken for women to reach this stage varied. Some 'moved on' when they felt the experience was over saying:

"I'm glad that she's finally here. You been waiting for months and months and then finally she's here and just not thinking about not having that fear any more that we're both at risk. I was really relieved about that" (4) "I was so relieved and happy that we were both OK that she was OK and I was OK and everything was going to be OK. I just felt like everyone 
was going to be OK. I was so grateful that when she came out she was, as we said, underdone but perfect" (16)

Staying in hospital for longer than expected slowed down women's ability to 'move on'. Once they had given birth and felt well, they wanted to go home to start their lives with their babies. Most accepted that even though they felt well, they were still at risk. They said:

"I was feeling fine on the second day but they said they wanted to keep me there just to be on the safe side and I'm like, 'Oh OK then but I feel fine'. If I could have, I would have liked to come home a bit earlier but they had to keep me in because of what happened" (9) "I just wanted to come home, just bring him home and get out of the hospital and start our life with him' (2)

'Moving on' also meant thinking about the next pregnancy. Recognising that HDP could recur made some feel anxious. Others felt comfortable that a next pregnancy would be monitored closely and they would be more informed of signs to be aware of, so considered another pregnancy. For example:

"I just decide to have one baby. I'm not sure if another, next pregnancy, what's going on. I have to save my life for my daughter" (19) "The doctor said I'll be closely monitored the second time around just in case it does happen again. So, hopefully......fingers crossed" (9) "I know what to look for and I'm a bit more informed this time so that's OK. They said that l'd need to see a renal physician next time I get pregnant so I'll be a bit more prepared for it I guess. It hasn't put me off having another baby" (18)

A strong theme was that women were ready to 'move on' at different times following the birth. This was evident through their desire to leave the hospital and discussing a subsequent pregnancy. The motivation for 'moving on' was often that the birth was over and it was time for her to care for her baby. 


\section{Mediating Factors}

Throughout the interviews, women described mediating factors that helped them cope with the situation: Feeling safe and trusting the care providers, Having continuity of care and carer and Valuing support from family and friends. Feeling safe and trusting the care providers.

All women felt safe in hospital and felt it was the best place for them to be. For example:

"I'm all right in the hospital. Nothing to worry about because if I'm home alone and something happen, it's more worry. I be OK there with doctors and midwives. In the hospital I was just confident with the doctor and midwife" (19)

"When they told me about what's going to happen I think I'm in the hospital and in the right place" (20)

"Then I need to stay in hospital because that's the safest place for me to be" (16)

Feeling informed about their progress and being included in decision making helped women feel safe. For example:

"They [midwives] put you at ease and they tell you each time they take your blood pressure how it's going" (10)

"They were always looking after me and letting me know each step of the way what was happening. I was really happy with that" (8)

Most women felt that the midwives and doctors were experts and they were 'in good hands'. They were less worried, anxious and concerned because they trusted these experts, saying:

"I found it a bit comforting knowing that I was in such a scary position and she [midwife] was very experienced in doing what she does so that's good to know" (12)

"You have to trust whoever's looking after you cause they will be the one who will help you at the end or if anything goes wrong" (3) 
Women felt confident that they were safe after forming a relationship with staff, trusting them and viewing them as experts. Feeling informed also contributed to them feeling safe.

Having continuity of care and carer

Continuity of care and carer was important to the women as their carers knew them and their history. For example:

"When everything was normal you just go there [antenatal clinic] wait to see whoever will look after you. But after they found I had the hypertension and they put me on the medication, I think I got good continuous care from one or two person" (3)

"It was nice to have one familiar face who knew my story and my case in the Delivery Suite" (2)

Being cared for by someone they knew and trusted helped them feel more comfortable and supported:

“Labour wasn't that bad and I had one of the educators with me the whole time. No midwives swapped and changed on me or anything. So everything went really smoothly. I think I was pretty lucky" (5) "She [the doctor] was there pretty much every day and I remember saying to her it was really lovely to see her everyday cause it was a familiar face consistently. She was obviously busy but she took time to explain and answer any questions. So that was good' (16)

Women enjoyed participating in the 'continuity of care experience,' as part of the clinical experience of midwifery students. They said:

"I actually had a trainee midwife with me so that made it a lot easier actually. It was good" (5)

"I had a student midwife with me the whole time that I was there. She was a tremendous support. So, being with her, I didn't really have any concerns at all. I was a bit nervous about the whole birth experience but she made it a whole lot better than what it would have been otherwise" (14) 
Women described how they felt well supported and their experience was improved though having continuity of care and carer.

Valuing social support from partner, family and friends

Support from partner, family and friends was important in helping them recover. Some women felt like they needed more support during the hospital stay and hospital rules were too restrictive to facilitate this. For example:

"I was talking a lot to friends and they were giving me a lot of support but it's so different over the phone or through text. You just want human contact. I know there's a period where no one's allowed to come into the hospital at night time with you, but I think that's when you do most of your thinking" (8)

"So the support that I had from those two [partner and mother] was just incredible. I couldn't have done it without them" (16)

Support was especially important for women with preterm babies in hospital. One woman said:

"I guess you could call it a traumatic experience in that it's not the norm, and it was fairly dramatic, but I don't feel like l've been left to flounder and a lot, a large part of this is because of the partner and mother I have. I'm very aware and very grateful for both of them" (16)

Having social support was a dominant theme. Women expressed that this support was necessary throughout the experience but was sometimes hampered by hospital rules.

\section{Discussion}

This study aimed to gain insight into women's experience of having GH or PE and report on mediating factors. The study provides a unique opportunity to understand the HDP experience from the woman's viewpoint, an area that currently lacks research. Such insights may help inform practice to improve the woman's experience and facilitate her coping strategies (Coster-Schulz \& 
Mackey 1998). In this study, the women described the challenges they faced when informed of the diagnosis, having the baby, being separated from their baby and 'moving on' from the experience. Feeling safe, having continuity of care and carer and support were identified as being important to the women.

Other studies have also shown that the separation of mother and baby is challenging for women adapting to being a mother (Engstrom \& Lindberg 2011). These challenges may not be due to the $\mathrm{GH}$ or $\mathrm{PE}$, rather the physical separation, especially if the woman is in an ICU. Social support was reported as being important for the women by Engstrom and Lindberg (2011) which is in line with this PhD study. Support from family members, friends, and health professionals is particularly important for women at risk of preterm birth (Hodnett, Fredericks \& Weston 2010). It has also been reported as being important for the development of maternal-fetal attachment (Yarcheski et al. 2009). In my study, it was evident that strategies such as flexibility in hospital visiting hours would help with the support available from family and friends while continuity of care would improve support from care providers.

Midwifery continuity of care has long been identified as being beneficial for women throughout pregnancy and childbirth (Homer, Davis, et al. 2002; Sandall et al. 2016; Tracy et al. 2013). Women who experience HDP require collaborative care from obstetric, medical and midwifery teams. Continuity of care from such a collaborative team is important and beneficial for women with a high risk pregnancy (Biro et al. 2003; Bradshaw, Lewis \& Steer 1995; Homer, Farrell, et al. 2002). Increased satisfaction with the birth experience has been reported by women with a complicated pregnancy who are cared for by a multidisciplinary team (Biro et al. 2003; Bradshaw, Lewis \& Steer 1995), and women with a pregnancy risk also reported less worry in an earlier study (Homer, Farrell, et al. 2002). Women participating in my PhD study described continuity of care as being helpful in improving their birth experience. Hence, care of women with a high risk pregnancy should be provided through a multidisciplinary, collaborative, continuity of care model. This model is 
realistically achievable in a tertiary obstetric referral service (Biro et al. 2003; Tracy et al. 2013).

Previous studies reporting on women's perspectives of their experience of a complicated pregnancy have focussed on the hospital admission and the postpartum period, usually only days or weeks. This study presents a comprehensive exploration of the woman's experience with $\mathrm{GH}$ or $\mathrm{PE}$, from diagnosis to the first year after the birth. The analysis has shown that women take time to realistically reflect on their experience and process what happened. This study has explored the birth experience for women who experienced $\mathrm{GH}$ or PE. This is the first time such a specific study has been undertaken. All women interviewed for this study had their pregnancy care at one hospital. This hospital has a multidisciplinary collaborative team whose focus is caring for women with HDP using firm evidence based policies and practice. This continuity of care model may have positively influenced the women's experience in this study.

The limitations to this study include that all women who participated had their pregnancy care at St George Hospital in Sydney. Accordingly, the majority of women reported on their experience of the less severe forms of $\mathrm{GH}$ or $\mathrm{PE}$ from a diverse range of gestational ages. All women in this study gave birth at greater than 30 weeks gestation. It is not clear whether women with earlier gestations would feel the same or if the experiences in other hospitals or other countries would be different.

\section{Conclusions}

Women have profound experiences after the diagnosis of GH or PE. They face challenges from the time of diagnosis through to many months after the birth of their baby. Their pregnancy, birth and postnatal care influence their experience, how they cope with the situation, and their mothering pathways. 
The implications of the findings for midwifery practice include having access to appropriate multidisciplinary continuity models of care that includes care from a known midwife and facilitating social support for these women. 


\section{CHAPTER 6: DISCUSSION}

This study investigated depression, anxiety, PTSD, birth experience and mother-infant relationship of women who were diagnosed with hypertension in their pregnancy, either gestational hypertension $(\mathrm{GH})$ or preeclampsia $(\mathrm{PE})$, and women who had normal blood pressure in pregnancy. The study was undertaken at St George Hospital, a metropolitan teaching hospital in Sydney, Australia, which caters for approximately 2500 women giving birth a year.

In total, 321 women participated in the study; 237 in the normotensive group and 84 in the hypertensive group. All participating women completed screening instruments regarding their mental health symptoms and their birth experience. In addition, 20 of the women who had hypertension in their pregnancy shared a more detailed recall of their birth experience through a semi structured face to face interview.

The study was divided into two phases and quantitative and qualitative approaches were used. Phase One compared the mental health and birth experiences of women who experienced either $\mathrm{GH}$ or PE with women who did not have hypertension, using a survey that was analysed quantitatively. Phase Two was the qualitative component where women who had experienced hypertension in pregnancy were interviewed and their data were analysed using thematic analysis. Data from each of the phases were triangulated or blended for the purpose of illustrating a more complete understanding of women's' birth experience. This convergence of data from different sources validated what women reported in the different phases of the study (Heale \& Forbes 2013). The women who participated in the interviews provided further information that helped to explain and support the results of the mental health screening instruments and the open ended questions.

In this final chapter, both the quantitative and qualitative findings are briefly summarised and then discussed in light of current evidence and research. The mental health disorders depression, anxiety and posttraumatic stress disorder 
(PTSD) will be discussed separately, followed by the women's birth experiences and the mother-infant relationship. This leads into a discussion, based on my findings, on what women may want and/or need to improve their birth experience, and recommendations, named essential elements of care, concerning the care of women with HIP. This chapter concludes with a discussion about the strengths and limitations of the study.

\section{Summary of findings}

Phase One

Women from both the HT and NT groups were similar in their general demographic characteristics, and the women in the HT group experienced more intervention during their labour and birth. Women from the HT group reported more depressive symptoms than women in the NT group and more met the threshold for possible diagnosis of depression and reported their birth experience as a traumatic event. Having the first baby, a history of mental health disorder and having a diagnosis of either $\mathrm{GH}$ or PE were predictors of depression. Being admitted to ICU was a predictor for reporting the birth as a traumatic event. Overall the women in the NT group were more positive about their labour and birth experience.

\section{Phase Two}

There were four main themes identified from the interview data. These were Reacting to the diagnosis, Challenges of being a mother, Processing and accepting the situation, and Moving on from the experience. Women also discussed mediating factors that helped to improve their birth experience. These were Feeling safe and trusting the care providers, Continuity of care and carer, and Valuing social support from partner, family and friends.

\section{Depression}

Postpartum depression is a major health issue for many women with reported rates of approximately $16 \%$ at some stage in the first year after birth in the 
Australian population (Howard et al. 2014; Woolhouse et al. 2012). The evidence on whether a pregnancy or obstetric complication influences maternal mental health after the birth is limited, unclear and uncertain, perhaps due to hypertension in pregnancy (HIP) being largely conceptualised as being limited to pregnancy (Kim et al. 2005) and the longer term, postpartum issues, are often not considered.

In my study, women who did not have HIP were less likely to report symptoms of depression at six months postpartum compared with women in the hypertensive (HT) group. This was apparent in both the mean Edinburgh Postnatal Depression Scale (EPDS) scores (4 versus $5, p=0.03$ ) and the proportion of women scoring above the threshold for the possible diagnosis of depression ( $2 \%$ versus $7 \%, p=0.03$ ). Although more depressive symptoms were reported by the women in the HT group, they were much lower than what is reported nationally. This may be due to the characteristics of the study women and is discussed later in this chapter as a limitation of the study.

Previous studies have generated rates of depression from three to more than $25 \%$ in the first postpartum year regardless of complexity of the pregnancy (Blom et al. 2010; Denis, Michaux \& Callahan 2012; Hoedjes, Berks, Vogel, Franx, Bangma, et al. 2011; Mautner et al. 2009). These rates vary according to sample size of the study, the instrument used, the cut-off score for that instrument and the timing of the assessment. Screening tools do not identify all women with depression, and some women who score high on the scales will not be clinically depressed (Guedeney et al. 2000). The Edinburgh Postnatal Depression Scale (EPDS) is the most commonly used screening tool around the world with the majority of studies reporting a positive predictive value for this tool around 70\% (Boyce, Stubbs \& Todd 1993; Cox et al. 1996; Harris et al. 1989; Murray \& Caruthers 1990).

The evidence on depression in women who have had a complicated pregnancy is mixed with some earlier studies showing that an obstetric or pregnancyrelated complication was unrelated to the development of PPD (Johnstone et al. 
2001; Nielsen et al. 2000), while others found the prevalence of depression higher in women who experienced HIP with rates being higher in those women with the more severe hypertensive disorders (Blom et al. 2010; Hoedjes, Berks, Vogel, Franx, Bangma, et al. 2011). In my study, the HT women spoke of having some depressive symptoms but they did not necessarily meet the criteria of suspected depression. These symptoms included sadness, guilt and blame.

The prevalence of depression in women following a pregnancy complicated by hypertension has been reported to range from 6.8\% to 39\% (Blom et al. 2010; Engelhard et al. 2002; Habli et al. 2009; Hoedjes, Berks, Vogel, Franx, Bangma, et al. 2011; Mautner et al. 2013; Rep et al. 2007; Stramrood et al. 2011). Again, this variation may be partly attributed to the severity of the hypertensive disorder being investigated, the instrument used, the cut-off score for that instrument or the timing of the measuring.

The study undertaken by Hoedjes, Berks, Vogel, Franx, Bangma, et al. (2011) in the Netherlands used the EPDS as the measuring tool, with a cut off score of greater than 12, and screened women for depression at several time points, including 26 weeks (six months) postpartum following a pregnancy complicated with PE. The 26 week stage of this study is comparable to the method used in this current research project. Hoedjes, Berks, Vogel, Franx, Bangma, et al. (2011) reported that $18 \%-21 \%$ of the women who experienced PE recorded a score greater than 12 at 26 weeks postpartum, depending on the severity of the hypertensive disorder. This is a higher rate of depression compared to the $7 \%$ found in my study. This may be attributed to differences in the study population characteristics, particularly the severity of the hypertensive disorder. The majority of women participating in the Hoedjes, Berks, Vogel, Franx, Bangma, et al. (2011) study gave birth at a tertiary referral hospital and generally experienced severe complications of PE, including Neonatal Intensive Care Unit (NICU) admission of the baby and perinatal death. A smaller number of women with less severe PE gave birth at a nearby, non- referral, hospital and were also included in the study. The authors propose that the relatively high number of 
women with severe preeclampsia in their cohort may have contributed to a higher prevalence of depressive symptoms and suggest that the rate may have been somewhat lower if the severity of PE was more evenly balanced across both groups in the cohort.

Another study (Kim et al. 2005), undertaken in the US, investigated mental health following HIP and reported that HIP was associated with the subsequent development of depressive symptoms in the postpartum period. They postulated that this may be due to the perceived lack of control women feel they have over the disorder as there are few options of prevention and selfmanagement of HIP. A lack of control was widely recognised by the women who participated in the interviews for my study. In the Reacting to the diagnosis theme, women expressed concerns about loss of control regarding what their body was doing, the speed of their diagnosis and subsequent treatment and interventions, their labour and birth plan and their input in decision making. Most of the women accepted this loss of control, justifying it for the sake of their health and that of their baby. None the less, this loss of control has the potential to contribute to postpartum mental health disorder. To add to this, the loss of control mentioned during the interviews corresponds with the results of the birth experience questions, where $62 \%$ of the women in the NT group reported feeling in control during their birth experience compared with $38 \%$ of women in the HT group.

Control is a prominent factor that contributes to women's birth experience and subsequent mental health (Gibbins \& Thomson 2001; Hardin \& Buckner 2004; Waldenström et al. 2004). It consists of an internal and external process, both of which are important and can impact a woman's birth experience (Cook \& Loomis 2008). Internal control refers to a woman's ability to control her feelings and to make decisions such as changing position during labor (Hardin \& Buckner 2004), while external control concerns a woman's ability to take part in decision making including those around medical interventions (Hardin \& Buckner 2004). A lack of control is more likely to be associated with a negative birth experience (Hardin \& Buckner 2004; Waldenström et al. 2004), and a 
negative birth experience may contribute to postnatal depression (Bell \& Andersson 2016). It was clear from the quantitative component of my study that the women from the NT group had a more positive birth experience although I recognise that satisfaction was measured using a rather blunt approach and is likely to be more nuanced. These women reported being two to three fold more satisfied with their experience, using the Likert Scale scores, and more than twice as many (63\% versus $29 \%$ ) reported being happy with their labour and birth experience compared with women in the HT group. Further details regarding the poorer birth experience for the women in the HT group was gained from the interview data. These details include the change of birth plan, loss of control and the issues around having a preterm baby who required admission to the nursery. This undesirable birth experience for the women with $\mathrm{HT}$ led to a less positive birth experience overall which has the potential to contribute to depression in the postpartum period.

\section{Anxiety}

Feeling stressed or worried is a normal response to a demanding situation such as pregnancy and parenthood (Austin, Highet \& the Expert Advisory Committee 2017). However for the majority of women, these feelings subside over time. For some women these feelings become unreasonable and persist, affecting their everyday activities including caring for their baby. Up to one in five Australian women will show signs of anxiety in the first postpartum year with about half of these women experiencing concurrent depression (Austin, Highet \& the Expert Advisory Committee 2017).

In contrast to postpartum depression, empirical results regarding postpartum anxiety are limited (Ross \& Mclean 2006). It has previously been reported that $16.2 \%$ of women are diagnosed with any anxiety disorder at six weeks postpartum with $82 \%$ of diagnoses occurring for the first time in the postpartum period (Matthey et al. 2003). In regards to general anxiety disorder, a prevalence rate of $8.2 \%$ at eight weeks postpartum has been reported by Wenzel, Haugen and Jackson (2005). Looking at a longer period of time, Miller, 
Pallant and Negri (2006) found that $10 \%$ of women reported symptoms of anxiety and stress at some time during the six week to six month postpartum timeframe.

An Australian study, that included over 4000 women who completed surveys including a validated anxiety and depression instrument (Depression Anxiety Stress Scale), showed that $13 \%$ of the women were experiencing anxiety at six months postpartum (Yelland, Sutherland \& Brown 2010). The authors conclude that stressful life events or social health issues, commonly death or illness of friend or family member, moving house or financial hardships contributed to the anxiety with $9.9 \%$ of the women reporting three or more social health issues. Similar to most other studies, there was no mention of pregnancy or birth complications in this study. Interestingly, this study reports that one in ten women reported both anxiety and depressive symptoms (Yelland, Sutherland \& Brown 2010).

It has long been recognised that anxiety and depression can coexist, including during the postpartum period, and can be harder to treat than a single disorder (Emmanuel, Simmonds \& Tyrer 1998). It has therefore been suggested by Matthey et al. (2003) that it is warranted to investigate both depression and anxiety in expectant and new parents.

There is limited evidence specifically about general anxiety following a complicated pregnancy, particularly HIP. A systematic review undertaken byDelahaije et al. (2013) included two studies that addressed anxiety following a pregnancy complicated by PE. Neither of these studies (Baecke, Spaanderman \& Van Der Werf 2009; Brusse et al. 2008) showed a significant association between PE and anxiety scores, however higher scores were recorded among women who had experienced PE compared to those women who had not.

In my study, using the GAD-7 screening tool, the proportion of women who scored in the moderate anxiety zone or higher was much less than what has 
been reported in the literature. In line with the systematic review by Delahaije et al. (2013), there was no difference found in the proportion of women from each group who met the criteria for moderate anxiety, however in contrast, there was no difference found in the mean scores recorded. As with the depression scores in my study, these findings may be due to the characteristics of the study cohort, in addition to factors such as the screening tool and the timing of the screening. The timing of the screening may be particularly important as evidenced by what the women said during their interview. Although most women voiced varying degrees of worry and anxiety following their diagnosis of HIP and during their Challenges of being a mother, they also expressed that once they knew that the birth was over, they were well and the baby survived and came home, most of this worry dissipated. If the anxiety screening had been carried out earlier than six months postpartum, the results may have been very different, as, by this time most women had made significant adjustments to parenthood and felt reassured by their health and their baby's health which may have affected how they responded to the questions.

Two previous studies, one from The Netherlands (Rep et al. 2007) and the other from the US (Habli et al. 2009) report on anxiety in women following a pregnancy complicated by PE. These authors report that $25-35 \%$ of the women showed signs of anxiety, which is higher than the Australian reports and my current study. However, these reported rates need to be interpreted with caution as a non-validated measuring instrument, and an instrument that did not measure anxiety specifically, were used in these studies. This could have resulted in inaccurate reporting. In addition, the Rep et al. (2007) study included only women with the more serious complications of PE at 24-34 weeks gestation, which could influence the scores as having a preterm birth has been associated with increased anxiety (Baecke, Spaanderman \& Van Der Werf 2009). The study by Habli et al. (2009) surveyed women up to 31 years following the birth with no clear information of any other events that may have contributed to the anxiety, such as a previous history of mental health disorder or traumatic life events (Martini et al. 2015). All of these factors have the potential to affect the reported rates, most likely over-reporting. Neither of these 
studies included a group of women who did not have PE to use as a comparison baseline, so it is not possible to conclude that the high rates of anxiety are due to the PE alone.

A previous study (Brusse et al. 2008) used a similar method to my study where women completed a validated questionnaire regarding anxiety at three to eight months following either a NT pregnancy or one complicated by PE. All gestations were included, all women had a caesarean birth and the groups were matched for age. The sample size was small, with only ten women in each group. Brusse et al. (2008) recorded median scores in their study and found no significant different between the scores from women who experienced PE to those who were normotensive in pregnancy $(P=0.21)$. These findings parallel those in my study, perhaps due to including all degrees of PE complications and gestations.

\section{Posttraumatic Stress Disorder (PTSD)}

PTSD is described by the American Psychiatric Association (2013) as a set of reactions following exposure to a traumatic event. Most people will have some symptoms of PTSD in the days following a traumatic event (Blanchard \& Hickling 2004) and will make a complete recovery, even in the absence of treatment (American Psychiatric Association 2013). If the emotional symptoms persist beyond 30 days following the traumatic event and cause significant distress and/or impairment of the person's everyday activities, PTSD may be considered (American Psychiatric Association 2013).

It is only recently that childbirth has been recognised as an event that could be perceived as traumatic and consequently lead to PTSD symptoms (Gamble \& Creedy 2007; Olde et al. 2006; Porcel et al. 2013). What makes a birth traumatic varies between women, is subjective and can be difficult to define (Simpson \& Catling 2016). For some women, childbirth can be a complex event and lead to a life threatening situation which may result in a variety of psychological responses (Borg-Cunen et al. 2014). A recent systematic review 
and meta-analysis by Yildiz, Ayers and Phillips (2017), reported a PTSD prevalence rate of $4.9 \%$ at six months postpartum in the general community, and $16.61 \%$ at six months postpartum in women from a high-risk pregnancy group which included women with HIP.

As with depression and anxiety, my study found a lower rate of PTSD in both the NT and HT groups compared to what has been reported around the world. Furthermore, there was no difference detected between the groups with $2 \%$ of women from each group scoring above the threshold score for PTSD. This is in contrast to several studies (Engelhard et al. 2002; Gaugler-Senden et al. 2012; Porcel et al. 2013; Stramrood et al. 2011; Yildiz, Ayers \& Phillips 2017) that have all reported higher rates of PTSD in women following a pregnancy complicated by hypertension compared to women who were normotensive in pregnancy.

Interestingly, Baecke, Spaanderman and Van Der Werf (2009) and Engelhard et al. (2002) report a difference in PTSD between women who gave birth preterm and term, with or without HIP, suggesting that the consequences of a preterm birth led to the symptoms of PTSD, rather than the hypertensive disorder. This current study had a similar finding, in that the strongest predictor of PTSD was having a preterm birth, although this was not statistically significant. In contrast, Harris and Ayers (2012) suggest that difficulties experienced personally by the woman may be a stronger trigger of PTSD than those that occur to the baby. They concluded that having a sick baby is more socially acknowledged to be stressful and therefore the women may be more supported by her family, friends and hospital staff during this time.

Despite finding no significant difference between the two groups for PTSD using the quantitative method, more women from the HT group reported their birth as a traumatic event. This was supported by the comments made by the women during the interviews and the qualitative analysis. Women spoke about how their experience was traumatic for them throughout the interviews. This was particularly evident in regards to the Reacting to the diagnosis and Challenges 
of being a mother themes were the women used words such as fear, scared, angry, terrible, traumatic and disappointed. They explained about feeling scared of the potential dangers and of not knowing what the outcome would be, not surviving and not being around for their baby. They stated that having a caesarean section or induction of labour was not what they had planned which was traumatic for some. The women who gave birth to a preterm baby who needed a nursery admission were the most traumatised, and disclosed feelings of sadness, emptiness and worry. Other researchers have suggested that a traumatic birth experience stems from the woman's perception of her treatment, complications including risks to her baby, and her perception of her choice and control over medical procedures (McKenzie-McHarg et al. 2015; Porcel et al. 2013; White et al. 2006). The majority of women who participated in this study reported being happy with the care they received but women in the HT group commented on the challenges they faced regarding their medical condition, risks and loss of control over the situation. It is possible that the women in the HT group had some protection from PTSD because of their collaborative care, but stressful situations, which are not modifiable due to the nature of HIP, may have contributed to PTSD symptoms. This may explain why there were more reports of a traumatic birth from women in the HT group and several women from this group reported symptoms of PTSD but did not meet the threshold for diagnosis.

\section{Mother infant bonding}

Mother-infant bonding has been described as the mother's concerns and actions about the safety and wellbeing of her baby, as well as her affection for her baby and the place he or she holds in her world. It is a unique, specific, and long-term emotional attachment between the mother and her child (Figueiredo et al. 2009). The quality of the maternal-infant relationship has a significant influence on maternal mental health and infant well-being, development, and adaptation throughout life (Johnson 2013). 
Factors that may disturb the mother-infant bond are poor maternal mental health (American Psychiatric Association 2013), having a preterm baby, being separated from the baby, inability to breast feed and reduced contact with the baby (Muzik et al. 2013). The four latter points are often observed with women who experience PE

In this study the mother- infant bond was well developed in both the NT and HT groups as evident by the six month postpartum MIB scales scores. Although many women, especially those who gave birth prematurely, reported challenges in the early postpartum period, they all reported good bonding at six months postpartum. Women who were interviewed described how they had trouble bonding initially, mainly due to the emotional hardships they faced, the baby being unwell and the physical separation from their baby (Challenges of being a mother), but over time the relationship developed. The good maternal infant bonding reported in this study may have stemmed from the low proportion of women who reported mental health disorder symptoms.

\section{The birth experience}

The concept of maternal perceptions of her birth can be puzzling as women's expectations and experiences differ (Lewis et al. 2016) and are subjective. A systematic qualitative review by Downe et al. (2018) suggested that women around the world hope for a positive labour and birth experience that enables them to use their innate ability to labour and give birth to a healthy baby in a clinically, culturally, and psychologically safe environment. To do this women want continuity of practical and emotional support, and kind, sensitive health professionals, who provide reassurance and skilful care (Downe et al. 2018). Lewis et al. (2016) studied an Australian cohort of women and concluded that women value a sensitive and respectful relationship with competent care providers who strive to provide woman focused care throughout pregnancy and childbirth. Another Australian study by Jenkins et al. (2014) agrees with this and suggests that women are more concerned with staff and relational issues than the facilities available to them. Another study, from Sweden, found that 
women related such things as their own ability and strength as well as forming a trusting and respectful relationship with the midwife, to a positive birth experience (Karlstrom, Nystedt \& Hildingsson 2015).

What constitutes a positive birth experience varies between women but Karlstrom, Nystedt and Hildingsson (2015) summarise what women want for a positive experience as having their expectations met. Women may have multiple expectations for birth with specific ones having priority over others (Hauck et al. 2007). If these priority expectations are met, the woman will usually perceive her birth as a positive experience (Hauck et al. 2007). Assisting women to achieve their expectations is a role midwives are well placed to do and when expectations are not fulfilled, midwifery care becomes even more important. It is crucial for the midwife to encourage involvement during birth to assist in the feelings of control and support which will help the woman to perceive her birth experience as a positive one (Hauck et al. 2007). The women who participated in my study often altered their expectations following the diagnosis of HIP. This was particularly clear during the interviews when women commented on how they didn't have the birth they planned for or wanted, but they were happy with their birth experience as their baby was born well, and they were well cared for. This shift of expectation, due to the complicated pregnancy, may have assisted with the acceptance of this birth experience. This alteration of expectations has been described (Hauck et al. 2007) in regards to the birth of a subsequent baby when expectations may not have been achieved with the first birth. When trying to understand the aspects of maternity care most important to women, it is important to consider all factors including any complications in the pregnancy.

When complications arise or intervention is required, women usually wish to retain a sense of personal achievement and control by being involved in the decision making (Downe et al. 2018). This is consistent with recent and important policy frameworks; the Lancet Quality of Maternal and Newborn Care Framework (Renfrew et al. 2014), and the 2015 WHO Quality of Care Framework for Maternal and Newborn Health (WHO et al. 2015). However, 
Harrison et al. (2003) undertook a qualitative study in Canada interviewing women who experienced a pregnancy complicated by hypertension or preterm labour, and reports that women with a complicated pregnancy are aware of the risk to themselves and their unborn baby, and this knowledge may alter their birth experience expectations. They report that while most women wanted to remain active in decision making regarding their care, some women preferred to take a more passive role and trust their care providers (Harrison et al. 2003). This concept was conveyed by some women in my study when they discussed how they accepted the decisions made around their care for the sake of their own health and that of their baby.

Factors that were important to the women who participated in my study were viewed as being helpful in improving the birth experience despite hypertension complicating the pregnancy. These mediating factors were Feeling safe and trusting care providers, Having continuity of care and carer, and Valuing social support from partner, family and friends.

The care women receive during pregnancy, birth and the postnatal period is likely to influence their birth experience, how they cope physically and emotionally, and their mothering pathways (Coates, Schaefer, \& Alexander 2004). Specifically, a positive birth experience has been linked with good postpartum mental health and inversely, a poor birth experience can detrimentally affect the woman's mental health (Coates, Schaefer, \& Alexander 2004). In order to improve the birth experience for women diagnosed with HIP, and to help maintain or support their mental health I suggest four essential elements of care.

In this next section, I discuss some key principles that will assist in improving the childbearing experience for these women based on my research and the literature in this area. It is hoped, but in many cases, untested, that these elements may ultimately contribute to improved social, emotional and mental health outcomes for women. These four essential elements of care are based 
on the quantitative and qualitative findings of my research and current evidence. The elements are:

1. Providing continuity of midwifery care in a collaborative model

2. Facilitating social support

3. Prevention and early identification of poor mental health

4. Keeping mother and baby connected

\section{Essential elements of care}

1. Providing continuity of midwifery care in a collaborative model Women who experienced HIP described continuity of care from midwifery and medical staff as being helpful in improving their birth experience. This was very clearly reported in the questionnaires that the women completed and reinforced in the narrative from the interviews. The women reported feeling safe knowing and trusting their care providers and felt good about having a known care giver. Therefore, the first essential element of care for women diagnosed with HIP is providing continuity of care while also taking a collaborative approach. Medical care, from an obstetrician and obstetric physician, for example, is essential for women diagnosed with HIP but it is equally important for midwifery care to continue. In the mediating theme Feeling safe and trusting care providers, women spoke favourably about having care from a known midwife and doctor and valued the trusting relationship they formed with these care providers.

\section{Continuity of care}

Haggerty et al. (2003) and Saultz (2003) summarise continuity of care as care over time with the focus on the individual patient, with the three levels of continuity differing depending on the type and setting of the care. The three stage hierarchical definitions of continuity of care are shown in Figure 6.1. 


\section{Figure 6.1 Levels of continuity of care}

\section{Informational}

An organised collection of medical and social information about each patient is readily available to any health care professional caring for the patient. $A$ systemic process also allows accessing and communicating about this information among those involved in the care

\section{Longitudinal}

Each patient has a "medical home" where they receive most health care, which allows the care to occur in an accessible and familiar environment from an organised team of providers. This team assumes responsibility for coordinating the quality of care, including preventive services

\section{Interpersonal}

An ongoing relationship exists between each patient and a personal physician. The patient knows the physician by name and has come to trust the physician on a personal basis. The patient uses this physician for basic health services and depends on the physician to assume personal responsibility for their overall health care. When the personal physician is not available, a coverage arrangement assures that longitudinal continuity occurs.

Adapted from (Saultz 2003)

When these levels of continuity of care are applied in a midwifery setting there is one midwife, or a team of midwives, providing care to each woman throughout the continuum of her pregnancy and birth. All three levels of continuity of care applied to the women with HIP who participated in my study, once the diagnosis had been made.

1. Informational support was provided through a well organised routine of care. This was made possible by the use of shared antenatal records and electronic records, using evidence based policy, giving information brochures, and using good communication between team members and the women. 
2. Longitudinal support was ensured by caring for women in an accessible and familiar environment from an organised collaborative team. Care was provided in the antenatal clinic, day assessment unit and/or on the maternity ward. The familiar collaborative team coordinated quality care.

3. Interpersonal support was provided from the team members and enabled the women, over a short space of time, to develop trust in the team and feel safe under their care.

Midwifery continuity of care has been identified as being beneficial for women throughout pregnancy and childbirth and is based on the woman having a relationship with one midwife or a small group of midwives (Sandall, Soltani, et al. 2016). A recent Cochrane review (Sandall, Soltani, et al. 2016) reported the benefits of continuity of midwifery care as fewer instrumental births, more spontaneous vaginal births, and a reduced risk of a preterm birth. Importantly, this review found that the majority of the studies reported higher rates of maternal satisfaction in midwife-led continuity models of care (Sandall, Soltani, et al. 2016). However, they conclude that, while most women should be offered midwife-led continuity of care, it is uncertain whether women with a high risk pregnancy would benefit, as the review did not include women with serious pregnancy or health complications. My study suggests that they do benefit from this model.

Women with a high risk, or complicated, pregnancy need continuity of midwifery care just as much as women with a low risk pregnancy do, and in many ways they are potentially in greater need. There has been limited research published regarding midwifery care for women with a high risk pregnancy, but studies have indicated that these women want continuity of midwifery care and find it satisfying (Berg 2005; Biro et al. 2003; Bode \& Lynch 2018).

Several policies and guidelines in Australia have drawn attention to midwifery continuity of care models. In response to a review of maternity services in Australia in 2009-2010 (DoHA 2009), the National Health and Medical Research Council was commissioned by the Department of Health and Ageing to develop 
national guidelines on collaborative maternity care (NHMRC 2010). These guidelines provide information for women and maternity care providers concerning continuity of care and collaborative practice. This model of care places the woman at the centre of her own care, while supporting the professionals who are caring for her. Such care is coordinated according to the woman's cultural, emotional, mental health and clinical needs. Three other examples of policy guidelines are the National Midwifery Guidelines for Consultation and Referral (ACM 2008), National Competency Standards for the Midwife (NMBA 2006), and the Royal Australian and New Zealand College of Obstetricians and Gynaecologists Guideline: Suitability Criteria for Models of Care and Indications for Referral within and between Models of Care (RANZCOG 2009). These documents aim to improve choice and access to maternity services, give families greater choice in the type of care they receive when having a baby including continuity models.

Policy drivers regarding continuity of care are not limited to Australia and New Zealand. Similar policies and guidelines have been published in the United Kingdom (UK); the National Maternity Review (NHS 2015) and the Green Templeton College Report (Sandall, Coxon, et al. 2016), and in Canada (Maternity Care Enhancement Project 2004), with a recurrent theme of women wanting continuity of care in maternity services.

The common theme from these documents is for maternity services to provide care in a manner that is safe, more personalised, professional, family friendly, and centred on the woman's individual needs and circumstances, regardless of her risks. The best way to do this is through continuity of care. Women who are diagnosed with HIP require care from midwives and doctors but this does not exclude them from being cared for by a continuity team model. Continuity of care can be maintained through providing care in a collaborative fashion.

\section{Collaborative care}

Collaboration is an essential part of maternity care but especially for women with HIP as shown in my study. Women especially valued the collaborative 
approach and felt confident that they were safe after forming a relationship with the team, trusting them and viewing them as experts. In the mediating themes Feeling safe and trusting care providers, and Having continuity of care women commented on 'being in safe hands' with having experienced midwives and doctors looking after them.

Comprehensive reviews of Australian maternity services have confirmed that collaboration is an important factor in reaching positive outcomes aligned with women's needs, preferences and expectations (Australian Health Ministers Advisory Council 2008). A collaborative approach to care will maximise a woman's continuity of care experience throughout her pregnancy (National Health and Medical Research Council 2010), especially when there is a medical complication in the pregnancy.

Collaboration is necessary for giving care that is beyond the abilities of an individual profession (Heatley \& Kruske 2011). It is a process of facilitating communication, trust and pathways that enable midwives and medical staff to provide woman centred care with the woman being an active participant in her care (National Health and Medical Research Council 2010). Effective multidisciplinary collaboration relies on having clearly defined roles for those involved in care (National Health and Medical Research Council 2010), an understanding of each profession's scope of practice, and is based on the fundamentals of mutual trust and respect for each profession's perspective (The Royal Australian and New Zealand College of Obstetricians and Gynaecologists 2017). Collaboration should be structured to develop interprofessional accord rather than practising in isolated professional groups (The Royal Australian and New Zealand College of Obstetricians and Gynaecologists 2017). Thus, collaboration means that midwives and medical staff work together collectively in order to care for the woman and her baby. This approach is viewed as the key to optimising outcomes for women and their babies (National Health and Medical Research Council 2010). 
Women who experience HIP require collaborative care from midwifery, obstetric, medical and, potentially, mental health teams to ensure that their physical, social and emotional and mental health needs are addressed. This multidisciplinary collaborative team approach is based on mutual respect, with all professions striving to help the women through her complicated pregnancy (Berg 2005). This model ensures that comprehensive care, using the specialised skills from each discipline, is provided to the women (Benagiano \& Brosens 2014) and reduces communication breakdowns between the medical staff, midwives and the women (Gonzalez \& Yukihiro 2013). Continuity of care from such a collaborative team is important and beneficial for women with a high risk pregnancy (Berg 2005; Biro et al. 2003; Bode \& Lynch 2018; Homer et al. 2002) and is realistically achievable in different centres including tertiary obstetric referral services (Biro et al. 2003; Tracy et al. 2013).

Although Government policy and researchers recommend collaborative care, there are few facilities where multidisciplinary collaboration is practised or successful. There are challenges to setting up collaborative models as they need to be able to exist within the established system (Australian Health Ministers Advisory Council 2008) and may be too prescriptive to suit the unique needs of different women (Way, Jones \& Busing 2000). Traditional hierarchical relationships between midwives and doctors can make trust and communication difficult (NHMRC 2010) affecting the functioning of the team. A further challenge to providing this service is that it requires flexibility, persistence (Maternity Care Enhancement Project 2004) and visionary leadership. Furthermore, maternity care providers may require training and experience in working in a collaborative model (Maternity Care Enhancement Project 2004) which is sometimes difficult to achieve due to staff shortages. Different degrees of understanding and commitment from different team members will hinder the functioning of the team and the care provided (National Health and Medical Research Council 2010).

Increased satisfaction with the birth experience has been reported by women with a complicated pregnancy who have been cared for by a multidisciplinary team (Berg 2005; Biro et al. 2003; Bode \& Lynch 2018). This is confirmed in this 
current study where women who experienced HIP described continuity of care from midwifery and medical staff as being helpful in improving their birth experience.

\section{Facilitating social support}

My study showed that having support from the partner, family, friends and care providers was valued by all the women. This was especially clear from the HT women who were interviewed, particularly for the women who gave birth preterm. These women spoke of needing support throughout the birth experience and for many months after as they processed what had happened. Having social support was a contributing factor to a better birth experience.

Therefore, the second essential element in caring for women diagnosed with HIP is facilitating social support. This is an important aspect of care as a lack of social support has been associated with an increased risk of antenatal and postnatal depression and anxiety (Biaggi et al. 2016). Maintaining good mental health during pregnancy and in the postpartum period is crucial for the woman, but also has important health implications for her baby (Elsenbruch et al. 2007; O'Hara \& McCabe 2013). Untreated postpartum depression and anxiety can have adverse long term effects for the woman as they can lead into chronic mental health disorder (Austin, Priest \& Sullivan 2008). In addition to this, a woman's ongoing depression can contribute to emotional, behavioural, cognitive and interpersonal problems in her child later in life (Austin, Priest \& Sullivan 2008; O'Hara \& McCabe 2013).

Social support is a multidimensional concept (Biaggi et al. 2016) that has been extensively studied. In his sentinel work, (House 1981) organised social support into four broad categories of supportive behaviours or acts. These categories remain contemporary and are summarised in the box below. 


\section{Figure 6.2 Categories of social support}

Emotional support involves the provision of empathy, love, trust, and caring. Instrumental support involves the provision of tangible aid and services that directly assist a person in need.

Informational support is the provision of advice, suggestions, and information that a person can use to address problems.

Appraisal support involves the provision of information that is useful for selfevaluation purposes (constructive feedback and affirmation).

Support has been shown to be of value and benefit for women during pregnancy and labour (Bohren et al. 2017), particularly emotional and informational support. For women who have a complicated pregnancy and/or labour, this supportive care may enhance the physiological labour processes, in addition to improving the women's feelings of control and confidence in their ability to give birth (Bohren et al. 2017) which can be impaired due to the complication. Overall, this support will contribute to an improved birth experience for the woman.

Pregnancy and the transition to parenthood are significant life events requiring adjustments (McKenzie \& Carter 2013). A lack of psychological and emotional adjustment during pregnancy is a risk factor for poor postpartum mental health (Elsenbruch et al. 2007; Orr 2004). Having social support during this time of adjustment, commonly provided by the partner, family and friends, is an important component for the woman's physical and emotional wellbeing (Negron et al. 2013) and has been shown to buffer the difficulties of the transition to parenthood and be protective against mental health disorders (Bilszta et al. 2008).

More than a decade ago, Glazier et al. (2004) suggested that social stability and participation provide emotional and instrumental support, safeguarding the impact of stress on women's emotional wellbeing. This is still valid today as 
more recent evidence has shown that social relationships provide women with a sense of self-worth and psychological wellbeing, in addition to giving them access to support during times of increased stress or adjustment (Tani \& Castagna 2016), such as during pregnancy and early parenthood. Elsenbruch et al. (2007) state that a lack of social support is a significant risk factor during pregnancy and the consequences may be intensified by additional risks or stress. None of the women who participated in my study reported a lack of social support, however women often commented on how beneficial support was to them. Having social support may have contributed to their good mental health.

Denis, Michaux and Callahan (2012) investigated depression and anxiety in women with a high risk pregnancy and found that these women placed great importance on having both emotional and informational support. The findings of my study are similar, as women spoke of emotional and informational support being mediating factors that gave them a better birth experience. Emotional support was most commonly provided by the partner, family and friends, while the informational support was largely conveyed by the woman's midwives and doctors, although some women did report using on-line platforms or forums for information.

To reduce the risk of mental health disorders in women diagnosed with HIP, it is important to facilitate their emotional support. The need for support was highlighted in my study as the women stressed the importance of having emotional support and felt that the restrictive hospital visiting hours interfered with this support from their partner, family and friends. Women criticised the hospital rules, saying that it was stressful to stay alone in the hospital after being informed that they had PE, especially during the night. At St George Hospital Maternity Unit the visiting hours during the time of this study were restricted to 12 hours for the partner (0900hrs-2100hrs) and from 1500hrs$2000 \mathrm{hrs}$ for other visitors. If visiting hours could be modified to be more lenient, this would provide maximum opportunity for the woman to receive emotional support from her partner, family and friends. Often the limiting factor is 
architectural and maternity units need to be better designed to include rooms that can accommodate the woman and her partner in privacy, to provide the emotional support. This concept was suggested back in 1978 after Scaer and Kortz (1978) surveyed over 600 women who had given birth in the previous 12 months. Women who completed this survey stated they wanted private postpartum rooms to allow unrestricted visiting of the partner and siblings. Currently at St George Hospital Maternity Unit visiting hours are unchanged, although there is some leniency for partners to stay with the woman in some circumstances such as following a poor outcome or complications. There remain, however, a limited number of private rooms for this to occur.

Informational support is also important, especially for women who have a complex pregnancy and postpartum recovery. Most of the women in my study wanted to know and understand what their diagnosis meant and the implications for themselves and their baby. They said that having a good understanding allowed them to accept the diagnosis and feel more involved in their care plan. There were a few women who talked about completely trusting their care providers and not wanting to know detailed information. All maternity care providers have the important role of communicating detailed information to the woman regarding her complication (Denis, Michaux \& Callahan 2012) and keeping her informed on her progress. In times of stress and worry, written information, in a simple format, containing evidence based information may be helpful for the woman and add to her understanding. In addition to being informed about the hypertensive complication, it is also important for women to be informed about mental health in the postpartum period. Orr (2004) states that when women are provided with information on postnatal depression, it acts as a protective factor.

Women also need to be informed of support services that are available to them outside of the hospital environment, such as the 'Ready To Cope' programme and the support group, Australian Action on PreEClampsia (AAPEC). 
'Ready to Cope' is a recent initiative from the Australian Centre of Perinatal Excellence (COPE) (Austin, Highet \& the Expert Advisory Committee 2017) and is dedicated to improving the emotional wellbeing of all parents before and during pregnancy, and for the year following the birth of the baby. COPE recognises the emotional realities and challenges of pregnancy and early parenthood and send regular emails to the woman that include supportive insights, strategies and advice about how she may be feeling. These emails are timed according to her gestation or date of baby's birth, providing her with relevant information and support. This information helps the women understand what is normal and when it is time to seek help.

To provide women with ongoing support following discharge, they should be informed of support groups such as AAPEC. AAPEC is a voluntary organisation established in Melbourne, Australia in 1993 to provide support and information to women who have experienced PE and their families (AAPEC 2018). AAPEC issues a regular newsletter and has resources available on line, which will assist with emotional and informational support, specifically for women who had their pregnancy complicated by PE. There are similar community support groups in other countries such as Action on Pre-Eclampsia (APEC) in the UK and the Preeclampsia Foundation in the US.

\section{Prevention and early identification of mental health disorders}

The next essential element of care for women who have experienced HIP is providing them with care that aims to prevent mental health disorder, being aware of who is at risk, identifying women who are showing signs of mental health disorder and referring the woman to mental health support services appropriately. There are barriers to screening and responding appropriately to women who are at increased risk of poor mental health such as staffing shortages, lack of knowledge and skills, fragmented care and the current focus on screening for depression and to a lesser extent, anxiety. These barriers are discussed further in the following section. 
The long-term consequences of postpartum mental health disorder and the fact that it affects about one in six women in the perinatal period, suggests that preventive approaches are warranted (Boorman et al. 2014; Dennis \& Dowswell 2013; National Health Service 2014; NSW Health 2008; World Health Organisation 2008). Prevention is a primary health care principle and concerns caring for people rather than simply treating specific conditions (World Health Organisation 2018) and is described by NSW Health (2008) as any intervention occurring before the onset of a disorder, to avoid the development of the disorder. The World Health Organisation (WHO) categorises health prevention into two sub categories; primary and secondary (World Health Organisation 2018). Primary prevention includes immunisations and lifestyle choices, and secondary prevention, which applies in this instance, regards early detection when this improves the chances for positive health outcomes. To improve women's postpartum mental health, measures that prevent and manage mental health disorders should be utilised during pregnancy and after the birth as this may offer the possibility of reducing these disorders and improving the health related quality of life for these women (Turkstra et al. 2015) .

My study identified a specific group of women at high risk of poor mental health in the postpartum period. These are the primiparous women, diagnosed with HIP, had a history of any previous mental health disorders, and, to a lesser extent, had a preterm baby. This group of women may benefit from a referral to social work or mental health services as part of their routine care in the early postpartum period. This proactive approach may help to prevent the symptoms of depression, anxiety and/or PTSD developing or reduce the severity and the impact they have on the woman's life (Austin, Fisher,. \& Reilly 2015).

The midwife has an important role and is well placed to identify women at risk and initiate prompt referral to appropriate services. Furthermore, maternity care providers should provide an opportunity for women to talk about and discuss their birth experience prior to being discharged from the service (World Health Organisation 2013). This discussion would form part of a mental health risk assessment and give the care provider the chance to identify a need for referral 
and link the woman with the appropriate services (Austin, Priest \& Sullivan 2008). The discussion could be considered a form of counselling and may require additional skills, which are achievable through training. A study undertaken at a tertiary referral hospital in Western Australia (Hauck et al. 2015) showed that midwives believe that it is their role to assess the mental health of women but many felt that they lacked the knowledge and skills to do this (Hauck et al. 2015). A study conducted in Queensland, Australia (Reed et al. 2014), trained midwives to conduct counselling sessions with women who reported a traumatic birth experience. Following this counselling training the midwives reported improved confidence when caring for women who experienced a traumatic birth, in addition to being able to better manage stressful situations that they faced in their everyday practice. A similar finding was reported by Fenwick et al. (2018) who investigated psychoeducational training for midwives with women who were fearful of childbirth. They demonstrated that the training improved the midwives' knowledge and confidence but was difficult to introduce into routine practice due to the fragmentation of care during pregnancy. However, the counselling was more easily instituted by midwives working in the continuity models of care. They suggested that for most women, counselling support should be offered soon after the birth and again at four to six weeks postpartum, although some women may require more support at closer intervals and/or referral to mental health services.

Not all women will have a negative emotional response to their perceived traumatic birth experience as demonstrated by the research undertaken by Boorman et al. (2014). In this study, about half the women did not show obvious signs of emotional response which emphasises the need for midwives to discuss the birth with every woman, and to be aware of those women at particular risk, to enable the provision of emotional care, reassurance (Boorman et al. 2014) and timely referral to support services. Postnatal care that is generally task orientated and hurried can be harmful to the woman's emotional wellbeing (Fenwick et al. 2010; Schmied et al. 2011) and needs to change to focus on better supporting women with specific physical, emotional and social needs (Fenwick et al. 2013). 
Early identification of postpartum women exhibiting signs and symptoms of poor mental health leads to a more timely and targeted referral to support services (Austin, Fisher, . \& Reilly 2015). Policies highlight the importance of implementing interventions targeting women displaying the early signs and symptoms of poor mental health (National Health Service 2014; NSW Health 2008; World Health Organisation 2008). The interventions should begin shortly after the need has been identified, and aim to reduce distress, shorten the episode of care required and minimise the level of intervention required (NSW Health 2008). Intervention is not only critical for preventing or reducing the progress of a mental health disorder, but for improving the woman's mental and physical health, and the health and development of her child (Beck \& Barnes 2006; Stein et al. 2014).

Currently, recommended mental health screening in NSW in the postnatal period, is mostly concerned with depression. It is recommended that all women complete the EPDS, looking for depressive symptoms and to a lesser degree, symptoms of anxiety, at six weeks postpartum (NSW Health 2009) This is usually undertaken at the Early Childhood Centre, GP or private obstetrician. In considering that PTSD is subjective, difficult to predict, and may have long term consequences, postpartum screening should also include PTSD screening. Following a positive screening, there should be referral pathways in place to ensure early intervention and treatment if required (Austin, Fisher,. \& Reilly 2015).

4. Keeping mother and baby connected

The challenge of being a mother following a pregnancy complicated with HT was a dominant theme in my study. These challenges were more evident with the women who gave birth preterm and/or were separated from their baby. Phase One of my study found women reported that they were unhappy about having a preterm baby, the baby needing admission to the SCN or NICU, not seeing their baby immediately and not being able to do skin to skin contact. Whereas meeting and cuddling their baby contributed to a better birth experience. The narrative from Phase Two of my study supports this and 
elaborates on the challenges. Those women who needed care in an acute care setting felt that they missed the birth or early parenting experience because of loss of recall and/or physical separation from the baby, which contributed to the disturbance of forming an early bond with their baby. On a positive note, women described how seeing, touching, holding and feeding their baby helped them cope with the separation and isolation, and be a mother. Perhaps the hardest challenge was for the women who were discharged from hospital but their baby remained in the nursery. These women disclosed sadness, emptiness and worry, particularly in regards to leaving their baby behind and struggling to connect with their baby. Therefore the final essential element of care that I propose is to keep the mother and baby connected in an effort to improve the early mother-infant bonding, the mother's overall birth experience and subsequent postpartum mental health.

Maternal bonding has been described by Figueiredo et al. (2009) as the mother's concerns and actions about the safety and wellbeing of her baby as well as the mother's affection for the infant and the place the infant holds in her world. It is structured as a dynamic emotional state that usually begins during pregnancy or immediately after the birth (Bicking Kinsey \& Hupcey 2013), and continues to develop progressively over the first few months of the infant's life (Muzik et al. 2013). Maternal bonding involves participation from both the mother and her baby (Johnson 2013) and infant behaviours, such as crying and facial expressions, enhance maternal attachment and encourage mutual emotional involvement (Figueiredo et al. 2009). Mother infant bonding is considered to be central to the wellbeing of the infant including their cognitive and emotional development (Cirulli, Berry \& Alleva 2003).

Bonding is influenced by physical contact between the mother and her baby and the quality of the bond can be altered by such factors as neonatal prematurity and maternal illness (Johnson 2013) necessitating the separation of the woman from her baby. In my study, the women reported the biggest challenge to being a mother was the separation from their baby. Keeping this in mind and the process and benefits of early maternal bonding, it is of utmost importance for 
midwives to strive to keep the mother and baby connected despite the difficult and challenging situations that may present. There are no acute care beds in the maternity unit at St George Hospital so if a woman requires extra care and monitoring due to a postpartum haemorrhage or magnesium sulphate infusion, she is transferred to the intensive care unit (ICU). This means that she is automatically separated from her baby as there are no facilities or staff to care for her baby in the ICU, and her baby is admitted to the special care nursery (SCN).

Being separated from your baby is an unfortunate situation, especially if the baby was born well, at or near term and the only reason the baby is admitted to the SCN is because the mother is in ICU. In this circumstance, it is important for the baby to visit and spend as much time with the mother as possible, a situation that was clearly evident in the Challenges of being a mother theme. This helps with the bond development and usually involves staff from the nursery accompanying the baby, which is not always feasible due to staffing levels. However, midwives and nursery staff must make an effort to facilitate this as being able to breastfeed their baby while in ICU was highly valued by the women in my study and it assisted in improving the overall birth experience.

Another effective solution would be for all maternity units to have the facilities to care for women who need increased care and monitoring, within the maternity unit. This would ensure midwifery care is provided and the well babies would not have to be separated from their mother. There are some barriers to this, particularly in relation to physical space, the need for monitoring equipment and the extra staff and training needed.

The situation is different for the woman who gives birth to a preterm baby who requires care in either a SCN or NICU for an extended period. These women begin their experience of parenthood in an unfamiliar and intimidating environment (Herman, Wilson \& Wilhelm 2005) and are vulnerable. They have most likely missed the opportunity to establish a relationship with their baby 
prior to the nursery admission and often struggle with their parenting role (Fenwick, Barclay \& Schmied 2001; Herman, Wilson \& Wilhelm 2005). Several researchers have explored the experience of mothers when their newborn baby requires admission to the NICU. Common themes arising include the importance of good communication between parents and health care providers and the power imbalance between mothers and care providers that inhibits the development of the maternal role (Bialoskurski, Cox \& Wiggins 2002; Bruns \& McCollum 2002; Fenwick, Barclay \& Schmied 2001; Jackson, Ternestedt \& Schollin 2003; Lupton \& Fenwick 2001). The issue of baby ownership has been highlighted previously (Lupton \& Fenwick 2001), describing the battle between nurses and women as to who is the expert carer. Fenwick, Barclay and Schmied (2001) report how mothers felt left out and unimportant due to the nursing interactions with their baby, Wigert, Berg and Hellstrom (2007) report that nursery staff dictated conditions for parental participation in baby care, and Hurst (2001) found that when mothers tried to negotiate a partnership with nursery staff, their actions were often misunderstood. This research was undertaken more than a decade ago and little has changed over time. In 2002, my first publication was based on my personal experience of struggling to mother my preterm baby in the NICU and SCN (Roberts 2002). The challenges have not changed as demonstrated by what the women participating in this study said in regards to the difficulties of being a mother. Issues around baby ownership, difficulties with caring for their baby and developing a relationship with their baby while in the nursery remain current problems.

Nursery staff has a unique opportunity to assist women through the experience of having a baby in the nursery. But they must understand the needs of the mother (Cleveland 2008), firstly by initiating communication with her (Corlett \& Twycross 2006; Ygge 2007). Creating a supportive nursery environment with a trusting bond between the nurse and parents may help to decrease parents' worry and facilitate the attachment process (Cleveland 2008). The formation of this nurse-parent relationship is essential and relies partly on the nurse's ability 
to engage with the parents through 'chatting' about matters outside of the nursery as well as the baby (Fenwick, Barclay \& Schmied 2001).

Parents need and want to be given opportunities in which they can act as normal parents, experiencing a sense of ownership and control, in the nursery (Bass 1991; Griffith 1990). To achieve this, care should be based on familycentred principles where the parents are acknowledged and viewed as the best carers for their baby (Fenwick, Barclay \& Schmied 2001). Parents should be involved in decision-making, doctors' rounds and caring for their baby whenever possible (Cleveland 2008). If this could be successfully implemented in NICUs and SCNs, it would provide an environment for the mother-infant bond to develop which would lead to an improved birth experience and better long term health of both the mother and her baby.

\section{Strengths and limitations}

The results of this study describe the mental health and birth experience of women who experienced either GH or PE, or had normal blood pressure in their pregnancy. There are several strengths and limitations to the study to acknowledge and consider.

\section{Strengths}

This study draws from both quantitative and qualitative approaches which can generate deep insights into a situation and result in a greater understanding of a complex health problem (Tariq \& Woodma 2013). The advantages of collecting both closed-ended quantitative data and open-ended qualitative data prove valuable to best understand a research problem (Creswell 2013), particularly when the research question is broad and complex (Tariq \& Woodma 2013). In my study quantitative methods were used to investigate depression, anxiety and PTSD in postpartum women and the qualitative exploration of the women's experience enhanced the findings by understanding the meaning of their experience from their view. Qualitative research methods are suitable for this 
approach because of their emphasis on women's lived experience (Al-Busaidi 2008) and in understanding the meanings that women place on events and their perceptions, presuppositions and assumptions (Al-Busaidi 2008). I have analysed the quantitative and qualitative data separately using the appropriate statistical, content and thematic analyses, and integrated the results to give a better understanding. This approach maintains data integrity and maximises the enhanced understanding of the problem (Tariq \& Woodma 2013).

The study was embedded in a larger study and undertaken at one hospital in one city in the most populated state in Australia, New South Wales. Each woman who attends this hospital for maternity care is cared for by midwives and doctors using current evidence-based policy and practice. This means that all women in this study received the same standard of care, even though the models of care and care providers may have differed. This minimises the diversity of practice between care providers and ensures that standardised care is provided to the women using a shared clinical decision-making framework (Sackett et al. 1996). This was especially important for the women who were diagnosed with HIP, where they were cared for according to National and International guidelines (Brown et al. 2018; Lowe et al. 2015; Tranquilli et al. 2014).

The process of data collection of the labour, birth and hypertension details was robust. The medical record for each woman was sourced from the Clinical Information Department at the hospital and details were recorded directly from the records and collected by myself. This process ensured consistency and accuracy of data collection and also avoided relying on the woman's recall for the details. Recall bias is a systematic error that can occur when study participants do not remember previous events or details potentially affecting the accuracy of data collected (Spencer, Brassey \& Mahtani 2017). The method used in this Study eliminated the risk of recall bias.

Having a system for correct diagnosis of the hypertensive disorder, and subsequent placement into the hypertensive group or exclusion from the study, was also important. The diagnosis was made using strict diagnostic criteria 
which is universally applied at this hospital, and based on both international and Australian and New Zealand guidelines (Brown et al. 2018; Lowe et al. 2015; Tranquilli et al. 2014). The integrity of data collected for a research project is pivotal to the validity of inferences drawn (Pan et al. 2005) and relies on accurate identification and screening of the participants. Any inaccuracies in participant group allocation and data collection could lead to invalid results (Pan et al. 2005). If the women's diagnosis was in doubt after reviewing her record, the details of her pregnancy were discussed with one of the research team doctors and a diagnosis of HIP was either confirmed or dismissed. This strategy ensured that the correct diagnosis was recorded which led to the woman being placed into the appropriate study group.

Each of the instruments used in this study had previously been validated for accuracy, reliability, and for use in the research setting (Cox et al. 1996; Foa et al. 1997; Spitzer et al. 2006). Using self-reported instruments to assess symptoms of depression, anxiety and PTSD is not as reliable as the gold standard clinical interview or assessment (Foa et al. 2016), however, in this research settling, such methods of assessment were not feasible. Using validated self-report questionnaires enabled the collection of quantitative data in a quick and easy manner, allowing a generalisation of the findings (Demetriou, Uzun Ozer \& Essau 2015). This ensured appropriate, reliable and meaningful data collection.

On completion of the data analysis it was evident that the two groups of women were very similar in general demographic characteristics. This included their age, ethnicity, education level, relationship status and early-pregnancy or previous mental health state. This meant that there was minimal effect of confounding variables with the main difference between the two groups being a history of HIP, or not, making the findings in terms of mental health, clearer to interpret in relation to the association with hypertension. 


\section{Limitations}

The findings in this study need to be considered in light of limitations. These are discussed in the following section.

Qualitative research produces large amounts of transcribed data that can be complex and difficult to manage (Pope, Ziebland \& Mays 2000). To help manage the data from my interview transcripts I used the Nvivo software. Although several programs exist to manage textual data, these programs support the sorting and organising of data, and are not able to conceptualise the data to extract meaningful themes and findings (Thorne 2000). Furthermore, this extraction of meaning is open to interpretation by the researcher (Thorne 2000). It has been suggested that multiple coding, or having several independent researchers code the same data, can lead to agreement of extracted themes (Barbour 2001), however this cross checking strategy was impractical for my project. In an effort to reach a degree of concordance, my supervisor and I worked together on the final stage on the analysis of the qualitative data, discussing our interpretations and agreeing on the themes.

The mixed methods approach presented further challenges. Combining the two methods was time consuming due to the collection and analysis of the different data types. Some researchers (Creswell 2013; Tariq \& Woodma 2013) have suggested that mixed method research is best suited to a team who can work well together to conduct such a study. Tariq and Woodma (2013) believe that having a team leader who is experienced in both quantitative and qualitative methods can be useful. I conducted this PhD project on my own but worked with another experienced qualitative researcher in the final analysis of the qualitative data to ensure accuracy.

The characteristics of the cohort were potentially affected by the overall P4 Study eligibility criteria. Exclusions such as existing maternal health conditions and having a stillbirth or neonatal death meant that not all women were invited to participate. Excluding these women was a necessary part of the P4 Study protocol, therefore unavoidable. These exclusions ensured that there were no 
confounding health issues present while investigating maternal cardiovascular health following a pregnancy complicated by hypertension. Current evidence on chronic health problems suggests an association with depression, with almost one in four adults with Type 2 diabetes experiencing depression (Ali et al. 2006) and an increased prevalence of depression in adults with hypertension, reported at $21.3 \%$ following clinical interview ( $\mathrm{Li}$ et al. 2015). The postpartum mental health of these women may have been a result of their other health problems, rather than the HIP. The P4 Study also followed the health and development of the infant which explains why women who had a stillbirth or neonatal death were excluded. Women who experienced the loss of their baby may have described their birth experience differently and reported their postpartum mental health differently. A systematic review on psychological health following stillbirth (Campbell-Jackson \& Horse 2014) concluded that, understandably, stillbirth can result in high levels of depression, anxiety and distress. These symptoms are greatest in the first few months postpartum but may persist for up to three years for some women (Campbell-Jackson \& Horse 2014). Furthermore, a study that investigated the mental health of women following either a stillbirth or neonatal death demonstrated that these women were almost four times more likely to screen positive for depression and seven times more likely to screen positive for PTSD (Gold et al. 2015).

Excluding women who could not read and speak English was another limitation of the study. There was no funding available for interpreters and translation of instruments so women from a non-English speaking background could not participate. St George Hospital provides care to women from a diverse range of ethnic backgrounds so limiting the study cohort to English speaking women meant that the results may not truly reflect the real postpartum population who give birth at St George Hospital. Furthermore, differences in culture, beliefs and experiences of coming to Australia, for example, may have significantly influenced their birth experience and mental health. However, this led to a reduction in the potential heterogeneity of the study population. The Australian Institute of Health and Welfare (2018) report that immigrants and refugees are often exposed to trauma, and refugees have been found to have high rates of 
poor mental health particularly depression, anxiety and PTSD (Shawyer et al. 2017).

The recruitment of volunteers to this study was a potential source of selection or volunteer bias. Selection or volunteer bias is a systematic error due to differences between those people who choose to participate in research studies and those who do not (Jordan et al. 2013). The women, who participated in my study, and those who chose not to, may have been different in important aspects such as their mental health state and social situation. For example, women who were not feeling mentally strong enough to attend the study appointments would most likely opt not to participate, making this group underrepresented. Furthermore, those women who had a bad experience during their pregnancy and birth may not have wished to return to the hospital environment for the study appointments. This self-elimination has the potential for the study cohort to be under representative of the population as a whole (Bartlett et al. 2005), making it difficult to generalise the results. Bias reduction is an important aspect of any study, but challenging to do in a prospective cohort observational study (Keeble et al. 2015). Some methods to reduce bias in a cohort observational study have been suggested by (Keeble et al. 2015). These are to recruit large numbers to the study, include the variables that may be foreseen to be an issue in the data collection, and collect data from nonparticipants and report those data as a comparison. In my study, the sample size was small due to time constraints, data such as sociodemographic data and early pregnancy EPDS scores were collected and reported, and there was no ethical approval given for data collection from non-participants, so this was not undertaken.

Conducting this study at one site was a strength but also a limitation. St George Hospital is a metropolitan teaching hospital that is classified to provide care for women who are expected to give birth at greater than 32 weeks gestation. In utero transfers are made to a higher level hospital when it becomes apparent that the woman may need to give birth prior to 32 weeks gestation and it is safe to transfer her. Neonatal transfers occur when the baby requires care in a 
Neonatal Intensive Care Unit (NICU) when an inutero transfer is not possible or not necessary earlier. The women participating in this study gave birth from 30 weeks gestation onwards. It was therefore not possible to investigate the mental health and birth experience of women who had a very preterm birth so external validity cannot be confirmed. Women who have a very preterm birth may report a different birth experience.

Another problem of a single site trial is the small size of the participating cohort. This was particularly evident when analysing and interpreting the mental health data. In this study, the proportion of women who met the threshold score for possible depression and/or PTSD was low and significantly less than what is reported nationally. This made the analysis, particularly the regression analysis, difficult to interpret. The small sample size meant that the study had insufficient power. Power is a measure of the likelihood of finding statistical significance in a sample, if the effect exists in the full population (Jones, Carley \& Harrison 2004). Sample size is a primary factor to ensure sufficient power and a small sample size may explain the results in this study. A Type 1 error may have occurred, where a supposed difference or relationship was seen but one does not really exist (false positive) (Argyrous 2005). These factors highlight the need for further data collection and larger studies to determine what women's mental health is like following a pregnancy complicated with hypertension.

A further limitation is the imbalance in the number of women in each group (237 in the NT group versus 84 in the HT group). The reason for this imbalance could be partly explained by $\mathrm{GH}$ and $\mathrm{PE}$ affecting about $8 \%$ of pregnancies, resulting in fewer women with hypertension being eligible for participation in the study leading to less enrolment. Another contributing factor could be volunteer bias where women with a health concern are more motivated to consent to a research project than women who are healthy (Jordan et al. 2013). The sample size calculation for the larger P4 Study had a planned imbalance of about three times the number of women in the NT group compared to the HT group. The reasoning behind this was that the greater number in the NT group were needed to establish normal ranges for postpartum blood pressure, which had 
not been done before. Equal-sized groups are not necessary to calculate accurate statistics and unequal sample sizes may be due to sound reasoning and practicality, as in this case (Vanhove, 2015). However, unequal sample sizes can lead to a loss of statistical power, an increase in Type 1 error and issues with confounding variables (Rusticus \& Lovato 2014).

The mental health instruments were completed by the women at six months postpartum. There was no reporting of significant life events during this postpartum period that could have contributed to mental health conditions. There was an opportunity for women to list a significant event in the PTSD screening instrument, but this was not limited to the six month time frame. This limitation means that it can't be certain that the mental health conditions that were reported were completely attributed to the pregnancy and birth experience.

Resilience, or the capacity to cope with and recover from difficult experiences, was not measured. Resilience could be the key to explaining endurance to risk and how women 'bounce back' and deal with various challenges presented (Windle, Bennett \& Noyes 2011), such as a complicated pregnancy and/or birth. Different degrees of resilience in the participating women may have influenced how they responded to the mental health instruments and reported their birth experience. A study by Mautner et al. (2013) examined resilience and mental health (depression and PTSD) in 67 women who had experienced PE, using validated instruments. The authors report that women with high resilience showed less depression compared to women with low resilience $(p=0.001)$. They conclude that having resilience has an important impact on women's mental health and may be protective and shield against mental health distress. Similarly, a study undertaken in China with women admitted to hospital with threatened preterm labour (Nie et al. 2017), found that women with low resilience reported more depressive symptoms and less coping mechanisms than women who scored high on the resilience instrument. 
There are validated instruments available that examine and measure resilience which may have provided unique and important information about the women coping with a complicated pregnancy. A review of resilience measures (Windle, Bennett \& Noyes 2011) reported five instruments that demonstrated reliability in testing resilience in adults, although not specific to the postpartum population.

The questions and Likert Scale used for the quantitative phase on birth experience were adapted from instruments used in previous studies which may not have been ideal for this study. This was a simple means of determining women's experience and could not go into depth given the context and the method.

Lastly, my professional and personal experience with preeclampsia could be considered a limitation of the study as my knowledge and experience cannot be eliminated from the interpretation of the qualitative data. However, this knowledge and experience meant I had a good understanding of the stories women shared during the interviews which contributed to a thorough and sensitive analysis. My experience and the concept of reflexivity were addressed in Chapter Three of this thesis.

\section{Conclusion}

This final chapter of the thesis has discussed the findings of my research in light of the current evidence and research available. Quantitative methods were used in this project to investigate women's mental health and birth experience with results compared between women who had hypertension in their pregnancy and those who were normotensive. The qualitative component of the research provided rich insight into the birth experience of the women who experienced a pregnancy complicated by hypertension and what helped them through the experience. The findings from both methods of data collection were triangulated to support the suggestion of four essential elements of care that could potentially be introduced into clinical practice to help improve women's birth experience. These elements of care were providing continuity of care with 
multidisciplinary collaboration, facilitating social support, prevention strategies, early detection and referral pathways to improve women's mental health, and overcoming the challenges of early maternal bonding with the baby.

The results of this research can add to the body of knowledge of mental health following HIP. A group of women at high risk of poor mental health has been identified: primiparous women following HIP with a history of previous or current mental health condition. It is uncertain whether having a preterm baby contributes to poor mental health, particularly PTSD. Aspects of the birth experience that may affect postpartum mental health were highlighted.

It is clear from this research that women who experience a pregnancy complicated by hypertension have profound experiences and face challenges for many months following the birth. It is hoped that if the suggested elements of care can be introduced to maternity services, the birth experience for these women will improve and an ensuing improvement of mental health observed. Further research is required into this field particularly in respects to women developing HIP in the earlier gestations. 


\section{APPENDICES}

\section{Appendix 1. P4 Study HREC approval letter}

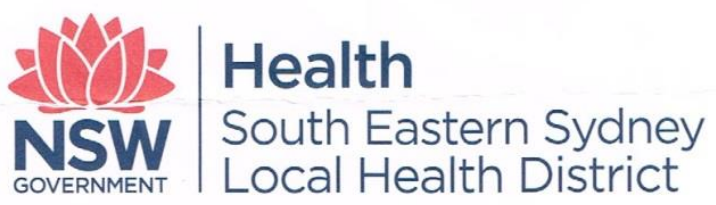

HUMAN RESEARCH ETHICS COMMITTEE

Room G71 East Wing Edmund Blacket Building

Prince of Wales Hospital

RANDWICK NSW 2031

Tel: 0293823587 Fax: 0293822813

8 March 2013

http://www.ses/hd.health.nsw.gov.au/POWH/researchsupport/default.asp

Dr Gregory Davis

Women's Health

Level 2, Prichard Wing

St George Hospital

KOGARAH NSW 2217

Attention: Lynne Roberts

RE: HREC ref no: 12/195 (HREC/12/POWH/395)

Project Title: Post partum Physiology, Psychology and Paediatric follow up Study (P4 Study)

Dear Dr Davis

Thank you for your letter dated 22 February 2013 to the Human Research Ethics Committee (HREC) addressing questions raised by the Committee. The application was first considered by the HREC on 30 October 2013

I am pleased to advise that the Executive Committee on 5 March 2013 agreed that satisfactory responses had been provided. The Committee granted ethical approval for the project to be conducted at St George Hospital.

The following documentation has been approved:

- NEAF submission code AU/1/E55F013

- Response Letter, dated 22 February 2013

- Protocol, version 3, dated February 2013

- Participant Information Sheet and Consent Form, version 3, dated February 2013

- Invitation Letter, version 3, dated February 2013

- Three Day Food Diary, version 1, dated 30 September 2012

\section{Conditions of approval}

1. This approval is valid for 5 years from the date of this letter

2. Annual reports must be provided on the anniversary of approval.

3. A final report must be provided at the completion of the project.

4. Proposed changes to the research protocol, conduct of the research, or length of approval will be provided to the Committee. 
5. The Principal Investigator will immediately report matters which might warrant review of ethical approval, including unforeseen events which might affect the ethical acceptability of the project and any complaints made by study participants.

Optional It is the responsibility of the sponsor or the principal (or co-ordinating) investigator of the project to register this study on a publicly available online registry (eg Australian New Zealand Clinical Trials Registry www.anzctr.org.au).

For NSW Public Health sites only: You are reminded that this letter constitutes ethical approval only. You must not commence this research project until you have submitted your Site Specific Assessment to the Research Governance Officer of the appropriate institution and have received a letter of authorisation from the General Manager or Chief Executive of that institution.

Should you have any queries, please contact the Research Support Office on (02) 9382 3587. The HREC Terms of Reference, Standard Operating Procedures, membership and standard forms are available from the Research Support Office website: http://www.ses/hd.health.nsw.gov.au/POWH/researchsupport/default.asp.

Please quote HREC ref no 12/195 in all correspondence.

We wish you every success in your research.

Yours sincerely

Production Note:

Signature removed prior to publication.

Deborah Adrian

Executive Officer, Human Research Ethics Committee

This HREC is constituted and operates in accordance with the National Health and Medical Research Council's (NHMRC) National Statement on Ethical Conduct in Human Research (2007), NHMRC and Universities Australia Australian Code for the Responsible Conduct of Research (2007) and the CPMP/CH Note for Guidance on Good Clinical Practice. 


\section{Appendix 2. UTS Ethic Ratification}

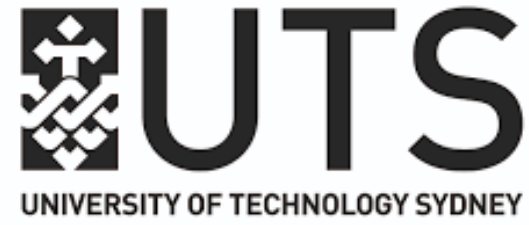

Human Research Ethics Committee Ethics Secretariat C/O Research and Innovation Office 15 Broadway, Ultimo NSW 2007 T: +61 295149681 Research.Ethics@uts.edu.au PO Box 123 Broadway NSW 2007 Australia www.uts.edu.au UTS CRICOS PROVIDER CODE 00099F 8

Distinguished Professor Caroline Homer

Faculty of Health UNIVERSITY OF TECHNOLOGY, SYDNEY

Dear Caroline,

UTS HREC 2013000234 - D/Prof Caroline HOMER, A/Prof Gregory DAVIS, Prof Mark BROWN, A/Prof George MANGOS, Dr Amanda HENRY, A/Prof Anthony O’Sullivan (for Ms Lynne ROBERTS, PhD student) - "Postpartum Physiology, Psychology and Paediatric Follow Up Study (P4 Study)" [External Ratification: South Eastern Sydney Local Health District Human Research Ethics Committee HREC approval - 12/195 HREC/12/POWH/365 - 08/03/2013 to 08/03/2018]

The UTS Human Research Ethics Expedited Review Committee reviewed your application and agreed that the application meets the requirements of the NHMRC National Statement on Ethical Conduct in Human Research (2007). I am pleased to inform you that your external ethics approval has been ratified.

Your UTS approval number is UTS HREC REF NO. 2013000234 Approval will be for the period specified above and subject to the provision of annual reports and evidence of continued support from the above-named Committee.

Please note that the ethical conduct of research is an on-going process. The National Statement on Ethical Conduct in Research Involving Humans requires us to obtain a 
report about the progress of the research, and in particular about any changes to the research which may have ethical implications. This report form must be completed at least annually, and at the end of the project (if it takes more than a year). The Ethics Secretariat will contact you when it is time to complete your first report. You must also provide evidence of continued approval from the Human Research Ethics Committee you originally received approval from.

I also refer you to the AVCC guidelines relating to the storage of data, which require that data be kept for a minimum of 5 years after publication of research. However, in NSW, longer retention requirements are required for research on human subjects with potential long-term effects, research with long-term environmental effects, or research considered of national or international significance, importance, or controversy. If the data from this research project falls into one of these categories, contact University Records for advice on long-term retention.

If you have any queries about your ethics approval, or require any amendments to your research in the future, please do not hesitate to contact the Ethics Secretariat at the Research and Innovation Office, on 0295149772.

Yours sincerely,

Professor Marion Haas

Chairperson

UTS Human Research Ethics Committee 


\section{Appendix 3. P4 Study Participant Information and Consent Form (V4)}

This version has been updated several times, however this is the version that the majority of women signed when consenting to this $\mathrm{PhD}$ study.
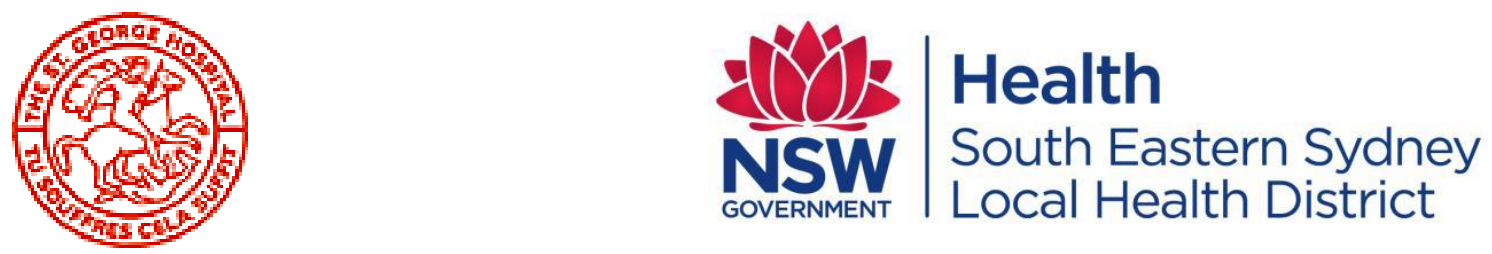

ST GEORGE HOSPITAL

PARTICIPANT INFORMATION SHEET AND CONSENT FORM CLINICAL TRIAL

Postpartum Physiology, Psychology and Paediatric follow-up Study

\section{Invitation}

You are invited to participate in a research study which aims to look at your physical and emotional health and the physical health and development of your baby between five and nine months after birth and two years after birth.

The study is being conducted by:

Associate Professor Gregory Davis, Obstetrician, Department of Women's Health Professor Mark Brown, Renal and Obstetric Physician, Departments of Renal Medicine and Women's Health

Associate Professor George Mangos, Renal and Obstetric Physician, Departments of Renal Medicine and Women's Health

Dr Amanda Henry, Obstetrician, Department of Women's Health

Associate Professor Anthony O'Sullivan, Endocrinologist, Department of Endocrinology

Professor Caroline Homer, Professor of Midwifery, University of Technology Sydney

Ms Lynne Roberts, Research Midwife, Department of Women's Health

Dr Joseph Khouri, Paediatrician, Department of Children's Health

Ms Clare Rowe, Educational and Developmental Psychologist, Sydney South Child Psychology

Before you decide whether or not you wish to participate in this study, it is important for you to understand why the study is being done and what it will involve. Please take the time to read the following information carefully and discuss it with others if you wish. 


\section{1. 'What is the purpose of this study?'}

The purpose of this study is to investigate whether women who have had high blood pressure in pregnancy and their babies have any persistent health problems 5-9 months and two years after birth. To do this we will also need to study women who did not have high blood pressure in pregnancy to provide a normal group for comparison.

\section{2. 'Why have I been invited to participate in this study?'}

You are eligible to participate in this study because you gave birth 5-9 months ago.

\section{3. 'What if I don't want to take part in this study or if I want to withdraw later?'}

Participation in this study is voluntary. It is completely up to you whether or not you participate. If you decide not to participate, it will not affect the treatment you receive now or in the future. Whatever your decision, it will not affect your relationship with the staff caring for you.

If you wish to withdraw from the study once it has started, you can do so at any time without having to give a reason.

\section{4. 'What does this study involve?'}

- If you agree to participate in this study, you will be asked to sign the Participant Consent Form. Some information about your recent pregnancy, labour, birth, and baby will be collected from your medical records. The pregnancy information that will be collected is whether you had high blood pressure, when the high blood pressure started, and details of any blood pressure medications taken. The labour and birth details being collected are the gestation at birth, whether labour started naturally or was induced, whether you had a vaginal birth or caesarean section, and if you had any complications. The baby's birth weight, length and Apgar scores will be collected as well as whether the baby needed to stay in the Special Care Nursery.

- You will be asked about your medical history and your family medical history. We will ask about any heart or kidney problems, diabetes, and any mental health problems.

- You will be required to attend the hospital for one assessment visit. This visit will take about 90 minutesand will take place at around 6 months after giving birth to your baby. You will be required to briefly visit the hospital within a few days after the assessment visit, to return the blood pressure monitor and armband. 
- You will be asked to take your child to see a paediatrician at 5-9 months of age and again at around two years of age. Additionally, you will be asked to take your child to a child developmental psychologist at two years of age.

- It is not necessary to bring your child to your assessment visit but you may do so if you have no other alternative. Please be mindful that there is no childcare available while your measurements are being recorded.

- At the assessment visit the following will be done:

- Your height, weight, abdominal circumference and blood pressure will be measured.

○ We will measure the stiffness of your blood vessels. This test is simple and painless, taking only a few minutes to perform. While you are seated in a comfortable position, a pencil-like sensor will be placed gently against the inside of your wrist to record the blood vessel stiffness.

- We will also measure your body composition. This is done by a simple procedure called bio-impedance analysis (BIA) where an electrode is attached to your right wrist and right ankle and a very small current is passed through your body. The current is so small you will not be able to detect it and the procedure takes only a few minutes. BIA enables us to measure the different aspects of your body composition, such as total fat, muscle and body water.

- You will be asked to give a blood sample from a vein. These blood tests are looking at your blood count, kidney and liver function, cholesterol, blood sugar and vitamin D. The amount of blood that will be taken will be about $40 \mathrm{mls}$ (two tablespoons). These blood tests will be used to determine your current state of health. You will be asked to provide a urine sample. The urine sample will be tested for protein, albumin and creatinine. This test will be used to help determine your current kidney function.

- You will be fitted with a blood pressure monitor for a day. A blood pressure cuff will be placed around your upper arm and remain in place for the next 24 hours, including overnight. This cuff is connected to a small recording device by a tube. The device will inflate the cuff and record your blood pressure every 30minutes for the next 24 hours.

- You will also be asked to wear an energy expenditure arm band for 24 hours, which measures how much energy you use in your day-to-day 
activity. It has a sensor, which detects skin temperature and can identify when you are sedentary, exercising and asleep.

- You will be asked to complete a food diary by recording all the food and drink you eat and drink over three consecutive days.

- There are four short questionnaires to complete about your emotional health since having your baby. The questionnaires will take about 15-20 minutes in total to complete.

- There will be one questionnaire for you to complete regarding your baby. The questionnaire will ask about your child's developmental milestones through a series of questions about your child's activities. You may need to try some of the activities before answering the questions. This questionnaire will be posted to you prior to each assessment visit and will take about 30-45 minutes to complete. You will need to bring the completed questionnaire with you to your assessment day.

- An appointment will be made for you to take your child to a Specialist Paediatrician for a general health check-up. This check-up will include measuring your child's weight, height and head circumference, as well as looking at physical development, any problems with hearing or sight, any illnesses or admissions to hospital. This visit will take about 30 minutes and will be carried out by a paediatrician located in Kogarah.

- About nine months after giving birth to your baby, you may be asked to take part in an interview with the research midwife. In this interview you be asked about your childbirth experience and any stress that you have had or currently have. The purpose of this interview is to better understand your emotional health. It is expected that the interview will take about 30-60 minutes.

- When your child is about two years of age four questionnaires, regarding your emotional health, will be posted to you for completion as well as one questionnaire about your child's developmental milestones. These five questionnaires will need to be returned in the provided stamped envelope. Also at this time two appointments will be made for you to take your child to

1. Paediatrician for a general health check-up. This appointment will take about 30 minutes and will be carried out by the Paediatrician in Kogarah.

2. Paediatric Developmental Psychologist for a developmental assessment. . In this assessment the psychologist will use toys, 
puzzles and games to look at your child's language and communication, cognitive development, as well as fine and gross motor skills. This assessment will take about 90 minutes and will be done at a centre located in Ramsgate.

\section{5. 'How is this study being paid for?'}

There is no external funding for this study. It is being conducted by staff already working within the Department of Women's Health, Medicine, Obstetric Medicine, Endocrinology and UTS as part of their usual duties.

\section{6. 'Are there risks to me in taking part in this study?'}

All medical procedures involve some risk of injury. In spite of all reasonable precautions, you might develop medical complications from participating in this study. The possible risks to you are:

- Some discomfort when the blood sample is taken and sometimes there is bruising around the vein.

- Wearing the 24 hour blood pressure cuff may cause some discomfort to your upper arm that will resolve once the monitoring is completed. You may experience some sleep disturbance through the night.

- The energy expenditure arm band is non-invasive, and for the vast majority of people, well tolerated and comfortable to wear. People with very sensitive skin or metal allergies may develop a slight irritation if they wear it for greater than 24 hours.

- You may experience some possible distress from uncovering unexpected health problems.

There may also be risks associated with this study that are presently unknown or unforeseeable.

\section{7. 'What happens if I suffer injury or complications as a result of the study?'}

If you suffer any injuries or complications as a result of this study, you should contact the study doctor as soon as possible, who will assist you in arranging appropriate medical treatment.

You may have a right to take legal action to obtain compensation for any injuries or complications resulting from the study. Compensation may be available if your injury or complication is caused by the procedures, or by the negligence of any of the parties involved in the study. If you receive compensation that includes an amount for medical 
expenses, you will be required to pay for your medical treatment from those compensation monies.

If you are not eligible for compensation for your injury or complication under the law, but are eligible for Medicare, then you can receive any medical treatment required for your injury or complication free of charge as a public patient in any Australian public hospital.

\section{8. 'Will I benefit from the study?'}

This study aims to further health and medical knowledge and may improve future care of women and their babies after childbirth; however it may not directly benefit you. As part of the study you will receive a thorough health check of both yourself and your baby. You will be informed of some results at the time of the assessment but not all results will be available on the day. A member of the research team will contact you if an abnormal result is reported and advise you to visit your local family doctor. All results will be sent to your local family doctor so the appropriate follow up can be made and a referral made for further treatment/care if necessary.

\section{9. 'Will taking part in this study cost me anything, and will I be paid?}

Participation in this study will not cost you anything; all assessment tests and the visits to the paediatrician and child psychologist will be free of charge to you.

There is free on street parking available at the hospital near to where your assessment visits will take place and free on street parking close to the paediatrician's rooms in Kogarah. These parking areas are time limited to two hours which is enough time to attend the visits. There is free, unlimited on site parking at the front of the psychologist's building in Ramsgate.

There are no payments made for being part of the study.

\section{0. 'How will my confidentiality be protected?'}

Of the people treating you, only A/Prof Davis, Prof Brown, A/Prof O'Sullivan, Prof Homer and Lynne Roberts will know whether or not you are participating in this study. Any identifiable information that is collected about you in connection with this study will remain confidential and will be disclosed only with your permission, or except as required by law. Only the researchers named above will have access to your details and results that will be held securely at St George Hospital. 


\section{1. 'What happens with the results?'}

If you give us your permission by signing the consent document, we plan to publish the results in a peer-reviewed journal and present at conferences or other professional forums.

In any publication, information will be provided in such a way that you cannot be identified. The results from the paediatric and developmental assessments will be recorded in your child's Personal Health Record (Blue Book). All study results will be sent to your family doctor and a copy of the developmental report for your child will be sent to the study paediatrician. Results of the study will be provided to you, if you wish.

\section{2. 'What happens to my treatment when the study is finished?'}

Your treatment will continue as normal.

\section{3. 'What should I do if I want to discuss this study further before I decide?'} When you have read this information, the researcher will discuss it with you and any queries you may have. If you would like to know more at any stage, please do not hesitate to contact Lynne Roberts (Research Midwife) on 0291132117.

\section{4. 'Who should I contact if I have concerns about the conduct of this study?'} This study has been approved by the South Eastern Sydney Local Health District Northern Sector Human Research Ethics Committee. Any person with concerns or complaints about the conduct of this study should contact the Research Support Office which is nominated to receive complaints from research participants. You should contact them on 029382 3587, or email ethicsnhn@sesiahs.health.nsw.gov.au and quote HREC project number 12/195.

Thank you for taking the time to consider this study. If you wish to take part in it, please sign the attached consent form. This information sheet is for you to keep. 


\section{Health}

South Eastern Sydney

Local Health District

ST GEORGE HOSPITAL

CONSENT FORM

Postpartum Physiology, Psychology and Paediatric follow-up Study

1.

of

agree to participate in the study described in the participant information statement set out above.

2. I acknowledge that I have read the participant information statement, which explains why I have been selected, the aims of the study and the nature and the possible risks of the investigation, and the statement has been explained to me to my satisfaction.

3. Before signing this consent form, I have been given the opportunity of asking any questions relating to any possible physical and mental harm I might suffer as a result of my participation and I have received satisfactory answers.

4. I understand that I can withdraw from the study at any time without prejudice to my relationship to the St George Hospital.

5. I understand that I will be informed of some results at the time of the assessment but not all results will be available on the day. I agree to be contacted by a member of the research team if an abnormal result is reported, and to have all results sent to my local family doctor so the appropriate follow up can be made and a referral made for further treatment/care if necessary.

6. I agree that research data gathered from the results of the study may be published, provided that I cannot be identified.

7. I understand that if I have any questions relating to my participation in this research, I may contact Lynne Roberts on telephone 029113 2117, who will be happy to answer them.

8. I acknowledge receipt of a copy of this Consent Form and the Participant Information Statement.

Complaints may be directed to the Research Ethics Secretariat, South Eastern Sydney Local Health District - Northern Sector, Prince of Wales Hospital, Randwick NSW 2031 Australia (phone 029382 3587, fax 0293822813.

Signature of participant

Signature of witness

Signature of investigator

\section{Please PRINT name Date}

\section{Please PRINT name Date}

Please PRINT name Date 


\section{Health \\ \begin{tabular}{l|l} 
NOVWVRMENT & South Eastern Sydney \\
Local Health District
\end{tabular} \\ ST GEORGE HOSPITAL \\ PERSON RESPONSIBLE CONSENT FORM \\ Postpartum Physiology, Psychology and Paediatric follow-up Study}

1.

of...

agree for my son/daughter.

.to participate in the

study described in the participant information statement set out above.

2. I acknowledge that I have read the participant information statement, which explains why he/she has been selected, the aims of the study and the nature and the possible risks of the investigation, and the statement has been explained to me to my satisfaction.

3. Before signing this consent form, I have been given the opportunity of asking any questions relating to any possible physical and mental harm he/she might suffer as a result of participating and I have received satisfactory answers.

4. I understand that I can withdraw my son/daughter from the study at any time without prejudice to my relationship to the St George Hospital.

5. I understand that I will be informed of some results at the time of the assessment but not all results will be available on the day. I agree to be contacted by a member of the research team if an abnormal result is reported and to have all results sent to my local family doctor so the appropriate follow up can be made and a referral made for further treatment/care if necessary. I agree to a copy of the Bayley III assessment being sent to the paediatrician.

6. I agree that research data gathered from the results of the study may be published, provided that he/she cannot be identified.

7. I understand that if I have any questions relating to my child's participation in this research, I may contact Lynne Roberts on telephone 029113 2117, who will be happy to answer them.

8. I acknowledge receipt of a copy of this Consent Form and the Participant Information Statement.

Complaints may be directed to the Research Ethics Secretariat, South Eastern Sydney Local Health District - Northern Sector, Prince of Wales Hospital, Randwick NSW 2031 Australia (phone 029382 3587, fax 0293822813.

Signature of participant's parent

Signature of witness

Signature of investigator
Please PRINT name

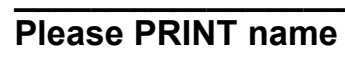

Please PRINT name
Date

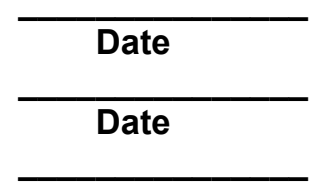




\section{ST GEORGE HOSPITAL}

\section{Postpartum Physiology, Psychology and Paediatric follow-up Study}

\section{REVOCATION OF CONSENT}

I hereby wish to WITHDRAW my consent to participate in the study described above and understand that such withdrawal WILL NOT jeopardise any treatment or my relationship with the St George Hospital.

Signature of participant
Please PRINT name

Date

The section for Revocation of Consent should be forwarded to A/Prof Greg Davis at Women's and Children's Health, St George Hospital, Kogarah NSW 2217. 


\section{Appendix 4. P4 Study Invitation (V4)}

This version has been updated several times, however this is the version that the majority of women signed when consenting to my study.

\section{YYs Health \\ NSW South Eastern Sydney GOVERNMENT Local Health District}

\section{Invitation to be part of: \\ The Postpartum Physiology, Psychology and Paediatric follow up (P4) Study St George Hospital}

The research team from the Maternity and Obstetric Medicine Departments at St George Hospital is conducting a study to look at what happens to women and their babies in the two years after birth when the women have had high blood pressure in pregnancy. We know that high blood pressure in pregnancy may have long term effects on the mothers but there have been very few studies of this nature and there is very little information about their babies. We will also have to study a number of women who did not have high blood pressure in pregnancy in order to have a normal group for comparison.

Please see the information below regarding the study. Further details are contained in the enclosed Information Sheet. If you are interested in participating or have any questions, please call our Research Midwife, Lynne Roberts on phone 91132117 . She will answer your questions and, if you agree to participate, make the first assessment appointment for you to see us 5-9 months following the birth of your baby. If we don't hear from you within two weeks of sending this letter, Lynne will contact you and ask if you have any questions and enquire whether you are interested in participating. If you are interested, Lynne will organise an appointment with us, 5-9 months after the birth of your baby. Just 
prior to the visit she will send you a questionnaire for you to fill out about your baby's development and health to that point. There are two parts to this study:

Part 1: When you attend on the day Lynne will go through your medical, family and pregnancy history, measure your height, weight and blood pressure, check the blood flow in your wrist, measure the water/fat composition in your body and take some blood and a urine sample for testing. She will organise for you to have a 24 hour monitor of your blood pressure and a 24 hour monitor to measure your energy usage in an entire day. You will be asked to fill out a food diary for three days which will be explained to you. As part of the study Lynne will also organise for you to take your baby to have a complete medical check-up with a specialist paediatrician. At this check up your baby's weight, length, head circumference and blood pressure will be measured. In addition, a general assessment of your baby's health will be done eg. hearing, sight, development, and history of illness and/or admission to hospital.

Part 2: The second part of this study will be to review you at two years after the birth. Five questionnaires will be posted to you for completion; four of them about your health and the other one about your baby's development. Lynne will also arrange for your baby to have a repeat physical check by a paediatrician and an assessment of the baby's development by an experienced child psychologist. This developmental assessment is called a Bayley III and uses games, toys and puzzles to look at your child's development in areas such as language, problem solving and motor skills.

All of the tests, measurements and visits to the paediatrician in both Part 1 and Part 2 of the study, as well as the visit to the psychologist at two years of age, are free of charge to you.

You will be informed of some results at the time of the assessment but not all results will be available on the day. A member of the research team will contact you if an abnormal result is reported and advise you to visit your local family doctor. All results will be sent to your local family doctor so the appropriate 
follow up can be made and a referral made for further treatment/care if necessary.

In addition to these assessments you may be invited to take part in an informal interview with Lynne when your baby is about 9 months old. At the interview you will be asked to chat about your birth experience and any stress that you may be experiencing or have experience in the past.

Participation in this study is voluntary. It is completely up to you whether or not you participate. If you decide not to participate, it will not affect the treatment you receive now or in the future. Whatever your decision, it will not affect your relationship with the staff caring for you and St George Hospital. We will ask you to sign a consent form prior to participating in the study. If you wish to withdraw from the study once it has started, you can do so at any time without having to give a reason.

Please consider this information carefully and if you have any questions, or agree to take part, please contact Lynne Roberts on phone number 91132117.

Yours sincerely,

A/ Professor Gregory Davis

Senior Staff Specialist Obstetrician

Principal Investigator, P4 Study 
Appendix 5. P4 Study six month maternal questionnaire

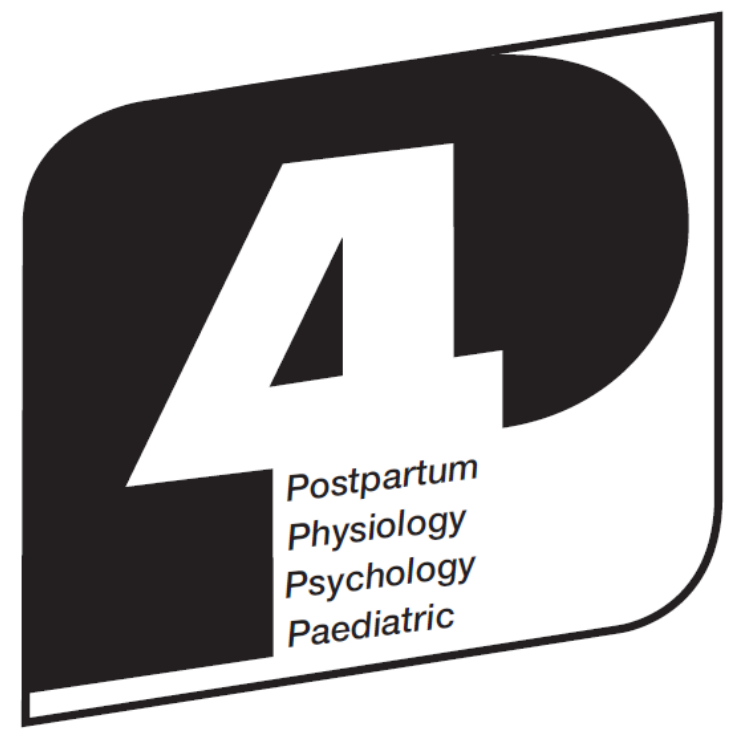

\section{POSTPARTUM PHYSIOLOGY, PSYCHOLOGY \& PAEDIATRIC FOLLOW-UP STUDY}

\section{FIRST ASSESSMENT (6 months)}

Thank you for taking part in the P4 Study where we are looking into women's and infant's health after pregnancy and birth. As part of this study, we are interested in hearing about you, your health and how you have been feeling. To assist us with our research please take the time to fill out the following questionnaire.

How to fill in the questionnaire Some of the questions require a short answer and some ask you to mark the answer that best applies to you. Separate instructions are given in the questionnaire where necessary to help you. 
Section One - About you Please circle your answer and give details as needed These first few questions are to find out about you, your background, and occupation.

A. What ethnic group do you and your partner identify with?

YOURSELF

1. Caucasian

2. Asian

3. Aboriginal or Torres Strait Islander Islander

4. Polynesian

5. European

6. Other

\section{PARTNER}

1. Caucasian

2. Asian

3. Aboriginal or Torres Strait

4. Polynesian

5. European

6. Other

7. N/A

B. What are you and your partner's highest level of formal education?

YOURSELF

1. Secondary school

2. Trade/Cert/Diploma

3. University degree

\section{PARTNER}

1. Secondary school

2. Trade/Cert/Diploma

3. University degree

4. N/A

C. What is/was the occupation of you and your partner?

YOURSELF (before the baby was born) PARTNER 
Section Two - Your Health Please circle your answer and give details as needed These next questions are about your general health habits.

A. Please provide the details of current medications you are taking.

B. Do you or anyone in your family have a history of the following? Please circle if answer is yes.

\section{YOU}

1. Stroke

2. Heart attack

3. Angina

4. High blood pressure

5. Kidney problems

6. Diabetes

7. Anxiety

8. Depression

9. Eating Disorder

10. Significant illness

11. Other

\section{FAMILY}

1. Stroke

2. Heart attack

3. Angina

4. High blood pressure

5. Kidney problems

6. Diabetes

7. Anxiety

8. Depression

9. Eating Disorder

10. Significant illness

11. Other

If you answered yes to any of the questions above, please provide further details

C. Do you currently smoke cigarettes?

1. No, I have never smoked

2. No, but I am an ex-smoker. Please state when you quit smoking

3. Yes I currently smoke. Please state how many cigarettes you smoke in a day

D. On average, how many standard drinks would you have in a week?

E. Have you ever taken any drugs (for example, marijuana, cocaine, heroin)? If yes, please provide details. 
F. How many times a week would you do physical activity that makes you breathless and sweaty? 
Section Three - Pregnancy Please circle your answer and give details as needed These next questions are about your pregnancy experiences.

A. Did you ever have problems with falling pregnant?

1. No

2. Yes. If yes, please provide details

B. How many times have you been pregnant?

Of these pregnancies how many have resulted in a

Miscarriage or termination?

Premature baby - born before 37 weeks of pregnancy?

Full-term baby - born after 37 weeks of pregnancy?

C. How many living children do you have?

D. Are you currently pregnant?

1. No

2. Yes. If yes, how many weeks pregnant are you?

E. Are you currently in a relationship?

1. No

2. Yes

F. Is your current partner the father of the baby you had about 6 months ago?

1. No

2. Yes

G. Have you had a change in partner between any of your pregnancies?

1. No

2. Yes. If yes, please provide details

3. Not applicable, this is my first baby

$\mathrm{H}$. Was the pregnancy that resulted in the birth of your baby 6 months ago

1. Planned?

2. Unplanned?

I. Have you had high blood pressure in any of your pregnancies?

1. No 
2. Yes. If yes, please provide details

J. Have you had gestational diabetes in any of your pregnancies?

1. No

2. Yes. If yes, please provide details

K. Are you currently breastfeeding?

1. No, I didn't breastfeed

2. No, I have stopped now. When did you stop?

3. Yes 


\section{Section Four - Labour and Birth}

A. Giving birth can be an overwhelming experience, physically as well as emotionally. How would you describe your experience of labour and birth?

Please complete this section whether you had a vaginal birth or a caesarean section. Please circle ONE number for each of the following statements. If the statement is not applicable go to the next one.

i. During labour and birth, I felt free to express my feelings....

$\begin{array}{lllllllll}\text { Strongly disagree } & 1 & 2 & 3 & 4 & 5 & 6 & 7 & \text { Strongly agree }\end{array}$

ii. During labour and birth, I felt I was....

$\begin{array}{llllllllll}\text { Completely out of control } & 1 & 2 & 3 & 4 & 5 & 6 & 7 & \text { In complete control }\end{array}$ iii. Physically, I coped....

$\begin{array}{lllllllll}\text { Worse than expected } & 1 & 2 & 3 & 4 & 5 & 6 & 7 & \text { Better than expected }\end{array}$ ix. Emotionally, I coped....

$\begin{array}{lllllllll}\text { Worse than expected } & 1 & 2 & 3 & 4 & 5 & 6 & 7 & \text { Better than expected }\end{array}$ v. When looking back at labour and birth, I feel....

$\begin{array}{lllllllll}\text { Not at all proud of myself } & 1 & 2 & 3 & 4 & 5 & 6 & 7 & \text { Very proud of myself }\end{array}$ vi. Overall, how would you describe your care during labour and birth?

$\begin{array}{lllllllll}\text { Very poor } & 1 & 2 & 3 & 4 & 5 & 6 & 7 & \text { Very good }\end{array}$

B. Please describe any things about your labour and/or the birth that you were i. Particularly happy with

ii. Particularly unhappy with 


\section{Section Five - Your health since your recent pregnancy Please}

circle your answer and give details as needed

Since having your baby about 6 months ago:

A. Have you seen a doctor about your blood pressure?

1. No

2. Yes. If yes, please give details

B. Have you seen your local doctor about any other health problems?

1. No

2. Yes, If yes, please give details

C. Have you been referred to a specialist doctor for health problems?

1. No

2. Yes. If yes, please give details

D. Have you seen your local doctor about any mental health concerns?

1. No

2. Yes, If yes, please give details

E. Have you been referred to a specialist doctor or psychologist for mental health concerns?

1. No

2. Yes. If yes, please give details

F. Have you been started on any new medications?

1. No

2. Yes. If yes, please give details

G. Have you experienced stress in the past 6 months (besides the stress of pregnancy and parenthood)?

1. No

2. Yes. If yes, was the stress due to

I. Financial difficulties 

II. Relationship worries
III. Loss/death
IV. Housing changes
V. Significant isolation
VI. Other 


\section{Section Six - How you have been feeling}

We would now like to hear about how you have been feeling emotionally since having your baby.

Please circle the answer that comes closest to how you have felt IN THE PAST 7 DAYS, not just how you feel today.

In the past 7 days:

1. I have been able to laugh and see the funny side of things

As much as I always could

Not quite so much now

Definitely not so much now

Not at all

2. I have looked forward with enjoyment to things

As much as I ever did

Rather less than I used to

Definitely less than I used to

Hardly at all

3. I have blamed myself unnecessarily when things went wrong

Yes, most of the time

Yes, some of the time

Not very often

No, never

4. I have been anxious or worried for no good reason

No, not at all

Hardly ever

Yes, sometimes

Yes, very often

5. I have felt scared or panicky for no very good reason

Yes, quite a lot

Yes, sometimes

No, not much

No, not at all 
6. Things have been getting on top of me

Yes, most of the time I haven't been able to cope at all

Yes, sometimes I haven't been coping as well as usual

No, most of the time I have coped quite well

No, I have been coping as well as ever

7. I have been so unhappy that I have had difficulty sleeping

Yes, most of the time

Yes, sometimes

Not very often

No, not at all

8. I have felt sad or miserable

Yes, most of the time

Yes, quite often

Not very often

No, not at all

9. I have been so unhappy that I have been crying

Yes, most of the time

Yes, quite often

Only occasionally

No, never

10. The thought of harming myself has occurred to me

Yes, quite often

Sometimes

Hardly ever

Never

Source: Cox, J.L., Holden, J.M., and Sagovsky, R. 1987. Detection of postnatal depression: Development of the 10-itemEdinburgh Postnatal Depression Scale. British Journal of Psychiatry 150:782-786.

For the following question please place a tick, alongside each phrase, in the box that best describes how you have felt in the PAST 2 WEEKS, not just how you feel today. 
Over the past 2 WEEKS how often have you been bothered by the following problems?

\begin{tabular}{|l|l|l|l|l|}
\hline & Not at all & $\begin{array}{c}\text { Several } \\
\text { days }\end{array}$ & $\begin{array}{c}\text { Over half } \\
\text { the days }\end{array}$ & $\begin{array}{c}\text { Nearly } \\
\text { every day }\end{array}$ \\
\hline $\begin{array}{l}\text { Feeling nervous, anxious, or } \\
\text { on edge }\end{array}$ & & & & \\
\hline $\begin{array}{l}\text { control being able to stop or } \\
\text { different things }\end{array}$ & & & & \\
\hline Trouble relaxing & & & & \\
\hline $\begin{array}{l}\text { Being so restless that it's } \\
\text { hard to sit still }\end{array}$ & & & & \\
\hline $\begin{array}{l}\text { Becoming easily annoyed or } \\
\text { irritable }\end{array}$ & & & & \\
\hline $\begin{array}{l}\text { Feeling afraid as if } \\
\text { something awful might } \\
\text { happen }\end{array}$ & & & & \\
\hline
\end{tabular}

If you checked off any problems, how difficult have these made it for you to do your work, take care of things at home, or get along with other people?

1. Not difficult at all

2. Somewhat difficult

3. Very difficult

4. Extremely difficult 
These next few questions are about your feelings for your child since he/she was born. Some words are listed below which describe some of the feelings mothers have had towards their baby. Please place a tick, alongside each word, in the box which best describes how you have felt towards your child in the

\section{PAST 2 WEEKS.}

\begin{tabular}{|l|l|l|l|l|}
\hline & Very much & A lot & A little & Not at all \\
\hline Loving & & & & \\
\hline Resentful & & & & \\
\hline $\begin{array}{l}\text { Neutral or felt } \\
\text { nothing }\end{array}$ & & & & \\
\hline Joyful & & & & \\
\hline Dislike & & & & \\
\hline Protective & & & & \\
\hline Disappointed & & & & \\
\hline Aggressive & & & & \\
\hline
\end{tabular}

Source: Taylor A, Atkins R, Kumar R, Adams D, and Glover V. 2005. A new Mother-to-Infant Bonding Scale: links with early maternal mood. Arch Women's Men Health 8:45-51. 


\section{PTSD Scale-Self Report for DSM-5}

\section{(PS-SR5)}

\section{TRAUMA SCREEN}

Have you ever experienced, witnessed, or been repeatedly confronted with any of the following: (Check all that apply)

Serious, life threatening illness (heart attack, etc.)

Physical Assault (attacked with a weapon, severe injuries from a fight, held at gunpoint, etc.)

Sexual assault (rape, attempted rape, forced sexual act with a weapon, etc.)

Military combat or lived in a war zone

Child abuse (severe beatings, sexual acts with someone 5 years older than you, etc.)

Accident (serious injury or death from a car, at work, a house fire, etc.)

Natural disaster (severe hurricane, flood, earthquake, etc.)

Other trauma (Please describe briefly):

None

*** If NONE, please STOP and return this questionnaire ***

If you marked any of the above items, which single traumatic experience is on your mind and currently bothers you the most:

(Check only one)

Serious, life threatening illness (heart attack, etc.)

Physical Assault (attacked with a weapon, severe injuries from a fight, held at gunpoint, etc.)

Sexual assault (rape, attempted rape, forced sexual act with a weapon, etc.)

Military combat or lived in a war zone

Child abuse (severe beatings, sexual acts with someone 5 years older than you, etc.)

Accident (serious injury or death from a car, at work, a house fire, etc.)

Natural disaster (severe hurricane, flood, earthquake, etc.)

Other trauma (Please describe briefly): 


\section{$\underline{\text { PTSD Scale-Self Report for DSM-5 }}$}

(PS-SR5)

Instructions: Below is a list of problems that people sometimes have after experiencing a traumatic event. Write down the most distressing traumatic event that you checked on the last page:

Please read each statement carefully and circle the number that best describes how often that problem has been happening and how much it upset you over THE LAST MONTH. Rate each problem with respect to the traumatic event that you wrote above.

For example, if you've talked to a friend about the trauma one time in the past month, you would respond like this: (because one time in the past month is less than once a week)

Talking to other people about the trauma

$\begin{array}{ccccc}0 & 1 & 2 & 3 & 4 \\ \text { Not at all } & \begin{array}{c}\text { Once a week or } \\ \text { less/a little }\end{array} & \begin{array}{c}2 \text { to } 3 \text { times a } \\ \text { week/somewhat }\end{array} & \begin{array}{c}4 \text { to } 5 \text { times a } \\ \text { week/very much }\end{array} & \begin{array}{c}\text { 6 or more times a } \\ \text { week/severe }\end{array}\end{array}$

1. Unwanted upsetting memories about the trauma

$\begin{array}{ccccc}0 & 1 & 2 & 3 & 4 \\ \text { Not at all } & \text { Once a week or } & 2 \text { to } 3 \text { times a } & 4 \text { to } 5 \text { times a } & \text { 6 or more times a } \\ & \text { less/a little } & \text { week/somewhat } & \text { week/very much } & \text { week/severe }\end{array}$

2. Bad dreams or nightmares related to the trauma

$\begin{array}{ccccc}0 & 1 & 2 & 3 & 4 \\ \text { Not at all } & \text { Once a week or } & 2 \text { to } 3 \text { times a } & 4 \text { to } 5 \text { times a } & \text { ler more times a } \\ & \text { less/a little } & \text { week/somewhat } & \text { week/very much } & \text { week/severe }\end{array}$

3. Reliving the traumatic event or feeling as if it were actually happening again

$\begin{array}{ccccc}0 & 1 & 2 & 3 & 4 \\ \text { Not at all } & \begin{array}{c}\text { Once a week or } \\ \text { less/a little }\end{array} & 2 \text { to } 3 \text { times a } & 4 \text { to } 5 \text { times a } & \text { week/somewhat } \\ & \text { week/very much } & \begin{array}{c}\text { or more times a } \\ \text { week/severe }\end{array}\end{array}$

4. Feeling very EMOTIONALLY upset when reminded of the trauma

$\begin{array}{ccccc}0 & 1 & 2 & 3 & 4 \\ \text { Not at all } & \begin{array}{c}\text { Once a week or } \\ \text { less/a little }\end{array} & 2 \text { to } 3 \text { times a } & 4 \text { to } 5 \text { times a } & \text { week/somewhat } \\ & & \text { or more times a } & \text { wery much } & \text { week/severe }\end{array}$

5. Having PHYSICAL reactions when reminded of the trauma (for example, sweating, heart racing)

$\begin{array}{ccccc}0 & 1 & 2 & 3 & 4 \\ \text { Not at all } & \text { Once a week or } & 2 \text { to } 3 \text { times a } & 4 \text { to } 5 \text { times a } & \text { less/a little } \\ & \text { week/somewhat } & \text { week/very much } & \text { week/severe }\end{array}$

6. Trying to avoid thoughts or feelings related to the trauma

$\begin{array}{ccccc}0 & 1 & 2 & 3 & 4 \\ \text { Not at all } & \text { Once a week or } & 2 \text { to } 3 \text { times a } & 4 \text { to } 5 \text { times a } & \text { 6 or more times a } \\ & \text { less/a little } & \text { week/somewhat } & \text { week/very much } & \text { week/severe }\end{array}$

Page 2

(C2013 Edna B. Foa

Reproduction or redistribution, in whole or in part, in any manner, without the prior written consent of the copyright holder, is a violation of copyright law. 


\section{$\underline{\text { PTSD Scale-Self Report for DSM-5 }}$}

$\underline{\text { (PS-SR5) }}$

7. Trying to avoid activities, situations, or places that remind you of the trauma or that feel more dangerous since the trauma

\begin{tabular}{|c|c|c|c|c|}
\hline 0 & 1 & 2 & 3 & 4 \\
\hline Not at & $\begin{array}{c}\text { Once a week or } \\
\text { less/a little }\end{array}$ & $\begin{array}{c}2 \text { to } 3 \text { times a } \\
\text { week/somewhat }\end{array}$ & $\begin{array}{c}4 \text { to } 5 \text { times a } \\
\text { week/very much }\end{array}$ & $\begin{array}{c}6 \text { or more times a } \\
\text { week/severe }\end{array}$ \\
\hline
\end{tabular}

8. Not being able to remember important parts of the trauma

$\begin{array}{ccccc}0 & 1 & 2 & 3 & 4 \\ \text { Not at all } & \begin{array}{c}\text { Once a week or } \\ \text { less/a little }\end{array} & \begin{array}{c}2 \text { to } 3 \text { times a } \\ \text { week/somewhat }\end{array} & \begin{array}{c}4 \text { to } 5 \text { times a } \\ \text { week/very much }\end{array} & \begin{array}{c}\text { 6 or more times a } \\ \text { week/severe }\end{array}\end{array}$

9. Seeing yourself, others, or the world in a more negative way (for example "I can't trust people," "I'm a weak person")

$\begin{array}{ccccc}0 & 1 & 2 & 3 & 4 \\ \text { Not at all } & \begin{array}{c}\text { Once a week or } \\ \text { less/a little }\end{array} & 2 \text { to } 3 \text { times a } & 4 \text { to } 5 \text { times a } & \text { week/somewhat } \\ & \text { week/very much } & \text { or more times a } & \text { week/severe }\end{array}$

10. Blaming yourself or others (besides the person who hurt you) for what happened

$\begin{array}{ccccc}0 & 1 & 2 & 3 & 4 \\ \text { Not at all } & \text { Once a week or } & 2 \text { to } 3 \text { times a } & 4 \text { to } 5 \text { times a } & 6 \text { or more times a } \\ & \text { less/a little } & \text { week/somewhat } & \text { week/very much } & \text { week/severe }\end{array}$

11. Having intense negative feelings like fear, horror, anger, guilt or shame

$\begin{array}{ccccc}0 & 1 & 2 & 3 & 4 \\ \text { Not at all } & \begin{array}{c}\text { Once a week or } \\ \text { less/a little }\end{array} & 2 \text { to } 3 \text { times a } & 4 \text { to } 5 \text { times a } & \text { week/somewhat } \\ & \text { week/very much } & \begin{array}{c}\text { or more times a } \\ \text { week/severe }\end{array}\end{array}$

12. Losing interest or not participating in activities you used to do

$\begin{array}{ccccc}0 & 1 & 2 & 3 & 4 \\ \text { Not at all } & \text { Once a week or } & 2 \text { to } 3 \text { times a } & 4 \text { to } 5 \text { times a } & \text { 6 or more times a } \\ & \text { less/a little } & \text { week/somewhat } & \text { week/very much } & \text { week/severe }\end{array}$

13. Feeling distant or cut off from others

$\begin{array}{ccccc}0 & 1 & 2 & 3 & 4 \\ \text { Not at all } & \begin{array}{c}\text { Once a week or } \\ \text { less/a little }\end{array} & \begin{array}{c}2 \text { to } 3 \text { times a } \\ \text { week/somewhat }\end{array} & \begin{array}{c}4 \text { to } 5 \text { times a } \\ \text { week/very much }\end{array} & \begin{array}{c}\text { 6 or more times a } \\ \text { week/severe }\end{array}\end{array}$

14. Having difficulty experiencing positive feelings

$\begin{array}{ccccc}0 & 1 & 2 & 3 & 4 \\ \text { Not at all } & \text { Once a week or } & 2 \text { to } 3 \text { times a } & 4 \text { to } 5 \text { times a } & \text { 6 or more times a } \\ & \text { less/a little } & \text { week/somewhat } & \text { week/very much } & \text { week/severe }\end{array}$

15. Acting more irritable or aggressive with others

$\begin{array}{ccccc}0 & 1 & 2 & 3 & 4 \\ \text { Not at all } & \text { Once a week or } & 2 \text { to } 3 \text { times a } & 4 \text { to } 5 \text { times a } & \text { 6 or more times a } \\ & \text { less/a little } & \text { week/somewhat } & \text { week/very much } & \text { week/severe }\end{array}$

Page 3

(C)2013 Edna B. Foa

Reproduction or redistribution, in whole or in part, in any manner, without the prior written consent of the copyright holder, is a violation of copyright law 


\section{PTSD Scale-Self Report for DSM-5}

\section{(PS-SR5)}

16. Taking more risks or doing things that might cause you or others harm (for example, driving recklessly, taking drugs, having unprotected sex)

$\begin{array}{ccccc}0 & 1 & 2 & 3 & 4 \\ \text { Not at all } & \text { Once a week or } & 2 \text { to } 3 \text { times a } & 4 \text { to } 5 \text { times a } & \text { 6 or more times a } \\ & \text { less/a little } & \text { week/somewhat } & \text { week/very much } & \text { week/severe }\end{array}$

17. Being overly alert or on-guard (for example, checking to see who is around you, being uncomfortable with your back to a door)

0

Not at all

Once a week or
$\begin{gathered}2 \text { to } 3 \text { times a } \\ \text { less/a little }\end{gathered} \quad$ week/somewhat

2 week/somewhat
3

4 to 5 times a week/very much
4

6 or more times a week/severe

18. Being jumpy or more easily startled (for example when someone walks up behind you)

$\begin{array}{ccccc}0 & 1 & 2 & 3 & 4 \\ \text { Not at all } & \text { Once a week or } & 2 \text { to } 3 \text { times a } & 4 \text { to } 5 \text { times a } & \text { 6 or more times a } \\ & \text { less/a little } & \text { week/somewhat } & \text { week/very much } & \text { week/severe }\end{array}$

19. Having trouble concentrating

$\begin{array}{ccc}0 & 1 & 2 \\ \text { Not at all } & \text { Once a week or } & 2 \text { to } 3 \text { times a } \\ & \text { less/a little } & \text { week/somewhat }\end{array}$

3
4 to 5 times a
week/very much
4
6 or more times a week/severe

20. Having trouble falling or staying asleep

Not at all

\section{2}

2 to 3 times a week/somewhat
3

4 to 5 times a week/very much
4

6 or more times a week/severe

\section{DISTRESS AND INTERFERENCE}

21. How much have these difficulties been bothering you?

$\begin{array}{ccccc}0 & 1 & 2 & 3 & 4 \\ \text { Not at all } & \begin{array}{c}\text { Once a week or } \\ \text { less/a little }\end{array} & \begin{array}{c}2 \text { to } 3 \text { times a } \\ \text { week/somewhat }\end{array} & \begin{array}{c}4 \text { to } 5 \text { times a } \\ \text { week/very much }\end{array} & \begin{array}{c}6 \text { or more times a } \\ \text { week/severe }\end{array}\end{array}$

22. How much have these difficulties been interfering with your everyday life (for example relationships, work, or other important activities)?

$\begin{array}{ccccc}0 & 1 & 2 & 3 & 4 \\ \text { Not at all } & \begin{array}{c}\text { Once a week or } \\ \text { less/a little }\end{array} & \begin{array}{c}2 \text { to } 3 \text { times a } \\ \text { week/somewhat }\end{array} & \begin{array}{c}4 \text { to } 5 \text { times a } \\ \text { week/very much }\end{array} & \begin{array}{c}\text { 6 or more times a } \\ \text { week/severe }\end{array}\end{array}$

\section{SYMPTOM ONSET AND DURATION}

23. How long after the trauma did these difficulties begin? [circle one]
a. Less than 6 months
b. More than 6 months

24. How long have you had these trauma-related difficulties? [circle one]
a. Less than 1 month
b. More than 1 month

Page 4 


\section{Appendix 6. Email from Edna Foa regarding the PDS-V}

\section{5/27/2019 Archive Manager}

Re: PDS

Sent: June 10, 2015 6:19 PM From: Edna Foa

To: Lynne Roberts (Midwife); CC: Ellen Work Kubis;

Dear Lynne:

My Assistant Ellen will send you a copy of the revised PDS for the DSM 5 called PDS- 5 and the manual. You can then copy it with no charge.

Best Edna Foa

Edna B. Foa, Ph.D

Professor of Psychology in Psychiatry

Director, Center for the Treatment and Study of Anxiety University of Pennsylvania

On Jun 10, 2015, at 07:52, Lynne Roberts (Midwife)

Lynne.Roberts@SESIAHS.HEALTH.NSW.GOV.AU wrote:

<image001.gif> Dear Professor Foa

I am a research midwife currently working through my PhD with the University of Technology, Sydney, Australia.

| am investigating the mental health of women following a pregnancy complicated by preeclampsia. | am particularly interested in PTSD, depression and anxiety.

I have been using your PDS hand scoring worksheets and scoring sheets in my research and have been purchasing them through Pearson Clinical in Australia. Recently it has come to my attention that Pearson Clinical are no longer distributing the PDS documents.

| have emailed Pearson Clinical to ask if there is another way | can purchase more documents so | can continue to use them in my research and | am awaiting their reply. In the meantime, | am wondering if you could help me with this problem? Any ideas that you have would be greatly appreciated.

Regards Lynne

Lynne Roberts Research Midwife St George Hospital Phone: 0291132117 Fax: 0291133642

Illawarra Shoalhaven Local Health District, South East Sydney Local Health District https://qam.health.nsw.gov.au/print.html\#/print-single?includelds=381 8368 1\%7CO 1/2 


\section{Appendix 7. HREC approval letter to undertake interviews}

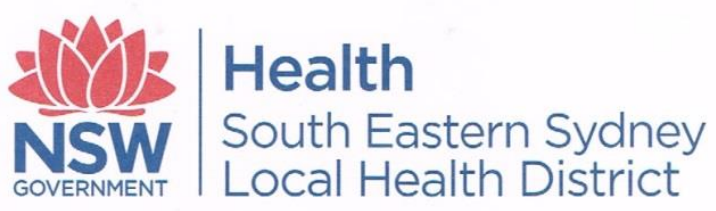

HUMAN RESEARCH ETHICS COMMITTEE

Room G71 East Wing

Edmund Blacket Building

Prince of Wales Hospital

RANDWICK NSW 2031

Tel: 0293823587 Fax: 0293822813

http://www.seslhd.health.nsw.gov.au/POWH/researchsupport/default.asp

12 November 2013

Dr Gregory Davis

Women's Health

Level 2, Prichard Wing

St George Hospital

Kogarah NSW 2217

Attention: Lynne Roberts

RE: HREC ref no: 12/195 (HREC/12/POWH/395)

Project Title: Post partum Physiology, Psychology and Paediatric follow up Study (P4 Study)

Dear Dr Davis

Thank you for your correspondence dated 8 November 2013 to the Human Research Ethics Committee (HREC) responding to questions which arose at the Executive Committee meeting on 6 November 2013.

Authority to grant final approval was delegated to the Executive Officer and I am pleased to advise that ethical approval has been given for the following:

- Amendment Form, dated 23 October 2013

- Response Email to the Executive, dated 8 November 2013

- Protocol, version 4, dated October 2013

- Participant Information Sheet \& Consent Form, version 4, dated October 2014

- Invitation Letter, version 4, dated October 2013

Ethical approval is valid for the following site(s):

- St George Hospital

This amendment has also been reviewed by the Research Governance Officer at SESLHD. Further authorisation of the above approved documents is not required for any site that has the Research Governance conducted by the SESLHD

Research Support Office. Implementation of this amendment can now proceed.

Prince of Wales Hospital Community Health Services

Barker Street
Randwick NSW 2031

2013.11.12. EO approval of amendments after responses.docX 
For multi-site projects reviewed by the HREC after 1 January 2011 a copy of this letter must be forwarded to all Principal Investigators at every site approved by the SESLHD HREC for submission to the relevant Research Governance Officer along with a copy of the approved documents.

Should you have any queries, please contact the Research Support Office on (02) 93823587 . The HREC Terms of Reference, Standard Operating Procedures, membership and standard forms are available from the Research Support Office website: $\underline{\mathrm{http}}$ ://www.seslhd.health.nsw.gov.au/POWH/researchsupport/default.asp

Please quote HREC ref no 12/195 in all correspondence.

We wish you every success in your research

Yours sincerely

Production Note:

Signature removed prior to publication.

Amanda Idan

Acting Executive Officer, Human Research Ethics Committee

This HREC is constituted and operates in accordance with the National Health and Medical Research Council's (NHMRC) National Statement on Ethical Conduct in Human Research (2007), NHMRC and Universities Australia Australian Code for the Responsible Conduct of Research (2007) and the CPMP/ICH Note for Guidance on Good Clinical Practice. 


\section{Appendix 8. Acknowledgement from Midwifery to use original paper}

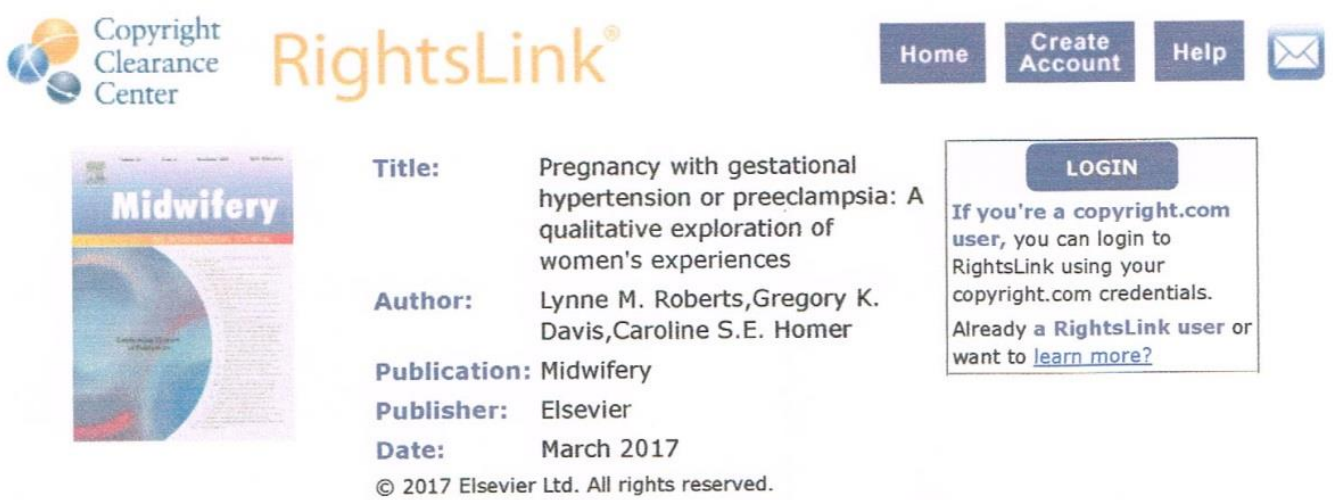

Please note that, as the author of this Elsevier article, you retain the right to include it in a thesis or dissertation, provided it is not published commercially. Permission is not required, but please ensure that you reference the journal as the original source. For more information on this and on your other retained rights, please visit: https://www.elsevier.com/about/our-business/policies/copyright\#Authorrights

\section{BACK CLOSE WINDOW}

Copyright (C) 2018 Copyright Clearance Center, Inc. All Rights Reserved. Privacy statement. Terms and Conditions. Comments? We would like to hear from you. E-mail us at customercare@copyright.com 


\title{
Appendix 9. Midwifery interview paper
}

Midwifery $46(2017) 17-23$

Contents lists available at ScienceDirect

Midwifery

journal homepage: www.elsevier.com/locate/midw

Pregnancy with gestational hypertension or preeclampsia: A qualitative exploration of women's experiences

Lynne M. Roberts, MMid, MHSc Research Midwife ${ }^{\mathrm{a}, \mathrm{b}, *, 1}$, Gregory K. Davis, MBChB, MD

FRCOG, FRANZCOG Staff Specialist Obstetrician ${ }^{\mathrm{a}, \mathrm{b}, 2}$, Caroline S.E. Homer, RM,

MMedSc(ClinEpi), PhD Professor of Midwifery ${ }^{\mathrm{b}, 3}$

a Department of Women's Health, St George Hospital, Sydney, Australia

b Faculty of Health, University of Technology Sydney, Australia

\begin{tabular}{l} 
A R T I C L E I N F O \\
\hline Keywords: \\
Hypertension in pregnancy \\
Complicated pregnancy \\
Qualitative descriptive \\
Birth experience \\
Multidisciplinary collaborative continuity \\
models of care \\
Support
\end{tabular}

\begin{abstract}
A B S T R A C T
Background: Hypertension complicates 10\% of pregnancies and involves specialised care of the woman and her baby, a longer stay in hospital, and an increased risk of physical and mental morbidity. There is limited research reporting the woman's perspective on her experience, how she coped with it psychologically, and whether the care she received influenced her experience.

Aim: To gain insight into women's experience of hypertension in pregnancy and to report on what mediating factors may help improve their experience.

Methods: A qualitative descriptive study was undertaken. Data were collected through a semi-structured, face to face interview at 10-12 months postpartum. In total, 20 women who had experienced hypertension in their pregnancy were interviewed. Thematic analysis was used to analyse the data

Findings: Four main themes were identified. These were: Reacting to the diagnosis, Challenges of being a mother, Processing and accepting the situation, and Moving on from the experience. The mediating factors that improved the experience were Feeling safe and trusting the care providers, Having continuity of care and carer, and Valuing social support from partner, family and friends.

Conclusion: The diagnosis of hypertension in pregnancy has a significant impact on women. This affects their pregnancy and birth experience and their pathway to motherhood. The implications of the findings for midwifery practice include having access to multidisciplinary continuity models of care and facilitating the support for these women.
\end{abstract}

\section{Introduction}

Hypertensive disorders of pregnancy (HDP) are the most commo medical complication of pregnancy, affecting $10 \%$ of pregnant women worldwide (Roberts and Gammill, 2005: American College of Obstetricians and Gynecologists, 2013). Hypertension may exist prior to pregnancy or develop during pregnancy. There are two pregnancyspecific hypertensive disorders: gestational hypertension (GH) and preeclampsia (PE). By definition, $\mathrm{GH}$ is hypertension that develops after 20 weeks of pregnancy without any organ involvement and is a benign condition that usually has good maternal and fetal outcomes (Tranquilli et al., 2014). In PE, hypertension develops after 20 week gestation and is associated with at least one other organ involvement, most often the kidneys, but also liver, central nervous system, haematological system or the placenta (Tranquilli et al., 2014). Preeclampsia is a more significant disorder associated with increased rates of maternal and perinatal morbidity and mortality (Steegers et al., 2010).

Women who are diagnosed with GH or PE often require specialised care from a multidisciplinary team, antenatal hospital admissions, and a longer postnatal stay that may include time in an acute care setting such as an Intensive Care Unit (ICU). There are reports of the physical such as an Intensive Care Unit (ICU). There are reports of the physical
and psychological outcomes following pregnancy complicated by hypertension (Anderson, 2007; Bushnell and Chireau, 2011; Williams, 2011. Andersgaard et al., 2012: Gigtere et al., 2012) and the long term health risks (Bellamy et al., 2007; McDonald et al.,

Corresponding author at: Department of Women's Health, St George Hospital, Sydney, Australi-

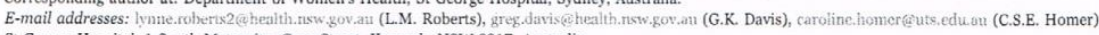

'St George Hospital, 1 South Maternity, Gray Street, Kogarah, NSW 2217, Australia

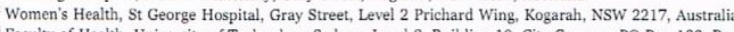

attp://dx.doi.cor/10.1016/j-midw,2017.01.004

Received 7 October 2016; Received in revised form 7 January 2017; Accepted 9 January 2017

0266-6138/ (؟) 2017 Elsevier Ltd. All rights reserved. 
2008), but there is scant research reporting on the woman's experience of HDP from her perspective, how she coped with it, and whether the care she received influenced her experience.

One the few studies specifically about the woman's experience of HDP explored the needs of women whithin three days of antenatal (Barlow et al., 2008). Interviewed within three days of antenatal
admission, this study showed that women sought support from admission, this study showed that women sought support from
partners and family and valued the support from other women in the partners and family and valued the support from other women in the
hospital ward as they seemed to have an intrinsic understanding of the hospital ward as they seemed to have an intrinsic understanding of the
situation. There was no subsequent follow-up so it is not clear how they coped over time.

In a study from the United Kingdom, women at the postnatal clinic interviewed after a pregnancy complicated by PE, were asked about their understandin were mostly concerned about the next pregnancy, especially the recurrence of the HDP, the health of the baby and a long hospital admission, rather than their own health.

In high income countries, women with HDP are usually well managed with prompt, appropriate and effective intervention (Furuta et al., 2014). Despite this, some experience a life threatening event which may lead to psychological sequelae (Vincent, 2006). This may impact adversely on mother-infant attachment and child development (Sharp et al., 1995) and their overall experience.

It is important to better understand the perspectives of women with HDP in order to enhance their quality of care and to improve their pregnancy and birth experience. The aim of this study was to explore women's experiences of a pregnancy complicated by either GH or PE using a qualitatives of a pregnancy complicated by either Grs or PE using a qualitative approach, to appreciate the woman's perspective,
how she coped with it psychologically, and whether the care she received influenced her experience.

\section{Methods}

A qualitative descriptive study, as described by Sandelowski (2000), A qualitative descriptive study, as described by sarca useful form of was undertaken. Qualitative descriptive methods are a useful form of
enquiry when investigating previously unexamined experiences enquiry when investigating previously unexamined experiences
(Sandelowski, 2000; Avis, 2003) and afford a detailed understanding of important and sometimes complex situations (Sandelowski, 2000). This approach enables life experiences to be explored in depth, and therefore gain insight and understanding of this experience from the participants' perspective (Vaismororadi et al., 2013).

Setting

The study was carried out at St George Hospital in Sydney, Australia, which caters for 2,500 births annually. The maternity unit is a regional referral metropolitan service where care can be provided to women and infants of medium to high risk (Centre for Epidemiolog: and Evidence, 2016).

Participants

Women who were diagnosed with either GH or PE in thei Women who were diagnosed with either preceding pregnancy were purposefully recruited. Participants had previously consented to a five year follow-up study (Davis et al.,2016) being conducted at the hospital, and attended the hospital at six months postpartum for study measurements. Women initially met the researcher at recruitment in the immediate postpartum period, invited to participate in a face-to-face interview about their pregnancy

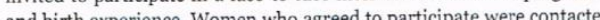
again at 10 months postpartum to confirm willingness to consent and organise a convenient place and time for the interview.

In total, 37 women were approached and 35 agreed to be contacted again. Six women were unable to be contacted and three declined consent at the second contact. Data saturation, where no new information or concepts arose from the interviews, was reached by the twentieth interview so recruitment ended at that point. The remaining six women were contacted and thanked for their offer of participation.

\section{Data collection}

Ethical approval was granted by the Local Health District Human Research Ethics Committee, the hospital Governance Unit and the university.

Semi-structured face-to-face interviews were conducted at 10-12 months postpartum. The timing of the interview was in line with suggestions from both Bennett (1985) and Simkin (1992) who propose that interviewing between months later and up to two years following the birth gives a more accurate perspective of the woman's experience.

Intervews were colve

Interviews were conducted at a mutully agrecable private place per story; 17 at the woman's home and three in a private office at the hospital. Each interview lasted about 45 minutes. The first five interviews wer conducted by two female midwives who had extensive knowledge and clinical experience in caring for women with HDP. One midwife ha considerable experience in interviewing women. The last 15 interview were conducted by one midwife (first author). A series of open-ended questions guided the interview with flexibility in the questioning to respond to the woman. The questions included:

How did you feel when you were told you had high blood pressure in your pregnancy?

How was your care from the midwives and doctors after you found out about your complication?

found out about your complication?

How did you feel after the birth?

How was your baby after the birth?
What worried you the most about having high blood pressure in What worried you
your pregnancy?

Looking back, how do you feel about your pregnancy now?

All interviews were digitally recorded. Recordings were de-identified and transcribed verbatim by the main interviewing midwife within three to four days of the interview and later transferred to the software programme NVivo for coding.

Data analysis

Data analysis began after all interviews had been transcribed. Firstly, data were separated into sections such as pregnancy, birth, infant and postpartum. This process is described by Saldana (2013) as preparing the data, giving a greater familiarity with the contents before preparing the data, giving a greater familiarity with the contents before more detailed examination begins. The second stage, initial coding, was performed using NVivo. Line by line analysis was then undertaken and
nodes, a collection of quotes about a specific area of interest (QSR International, 2014), were created. Transcripts were reread and recoded to ensure that initial coding was accurate and all useful data were included. The final stage of analysis was performed by two researchers and themes were derived from the data codes. This themetic andysis was applied in order to describe different concepts thematic analysis was applied in onder in relation to the research question (

Direct quotes are provided to illustrate the themes. Numbers at the end of each quote have replaced names to protect the woman's identity and to show how different women had similar experiences.

\section{Findings}

The women interviewed were aged between 20 and 40 years, 15 were first time mothers and the gestation at which they gave birth varied from 30 to 41 weeks (Table 1 ).

There were four main themes identified from the data: Reacting to 
Table 1
Demographics of women interviewed.

\begin{tabular}{|c|c|c|c|c|c|c|c|c|c|}
\hline ID & Age & Ethnicity & Parity & Diagnosis & History of HDP & Postpartum ICU admission & Gestation at birth (weeks) & Birth Weight (grams) & Days in SCN/NICU \\
\hline 1 & $30-35$ & Caucasian & $\mathrm{M}$ & PE & GH & no & $34-36$ & 2720 & 0 \\
\hline 2 & $25-30$ & Caucasian & $\mathrm{P}$ & PE & $\mathrm{N} / \mathrm{A}$ & yes & $34-36$ & 2960 & $1-7$ \\
\hline 3 & $25-30$ & Asian & $\mathrm{P}$ & $\mathrm{PE}$ & $\mathrm{N} / \mathrm{A}$ & no & $34-36$ & 2020 & $7-14$ \\
\hline 4 & $35-40$ & Asian & $\mathrm{P}$ & $\mathrm{PE}$ & $\mathrm{N} / \mathrm{A}$ & no & $37-40$ & 2670 & 0 \\
\hline 5 & $20-25$ & Caucasian & $\mathrm{p}$ & $\mathrm{PE}$ & $\mathrm{N} / \mathrm{A}$ & no & $37-40$ & 2830 & 0 \\
\hline 6 & $35-40$ & Other & M & $\mathrm{PE}$ & No & yes & $30-33$ & 1520 & $>28$ \\
\hline 7 & $25-30$ & Other & $\mathrm{P}$ & $\mathrm{PE}$ & $\mathrm{N} / \mathrm{A}$ & no & $37-40$ & 3250 & \\
\hline 8 & $20-25$ & Other & $\mathrm{P}$ & PE & $\mathrm{N} / \mathrm{A}$ & no & $37-40$ & 2915 & $1-7$ \\
\hline 9 & $30-35$ & Other & $\mathrm{P}$ & $\mathrm{PE}$ & $\mathrm{N} / \mathrm{A}$ & yes & $40-42$ & 3720 & $1-7$ \\
\hline 10 & $30-35$ & Caucasian & $\mathrm{p}$ & $\mathrm{GH}$ & $\mathrm{N} / \mathrm{A}$ & no & $37-40$ & 3360 & 0 \\
\hline 11 & $30-35$ & Asian & M & $\mathrm{PE}$ & $\mathrm{PE}$ & no & $37-40$ & 2640 & 0 \\
\hline 12 & $20-25$ & Caucasian & $\mathrm{P}$ & PE & N/A & no & $37-40$ & 3350 & 0 \\
\hline 13 & $30-35$ & Asian & M & PE & No & no & $37-40$ & 2680 & 0 \\
\hline 14 & $30-35$ & Caucasian & P & $\mathrm{PE}$ & N/A & no & $37-40$ & 3190 & 0 \\
\hline 15 & $30-35$ & Caucasian & M & GH & No & no & $37-40$ & 4140 & 0 \\
\hline 16 & $30-35$ & Caucasian & $\mathrm{P}$ & $\mathrm{PE}$ & $\mathrm{N} / \mathrm{A}$ & no & $30-33$ & 1350 & $>28$ \\
\hline 17 & $30-35$ & Caucasian & $\mathrm{P}$ & $\mathrm{PE}$ & $\mathrm{N} / \mathrm{A}$ & no & $37-40$ & 3405 & $1-7$ \\
\hline 18 & $30-35$ & Caucasian & $\mathrm{P}$ & $\mathrm{PE}$ & $\mathrm{N} / \mathrm{A}$ & no & $37-40$ & 2630 & \\
\hline 19 & $35-40$ & Asian & P & PE & N/A & no & $34-36$ & 2470 & $1-7$ \\
\hline 20 & $30-35$ & Asian & P & PE & $\mathrm{N} / \mathrm{A}$ & no & $30-33$ & 1775 & $>28$ \\
\hline
\end{tabular}

Note: Only ranges are provided for age, gestation and days in NICU/ICU to protect anonymity.

M, multiparous; P, primiparous; PE, preeclampsia; GH, gestational hypertension; ICU=Intensive Care Unit; $\mathrm{SCN}=$ Special Care Nursery; NICU, Neonatal Intensive Care Unit

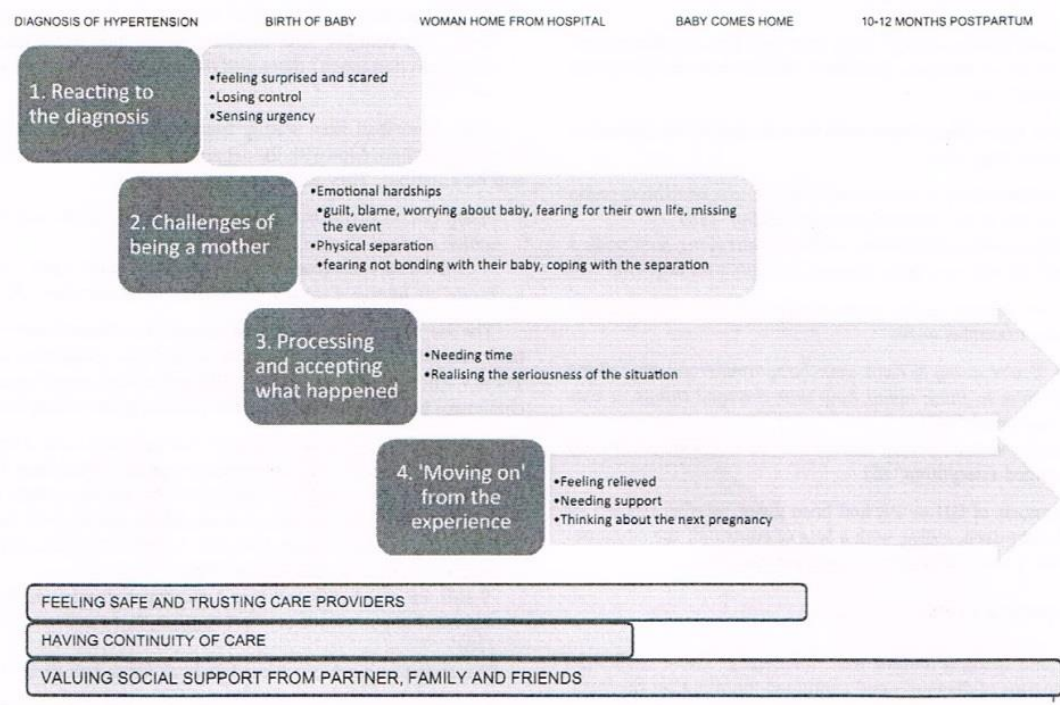

Fig. 1. : Women's experiences of havng either gestational hypertension or preeclampsia

the diagnosis, Challenges of being a mother, Processing and accepting the situation, and Moving on from the experience. Mediating factors that improved the experience were Feeling safe and trusting the care providers, Continuity of care and carer, and Valuing social support
that improved the experience were Feeling safe and trusting the care from partner, family and friends (Fig. 1).

\section{Reacting to the diagnosis}

When women were informed of their diagnosis, they reacted by feeling surprised, scared or guilty. They described feeling unprepared and needed time to understand the significance of the diagnosis. This took time for all of them and often occurred well after the birth.
For some women, the diagnosis was unexpected. They said:

"I really don't know why it caused the blood pressure problem. I can't find out why, so I'm a bit surprised because I didn't have a blood pressure problem before" (20)

"When they said it had turned into preeclampsia, it was all a bit shocking. I don't think I processed at all about how I felt about it" (7)

For three women, the diagnosis came as no surprise due to a family history of hypertension. They said:

"All my life I remember mum saying she had preeclampsia and 
blood pressure and she'd had Caesars [caesarean sections] because of the preeclampsia. I hadn't appreciated the genetic link to preeclampsia which I now know is obviously exceptionally strong. So when I got admitted it was like, well, mum had preeclampsia" (16)

"I didn't need to worry about it, people are a lot worse and they come through and that kind of kept me aware that, and my mother had it as well and my grandmother, so, I'd sort of expected it" (1)

Many women felt scared of the potential dangers such as having a stroke or their baby dying, and of not knowing that something could be wrong. For example:

"You have that fear but you don't want to think about it or linger on that, you just want to make sure that baby's $O K$ and you're $O K$. Just hope things go well" (4)

"It's a bit scary. Just the tablets and you know when you can have either infarct or something. You can have a stroke; you can have everything from hypertension" (3)

"It's just too scary and I think the bit that scared me the most was I "It's just too scary and I think the bit that scared

Most women also reacted by expressing guilt and questioned themselves. For example:

"Why did it happen to me? Could I have done something to prevent it?" (6)

"I've been questioning myself. I say why you have preeclampsia? Why your blood pressure is a problem? I think I have to change the way I'm living" (20)

A few women were disappointed with the subsequent loss of control over the situation. They said:

"I felt like I didn't have a voice and I didn't know what was going to happen to me so it was really nerve-racking" (15)

"I was pretty emotional because I couldn't control my own body. I felt betrayed by my own body because I couldn't do anything" (8)

Many women reacted to the sense of urgency once the diagnosis was given. Some examples were:

'They said 'You're going to have your baby tomorrow'. So I didn't really have time to think about how that changed things, it was just rush, rush, rush" (1)

"I think all of a sudden people were a lot more concerned. It very quickly changed everything" (5)

Once a diagnosis of GH or PE had been given, women reacted by feeling scared, surprised, guilty, with a loss of control of the situation. Women also felt a sense of urgency regarding the birth.

\section{Challenges of being a mother}

Becoming and being a mother was challenging. These challenges bectoms birth. All women worried about the health of their infant, what a preterm birth would involve and how this would affect their mothering. They said:

"I was thinking as long as he grows up fine, he comes out alive and kicking and there's no problems, that's all I been thinking of. I'm not thinking about myself" (3)

"I was worried about him. I was not worried about my own wellbeing. I think I just assumed that I would be OK and it was all about getting him delivered" (7)

Some women worried about not surviving and not being around for their infant. Some of the more dramatic examples included:

"I'm a little bit worried if my blood pressure is high or if something happen, if it too high I can die" (19)
"It crosses my mind that if I won't be around, who will take care of them? It's a scary thought - I just try not to dwell on that part (11)

Those women who needed care in an acute care setting felt that they missed the birth or early parenting experience because of loss of recal and/or physical separation from the infant. For example, women who spent time in ICU at one hospital while their baby was transferred to another commented:

"I saw her one week later when I came out of the coma. I think initially when I came out I hadn't even realised that I had given birth" (6)

"I got my partner to take a photo when he went over but I would have rather seen her properly" (16)

"My husband went to see him every day and he brought the photos to me. I even can't see his face in all the photos because he has all the CPAP and tubes" (20)

Some women voiced the challenges of being a mother and forming a bond with their infant after the birth. One woman said:

“Being away from her, it's not an easy thing you know. You think you've got another two months to prepare before she comes hom and all of a sudden she's here and yet she's nowhere to be seen" (6) "It just didn't feel real. It was like I'd had her but It was like going to visit someone else's child in a way. I just didn't get that bond........ couldn't stop thinking about her, but I just felt that the connection wasn't there and that obviously made me even more the conn "6)

Some described how seeing, touching, holding and feeding their baby helped them cope with the separation and isolation from the baby, and be a mother. They said:

"They got to bring him up to me in HDU, so he came up twice which was really nice" (7)

"I insisted on breastfeeding so every three hours I got a visit which made me happy. I wasn't so isolated from her then" (8)

The few women who were discharged from hospital care while their baby remained in a nursery disclosed sadness, emptiness and worry. These women were upset sharing this part of their story, expressing the challenges that they faced as a new mother. Some examples include:

"It was really horrible. That was really, really hard. I knew it was going to be hard but I didn't think it would be that hard. I was very afraid that he wouldn't be OK left in the hospital which is strange because you think he was around all the nurses and doctors and everyone's looking after him, but I think I just felt very worried that I was leaving him behind" (7)

"I still felt short changed that I didn't get to take my baby home. My head knew why it couldn't happen, but I still wished it could" (16)

"I just feel so sorry for him; I have to leave him there" (20)

Women described several challenges they faced while trying to be a mother to their infant. These challenges were more evident in those who had a preterm baby or were physically separated.

Processing and accepting the situation

Processing and accepting the situation took time. Women needed time to appreciate the seriousness of the problem and the effect that hypertension had on their pregnancy and birth plans.

Despite the urgency of the situation, they needed time to process the information at the time of diagnosis. For example:

"Ok, just take a few steps back now and let me digest" (9)

"I can't process that, I don't want to know yet. And then $I$ remember thinking well what exactly does this mean?" (16) 
"When everything was normal you just go there [antenatal clinic] wait to see whoever will look after you. But after they found I had the hypertension and they put me on the medication, I think I got good continuous care from one or two person" (3)

"It was nice to have one familiar face who knew my story and my case in the Delivery Suite" (2)

Being cared for by someone they knew and trusted helped them feel more comfortable and supported:

"Labour wasn't that bad and I had one of the educators with me the whole time. No midwives swapped and changed on me or anything. So everything went really smoothly. I think I was pretty lucky" (5)

"She [the doctor] was there pretty much every day and I remember saying to her it was really lovely to see her everyday cause it was a familiar face consistently. She was obviously busy but she took time to explain and answer any questions. So that was good' (16)

Women enjoyed participating in the 'continuity of care experience, as part of the clinical experience of midwifery students. They said:

"I actually had a trainee midwife with me so that made it a lot easier actually. It was good" (5)

"I had a student midwife with me the whole time that I was there. She was a tremendous support. So, being with her, I didn't really have any concerns at all. I was a bit nervous about the whole birth experience but she made it a whole lot better than what it would have been otherwise" (14)

Women described how they felt well supported and their experience was improved though having continuity of care and carer.

Valuing social support from partner, family and friends

Support from partner, family and friends was important in helping them recover. Some women felt like they needed more support during the hospital stay and hospital rules were too restrictive to facilitate this. For example:

"I was talking a lot to friends and they were giving me a lot of support but it's so different over the phone or through text. You just want human contact. I know there's a period where no one's allowed to come into the hospital at night time with you, but I think that's when you do most of your thinking" (8)

"So the support that I had from those two [partner and mother] was just incredible. I couldn't have done it without them" (16)

Support was especially important for women with preterm babies in hospital. One woman said:

"I guess you could call it a traumatic experience in that it's not the norm, and it was fairly dramatic, but I don't feel like I've been left to flounder and a lot, a large part of this is because of the partner and mother I have. I'm very aware and very grateful for both of them" (16)

Having social support was a dominant theme. Women expressed that this support was necessary throughout the experience but was sometimes hampered by hospital rules.

\section{Discussion}

This study aimed to gain insight into women's experience of having $\mathrm{GH}$ or PE and report on mediating factors. The study provides a unique opportunity to understand the HDP experience from the woman's viewpoint, an area that currently lacks research. Such insights may help inform practice to improve the woman's experience and facilitate he coping strategies (Coster-Schulz and Mackey, 1998). In this study, the women described the challenges they faced when informed of the diagnosis, having the infant, being separated from their infant and 'moving on' from the experience. Feeling safe, having continuity of care and carer and support were identified as being important to the women.

Other studies have also shown that the separation of mother and nfant is challenging for women adapting to being a mother (Engstrom and Lindberg, 2011). These challenges may not be due to the $\mathrm{GH}$ or $\mathrm{PE}$ rather the physical separation, especially if the woman is in an ICU. Social support was reported as being important for the women by Enestrom and Lindherg (2011) which is in line with our study. Support from family members, friends, and health professionats is particularly from family mers Hodnett et al., 2010). 1 has also been reported as being important for the development of maternal-fetal attachment (Yarcheski et al.. 2009). In our study, it wa evident that strategies such as flexibility in hospital visiting hour would help with the support available from family and friends while continuity of care would improve support from care providers.

Midwifery continuity of care has long been identified as being beneficial for women throughout pregnancy and childbirth (Homee et al, 2002: Trucy et at, 2013; Smdall et al, 2016). Women who experience HDP require collaborative care from obstetric, medical an midwifery teams. Continuity of care from such a collaborative team is important and beneficial for women with a high risk pregnancy (Bradshaw et al.. 1995: Homer et al., 2002: Biro et al., 2003). Increased satisfaction with the birth experience has been reported by women with a complicated pregnancy who are cared for by a multidisciplinary team (Bradshaw et al., 1995; Biro et al., 2003), and women with a pregnancy risk also reported less worry in an earlier study (Homer et al., 2002). Women participating in our study described continuity of care as being heloful in improving their birth experience. Hence, care of women wit , through a multidisciplinary, collaborative, continuity of care model This model is realistically achievable in a tertiary obstetric referral service (Biro et al., 2003; Tracy et al., 2013).

Previous studies reporting on women's perspectives of their experience of a complicated pregnancy have focussed on the hospita admission and the postpartum period, usually only days or weeks. This study presents a comprehensive exploration of the woman's experience with $\mathrm{GH}$ or $\mathrm{PE}$ from diannosis to the first year after the bitth. Ou nalysis bas shown that women take time to realistically reflect on their experience and process what happened.

Our study has explored the birth experience for women who experienced $\mathrm{GH}$ or $\mathrm{PE}$. This is the first time such a specific study has been undertaken. All women interviewed for this study had thei pregnancy care at one hospital. This hospital has a multidisciplinary collaborative team whose focus is caring for women with HDP usin firm evidence based policies and practice. This continuity of care model may have positively influenced the women's experience in this study.

The limitations to this study include that all women who partici-

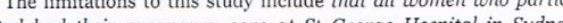
pated had their pregnancy care at St George Hospital in Sydney. Accordingly, the majority of women reported on their experience of the less severe forms of $\mathrm{GH}$ or $\mathrm{PE}$ from a diverse range of gestational ages.
All women in this study gave birth at greater than 30 weeks gestation. It is not clear whether women with earlier gestations would feel the same or if the experiences in other hospitals or other countries would be different.

\section{Conclusions}

Women have profound experiences after the diagnosis of $\mathrm{GH}$ or $\mathrm{PE}$ They face challenges from the time of diagnosis through to many months after the birth of their infant. Their pregnancy, birth and postnatal care influences their experience, how they cope with the situation, and their mothering pathways. The implications of the findings for midwifery practice include having access to appropriate multidisciplinary continuity models of care that includes care from known midwife and facilitating social support for these women. 
Most women accepted the situation as they felt that it was out of their control and they couldn't change things. They said:

"It just happened. Just deal with it........you can't do anything about it; you can't change what is going to happen" (2)

"It was a case of well if that's what it is, then that's what it is" (17)

Some expressed disappointment that the birth did not go as planned but they accepted that the plan had to change. They said:

"I wanted to have a water birth with no intervention, so I was a bit disappointed in that but you know, stuff happens, you can't really change it" (14)

"I didn't have a choice. That upset me more than anything, having the caesarean. At the same time, the baby's first so it was mor like, get her out, do whatever you have to do" (15)

Some women said they were busy focussing on what was going on caring for or visiting the infant and did not accept the seriousness until both were home. Their processing and acceptance came later. Fo example:

"You don't realise until you're well past that point, just how hard and stressful it was. You just get on with it at the time. That's just what you've got to do" (16)

"I don't think I dwelled on it too much. It was more like that happened and I have to push on with caring for a child and learning how to do that" (10)

Processing and acceptance sometimes occurred months later, for example:

"Afterwards when I think about it, I think gee, that was pretty scary and I was a lot sicker than I thought or wanted to admit to myself at the time. I don't like thinking about it too much because it still makes me feel anxious" (7)

"I didn't really deal with it till at least six months afterwards and that's when I really started to think about the birth and how it could have been better. So it was all about learning to let go" (8)

Processing and accepting the situation occurred at different times for different women, and took up to many months depending on the severity of the disorder and the situation.

'Moving on' from the experience

Moving on from the experience meant that women expressed relie and felt that everything was going to be all right. The time taken for women to reach this stage varied. Some 'moved on' when they felt the experience was over saying:

"I'm glad that she's finally here. You been waiting for months and months and then finally she's here and just not thinking about not having that fear any more that we're both at risk. I was really relieved about that" (4)

"I was so relieved and happy that we were both $O K$ that she was $O K$ and $I$ was $O K$ and everything was going to be $O K$. I just felt like everyone was going to be OK. I was so grateful that when she came out she was, as we said, underdone but perfect" (16)

Staying in hospital for longer than expected slowed down women's ability to 'move on'. Once they had given birth and felt well, they wanted to go home to start their lives with their infants. Most accepted that even though they felt well, they were still at risk. They said:

"I was feeling fine on the second day but they said they wanted to keep me there just to be on the safe side and I'm like, 'Oh OK then but I feel fine.' If I could have, I would have liked to come home bit earlier but they had to keep me in because of what happened" (9)

"I just wanted to come home, just bring him home and get out of the hospital and start our life with him' (2)

'Moving on' also meant thinking about the next pregnancy. Recognising that HDP could recur made some feel anxious. Others felt comfortable that a next pregnancy would be monitored closely and they would be more informed of signs to be aware of, so considered another pregnancy. For example:

"I just decide to have one baby. I'm not sure if another, next pregnancy, what's going on. I have to save my life for my daughter" (19)

"The doctor said I'll be closely monitored the second time around just in case it does happen again. So, hopefully......fingers crossed" (9)

"I know what to look for and I'm a bit more informed this time so that's $O K$. They said that I'd need to see a renal physician next time I get pregnant so I'll be a bit more prepared for it I guess. It hasn't put me off having another baby" (18)

A strong theme was that women were ready to 'move on' at different times following the birth. This was evident through their desire to leave the hospital and discussing a subsequent pregnancy. The motivation for 'moving on' was often that the birth was over and it was time for her to care for her infant.

\section{Mediating factors}

Throughout the interviews, women described mediating factors that helped them cope with the situation: Feeling safe and trusting the care providers, Having continuity of care and carer and Valuing support from family and friends.

Feeling safe and trusting the care providers

All women felt safe in hospital and felt it was the best place for them to be. For example:

"I'm all right in the hospital. Nothing to worry about because if I'm home alone and something happen, it's more worry. I be OK there with doctors and midwives. In the hospital I was just confident with the doctor and midwife" (19)

"When they told me about what's going to happen I think I'm in the "When they told me about what's going

"Then I need to stay in hospital because that's the safest place for me to be" (16)

Feeling informed about their progress and being included in decision making helped women feel safe. For example:

"They [midwives] put you at ease and they tell you each time they take your blood pressure how it's going" (10)

"They were always looking after me and letting me know each step of the way what was happening. I was really happy with that" (8)

Most women felt that the midwives and doctors were experts and they were 'in good hands'. They were less worried, anxious and concerned because they trusted these experts, saying:

"I found it a bit comforting knowing that I was in such a scary position and she [midwife] was very experienced in doing what she does so that's good to know" (12)

"You have to trust whoever's looking after you cause they will be the one who will help you at the end or if anything goes wrong" (3)

Women felt confident that they were safe after forming a relationship with staff, trusting them and viewing them as experts. Feeling informed also contributed to them feeling safe.

Having continuity of care and carer

Continuity of care and carer was important to the women as their carers knew them and their history. For example: 
This research did not receive any specific grant from funding agencies in the public, commercial, or not-for-profit sectors.

All authors declare that there are no actual or potential conflicts of interest.

\section{Acknowledgements}

The authors wish to gratefully acknowledge Nicki Watts who assisted with the first five interviews and proof read the final manuscript, and Christine Catling who proof read the final manuscript. A special acknowledgement goes to the women who shared their, sometimes emotional, story about their experience.

\section{References}

American College of Obstetricians and Gynecologists, 2013. Hypertension in Pregnancy. Washington, DC.

Aersgatard, A.B... Acharya, G., Mathicsen, E.B., Johnsen, S.rt., Straume, B., Oian, P.. pregnancy: a population-based study. American Journal of Ohsietrics \& Gyaecolog 206, 1+3., e1-8.

Anderson. C.M. 2007. Preeclampsia: exposing fiture cardiovascutar risk in mothers and their cisildren, Journal of Obsietric, Graecologic, \& Neonntal Nursing: Clinical fis, M, 2003. Do we need methodological theory to do qualitative restearch? Qualitative Health Research 13, 995-1004.

arlow, J., Hainsworth, J. Thiornton, S., 2008. Women's experience of hospitaissation Homy, Casas, J.1', Himporani

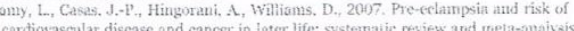
British Medical Jnurnat 335, 974.

.

13. 15.3-1.58.
Eiro. M., Waidenstrom, U.. Bromn. S.. Pannifex, J., 2003. Satisfactiun with team midwirery ure for low- and high-risk wonten: 2 rondomized controlled trial. Birth

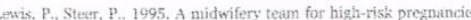
Modern Midwife 5, 26-29.

faum, V., Clarke, V., 2006. Using thematic analyyis in paychology. Quailtative Research

Brown., M. Bell, R. Collins, C., Waring, G., Robson, S, Waugh, J., Finch, T., 2013. Women's perspective of furure risk following pregnancies complicated by preeclampsta twpertension in pregnancy 32, 60-73.

Buslinell, C.. Chirenu, M... 2011. Preeclanipgsia snd stroke: risks during and after pregnancy. Stroke Research and Treatment 2011, 85813

Centre for Epidemiology and Evidence, 2016, New South Wales Mothers and Babies 2014, Sydney.

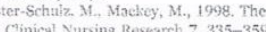

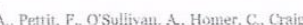

M., Harvyy, S., Brumn, M., 2016. Pustyartum physiolozy, poycholugu and paediatric follow up studly (P4 Study) - study protocol. Pregnancy Hyperetension: A

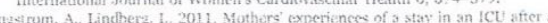
complicated drildtirth. Nursing in Critical Core 17, 64-71)

Furuta, M., Sandall, J., Bick, D., 2014. Women's perseptionsts and experiences of sever"

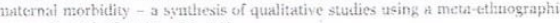

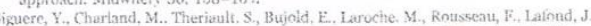

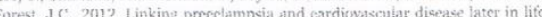

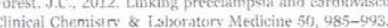

Hodneit, E., Fredericks, S., Weston, J., 2010. Stupsort during pregnancy for women at increased rick of luw birtiweight babies. Cochrame Datubase of Systentatic Revicws.

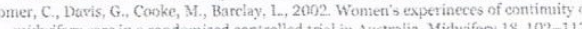

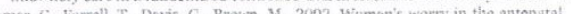
period. Britist Jomanal of Mintwifery $10,356-360$.

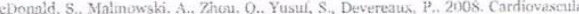

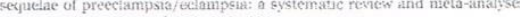
Anterican Heart Journal 156, 918-930.

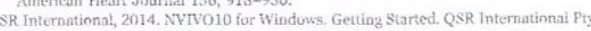
Lid. Lerts. J.M.. Gammill,
Lancet 366, 961-962.

Saldana. J., 2013. The Coding Monual for Qualitative Researchers 2 nd ein. SAGE

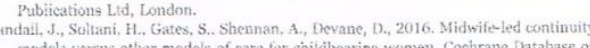

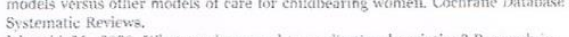

sondelaweli, it, 2000 . What

Sharp, D., Hazy, D., Pawiby. S., Schumucker. G., Allen, H., Kumar, R., 1995. The impact of postnatal depression on boys' inteliestual deveriopment. Journal of Child Psychotog

s.mkin. P. 1992 Jut another day in a woman's life? Part II: Nature and consistency of wometr's long-tern memories of their first birtil eperience. Birth 19. 64-81. teegers. E, von Dad

facy. S. Harth, D, Tracy, M. Kildea, S, Allen, Y., Forti, A., Hall. B., Lainclibury, A. stapteton, H, Beckmanth. M.. Bivits, A, Hotner, C.. Foureur, M., White, J., Weist. A.

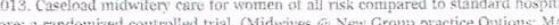
SCO trial) Lancet 382, 1723-1732.

Tranquilli, A., Dekker, G.. Mazee, L., Roberts, J., Sibai, B., Steyn. W. Zereman, G.. Brown, M., 2014. The classification, diagnissis snd managen:ent of the hypertensive fisorders of presnancy: a revised statement from the 1SSHP. Pregnaticy 97-104.

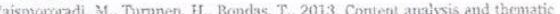
andysis: implications for conducting a qualitative desriptive study. Nursing an Health Sciences 15, 398-405.

Vincent, C., 2006. Patient Siftety. Churchinill Livingstone, New Ynsk.

teptrolosy

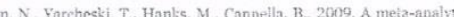
stutly of predictors
studies $46,708-715$. 


\section{REFERENCES}

AAPEC 2018, Australian Action on PreEClampsia, Oven Creative, viewed 5.09.2018, $<$ http://www.aapec.org.au/about-aapec/>.

Abedian, Z., Soltani, N., Mokhber, N. \& Esmaily, H. 2015, 'Depression and anxiety in pregnancy and postpartum in women with mild and severe preeclampsia', Iranian Journal of Nursing and Midwifery Research, vol. 20, no. 4, pp. 454-9.

ABS 2018, Australian Bureau of Statistics, Australian Government, viewed 4.08.18 2018, $<$ http://abs.gov.au/>.

ACM 2008, 'National Midwifery Guidelines for Consultation and Referral 2nd edition', Australian College of Midwives, Canberra.

Adler, A. 1945, 'Two different types of post-traumatic neurosis', American Journal of Psychiatry, vol. 102, pp. 237-40.

Al-Busaidi, Z. 2008, 'Qualitative Research and its Uses in Health Care', Sultan Qaboos University Medical Journal, vol. 8, no. 1, pp. 11-9.

Alcorn, K., O'Donovan, A., Patrick, J., Creedy, D. \& Devilly, G. 2010, 'A prospective longitudinal study of the prevalence of post-traumatic stress disorder resulting from childbirth events', Psychological Medicine, vol. 40, no. 1, pp. 1849-59.

Alcorn, K.L., O'Donovan, A., Patrick, J.C., Creedy, D. \& Devilly, G.J. 2010, 'A prospective longitudinal study of the prevalence of post-traumatic stress disorder resulting from childbirth events', Psychol Med, vol. 40, no. 11, pp. 1849-59.

Ali, S., Stone, M., Peters, J., Davies, M. \& Khunti, K. 2006, 'The prevalence of co-morbid depression in adults with type 2 diabetes: a systematic review and meta-analysis', Diabetes Medicine, vol. 23, pp. 1165-73.

Amaral, LM., Wallace, K., Owens, M., \& LaMarca, B. 2017, 'Pathophysiology and current clinical management of preeclampsia', Current Hypertension Reports, vol. 19, no. 8, pp. 61.

American College of Obstetricians and Gynecologists 2002, 'Diagnosis and management of preeclampsia and eclampsia', International Journal of Gynecology and Obstetrics, vol. 77, pp. 67-75.

American Psychiatric Association 1952, Diagnostic and Statistical Manual of Mental Disorders American Psychiatric Association, Washington, D.C.

American Psychiatric Association 1994, Diagnostic and statistical manual of mental health disorders 4th Edition, American Psychiatric Association, Washington, DC.

American Psychiatric Association 2013, Diagnostic and statistical manual of mental health disorders 5th Edition, American Psychiatric Association, Washington, DC.

Andersen, L., Melvaer, L., Videbech, P., Lamont, R. \& Joergensen, J. 2012, 'Risk factors for developing posttraumatic stress disorder following childbirth: a systematic review', Acta Obstetricia et Gynecologica Scandinavica, vol. 91, pp. 1261-72.

Andreasen, N. 2010, 'Posttrumatic stress disorder: A history and critique', Annals of the New York Academy of Sciences, vol. 1208, no. 1, pp. 67-71.

Andrews, I., Sullivan, G. \& Minichiello, V. 2004, The philosophical and theoretical context of qualitative research, Pearsons Education Sydney, Australia.

Annells, M. 2007, 'What's common with qualitative nursing research these days?', Journal of Clinical Nursing, vol. 16, no. 2, pp. 223-4.

Argyrous, G. 2005, Statistics for research with a guide to SPSS Second Edition, Sage Pubications, London, UK.

Austin, M.-P., Hadzi-Pavlovic, D., Priest, S., Reilly, N., Wilhelm, K., Siaint, K. \& Parker, G. 2010, 'Depressive and anxiety disorders in the postpartum period: how prevalent are they and can we improve their detection?', Archives of Women's Mental Health, vol. 13, pp. 395-401. 
Austin, M.-P., Highet, N. \& the Expert Advisory Committee 2017, Mental Health Care in the Perinatal Period: Australian Clinical Practice Guideline, Melbourne: Centre of Perinatal Excellence.

Austin, M.-P., Priest, S. \& Sullivan, E. 2008, 'Antenatal psychosocial assessment for reducing perinatal mental health morbidity', Cochrane Database of Systematic Reviews vol. 4, no. CD005124.

Austin, M., Fisher, J. \& Reilly, N. 2015, Psychosocial assessment and integrated perinatal care. In: Identifying Perinatal Depression and Anxiety: Evidence-based Practice in Screening, Psychosocial Assessment and Management, Wiley-ISTE, Chichester, West Sussex, UK

Austin, M., Hadzi-Pavlovic, D., Priest, S., Reilly, N., Wilhelm, K., Saint, K. \& Parker, G. 2010, 'Depressive and anxiety disorders in the postpartum period: how prevalent are they and can we improve their detection?', Archives of Womens Mental Health, vol. 13, pp. 395-401.

Australian Government Department of Health 2017, 'New requirements for mental health assessments (Items 16590, 16591, and 16407)', viewed 11.10.2018, $<$ http://www.mbsonline.gov.au/internet/mbsonline/publishing.nsf/Content/Obstetric sServices-FAQ>.

Australian Health Ministers Advisory Council 2008, 'Primary Maternity Services in Australia-A Framework for Implementation', $<$ www.ahmac.gov.au/cms documents/Primary\%20Maternity\%20Services\%20in\%20Au stralia.pdf $>$.

Australian Institute of Health and Welfare 2012, Experience of perinatal depression: data from the 2010 Australian National Infant Feeding Survey., AlHW, Canberra.

Australian Institute of Health and Welfare 2018, Australia's health 2018, Canberra.

Australian Institute of Health and Welfare 2018, National Core Maternity Indicators, viewed 25 May 2019 2019, <https://www.aihw.gov.au/reports/mothers-babies/ncmi-datavisualisations/contents/labour-and-birth-indicators/>.

Ayers, S. \& Pickering, A. 2011, 'Do women get posttraumatic stress disorder as a result of childbirth? A prospective study of incidence', Birth, vol. 28, pp. 111-8.

Baecke, M., Spaanderman, M.E. \& Van Der Werf, S.P. 2009, 'Cognitive function after preeclampsia: an explorative study', Journal of Psychosomatic Obstetrics \& Gynecology, vol. 30 , no. 1 , pp. 58-64.

Baker, P. \& Kingdom, C. 2004, Pre-eclampsia current perspectives on management, Parthenon, London.

Barbour, R. 2001, 'Checklists for improving rigour in qualitative research: a case of the tail wagging the dog?', British Medical Journal, vol. 322, pp. 1115-7.

Bartlett, C., Doyal, L., Ebrahim, S., Davey, P., Bachmann, M., Egger, M. \& Dieppe, P. 2005, 'The causes and effects of socio-demographic exclusions from clinical trials', Health Technology Assessment, vol. 9, no. 38, pp. iii-iv, ix-x, 1-152.

Bass, L. 1991, 'What do parents need when their infant is a patient in the NICU?', Journal of Neonatal Nursing, vol. 10, no. 4, pp. 25-33.

Beck, A., Epstein, N., Brown, G. \& Steer, R. 1988, 'An inventory for measuring clinical anxiety: psychometric properties', Journal of Consulting and Clinical Psychology, vol. 56, pp. 893-7.

Beck, A., Steer, R. \& Carbin, M. 1988, 'Psychometric properties of the Beck Depression Inventory: Twenty-five years of evaluation', Clinical Psychology Review, vol. 8, no. 1, pp. 77-100.

Beck, C. 2004, 'Birth trauma in the eye of the beholder', Nursing Research, vol. 53, no. 1, pp. 28-35.

Beck, C. 2006, 'Postpartum depression: it isn't just the blues', American Journal of Nursing, vol. 106, pp. 40-50. 
Beck, C.T. \& Barnes, D.L. 2006, 'Post-traumatic stress disorder in pregnancy', Annals of the American Psychotherapy Association, vol. 9, no. 2, pp. 5-9.

Bell, A. \& Andersson, E. 2016, 'The birth experience and women's postnatal depression: A systematic review', Midwifery, vol. 39, pp. 112-23.

Bell, M. 2010, 'A historical overview of preeclampsia-eclampsia', Journal of Obstetric, Gynecologic, and Neonatal Nursing, vol. 39, no. 5, pp. 510-8.

Bellamy, L., Casas, J., Hingorani, A. \& Williams, D. 2007, 'Pre-eclampsia and risk of cardiovascular disease and cancer in later life: systematic review and meta-analysis', British Medical Journal, vol. 335, no. 974.

Benagiano, G. \& Brosens, I. 2014, 'The multidisciplinary approach', Best Practice and Research Clinical Obstetrics and Gynaecology, vol. 28, pp. 1114-22.

Bener, A., Gerber, L. \& Sheikh, J. 2012, 'Prevalence of psychiatric disorders and associated risk factors in women during their postpartum period: A major public health problem and global comparison', International Journal of Womens Health, vol. 4, pp. 191-200.

Bennett, A. 1985, 'The birth of a first child: Do women's reports change over time?', Birth, vol. 13 , no. 3, pp. 153-8.

Berg, M. 2005, 'A midwifery model of care for childbearing women at high risk: Genuine caring in caring for the genuine', Journal of Perinatal Education, vol. 14, no. 1, pp. 9-21.

Beyond Blue 2019, What is mental health, Beyond Blue, viewed 24.07.2019 2019, <https://www.beyondblue.org.au/the-facts/what-is-mental-health>.

Bhui, K., Mohamud, S., Warfa, N., Craig, T. \& Stansfeld, S. 2003, 'Cultural adaptation of mental health measures: improving the quality of clinical practice and research.', British Journal of Psychiatry, vol. 183, pp. 184-6.

Biaggi, A., Conroy, S., Pawlby, S. \& Pariante, C. 2016, 'Identifying the women at risk of antenatal anxiety and depression: A systematic review', Journal of Affective Disorders, vol. 191, pp. 62-77.

Bialoskurski, M., Cox, C. \& Wiggins, R. 2002, 'The relationship between maternal needs and priorities in a neonatal intensive care environment', Journal of Advanced Nursing, vol. 27, no. 1, pp. 62-9.

Bicking Kinsey, D. \& Hupcey, J. 2013, 'State of the science of maternal-infant bonding: A principle-based concept analysis', Midwifery, vol. 29, no. 12, pp. 1314-20.

Bilszta, J., Tang, M., Meyer, D., Milgrom, J., Ericksen, J. \& Buist, A. 2008, 'Single motherhood versus poor partner relationship: outcomes for antenatal mental health', Australian and New Zealand Journal of Psychiatry, vol. 42, pp. 56-65.

Biro, M., Waldenstrom, U., Brown, S. \& Pannifex, J. 2003, 'Satisfaction with Team Midwifery care for low and high risk women: a randomized controlled trial', Birth, vol. 30, no. 1, pp. 1-10.

Blanchard, E. \& Hickling, E. 2004, After the Crash: Psychological Assessment and Treatment of Survivors of Motor Vehicle Accidents, Second Edition, American Psychological Association, Washington, D.C.

Bloch, M., Rubinow, D., Schmidt, P., Lotsikas, A., Chrousos, G. \& Cizza, G. 2005, 'Cortisol response to ovine corticotropin-releasing hormone in a model of pregnancy and parturition in euthymic women with and without a history of postpartum depression', Journal of Clinical Endocrinology and Metabolism, vol. 90, pp. 695-9.

Blom, E.A., Jansen, P.W., Verhulst, F.C., Hofman, A., Raat, H., Jaddoe, V.W., Coolman, M., Steegers, E.A. \& Tiemeier, H. 2010, 'Perinatal complications increase the risk of postpartum depression. The Generation R Study', British Journal of Obstetrics and Gynecology, vol. 117, no. 11, pp. 1390-8.

Bode, T. \& Lynch, K. 2018, 'Midwifery care for women with high risk pregnancies', Women and Birth, vol. 30, no. S1, pp. 1-47. 
Bohren, M., Hofmeyr, G., Sakala, C., Fukuzawa, R. \& Cuthbert, A. 2017, 'Continuous support for women during childbirth', Cochrane Database of Systematic Reviews, vol. 7, no. CD003766.

Boorman, R., Devilly, G., Gamble, J., Creedy, D. \& Fenwick, J. 2014, 'Childbirth and criteria for traumatic events', Midwifery, vol. 30, no. 2, pp. 255-61.

Borg-Cunen, N., McNeill, J., Murray, K. \& Borg Cunen, N. 2014, 'A systematic review of midwife-led interventions to address postpartum post-traumatic stress', Midwifery, vol. 30, no. 2, pp. 170-84.

Boulanger, L., Zhao, Y., Bao, Y. \& Russell, M., BMC Health Serv Res 2009;9:111. 2009, 'A retrospective study on the impact of comorbid depression or anxiety on healthcare resource use and costs among diabetic neuropathy patients', BMC Health Services Research., vol. 9, p. 111.

Bowen, A., Bowen, R., Butt, P. \& Rahman, K. 2012, 'Patterns of depression and treatment in pregnant and postpartum women', Canadian Journal of Psychiatry, vol. 57, no. 3, pp. 161-7.

Boyce, P., Stubbs, J. \& Todd, A. 1993, 'The Edinburgh Postnatal Depression Scale: Validation for an Australian Sample', Australian and New Zealand Journal of Psychiatry, vol. 27, pp. 472-6.

Braun, V. \& Clarke, V. 2006, 'Using thematic analysis in psychology', Qualitative Research Psychology, vol. 3, pp. 77-101.

Braun, V. \& Clarke, V. 2013, Successful Qualitative Research, Sage Publications Ltd, Londaon, UK.

Breslau, N., Peterson, E., Kessler, R. \& Schultz, L. 1999, 'Short screening scale for DSM-IV PTSD', American Journal of Psychiatry, vol. 156, pp. 908-11.

Brockington, I., Butterworth, R. \& Glangeaud-Freudenthal, N. 2016, 'An international position paper on mother-infant (perinatal) mental health, with guidelines for clinical practice ', Archives of women's mental health, vol. 20, no. 1, pp. 113-20.

Brown, M., Hague, W., Higgins, J., Lowe, S., McCowan, L., Oats, J., Peek, M., Rowan, J. \& Walters, B. 2000, 'The detection, investigation and management of hypertension in pregnancy: full consensus statement', Australian \& New Zealand Journal of Obstetrics and Gynaecology, vol. 40, no. 2, pp. 139-55.

Brown, M., Magee, L., Kenny, L., Ananth Karumanchi, S., McCarthy, F., Saito, S., Hall, D., Warren, S., Adoyi, G. \& Ishaku, S. 2018, 'The hypertensive disorders of pregnancy: ISSHP classification, diagnosis and management recommendations for international practice', Pregnancy Hypertension, vol. 72, no. 1, pp. 24-43.

Bruns, D. \& McCollum, J. 2002, 'Partnerships between mothers and professionals in the NICU: Caregiving, information exchange, and relationships', Neonatal Network, vol. 27, no. 7, pp. 15-23.

Brusse, I., Duvekot, J., Jongerling, J., Steegers, E. \& De Koning, I. 2008, 'Impaired maternal cognitive functioning after pregnancies complicated by severe pre-eclampsia: a pilot case-control study', Acta Obstetricia et Gynecologica vol. 87, pp. 408-12.

Buchbinder, A., Sibai, B., Caritis, S., Macpherson, C., Hauth, J., Lindheimer, M., Klebanoff, M., Vandorsten, P., Landon, M., Paul, R., Miodovnik, M., Meis, P. \& Thurnau, G. 2002, 'Adverse perinatal outcomes are significantly higher in severe gestational hypertension than in mild preeclampsia', American Journal of Obstetrics \& Gynecology, vol. 186, no. 1, pp. 66-71.

Buist, A. \& Bilsztra, J. 2006, The beyondblue national postnatal screening program, prevention and early intervention 2001-2005. Final report, vol. 1, beyondblue, Melbourne.

Burnard, P., Gill, P., Stewart, K., Treasure, E. \& Chadwick, B. 2008, 'Analysing and presenting qualitative data', British Dental Journal, vol. 204, no. 8, pp. 429-32. 
Burns, Fenwick, J., Schmied, V. \& Sheehan, A. 2012, 'Reflexivity in midwifery research: The insider/outsider debate', Midwifery vol. 28, pp. 52-60.

Burns, N. \& Grove, S. 2005, The Practice of Nursing Research. Conduct, Critique and Utilization. 5th Ed, WB Saunders, Philadelphia, US.

Callahan, J. \& Borja, S. 2008, 'Psychological outcomes and measurement of maternal posttraumatic stress disorder during the perinatal period', Journal of Perinatal \& Neonatal Nursing, vol. 22, no. 1, pp. 49-59.

Campbell-Jackson, L. \& Horse, A. 2014, 'The Psychological Impact of Stillbirth on Women: A Systematic Review ', Illness, Crisis and Loss, vol. 2, no. 3, pp. 237-56.

Centre for Epidemiology and Evidence 2018, New South Wales Mothers and Babies 2017, Sydney.

Chen, L., Wang, X., Ding, Q., Shan, N. \& Qi, H. 2019, 'Development of postpartum depression in pregnant women with preelampsia: A retrospective study', Biomed Research International, vol. 2019, pp. 1-7.

Chesley, L. 1978, Hypertensive disorders in pregnancy, Appleton-Century-Crofts, New York.

Cianfrani, T. 1960, A short history of obstetrics and gynecology, Thomas Books, Springfield, Illinois.

Cirulli, F., Berry, A. \& Alleva, E. 2003, 'Early disruption of the mother-infant relationship: Effects on brain plasticity and implications for psychopathology', Neuroscience and Behavioural Reviews, vol. 27, no. 1, pp. 73-82.

Clarke, A. 2006, 'Qualitative interviewing: Encountering ethical issues and challenges', Nurse Researcher, vol. 13, no. 4, pp. 19-29.

Cleveland, L. 2008, 'Parenting in the Neonatal Intensive Care Unit', Journal of Obstetric, Gynecologic, and Neonatal Nursing, vol. 37, pp. 666-91.

Closa-Monasterolo, R., Gispert-Llaurado, M., Canals, J., Luque, V., Zaragoza-Jordana, M., Koletzko, B., Grote, V., Weber, M., Gruszfeld, D., Szott, K., Verduci, E., ReDionigi, A., Hoyos, J., Brasselle, G. \& Escribano Subías, J. 2017, 'The effect of postpartum depression and current mental health problems of the mother on child behaviour at eight years', Maternal and Child Health Journal, vol. 21, no. 7, pp. 1563-72.

Coates, A., Schaefer, C. \& Alexander, J. 2004, 'Detection of postpartum depression and anxiety in a large health plan', The Journal of Behavioral Health Services and Research, vol. 31, no. 2, pp. 117-33.

Cook, K. \& Loomis, C. 2008, 'The Impact of Choice and Control on Women's Childbirth Experiences', Journal of Perinatal Education, vol. 21, no. 3, pp. 158-68.

Corbin, J. \& Strauss, A. 2014, Basics of Qualitative Research: Techniques and Procedures for Developing Grounded Theory. Fourth Edition, Sage Publications, California, USA.

Corlett, J. \& Twycross, A. 2006, 'Negotiation of parental roles within family centred care: A review of the literature', Journal of Clinical Nursing, vol. 15, pp. 1308-16.

Cowan, J., Redman, C. \& Walker, I. 2016, Understanding pre-eclampsia: a guide for parents and health professionals, Clearay Publishing, UK.

Cox, J., Chapman, G., Murray, D. \& Jones, P. 1996, 'Validation of the Edinburgh postnatal depression scale (EPDS) in non-postnatal women', Journal of Affective Disorders, vol. 39, pp. 185-9.

Cox, J.L., Holden, J. \& Sagovsky, R. 1987, 'Detection of postnatal depression. Development of the ten point Edinburgh Postnatal Depression Scale', British Journal of Psychiatry, vol. 150, pp. 782-6.

Creswell, J. 2013, Research Design. Qualitative, Quantitative and Mixed Methods Approaches (Fourth Ed.), SAGE Publications, Inc, California, USA.

Critical Appraisal Skills Programme 2010, 'Critical Appraisal Skills Programme: making sense of evidence', Ontario, Canada, <http//:www.casp-uk.net/>. 
Cuijpers, P., Beekman, A. \& Reynolds, C. 2012, 'Preventing depression. A global priority', Journal of American Medical Association, vol. 307, pp. 1033-4.

Cuijpers, P., Berking , M., Andersson, G., Quigley, L., Kleiboer, A. \& Dobson, K. 2012, 'A MetaAnalysis of Cognitive-Behavioural Therapy for Adult Depression, Alone and in Comparison With Other Treatments', Canadian Journal of Psychiatry, vol. 58, no. 7, pp. 376-85.

Cutcliffe, J. \& McKenna, H. 2002, 'When do we know that we know? Considering the truth of research findings and the craft of qualitative research', International Journal of Nursing Studies, vol. 39, pp. 611-8.

Cypress, B. 2015, 'Qualitative research. The "What", "Why", "Who" and "How', Dimensions of Critical Care Nursing, vol. 34, no. 6, pp. 356-61.

Daly, J., Willis, K., Small, R., Green, J., Welch, N., Kealy, M. \& Hughes, E. 2007, 'A hierarchy of evidence for assessing qualitative health research', Journal of Clinical Epidermiology, vol. 60, no. 1, pp. 43-9.

Daly, R. 1983, 'Samuel Pepys and Post-Traumatic Stress Disorder', British Journal of Psychiatry, vol. 143, pp. 64-8.

Davies, J., Slade, P., Wright, I. \& Stewart, P. 2008, 'Posttraumatic stress symptoms following childbirth and mother's perceptions of their infants', Infant Mental Health Journal, vol. 29, no. 6, pp. 537-54.

Davis, G., Roberts, L., Mangos, G., Henry, A., Pettit, F., O'Sullivan, A., Homer, C., Craig, M., Harvey, S. \& Brown, M. 2016, 'Postpartum physiology, psychology and paediatric follow up study (P4 Study) - Study protocol', Pregnancy Hypertension: An International Journal of Women's Cardiovascular Health, vol. 6, no. 4, pp. 374-9.

De Schepper, S., Vercauteren, T., Tersago, J., Jacquemyn, Y., Raes, F. \& Franck, E. 2015, 'Posttraumatic stress disorder after childbirtth and the influence of maternity team care during labour and birth: A cohort study', Midwifery, vol. 32, pp. 87-92.

Delahaije, D., Dirksen, C., Peeters, L. \& Smits, L. 2013, 'Anxiety and depression following preeclmpsia or hemolysis, elevated liver enzymes, and low platelets syndrome. A sytematic review.', Acta Obstetricia et Gynecologica Scandinavica, vol. 92, pp. 746-61.

Demetriou, C., Uzun Ozer, B. \& Essau, C. 2015, Self-Report Questionnaires. In The Encyclopedia of Clinical Psychology, First Edition, JohnWiley \& Sons, Inc., New Jersey, US.

Denis, A., Michaux, P. \& Callahan, S. 2012, 'Factors implicated in moderating the risk for depression and anxiety in high risk pregnancy', Journal of Reproductive and Infant Psychology, vol. 30, no. 2, pp. 124-34.

Dennis, C. \& Dowswell, T. 2013, 'Psychosocial and psychological interventions for preventing postpartum depression ', Cochrane Systematic Review, vol. 28, no. CD001134.

DiCicco-Bloom, B. \& Crabtree, B. 2006, 'The qualitative research interview', Medical Education, vol. 40, pp. 314-21.

Dikmen-Yildiz, P., Ayers, S. \& Phillips, L. 2018, 'Longitudinal trajectories of post-traumatic stress disorder (PTSD) after birth and associated risk factors', Journal of Affective Disorders, vol. 229, pp. 377-85.

DoHA 2009, 'Improving Maternity Services in Australia: The Report of the Maternity Services Review', Australian Government Department of Health and Aging, Canberra, $<$ www.tinyurl.com/c9zxad $>$.

Doorenbos, A. 2014, 'Mixed methods in nursing research: An overview and practical examples', National Institute of Health Public Access, vol. 47, no. 3, pp. 207-17.

Downe, S., Finlayson, K., Oladapo, O., Bonet, M. \& Gülmezoglu, A. 2018, 'What matters to women during childbirth: A systematic qualitative review', Public Library of Science, vol. 134, no. 4.

Dudovskiy, J. 2018, The Ultimate Guide to Writing a Dissertation in Business Studies: A Step-byStep Assistance, research-methodology.net e-book. 
Duetsche Gesellschaft fur Gynakologie und Geburtshilfe (DGGG) 2007, 'Diagnostik und Therapie hypertensiver Schwangerschaftserkrankungen Leitinien Empfehlungen, Stellungnahmen', Association of the Scientific Medical Societies in Germany, pp. 1-36.

Duffy, J., Thompson, T., Hinton, L., Salinas, M., McManus, R. \& Ziebland, S. 2019, 'What outcomes should researchers select, collect and report in pre-eclampsia research? A qualitative study exploring the views of women with lived experience of preeclampsia', British Jouranl of Obstetrics and Gynaecology, vol. 126, no. 5, pp. 637-46.

Elsenbruch, S., Benson, S., Rucke, M., Rose, R., Dudenhausen, J., Pincus-Knackstedt, M. \& Klapp, P. 2007, 'Social support during pregnancy: Effects on maternal depressive symptoms, smoking and pregnancy outcome', Human Reproduction, vol. 22, no. 3, pp. 869-77.

Emmanuel, J., Simmonds, S. \& Tyrer, P. 1998, 'Systematic review of the outcome of anxiety and depressive disorders', British Journal of Psychiarty, vol. 173, no. 34, pp. 35-41.

Engelhard, I., Van Den Hout, M. \& Arntz, A. 2001, 'Posttraumatic stress disorder after pregnancy loss', General Hospital Psychiatry, vol. 23, pp. 62-6.

Engelhard, I., van Rij, M., Boullart, I., Ekhart, T., Spaanderman, M., van den Hout, M. \& Peeters, L. 2002, 'Posttraumatic stress disorder after pre-eclampsia: an exploratory study', General Hospital Psychiatry, vol. 24, no. 4, pp. 260-4.

Fairbrother, N., Young, A., Zhang, A., Janssen, P. \& Antony, M. 2016, 'The prevalence and incidence of perinatal anxiety disorders among women experiencing a medically complicated pregnancy', Archives of Womens Mental Health, vol. 20, pp. 311-9.

Fenwick, J, Butt, J., Dhaliwal, S., Hauck, S. \& Schmied, V. 2010, 'Western Australian women's perceptions of the style and quality of midwifery postnatal care in hosptial and at home', Women and Birth, vol. 23, pp. 10-21.

Fenwick, J., Barclay, L. \& Schmied, V. 2001, 'Struggling to Mother: A Consequence of Inhibitive Nursing Interactions in the Neonatal Nursery', Journal of Perinatal and Neonatal Nursing, vol. 15, no. 2, pp. 49--64.

Fenwick, J., Gamble, J., Creedy, D., Barclay, L., Buist, A. \& Ryding, A. 2013, 'Women's perceptions of emotional support following childbirth: A qualitative investigation', Midwifery, vol. 29, no. 3, pp. 217-24.

Fenwick, J., Toohill, J., Slavin, V., Creedy, D. \& Gamble, J. 2018, 'Improving psychotherapy for women fearful of childbirth: Evaluation of a research translation project', Women and Birth, vol. 31, pp. 1-9.

Field, T., Beeson, E. \& Jones, L. 2015, 'The New ABCs: A Practitioner's Guide to NeuroscienceInformed Cognitive-Behavior Therapy', Journal of Mental Health Counseling, vol. 37, no. 3, pp. 206-20.

Field, T., Diego, M., Hernandez-Reif, M., Figueiredo, B., Deeds, O., Ascencio, A., Schanberg, S. \& Kuhn, C. 2010, 'Comorbid depression and anxiety effects on pregnancy and neonatal outcome', Infant Behaviour and Development vol. 33, no. 1, pp. 23-9.

Fields, J., Garovic. V, Mielke, M., Kantarci, K., Jayachandran, M., White, W., Butts, A., GraffRadford, J., Lahr, B., Bailey, K. \& Miller, V. 2017, 'Preeclampsia and cognitive impairment later in life', American Journal of Obstetrics \& Gynecology, vol. 217, no. 74, pp. e1-11.

Figueiredo, B., Costa, R., Pacheco, A. \& Pais, A. 2009, 'Mother to infant emotional involvement at birth', Maternal and Child Health Journal, vol. 13, no. 4, pp. 539-49.

Flick, U., von Kardorff, E. \& Steinke, I. 2004, A companion to qualitative research, Sage Publications, London.

Foa, E. 1995, 'Posttraumatic Stress Diagnostic Scale Manual', PsychCorp Pearson Clinical Assessment, USA. 
Foa, E., Cashman, L., Jaycox, L. \& Perry, K. 1997, 'The validation of a self-report measure of posttraumatic stress disorder: the Posttraumatic Diagnostic Scale', Psychological Assessment, vol. 9, no. 4, pp. 44-5451.

Foa, E., McLean, C., Zang, Y., Zhong, J., Powers, M., Kauffman, B., Rauch, S., Porter, K. \& Knowles, K. 2016, 'Psychometric properties of the Posttraumatic Diagnostic Scale for DSM-5 (PDS-5)', Psychological Assessment, vol. 28, no. 10, pp. 1166-71.

Foa, E., Riggs D, Dancu C \& Rothbaum B 1993, 'Reliability and validity of a brief istrument for assessing posttraumatic stress disorder.', Journal of Trauma Stress, vol. 6, no. 4, pp. 459-73.

Foddy, W. 1993, Constructing Questions for Interviews and Questionnaires, Cambridge University Press, Cambridge.

Forster, D., McLachlan, H., Davey, M., Biro, M., Farrell, T., Gold, L., Flood, M., Shafiei, T. \& Waldenström, U. 2016, 'Continuity of care by a primary midwife (caseload midwifery) increases women's satisfaction with antenatal, intrapartum and postpartum care: results from the COSMOS randomised controlled trial', BMC Pregnancy and Childbirth, vol. 16, no. 1, p. 28.

Furuta, M., Sandall, J. \& Bick, D. 2012, 'A systematic review of the relationship between severe maternal morbidity and post-traumatic stress disorder', BMC Pregnancy \& Childbirth, vol. 12, p. 125.

Gamble, D., Brikinns, B., Myint, P. \& Bhattacharya, S. 2019, 'Hypertensive Disorders of Pregnancy and Subsequent Cardiovascular Disease: Current National and International Guidelines and the Need for Future Research ', Frontiers of Cardiovascular Medicine, vol. 17 May 2019.

Gamble, J. \& Creedy, D. 2007, 'A counselling model for postpartum women after distressing birth eperiences', Midwifery, vol. 25, pp. e21-e30.

Gaugler-Senden, I., Duivenvoorden, H., Filius, A., De Groot, C., Steegers, E. \& Passchier, J. 2012, 'Maternal psychological outcome after early onset preeclampsia and preterm birth', The Journal of Maternal-Fetal and Neonatal Medicine, vol. 25, no. 3, pp. 272-6.

Gavin, N., Gayne, S., Lohr, K., Meltzer-Brody, S., Gartlehner, G. \& Swinson, T. 2005, 'Perinatal depression: a systematic review of prevalence and incidence', Obstetrics \& Gynecology, vol. 106, pp. 1071-83.

Giallo, R., Cooklin, A. \& Nicholson, J. 2014, 'Risk factors associated with trajectories of mothers' depressive symptoms across the early parenting period: an Australian populationbased longitudinal study', Archives of Womens Mental Health, vol. 17, no. 2, pp. 11525.

Giallo, R., Pilkington, P., McDonald, E., Gartland, D., Woolhouse, H. \& Brown, S. 2017, 'Physical, sexual and social health factors associated with the trajectories of maternal depressive symptoms from pregnancy to 4 years postpartum', Social Psychiatry and Psychiatric Epidemiology, vol. 52, no. 7, pp. 815-28.

Gibbins, J. \& Thomson, A. 2001, 'Women's expectations and experiences of childbirth', Midwifery, vol. 17, no. 4, pp. 302-13.

Gillon, T., Pels, A., von Dadelszen, P., MacDonell, K. \& Magee, L. 2014, 'Hypertensive disorders of pregnancy: a systematic review of international clinical practice guidelines', PLoS One, vol. 9, no. 12, p. e113715.

Glazier, R., Algar, F., Goel, V. \& Holzapfel, S. 2004, 'Stress, social support and emotional distress in a community of pregnant women', Journal of Psychosomatic Obstetrics and Gynecology, vol. 25, pp. 247-55.

Gold, K., Leon, I., Boggs, M. \& Sen, A., . 2015, 'Depression and Posttraumatic Stress Symptoms After Perinatal Loss in a Population-Based Sample', Journal of Women's Health, vol. 25, no. 3, pp. 263-9. 
Gonzalez, K. \& Yukihiro, D. 2013, 'Multidisciplinary team strives to improve care of high risk patients using a proactive collaborative approach', Journal of Obstetric, Gynecologic and Neonatal Nursing, vol. 42, no. 1, p. S27.

Greenhaigh, T., Annandale, E., Ashcroft, R., Barlow, J., Black, N, \& Bleakley, A. 2016, 'An open letter to The BMJ editors on qualitative research', British Medical Journal, vol. 563, p. i563.

Griffith, T. 1990, 'Nurse barriers to parenting in the special care nursery', Journal of Prenatal and Neonatal Nursing, vol. 4, no. 2, pp. 56-67.

Guamaccia, P. 1991, 'The role of culture on psychiatric epidemiology: an examination of research on Latin American mental health', Sante Mentale au Quebec, vol. 16, no. 1, pp. 27-43.

Guedeney, N., Fermanian, J., Guelfi, J. \& Kumar, R. 2000, 'The Edinburgh Postnatal Depression Scale (EPDS) and the detection of major depressive disorders in early postpartum: some concerns about false negatives', Journal of Affect Disorders, vol. 61, pp. 107-12.

Habli, M., Eftekhari, N., Wiebracht, E., Bombrys, A., Khabbaz, M., How, H. \& Sibai, B. 2009, 'Long-term maternal and subsequent pregnancy outcomes 5 years after hemolysis, elevated liver enzymes, and low platelets (HELLP) syndrome', American Journal of Obstetrics \& Gynecology, vol. 201, no. 4, pp. 385.e1-5.

Hairston, I., Handelzalts, J., Assis, C. \& Kovo, M. 2018, 'Postpartum bonding difficulties and adult attachment styles: The mediating role of postpartum depression and childbirthrelated PTSD', Infant Mental Health Journal, vol. 39, no. 2, pp. 98-208.

Hamburg, D., Artz, C. \& Reiss, E. 1953, 'Clinical importance of emotional problems in the care of patients with burns', New England Journal of Medicine, vol. 248, pp. 355-9.

Han, S. \& Shavitt, S. 1994, 'Persuasion and culture: Advertising appeals in individualistic and collective societies', Journal of Experimental Social Psychology, vol. 30, pp. 326-50.

Hardin, A. \& Buckner, E. 2004, 'Characteristics of a positive experience for women who have unmedicated childbirth', Journal of Perinatal Education, vol. 13, no. 4, pp. 10-6.

Harrell, F. 2001, Regression Modeling Strategies, Springer, New York.

Harris, B., Huckle, P., Thomas, R., Johns, S. \& Fung, H. 1989, 'The use of rating scales to identify post-natal depression', British Journal of Psychiatry, vol. 154, no. 6, pp. 813-7.

Harris, R. \& Ayers, S. 2012, 'What makes labour and birth traumatic? A survey of intrapartum 'hotspots", Psychology and Health, vol. 27, no. 10, pp. 1166-77.

Harrison, M., Eastlick Kushner, K., Benzies, K., Rempel, G. \& Kimak, C. 2003, 'Women's Satisfaction with Their Involvement in Health Care Decisions During a High-Risk Pregnancy', Birth vol. 30, no. 2, pp. 109-15.

Hauck, Y., Fenwick, J., Downie, J. \& Butt, J. 2007, 'The influence of childbirth expectations on Western Australian women's perceptions of their birth experience', Midwifery, vol. 23, pp. 235-47.

Hauck, Y., Kelly, G., Dragovic, M., Butt, J., Whittaker, P. \& Badcock, J. 2015, 'Australian midwives knowledge, attitude and perceived learning needs around perinatal mental health', Midwifery, vol. 31, no. 1, pp. 247-55.

Heal, R., \& Forbes, D. 2013, ' Understanding triangulation in research', Evidence Based Nursing, vol 16, no. 4, pp. 98.

Health System Planning and Investment Branch 2017, Guide to the Role Delineation of Clinical Services Second edn, NSW Ministry of Health.

Heatley, M. \& Kruske, S. 2011, 'Defining collaboration in Australian maternity care', Women and Birth, vol. 24, pp. 53-7.

Herman, J., Wilson, M. \& Wilhelm, P. 2005, 'Mothers in the NIC: Outsiders to partners', Pediatric Nursing, vol. 31, no. 3, pp. 176-200.

Hibbard, B. 1988, Principles of obstetrics, Butterworths, Boston, Massachusetts. 
Hoedjes, M., Berks, D., Vogel, I., Franx, A., Bangma, M., Darlington, A., Visser, W., Duvekot, J.J., Habbema, J., Steegers, E. \& Raat, H. 2011, 'Postpartum depression after mild and severe preeclampsia', Journal of Women's Health, vol. 20, no. 10, pp. 1535-42.

Hoedjes, M., Berks, D., Vogel, I., Franx, A., Visser, W., Duvekot, J., Habbema, J., Steegers, E. \& Raat, H. 2011, 'Symptoms of post-traumatic stress after preeclampsia', Journal of Psychosomatic Obstetrics and Gynecology, vol. 32, no. 3, pp. 126-34.

Holditch-Davis, D., Bartlett, T., Blickman, A. \& Miles, M. 2003, 'Posttraumatic stress symptoms in mothers of premature infants', Journal of Obstetric, Gynecologic and Neonatal Nursing, vol. 32, pp. 161-71.

Holloway, I. \& Todres, L. 2005, 'The status of method: flexibility, consistency and coherence', Qualitative Research, vol. 3, pp. 345-57.

Homer, C., Farrell, T., Davis, G. \& Brown, M. 2002, 'Women's worry in the antenatal period', British Journal of Midwifery, vol. 10, no. 6, pp. 356-60.

Horowitz, M., Wilner, N. \& Alvare, W. 1979, 'Impact of Event Scale: A Measure of Subjective Stress', Psychosomatic Medicine vol. 41, no. 3, pp. 209-18.

House, J. 1981, Work Stress and Social Support, Addison-Wesley, Reading, USA.

Hovens, J., van der Ploeg, H., Bramsen I, Klaarenbeek, M., Schreuder, N. \& Rivero, V. 1994, 'The development of the Self-Rating Inventory for Posttraumatic Stress Disorder', Acta Psychiatr Scand, vol. 90, no. 3, pp. 172-83.

Howard, L., Molyneaux, E., Dennis, C., Rochat, T., Stein, A. \& Milgrom, J. 2014, 'Non-psychotic mental disorders in the perinatal period', Lancet, vol. 384, pp. 1775-88.

Hurst, I. 2001, 'Mothers strategies to meet their needs in the NICU', Journal of Perinatal \& Neonatal Nursing, vol. 15, no. 2, pp. 65-82.

Jackson, K., Ternestedt, B. \& Schollin, J. 2003, 'From alienation to familiarity: Experiences of mothers and fathers of preterm infants', Journal of Advanced Nursing, vol. 43, no. 2, pp. 120-9.

Jenkins, M., Ford, J., Morris, J. \& Roberts, C. 2014, 'Women's expectations and experiences of maternity care in NSW - what women highlight as important', Women and Birth, vol. 27 , no. 3, pp. 214-9.

Johns, R. 1843, 'Observations of puerperal convulsions', Dublin Journal of Medical Science, vol. 24, no. 1, pp. 101-15.

Johnson, K. 2013, 'Maternal-Infant Bonding: A Review of Literature', International Journal of Childbirth Education, vol. 28, no. 3, pp. 17-22.

Johnstone, S., Boyce, P., Hickey, A., Morris-Yatees, A. \& Harris, M. 2001, 'Obstetric risk factors for postnatal depression in urban and rural community samples', Australian and New Zealand Journal of Psychiatry, vol. 35, no. 1, pp. 69-74.

Jones, S., Carley, S. \& Harrison, M. 2004, 'An introduction to power and sample size estimation', Emergency Medicine Journal, vol. 20, no. 5, pp. 453-8.

Jootun, D., McGhee, G. \& Marland, G. 2009, 'Reflexivity: promoting rigour in qualitative research', Nursing Standard, vol. 23, no. 23, pp. 42-6.

Jordan, S., Watkins, A., Storey, M., Allen, S., Brooks, C., Garaiova, I., Heaven, M., Jones, R., Plummer, S., Russell, I., Thornton, C. \& Morgan, G. 2013, 'Volunteer bias in recruitment, retention, and blood sample donation in a randomised controlled trial involving mothers and their children at six months and two years: a longitudinal analysis', PLoS One, vol. 8, no. 7, p. e67912.

Karlstrom, A., Nystedt, A. \& Hildingsson, I. 2015, 'The meaning of a very positive birth experience: Focus groups discussions with women', BMC Pregnancy \& Childbirth, vol. 15, no. 251, pp. 1-9.

Keeble, C., Law, G., Barber, S. \& Baxter, P. 2015, 'Choosing a Method to Reduce Selection Bias: A Tool for Researchers', Open Journal of Epidemiology, vol. 5, pp. 155-62. 
Kim, C., Brawarsky, P., Jackson, R., Fuentes-Afflick, E. \& Haas, J. 2005, 'Changes in health status experienced by women with gestational diabetes and pregnancy induced hypertension', Journal of Women's Health, vol. 14, no. 8, pp. 729-36.

Kingdon, C. 2005, 'Reflexivity: Not just a qualitative methodological research tool', British Journal of Midwifery, vol. 13, no. 1, pp. 622-7.

Kleinbaum, D. \& Klein, M. 2010, Logistic Regression. A self learning text, Springer New York. Kroenke, K., Spintzer, R., Williams, J., Monahan, P. \& Lo, B. 2007, 'Anxiety disorders in primary care: prevalence, impairment, comorbidity, and detection', Annals of Internal Medicine, vol. 146, no. 5, pp. 317-25.

Kroenke, K., Spitzer, R. \& Williams, W. 2001, 'The PHQ-9; Validity of a brief depression severity measure', Journal of General Internal Medicine vol. 16, pp. 606-16.

Lambert, C., Jomeen, J. \& McSherry, W. 2010, 'Reflexivity: A review of the literature in the context of midwifery research', British Journal of Midwifery, vol. 18, no. 5, pp. 321-6.

Latham, G. 2006, Work motivation: History, theory, research and practice, Sage Publications, Thousand Oaks, California.

Leslie, H. \& McAllister, M. 2002, 'The Benefits of Being a Nurse in Critical Social Research Practice', Qualitative Health Research, vol. 12, no. 5, pp. 700-12.

Lewis, L., Hauck, Y., Ronchi, F., Crichton, C. \& Waller, L. 2016, 'Gaining insight into how women conceptualize satisfaction: Western Australian women's perception of their maternity care experinces', BMC Pregnancy and Childbirth, vol. 16, no. 29, pp. 1-9.

Li, Z., Li, Y., Chen, L., Chen, P. \& Hu, Y. 2015, 'Prevalence of Depression in Patients With Hypertension: A Systematic Review and Meta-Analysis', Medicine (Baltimore), vol. 94, no. 31, p. e1317.

Likert, R. 1932, 'A technique for the measurement of attitudes', Archives of Psychology, vol. 22, no. 140 , p. 55.

Long, T. \& Johnson, M. 2000, 'Rigour, reliability and validity in qualitative research', Clinical Effectiveness in Nursing, vol. 4, pp. 30-7.

Lowdermilk, D., Perry, S. \& Cashion, M. 2010, Maternity Nursing 8th Edition, Mosby, Elsevier, United States of America.

Lowe, B., Decker, O., Muller, S., Brahler, E., Schellberg, D., Herzog, W. \& Yorck, P. 2008, 'Validation and standardization of the generalized Anxiety Disorder Screener (GAD-7) in the general population', Medical Care, vol. 46, no. 3, pp. 266-74.

Lowe, S., Bowyer, L., Lust, K., McMahon, L., Morton, M., North, R., Paech, M. \& Said, J. 2015, 'The SOMANZ Guidelines for the Management of Hypertensive Disorders of Pregnancy 2014', Australian and New Zealand Journal of Obstetrics and Gynaecology, vol. 55, no. 1, pp. 11-6.

Lupton, D. \& Fenwick, J. 2001, 'They've forgotten that I'm the mum': constructing and practising motherhood in special care nurseries', Social Science and Medicine, vol. 53, pp. 1011-21.

Marshall, C. \& Rossman, G. 2006, Designing Qualitative Research, Sage, California, US.

Martini, J., Petzoldt, J., Einsle, F., Beesdo-Baum, K., Höfler, M. \& Wittchen, H. 2015, 'Risk factors and course patterns of anxiety and depressive disorders during pregnancy and after delivery: A prospective-longitudinal study', Journal of Affective Disorders, vol. 175, pp. 385-95.

Maternity Care Enhancement Project 2004, 'Supporting Local Collaborative Models for Sustainable Maternity Care in British Columbia', Ministry of Health Services, British Columbia, $<$ www.health.gov.bc.ca/library/publications/year/2004/mcep recommend dec2004.p $\underline{d f>}$. 
Matthey, S., Barnett, B., Howie, P. \& Kavanagh, D. 2003, 'Diagnosing postpartum depression in mothers and fathers: whatever happened to anxiety?', Journal of Affect Disorders, vol. 74, pp. 139-47.

Mautner, E., Greimel, E., Trutnovsky, G., Daghofer, F., Egger, J. \& Lang, U. 2009, 'Quality of life outcomes in pregnancy and postpartum complicated by hypertensive disorders, gestational diabetes, and preterm birth', Journal of Psychosomatic Obstetrics and Gynecology, vol. 30, no. 4, pp. 231-7.

Mautner, E., Stern, C., Deutsch, M., Nagele, E., Greimel, E., Lang, U. \& Cervar-Zivkovic, M. 2013, 'The impact of resilience on psychological outcomes in women after preeclampsia: an observational study', Health and Quality of Life Outomes, vol. 11, no. 194, pp. 1-6.

McCarthy, S. 2008, 'Post-Traumatic Stress Diagnostic Scale (PDS)', Occupational Medicine, vol. 58, p. 379.

McDonald, S., Malinowski, A., Zhou, Q., Yusuf, S. \& Devereaux, P. 2008, 'Cardiovascular sequelae of preeclampsia/eclampsia: a systematic review and meta-analyses.', American Heart Journal, vol. 56, pp. 918-30.

McGhee, G., Marland, G. \& Atkinson, A. 2007, 'Grounded theory research: Literature reviewing and reflexivity', Journal of Advnaced Nursing, vol. 60, no. 3, pp. 334-42.

McKenzie-McHarg, K., Ayers, S., Ford, E., Horsch, A., Jomeen, J., Sawyer, A., Stramrood, C., Thomson, G. \& Slade, P. 2015, 'Posttraumatic stress disorder following childbirth: an update of current issues and recommendations for future research', Journal of Reproductive and Infant Psychology, vol. 33, no. 3, pp. 219-37.

McKenzie, S. \& Carter, K. 2013, 'Does transition into parenthood lead to changes in mental health? Findings from three waves of a population based panel study', Journal of Epidemiology and Community Health, vol. 37, pp. 339-45.

McLeod, S. 2008, Likert Scale, viewed 3.03.2018 2018, <www.simplypsychology.org/likertscale.html>.

Miller, R., Pallant, J. \& Negri, L. 2006, ' Anxiety and stress in the postpartum: is there more to postpartum distress than depression?', BMC Psychiatry, vol. 6, no. 12.

Mommersteeg, P., Drost, J., Ottervanger, J. \& Maas, A. 2016, 'Long-term followup of psychosocial distress after early onset preeclampsia: the Preeclampsia Risk EValuation in FEMales cohort study', Journal of Psychosomatic Obstetrics \& Gynecology, vol. 37, no. 3, pp. 101-9.

Murray, D. \& Cox, J. 1990, 'Screening for depression during pregnancy with the Edinburgh Postnatal Depression Scale", Journal of Reproductive and Infant Psychology, vol. 8, pp. 99-107.

Murray, L. \& Caruthers, A. 1990, 'The validation of the Edinburgh Postnatal Depression Scale on a community sample', British Journal of Psychiatry, vol. 157, pp. 288-90.

Murray, L., Halligan, S. \& Cooper, P. 2010, Effects of Postnatal Depression on Mother-Infant Interactions and Child Development, Blackwell Publishing Ltd, Oxford, United Kingdom.

Muzik, M., London Bocknek, E., Broderick, A., Richardson, P., Rosenblum, K., Thelen, K. \& Seng, J. 2013, 'Mother-infant bonding impairment across the first six months postpartum: The primacy of psychopathology in women with childhood abuse and neglect histories', Archives of Womens Mental Health, vol. 16, no. 1, pp. 29-38.

National Health and Medical Research Council 2010, National Guidance on Collaborative Maternity Care, National Health and Medical Research Council, Canberra.

National Health Service 2014, Five year forward view, NHS, England.

National High Blood Pressure Education Program Working Group 2000, 'Report of the National High Blood Pressure Education Program Working Group on high blood pressure in pregnancy', American Journal of Obstetrics and Gynecology, vol. 183, no. 1, pp. S1-S22. 
Negron, R., Martin, A., Almog, M., Balbierz, A. \& Howell, E. 2013, 'Social Support During the Postpartum Period: Mothers' Views on Needs, Expectations, and Mobilization of Support', Maternal and Child Health Journal, vol. 17, no. 4, pp. 616-23.

Nemiah, J. 1963, 'Psychological complications in industrial injuries', Archives of Environmental Health, vol. 7, pp. 481-7.

NHMRC 2010, 'National Guidance on Collaborative Maternity Care', National Health and Medical Research Council, Canberra.

NHMRC 2015, National Statement on Ethical Conduct in Human Research National Health and Medical Research Council, Canberra, $<$ www.nhmrc.gov.au/guidelines/publications/e72>.

NHS 2015, 'The National Maternity Review. Better births, improving outcomes of maternity services in England. A Five Year Forward View for maternity care', England, $\langle$ www.england.nhs.uk/ourwork/futurenhs/mat-review $>$.

NICE 2014, Antenatal and postnatal mental health: clinical management and service guidance, National Health Service (NHS), London, England.

NICE 2015, Antenatal and Postnatal Mental Health. The NICE Guideline on Clinical Management and Service Guidance, National Health Service (NHS), London, England.

Nie, C., Dai, Q., Zhao, R., Dong, Y., Chen, Y. \& Ren, H. 2017, 'The impact of resilience on psychological outcomes in women with threatened premature labor and spouses: a cross-sectional study in Southwest China', Health and Quality of Life Outcomes, vol. 15, no. 26.

Nielsen, D., Videbech, P., Hedegaard, M., Dalby, J. \& Secher, N. 2000, 'Postpartum depression: identification of women at risk', British Journal of Obstetrics and Gynaecology, vol. 107, pp. 1210-7.

NMBA 2006, 'National Competency Standards for the Midwife', Nursing and Midwifery Board of Australia Canberra, Australia.

NSW Health 2008, Community Mental Health Strategy 2007-2012: From prevention and early intervention to recovery, Better Health Centre - Publications Warehouse, Gladesville, NSW, https://www.health.nsw.gov.au/mentalhealth/programs/mh/Publications/mentalhealth-strategy.pdf>.

NSW Health 2009, NSW Health/Families. NSW Supporting Families Early Package - SAFE START Guidelines: Improving mental health outcomes for parents and infants, NSW Department of Health.

NSW Health 2010, NSW Supporting Families Early Package - maternal and child health primary health care policy, NSW Department of Health.

O'Higgins, M., Roberts, I., Glover, V. \& Taylor, A. 2013, 'Mother-child bonding at 1 year; associations with symptoms of postnatal depression and bonding in the first few weeks', Archives of Womens Mental Health, vol. 16, no. 5, pp. 381-9.

O’Hara, M. \& McCabe, J. 2013, 'Postpartum depression: Current status and future directions', Annual Review of Clinical Psychology, vol. 9, pp. 379-407.

Olde, E., van der Hart, O., Kleber, R. \& van Son, M. 2006, 'Posttraumatic stress following childbirth: A review', Clinical Psychology Review, vol. 26, no. 1, pp. 1-16.

Ong, S. 2004, Pre-eclampsia: A historical perspective. In: Pre-eclampsia: Current perspectives on management, The Parthenon Publishing Group, New York.

Orr, S. 2004, 'Social support and pregnancy outcome: A review of the literature', Clinical Obstetrics and Gynecology, vol. 47, no. 4, pp. 842-55.

PACT Consortium 2015, 'Heterogeneity of postpartum depression: a latent class analysis', Lancet Psychiatry, vol. 2, no. 1, pp. 59-67. 
Pan, L., Fergusson, D., Schweitzer, I. \& Hebert, P. 2005, 'Ensuring high accuracy of data abstracted from patient charts: the use of a standardized medical record as a training tool', Journal of Clinical Epidemiology, vol. 58, no. 9, pp. 918-23.

Parent Infant Research Institute 2009, Perinatal depression and anxiety. Evidence relating to infant cognitive and emotional development, pamphlet.

Paulhus, D. 1984, 'Two-component models of socially desirable responding', Journal of Personality and Social Psychology, vol. 46, no. 3, p. 598.

Petrovska, K., Watts, N., Catling, C., Bistits, A. \& Homer, C. 2017, 'Stress, anger, fear and injustice: An international qualitative survey of women's experiences planning a vaginal breech birth', Midwifery, vol. 44, pp. 41-7.

Polit, D. \& Beck, C. 2014, Essentials of Nursing Research: Appraising Evidence for Nursing Practice, Wolters Kluwer/Lippincott Williams and Wilkins, Philadelphia, US.

Pollack, M. 2005, 'Comorbid anxiety and depression', Journal of Clinical Psychiatry, vol. 66, no. Supp 8, pp. 22-9.

Pope, C., Ziebland, S. \& Mays, N. 2000, 'Analysing qualitative data', British Medical Journal, vol. 320, no. 7227, pp. 114-6.

Porcel, J., Feigal, Poye, L., Postma, I., Zeeman, G., Olowoyeye, A., Tsigas, E. \& Wilson, M. 2013, 'Hypertensive disorders of pregnancy and risk of screening positive for Posttraumatic Stress Disorder: A cross sectional study', Pregnancy Hypertension, vol. 3, pp. 254-60.

Porcel, J., Tsigas, E., Poye, L. \& Wilson, M. 2012, 'Pregnancies involving hypertensive disorders of pregnancy are associated with posttraumatic stress disorder', Pregnancy Hypertension, vol. 2, no. 3, pp. 237-8.

Postma, I., Bouma, A., Ankersmit, F. \& Zeeman 2014, 'Neurocognitive functioning following preeclampsia and eclampsia: a long-term follow-up study', American Journal of Obstetrics and Gynecology, vol. 211, no. 37, pp. e1-9.

Postma, I., Bouma, A., de Groot, J., Aukes, A., Aarnoudse, J. \& Zeeman, G. 2016, 'Cerebral white matter lesions, subjective cognitive failures and objective neurocognitive functioning: A follow-up study in women after hypertensive disorders of pregnancy', Journal of Clinical and Experimental Neuropsychology, vol. 38, no. 5, pp. 585-98.

QSR International 2014, NVIVO10 for Windows. Getting Started, QSR International Pty Ltd.

Radloff, L. 1977, 'The CES-D scale: a self report depression scale for research in the general population', Applied Psychological Measurements, vol. 1, pp. 385-401.

RANZCOG 2009, 'Royal Australian and New Zealand College of Obstetricians and Gynaecologists Guideline: Suitability Criteria for Models of Care and Indications for Referral within and between Models of Care', RANZCOG, Melbourne, $<$ www.ranzcog.edu.au/publications/statements/C-obs30.pdf $>$.

RANZCOG 2016, Induction of labour, viewed 22 May 20192019.

Reed, M., Fenwick, J., Hauck, Y., Gamble, J. \& Creedy, D. 2014, 'Australian midwives' experience of delivering a counselling intervention for women reporting a traumatic birth', Midwifery, vol. 30, no. 2, pp. 269-75.

Renfrew, M., McFadden, A., Bastos, M., Campbell, J., Amos Channon, A. \& Cheung, N. 2014, 'Midwifery and quality care: findings from a new evidence informed framework for maternal and newborn care', The Lancet, vol. 384, pp. 1129-45.

Rep, A., Ganzevoort, W., Bonsel, G., Wolf, H. \& de Vries, J. 2007, 'Psychosocial impact of earlyonset hypertensive disorders and related complications in pregnancy', American Journal of Obstetrics and Gynecology, vol. 197, no. 2, pp. 158.e1-.e6.

Riiskjaer, E., Ammentorp, J. \& Kofoed, P. 2012, 'The value of open-ended questions in surveys on patient experience: number of comments and perceived usefulness from a hospital perspective', International Journal for Quality in Health Care, vol. 24, no. 5, pp. 509-16.

Roberts, C., Ford, J., Algert, C., Antonsen, S., Chalmers, J., Cnattingius, S., Gokhale, M., Kotelchuck, M., Melve, K., Langridge, A., Morris, C., Morris, J., Nassar, N., Norman, J., 
Norrie, J., Sørensen, H., Walker, R. \& Weir, C. 2011, 'Population-based trends in pregnancy hypertension and pre-eclampsia: an international comparative study', British Medical Journal, vol. 1, no. 1, p. e000101.

Roberts, L. 2002, 'Whose baby is it? Promoting parental bonding with the sick neonate', Midwifery Matters. Newsletter of the NSW Midwives Association, vol. 20, no. 3, pp. 167.

Roberts, L., Davis, G. \& Homer, C. 2017, 'Pregnancy with gestational hypertension or preeclampsia: A qualitative exploration of women's experiences', Midwifery, vol. 46, pp. 17-23.

Robertson, E., Grace, S., Wallington, T. \& Stewart, D. 2004, 'Antenatal risk factors for postpartum depression: a synthesis of recent literature', General Hospital Psychiatry, vol. 26, no. 4, pp. 289-95.

Rose, S., Spinks, N. \& Canhoto, A. 2015, Management Research: Applying the Principles, Routledge., London.

Ross, L. \& Mclean, L. 2006, 'Anxiety disorders during pregnancy and the postpartum period: a systematic review', Journal of Clinical Psychiatry, vol. 67, pp. 1285-98.

Rossen, L., Hutchinson, D., Wilson, J., Burns, L., Olsson, C., Allsop, S., Elliott, E., Jacobs, S., Macdonald, J. \& Mattick, R. 2016, 'Predictors of postnatal mother-infant bonding: the role of antenatal bonding, maternal substance use and mental health', Archives of Womens Mental Health, vol. 19, no. 4, pp. 609-22.

Rusticus, S. \& Lovato, C. 2014, 'Impact of Sample Size and Variability on the Power and Type I Error Rates of Equivalence Tests: A Simulation Study', Practical Assessment, Research and Evaluation, vol. 19, no. 11, pp. 1-10.

Sabone, M. 2009, 'The promotion of mental health through cultural values, institutions, and practices: a reflection on some aspects of Botswana culture', Issues in Mental Health Nursing, vol. 30, pp. 777-87.

Sackett, D., Rosenberg, W., Gray, M., Haynes, R. \& Richardson, S. 1996, 'Evidence based medicine: what it is and what it isn't', British Medical Journal, vol. 312, pp. 71-2.2.

Salcedo, B. 2018, The Comorbidity of Anxiety and Depression, viewed 1.08.20192019.

Saldana, J. 2013, The Coding Manual for Qualitative Researchers. Second Edition, SAGE Publications Ltd, London, UK.

Sandall, J., Coxon, K., Mackintosh, N., Rayment-Jones, H., Locock, L. \& Page, L. 2016, 'Relationships: the pathway to safe, high-quality maternity care. Report from the Sheila Kitzinger symposium at Green Templeton College October 2015', Green Templeton College, Oxford.

Sandall, J., Soltani, H., Gates, S., Shennan, A. \& Devane, D. 2016, 'Midwife-led continuity models versus other models of care for childbearing women', in C.D.o.S. Reviews (ed.)John Wiley \& Sons, Ltd.

Sandelowski, M. 2000, 'Whatever happened to qualitative description?', Research in Nursing \& Health, vol. 23, pp. 334-40.

Sandelowski, M. 2000, 'Whatever happened to qualitative description?', Research in Nursing and Health, vol. 23, pp. 334-40.

Sandelowski, M. 2003, 'Using qualitative research', Qualitative Health Research, vol. 14, no. 1, pp. $1366-86$.

Sandelowski, M. 2010, 'What's in a name? Qualitative description revisited', Research in Nursing and Health, vol. 33, no. 1, pp. 77-84.

Saudan, P., Brown, M., Buddle, M. \& Jones, M. 1998, 'Does gestational hypertension become pre-eclampsia?', British Journal of Obstetrics and Gynaecology, vol. 105, pp. 1177-84.

Saultz, J. 2003, 'Defining and Measuring Interpersonal Continuity of Care', Annals of Famiy Medicine vol. 1, pp. 134-43. 
Saunders, B., Sim, J., Kingstone, T., Baker, S., Waterfield, J., Bartlam, B., Burroughs, H. \& Jinks, C. 2018, 'Saturation in qualitative research: exploring its conceptualization and operationalization', Quality and Quantity, vol. 52, no. 4, pp. 1893-907.

Sauro, J. \& Lewis, J. 2011, 'When designing usability questionnaires, does it hurt to be positive?', paper presented to the SIGCHI Conference on Human Factors in Computing Systems, Vancouver, BC, Canada.

Scaer, R. \& Kortz, D. 1978, 'MOM survey: Maternity Options for Mothers-What do women want in maternity care?', Birth and the Family Journal, vol. 5, no. 1, pp. 20-6.

Schmied, V., Beake, S., Sheehan, A., McCourt, C. \& Dyles, F. 2011, 'Women's perceptions and experiences of breastfeeding support: A metasynthesis', Birth, vol. 31, pp. 49-60.

Schmitz, N., Hartkamp, N., Brinschwitz, C., Michalek, S. \& Tress, W. 2000, 'Comparison of the standard and the computerized versions of the Symptom Check List (SCL-90-R): a randomized trial', Acta Psychiatrica Scandinavica, vol. 102, pp. 147-52.

Seale, C. 2000, Analysing your data. In Silverman D (ed) Doing qualitative research, Sage Publications, London.

Shawyer, F., Enticott, J., Block, A., Cheng, I. \& Meadows, G. 2017, 'The mental health status of refugees and asylum seekers attending a refugee health clinic including comparisons with a matched sample of Australian-born residents', BMC Psychiatry, vol. 17, no. 76.

Sibai, B., Ramadan, M., Usta, I., Salama, M., Mercer, B. \& Friedman, S. 1993, 'Maternal morbidity and mortality in 442 pregnancies with hemolysis, elevated liver enzymes, and low platelets (HELLP syndrome)', American Journal of Obstetrics \& Gynecology, vol. 169 , no. 4, pp. 1000-6.

Simkin, P. 1992, 'Just another day in a woman's life? Part II: Nature and consistency of women's long-term memories of their first birth experience', Birth, vol. 19, no. 2, pp. 64-81.

Simpson, M. \& Catling, C. 2016, 'Understanding psychological traumatic birth experiences: A literature review', Women and Birth, vol. 29, pp. 203-7.

Soltani, N., Abedian, Z., Mokhber, N. \& Esmaily, H. 2015, 'The association of family support after childbirth with posttraumatic stress in women with preeclampsia', Iranian Red Crescent Medical Journal, vol. 17, no. 10, p. e17865.

Spencer, E., Brassey, J. \& Mahtani, K. 2017, Recall bias In: Catalogue of Bias Collaboration, viewed 1.07.2019 2019, <https://www.catalogueofbiases.org/biases/recall-bias >.

Sperande, S. 2014, 'Understanding logistic regression analysis', Biochemia Medica, vol. 24, no. 1, pp. $12-8$.

Spielberger, C. \& Sydeman, S. 1994, State-Trait Anxiety Inventory and State-Trait Anger Expression Inventory. In M. E. Maruish (Ed.), The use of psychological testing for treatment planning and outcome assessment Lawrence Erlbaum Associates Inc, Hillsdale, New Jersey, US.

Spitzer, R., Kroenke, K., Williams, J. \& Lowe, B. 2006, 'A brief measure for assessing generalised anxiety disorder: the GAD-7', Archives of Internal Medicine, vol. 166, no. 10, pp. 10927.

Stein, A., Pearson, R., Goodman, S., Rapa, E., Rahman, A., McCallum, M., Howard, L. \& Pariante, C. 2014, 'Effects of perinatal mental disorders on the fetus and child', Lancet, vol. 384, pp. 1800-19.

Stramrood, C., Wessel, I., Doornbos, B., Aarnoudse, J., Van Den Berg, P., Schultz, W. \& Van Pampus, M. 2011, 'Posttraumatic stress disorder following preeclampsia and PPROM: a prospective study with 15 months follow-up', Reproductive Sciences, vol. 18, no. 7, pp. 645-53.

Streubert Speziale, H. \& Carpenter, D. 2007, Qualitative Reseach in Nursing: Advancing the Humanistic Imperative (4th Ed), Lippincott Williams and Wilkins, Philadelphia, US. 
Sullivan, G. \& Artino, A. 2013, 'Analysing and interpreting data from Likert-Type Scales', Journal of Graduate Medical Education, vol. 5, no. 4, pp. 541-4.

Swinson, R. 2006, 'The GAD-7 scale was accurate for diagnosing generalized anxiety disorder', Evidence Based Medicine, vol. 11, no. 6, p. 184.

Tai, J. \& Rola, A. 2016, 'Undertaking and reporting qualitative research', The Clinical Teacher, vol. 13, pp. 175-82.

Tan, P., Evsen, M., Soydinc, H., Sak, M., Ozler, A., Turget, A., Bez, Y. \& Gul, T. 2013, 'Increased psychological trauma and decreased desire to have children after a complicated pregnancy', Journal of Turkish-German Gynecology Association, vol. 14, pp. 11-4.

Tani, F. \& Castagna, V. 2016, 'Maternal social support, quality of bith experience, and postpartum depression in primiparous women', The Journal of Maternal-Fetal and Neonatal Medicine, vol. 30, pp. 689-92.

Tariq, S. \& Woodma, J. 2013, 'Using mixed methods in health research', Journal of the Royal Society of Medicine, vol. 4, no. 6.

Taylor, A., Atkins, R., Kumar, R., Adams, D. \& Glover, D. 2005, 'A new Mother-to-Infant Bonding Scale: links with early maternal mood', Archives of Womens Mental Health, vol. 8, pp. 45-51.

Temkin, O. 1971, The falling sickness: A history of epilepsy from Greeks to the beginning of modern neurology, The Johns Hopkins Press, Baltimore.

Tenhola, S., Rahiala, E., Halonen, P., Vanninen, E. \& Voutilainen, R. 2006, 'Maternal preeclampsia predicts elevated blood pressure in 12-year-old children: evaluation by ambulatory blood pressure monitoring', Paediatric Research, vol. 59, pp. 320-4.

The Royal Australian and New Zealand College of Obstetricians and Gynaecologists 2017, Maternity Care in Australia. 1st Edition. A framework for a healthy new generation of Australians., The Royal Australian and New Zealand College of Obstetricians and Gynaecologists.

Thomas, H. 1935, Classical contributions to obstetrics and gynecology, Charles C Thomas, Baltimore, Maryland.

Thorne, S. 2000, 'Data analysis in qualitative research', Evidence-Based Nursing, vol. 3, pp. 6870.

Thornton, C., Dahlen, H., Korda, A. \& Hennessy, A. 2013, 'The incidence of preeclampsia and eclampsia and associated maternal mortality in Australia from population-linked datasets: 2000-2008', American Journal of Obstetrics and Gynecology, vol. 208, no. 6, pp. 476.e1-.e5.

Tranquilli, A., Dekker, G., Magee, L., Roberts, J., Sibai, B., Steyn, W., Zeeman, G. \& Brown, M. 2014, 'The classification, diagnosis and management of the hypertensive disorders of pregnancy: A revised statement from the ISSHP', Pregnancy Hypertension, vol. 4, no. 2, pp. 97-104.

Turkstra, E., Creedy, D., Fenwick, J., Buist, A., Scuffham, P. \& Gamble, J. 2015, 'Health services utilization of women following a traumatic birth', Archives of Womens Mental Health, vol. 18 , no. 6, pp. 829-32.

Turnbull, D., Wilkinson, C., Gerard, K., Shanahan, M., Ryan, P., Griffith, E., Kruzins, G. \& Stamp, G. 2004, 'Clinical, psychosocial, and economic effects of antenatal day care for three medical complications of pregnancy: a randomised controlled trial of 395 women', Lancet, vol. 363, no. 941, pp. 1104-9.

Turton, P., Hughes, P., Evans, C. \& Fainman, D. 2001, 'Incidence, correlates and predictors of post-traumatic stress disorder in the pregnancy after stillbirth', British Journal of Psychiatry, vol. 178, pp. 556-60.

Uzan, J., Carbonnel, M., Piconne, O., Asmar, R. \& Ayoubi, J.-M. 2011, 'Pre-eclampsia: Pathophysiology, diagnosis, and management', Vascular Health and Risk Management vol. 7, pp. 467-74. 
Vaismororadi, M., Turunen, H. \& Bondas, T. 2013, 'Content analysis and thematic analysis: Implications for conducting a qualitative desriptive study', Nursing and Health Sciences, vol. 15, pp. 398-405.

van Bussel, J., Spitz, B. \& Demyttenaere, K. 2010, 'Three self-report questionnaires of the early mother-to-infant bond: reliability and validity of the Dutch version of the MPAS, PBQ and MIBS', Archives of Womens Mental Health, vol. 13, pp. 373-84.

Vanhove, J. 2015, Causes and consequences of unequal sample sizes, viewed 28.06.2019 2019, <https://janhove.github.io/design/2015/11/02/unequal-sample-sized>.

Waldenström, U., Hildingsson, I., Rubertsson, C. \& Rådestad, I. 2004, 'A negative birth experience: prevalence and risk factors in a national sample', Birth, vol. 31, no. 1, pp. 17-27.

Warner, P. 2008, 'Ordinal logistic regression', Journal of Family Planning and Reproductive Health Care, vol. 34, no. 3, pp. 169-70.

Watson, D. 1992, 'Correcting for Acquiescent Response Bias in the Absence of a Balanced Scale: An Application to Class Consciousness', Sociological Methods and Research, vol. 21, no. 1, pp. 52-88.

Way, D., Jones, L. \& Busing, N. 2000, 'Implementation Strategies: Collaboration in Primary Care-Family Doctors and Nurse Practitioners Delivering Shared Care', Ontario College of Family Physicians, Ontario.

Weinstein, L. 1982, 'Syndrome of hemolysis, elevated liver enzymes and low platelet count: a severe consequence of hypertension in pregnancy', American Journal of Obstetrics and Gynecology, vol. 142, pp. 159-67.

Wenzel, A., Haugen, E. \& Jackson, L. 2005, 'Anxiety symptoms and disorders at eight weeks postpartum', Journal of Anxiety Disorders, vol. 19, pp. 295-311.

White, T., Matthey, S., Boyd, K. \& Barnett, B. 2006, 'Postnatal depression and post-traumatic stress after childbirth: Prevalence, course and co-occurrence', Journal of Reproductive and Infant Psychology, vol. 24, no. 02, pp. 107-20.

Whitehead, D. 2007, Common qualitative methods, Elsevier, Australia.

Whiting, L. 2008, 'Semi-structured interviews: guidance for novice researchers', Nursing Standard, vol. 22, pp. 35-40.

WHO, World Bank, UNFPA \& UNICEF 2015, 'Trends in maternal mortality: 1990 to 2013', World Health Organization, Geneva.

Wigert, H., Berg, M. \& Hellstrom, A. 2007, 'Health care professionals' experiences of parental presence and participation in neonatal intensive care unit', Interantional Journal of Qualitative Studies on Health and Well-being, vol. 2, pp. 45-54.

Wikström, A., Haglund, B., Olovsson, M. \& Lindeberg, S. 2015, 'The risk of maternal ischaemic heart disease after gestational hypertensive disease', British Journal of Obstetrics and Gynaecology, vol. 112, pp. 1486-91.

Williams, D. 2011, 'Long-term complications of preeclampsia', Seminars in Nephrology, vol. 31, no. 1 , pp. 111-22.

Windle, Bennett, K. \& Noyes, J. 2011, 'A methodological review of resilience measurement scales', Health Quality of Life Outcomes, vol. 9, no. 8.

Winston, R. \& Chicot, R. 2016, 'The importance of early bonding on the long-term mental health and resilience of children', London Journal of Primary Care, vol. 8, no. 1, pp. 124.

Wittkowski, A., Wieck, A. \& Mann, S. 2007, 'An evaluation of two bonding questionnaires: a comparison of the Mother-to-Infant Bonding Scale with the Postpartum Bonding Questionnaire in a samle of primiparous mothers', Archives of Womens Mental Health, vol. 10, pp. 171-5.

Woolhouse, H., Gartland, D., Hegarty, K., Donath, S. \& Brown, S. 2012, 'Depressive symptoms and intimate partner violence in the 12 months after childbirth: a prospective 
pregnancy cohort study', British Journal of Obstetrics and Gynecology, vol. 119, no. 3, pp. 315-23.

World Health Organisation 2008, 'Improving maternal mental health', World Health Organisation, Geneva, Switzerland, $<$ http://www.who.int/mental health/prevention/suicide/Perinatal depression mmh final.pdf?ua=1>.

World Health Organisation 2013, 'WHO recommendations on postnatal care of the mother and newborn', World Health Organisation, Geneva, Switzerland, $<$ http://www.who.int/maternal child adolescent/documents/postnatal-carerecommendations/en/>.

World Health Organisation 2014, Mental health: a state of well being, World Health Organisation, viewed 24.07.2019 2019, <https://www.who.int/features/factfiles/mental health/en/>.

World Health Organisation 2018, 'Health promotion and disease prevention through population-based interventions, including action to address social determinants and health inequity', World Health Organistaion, Geneva, Switzerland, viewed 1.10.18, $<$ http://www.emro.who.int/about-who/public-health-functions/health-promotiondisease-prevention.html>.

World Health Organisation 2019, Maternal Mental Health, viewed 1.08.19 2019, $<$ https://www.who.int/mental health/maternal-child/maternal mental health/en/ $>$.

Wu, C., Nohr, E., Bech, B., Vestergaard, M., Catov, J. \& Olsen, J. 2009, 'Health of children born to mothers who had preeclampsia: a population-based cohort study', American Journal of Obstetrics and Gynecology, vol. 201, no. 3, pp. 269.e1-10.

Wu, P., Haththotuwa, R., Kwok, C., Babu, A., Kotronias, R., Rushton, C., Zaman, A., Fryer, A., Kadam, U., Chew-Graham, C. \& Mamas, M. 2017, 'Preeclampsia and future cardiovascular health: a systematic review and meta-analysis', Circulation: Cardiovascular Quality and Outcomes, vol. 10, no. 12, p. 10:e003497.

Yelland, J., Sutherland, G. \& Brown, S. 2010, 'Postpartum anxiety, depression and social health: findings from a population-based survey of Australian women', BMC Public Health, vol. 10, no. 771.

Ygge, B. 2007, 'Nurses' perceptions of parental involvment in hospital care', Paediatric Nursing, vol. 19 , no. 5, pp. 38-40.

Yildiz, P., Ayers, S. \& Phillips, L. 2017, 'The prevalence of posttraumatic stress disorder in pregnancy and after birth: A systematic review and meta-analysis', Journal of Affective Disorders, vol. 208, pp. 634-45.

Zigmond, A. \& Snaith, R. 1983, 'The hospital anxiety and depression scale', Acta Psychiatr Scand, vol. 67, no. 6, pp. 361-70.

Zung, W. 1965, 'A self-rating depression scale', Archives of General Psychiatry, vol. 12, pp. 6370. 